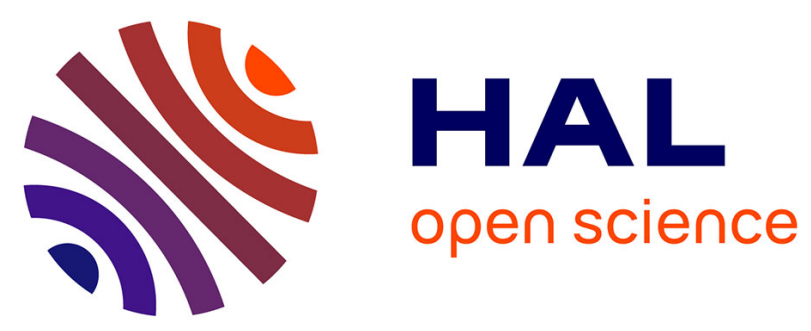

\title{
Costos y beneficios de la carbono-neutralidad en Perú: Una evaluación robusta
}

\author{
Jairo Quirós-Tortós, Guido Godínez- Zamora, Daniel Gerardo de La Torre \\ Ugarte, Carlos Heros, Juan Lazo Lazo, Elías Ruiz, Berioska Quispe, Daniella \\ Diez Canseco, Freddy Garro, Jimena Mora, et al.
}

\section{To cite this version:}

Jairo Quirós-Tortós, Guido Godínez- Zamora, Daniel Gerardo de La Torre Ugarte, Carlos Heros, Juan Lazo Lazo, et al.. Costos y beneficios de la carbono-neutralidad en Perú: Una evaluación robusta. Inter-American Development Bank, 2021, 10.18235/0003286 . halshs-03318133

\section{HAL Id: halshs-03318133 \\ https://shs.hal.science/halshs-03318133}

Submitted on 9 Aug 2021

HAL is a multi-disciplinary open access archive for the deposit and dissemination of scientific research documents, whether they are published or not. The documents may come from teaching and research institutions in France or abroad, or from public or private research centers.
L'archive ouverte pluridisciplinaire HAL, est destinée au dépôt et à la diffusion de documents scientifiques de niveau recherche, publiés ou non, émanant des établissements d'enseignement et de recherche français ou étrangers, des laboratoires publics ou privés. 


\section{SBID}

\section{Costos}

y beneffcios de la

carbono-neutralfdad

en Perú

Una evaluación

robusta 
Catalogación en la fuente proporcionada por la
Biblioteca Felipe Herrera

del Banco Interamericano de Desarrollo

Costos y beneficios de la carbono-neutralidad en el Perú: una evaluación robusta / Jairo Quirós-Tortós, Guido GodínezZamora, Daniel Gerardo De La Torre Ugarte, Carlos Heros, Juan Lazo Lazo, Elías Ruiz, Berioska Quispe, Daniella Diez Canseco, Freddy Garro, Jimena Mora, Lorenzo Eguren, Milagros Sandoval, Silke Campos, Micol Salmeri, Richard Baron, Jaime Fernandez-Baca, Ana Saori lju Fukushima, Pamela Ferro Cornejo, Valentina Saavedra, Adrien Vogt-Schilb.

p. cm. - (Monografía del BID ; 895)

Incluye referencias bibliográficas.

1. Carbon dioxide mitigation-Peru-Costs. 2. Greenhouse gas mitigation-Peru-Costs. 3. Climate change mitigation-PeruCosts. 4. Climatic changes-Government policy-Peru. I. Quirós-Tortós, Jairo. II. Godínez-Zamora, Guido. III. De La Torre Ugarte, Daniel Gerardo. IV. Heros, Carlos. V. Lazo Lazo, Juan. VI. Ruiz, Elías. VII. Quispe, Berioska. VIII. Diez Canseco, Daniella. IX. Garro, Freddy. X. Mora, Jimena. XI. Eguren C., Lorenzo. XII. Sandoval Díaz, Milagros. XIII. Campos, Silke. XIV. Salmeri, Micol. XV. Baron, Richard. XVI. Fernandez-Baca, Jaime. XVII. Iju Fukushima, Ana Saori. XVIII. Ferro Cornejo, Pamela. XIX. Saavedra, Valentina. XX. Vogt-Schilb, Adrien. XXI. Banco Interamericano de Desarrollo. División de Cambio Climático. XXII. Serie.

IDB-MG-895

Códigos JEL: Q54, Q10, Q20, Q30, Q40, Q50

Palabras clave: Perú, mitigación del cambio climático, descarbonización, análisis de costo-beneficio.

Copyright (c) 2021 Banco Interamericano de Desarrollo. Esta obra se encuentra sujeta a una licencia Creative Commons IGO 3.0 Reconocimiento-NoComercial-Compartirlgual (CC-IGO 3.0 BY-NC-SA) (https://creativecommons.org/licenses/ by-nc-sa/3.0/igo/legalcode) y puede ser reproducida para cualquier uso no-comercial, sea como obra original o como cualquier obra derivada, siempre que se le otorgue el reconocimiento al BID y que las obras derivadas estén sujetas a una licencia que prevea los mismos términos y condiciones que la licencia aplicable a la obra original.

Cualquier disputa relacionada con el uso de las obras del BID que no pueda resolverse amistosamente se someterá a arbitraje de conformidad con las reglas de la CNUDMI (UNCITRAL). El uso del nombre del BID para cualquier fin distinto al reconocimiento respectivo y el uso del logotipo del BID, no están autorizados por esta licencia CC-IGO y requieren de un acuerdo de licencia adicional.

Note que el enlace URL incluye términos y condiciones adicionales de esta licencia.

Las opiniones expresadas en esta publicación son de los autores y no necesariamente reflejan el punto de vista del Banco Interamericano de Desarrollo, de su Directorio Ejecutivo ni de los países que representa.

\section{(9) $(100$}

Este estudio es producto de una colaboración entre la Universidad del Pacífico, el Laboratorio de Investigación de Potencia y Energía Eléctrica (EPERLab) de la Universidad de Costa Rica (UCR), el Ministerio del Ambiente (MINAM) de la República del Perú, la 2050 Pathways Platform y el Banco Interamericano de Desarrollo (BID).
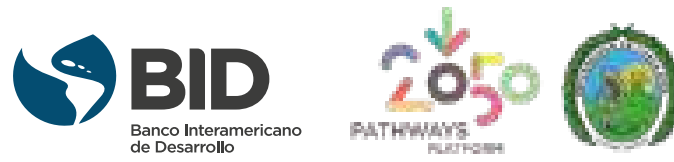


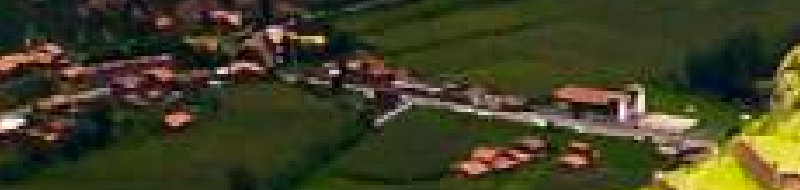

-

45

$\mathrm{X}=\mathrm{x}$

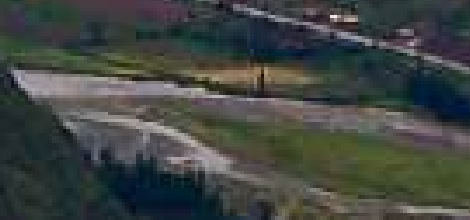
exise

\section{Q⿱一𫝀口:}

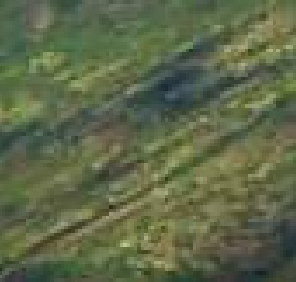
F. 


\section{Tabla de contenidos}

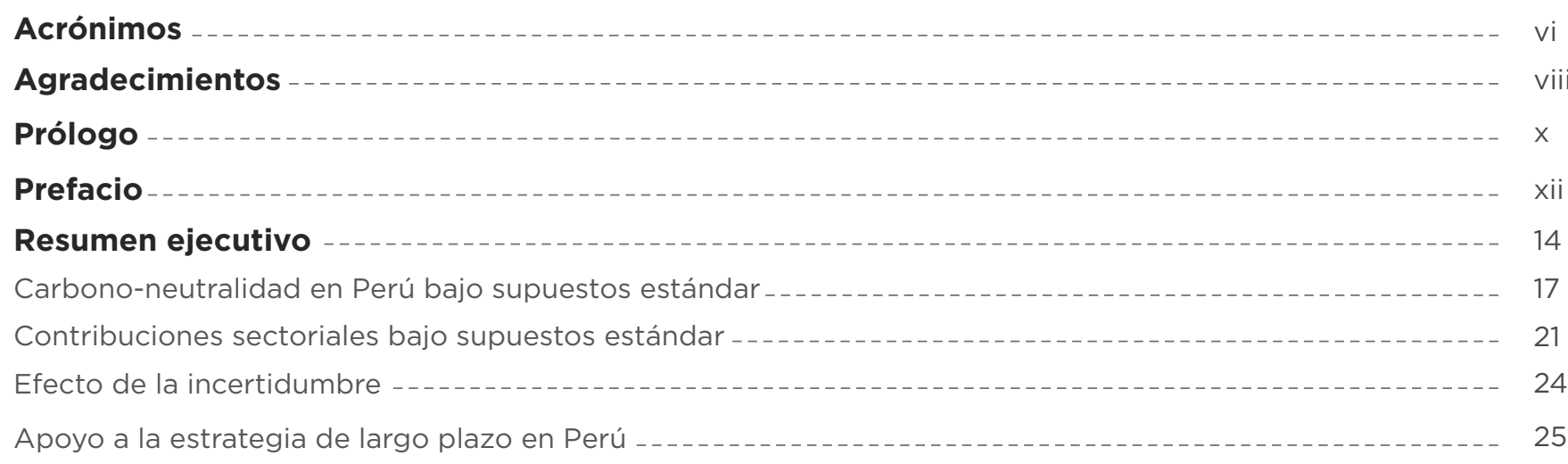

Capítulo 1: Carbono-neutralidad en Perú

1.1. Actualización de la ENCC y carbono-neutralidad en Perú _

1.2. El proyecto DDPLAC y el apoyo al gobierno peruano

1.3. Proceso co-constructivo

1.4. Estimación de emisiones, beneficios y costos: metodología y modelos

1.4.1. Energía - -

1.4.2. Transporte -

1.4.3. Agricultura, silvicultura y otros usos de la tierra (AFOLU)

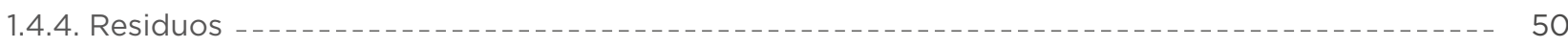

1.4.5. Procesos industriales y uso de productos (PIUP)

1.5. Exploración de la incertidumbre

1.6. Otros beneficios y costos no estimados $\ldots \ldots \ldots \ldots \ldots$

Capítulo 2: La ruta de descarbonización y su efecto en emisiones, beneficios y costos _

2.1. Análisis total de las emisiones, beneficios y costos $\ldots \ldots \ldots$

2.2. Análisis sectorial: transformaciones, emisiones, beneficios y costos

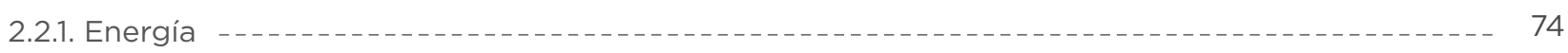

2.2.2. Transporte -

2.2.3. Agricultura, silvicultura y otros usos de la tierra (AFOLU)

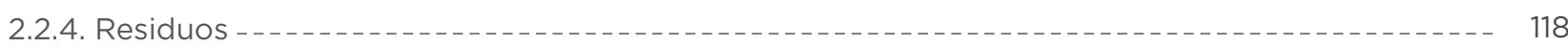

2.2.5. Procesos industriales y uso de productos (PIUP) $\ldots \ldots \ldots$

Capítulo 3: Efecto de la incertidumbre en la carbono-neutralidad en Perú

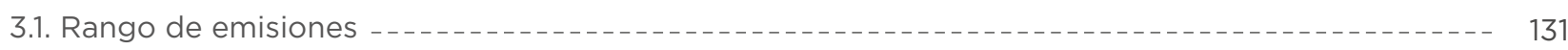

3.2. Rango de beneficios netos $\ldots \ldots \ldots$

3.3. Beneficios netos acumulados versus emisiones netas en 2050

3.4. Rango de costos $\ldots \ldots$ 
Epílogo

Referencias

Anexos -

A. Proceso participativo y matriz DAMI

A.1. Lista de participantes de los talleres $\ldots \ldots \ldots$

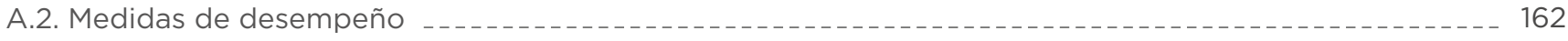

A.3. Acciones de política

A.4. Modelos y datos $\ldots \ldots$

A.5. Incertidumbres _-_._.

B. Metodología y modelos

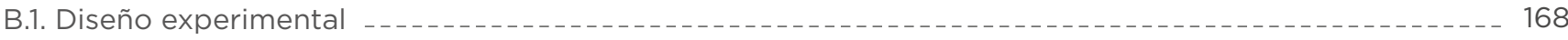

B.2. Estimación de emisiones, beneficios y costos $\ldots \ldots \ldots$

B.2.1. Parámetros transversales en los modelos $\ldots$

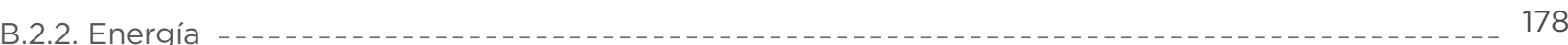

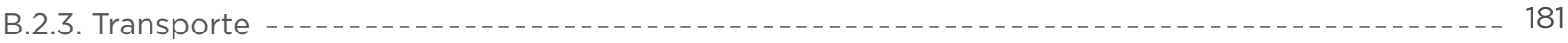

B.2.4. Agricultura, silvicultura y otros usos de la tierra (AFOLU)

B.2.5. Residuos

B.2.6. Procesos industriales y uso de productos (PIUP)

C. Referencias de los anexos 


\section{Acrónimos}

AFOLU agricultura, silvicultura y otros usos de la tierra

AlE Agencia Internacional de Energía

ASOCEM Asociación de Productores de Cemento

BID Banco Interamericano de Desarrollo

CEPLAN Centro Nacional de Planeamiento Estratégico

$\mathrm{CO}_{2} \quad$ dióxido de carbono

$\mathrm{CO}_{2 e} \quad$ dióxido de carbono equivalente

DAMI desempeño, acciones, modelos e incertidumbres

DBO demanda bioquímica de oxígeno

DDPLAC Rutas de Descarbonización Profunda en Latinoamérica y el Caribe

ELP estrategia de largo plazo

ENCC Estrategia Nacional ante el Cambio Climático de Perú

FICEM Federación Internacional de Cemento

GEI gases de efecto invernadero

Gpkm giga pasajeros kilómetro

Gtkm giga toneladas kilómetro

GW gigavatios

$\mathrm{Ha}$ hectáreas

ICRAF Centro Internacional de Investigación en Agroforestería

IPCC

Grupo Intergubernamental de Expertos sobre el Cambio Climático

kcal kilocalorías

MEF Ministerio de Economía y Finanzas

MIDAGRI Ministerio de Desarrollo Agrario y Riego

MINAM Ministerio del Ambiente

MINEM Ministerio de Energía y Minas

$\mathrm{MtCO}_{2 \mathrm{e}}$ megatonelada de dióxido de carbono equivalente

Mton megatonelada métrica

MVCS

Ministerio de Vivienda, Construcción y Saneamiento

NDC contribuciones determinadas a nivel nacional

$\mathrm{PIB}$

producto interno bruto

PIUP procesos industriales y uso de productos

PJ

petajulios

RDM toma de decisiones robustas

SERFOR Servicio Nacional Forestal y de Fauna Silvestre

UCR Universidad de Costa Rica

UP Universidad del Pacifico

US\$ dólares de EE.UU.

UTCUTS uso de la tierra, cambio de uso de la tierra y silvicultura 


\section{Agradecimientos}

Este documento ha sido escrito por Jairo Quirós-Tortós y Guido Godínez-Zamora de la Universidad de Costa Rica; Daniel Gerardo De La Torre Ugarte Pierrend, Carlos Heros, Juan Lazo Lazo y Elías Ruiz de la Universidad del Pacifico; Berioska Quispe, Daniella Diez Canseco, Freddy Garro, Jimena Mora, Lorenzo Eguren, Milagros Sandoval y Silke Campos del Ministerio del Ambiente; Micol Salmeri y Richard Baron de la 2050 Pathways Platform; Jaime Fernández-Baca, Ana Saori Iju Fukushima, Valentina Saavedra y Adrien Vogt-Schilb del Banco Interamericano de DesarroIlo (BID), bajo la coordinación de Valentina Saavedra.

Agradecemos profundamente a la directora de la Dirección General de Cambio Climático y Desertificación del Ministerio del Ambiente, Rosa Morales, por su apoyo en la realización de este proyecto, así como a Laura Secada, por el soporte brindado durante la gestión anterior. Extendemos nuestro sincero reconocimiento al equipo de la Dirección de Mitigación de Gases de Efecto Invernadero del Ministerio del Ambiente de la República del Perú por su constante apoyo durante la realización del estudio.

Deseamos plasmar también nuestro especial agradecimiento a Hans Buttgenbach, Jorge Elliot, Fernando Acosta, Marco Tinoco, Guillermo León, Ximena Guardia, Anny López, Diego Cebreros y Elizabeth Merino, por su compromiso con el proyecto. 
Agradecemos también a los ministerios y otras entidades gubernamentales por su compromiso con este proyecto. En particular, expresamos nuestro reconocimiento al Ministerio de Economía y Finanzas, al Ministerio de Energía y Minas, al Ministerio de Desarrollo Agrario y Riego, al Centro Nacional de Planeamiento Estratégico, al Servicio Nacional Forestal y de Fauna Silvestre, y al Ministerio de Vivienda, Construcción y Saneamiento. Además, agradecemos a los representantes del sector privado y de la academia que concurrieron a los talleres.

Nuestro sincero agradecimiento se extiende a cada uno de los más de 130 participantes de los talleres que activamente brindaron insumos valiosos para este proyecto.

Queremos asimismo expresar nuestro reconocimiento en particular a los siguientes revisores (en orden alfabético): Arturo Alarcón, Juan Carlos Altamirano, Ricardo Argüello, Rafael Capristán, Ricardo Delgado, Carlos Echeverría, Esperanza González, Edmundo Molina, Tania Páez, Alberto Ríos, Lucía Ruiz Ostoic, Gustavo Suárez de Freitas, así como al equipo del Banco Mundial y de la Organización para la Cooperación y el Desarrollo Económicos (OCDE), que en conjunto proporcionaron valiosos comentarios en el proceso de revisión final del documento.

Este trabajo es producto de una colaboración entre la Universidad del Pacífico, el Laboratorio de Investigación en Potencia y Energía (EPERLab) de la Universidad de Costa Rica, la 2050 Pathways Platform y el Banco Interamericano de Desarrollo (BID). Ha sido financiado por el Fondo Francés para el Clima del BID (RG-T3575) y por la 2050 Pathways Platform. 


\section{Prólogo}

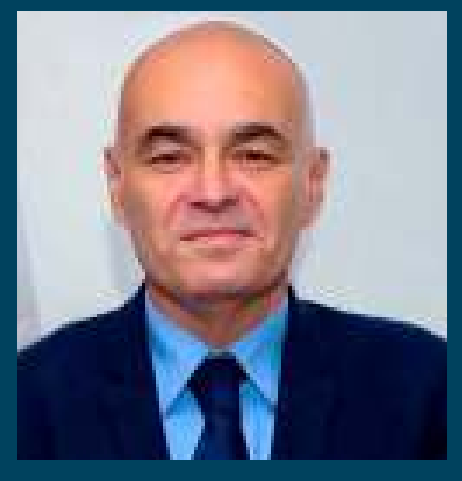

Gabriel Quijandría

Los informes especiales del Grupo Intergubernamental de Expertos sobre el Cambio Climático (IPCC) de 2018 y 2019 sobre el calentamiento global de $1,5^{\circ} \mathrm{C}$ nos indican que ya vivimos las consecuencias de un calentamiento global de $1^{\circ} \mathrm{C}$. Dichas consecuencias ya son una realidad que se evidencia en el año 2018, donde el $80,88 \%$ del total de emergencias ocurridas durante el primer semestre en Perú fueron causadas por fenómenos de origen climático que corresponden, en su mayoría, a inundaciones, lluvias intensas, vientos fuertes, sequías, bajas temperaturas y maretazos, entre otros; generando daños, pérdidas y alteraciones sobre bienes materiales, ambientales y humanos.

Asimismo, la pandemia de COVID-19 nos ha revelado que necesitamos una economía que cuide nuestra salud y la del planeta. Tenemos que repensar la forma en que hemos tratado a la naturaleza, cómo nos hemos relacionado con ella. Esta situación nos ha mostrado que estamos estrechamente vinculados a ella, y que el planeta es nuestra casa y debemos cuidarlo. La COVID-19 nos enseña que los problemas globales están vigentes; así, el cambio climático se plantea como un desafío actual y futuro. En ese contexto, la acción climática hoy representa una necesidad y una oportunidad para encaminarnos a una economía resiliente y baja en carbono.

Perú se ha comprometido a aumentar la capacidad de adaptación, fortalecer la resiliencia y reducir la vulnerabilidad al cambio climático, cumpliendo con lo establecido en el artículo 2 del Acuerdo de París; así como a contribuir a limitar el aumento de la temperatura media mundial, incrementando su ambición climática a una reducción del $40 \%$ de sus emisiones de gases de efecto invernadero (GEI) para 2030. Esto último está en línea con el compromiso de alcanzar un equilibrio entre sus emisiones y absorciones de GEI en la segunda mitad del presente siglo, tal y como se establece en el artículo 4.1. 
Para lograrlo, es necesario que los diferentes actores establezcan un diálogo basado en la ciencia para la toma de decisiones informadas. El presente estudio, realizado por la Universidad del Pacífico y la Universidad de Costa Rica con el apoyo del 2050 Pathways Proyect y del Banco Interamericano de Desarrollo (BID) es un importante insumo en este sentido. El estudio recoge las preocupaciones sobre las incertidumbres de diversos actores gubernamentales y no gubernamentales de los sectores evaluados: energía; transporte; agricultura; silvicultura y otros usos del suelo; residuos; y procesos industriales y uso de productos.

Los resultados nos señalan que el logro de los compromisos climáticos del país para 2030 son alcanzables; sin embargo, se requiere una acción climática decidida. Asimismo, nos indican que la descarbonización para 2050 es posible y que los beneficios de alcanzarla son mayores a las inversiones adicionales que requiere, a pesar de las incertidumbres existentes.

Finalmente, los resultados serán tomados en cuenta en el proceso de actualización de la Estrategia Nacional ante el Cambio Climático a 2050, liderado por el Ministerio del Ambiente, a fin de orientar el cumplimiento del compromiso asumido por el país, además de ser un valioso insumo que muestra las transformaciones que permitirían el logro de las metas asumidas. La actual coyuntura nos desafía, el reto es grande y debemos actuar ahora. En el marco del bicentenario de Perú, apostamos por una reactivación económica verde con un sentido de urgencia, con soluciones basadas en la naturaleza y ambición para hacer frente al cambio climático. 


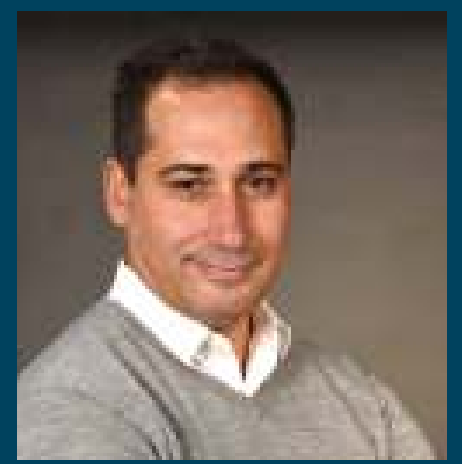

Tomás Bermudez

Gerente del Departamento de Países del Grupo Andino y Representante del BID en Perú

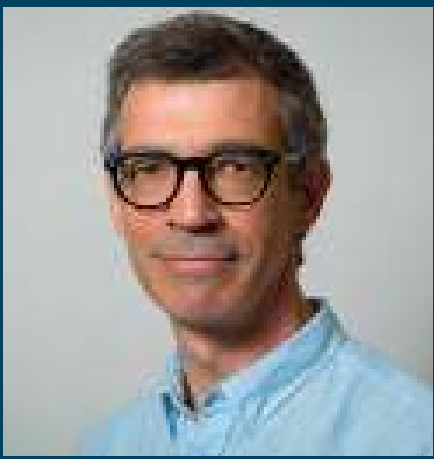

Richard Baron

Director Ejecutivo de 2050 Pathways Platform

\section{Prefacio}

La pandemia de COVID-19 ha acentuado las inequidades socioeconómicas que existen en Perú. Las vulnerabilidades estructurales de la economía peruana, en especial la informalidad, han limitado el cumplimiento de las medidas de confinamiento y el alcance de la ayuda financiera para las familias y las empresas. Sumado a ello, el impacto del cambio climático sobre los recursos naturales y las migraciones oceánicas comprometen la seguridad alimentaria de las poblaciones rurales altoandinas e indígenas de la Amazonía y de los hogares costeros que dependen de recursos pesqueros. Las crisis sanitaria y climática están arraigadas en las mismas vulnerabilidades sociales y económicas.

Una recuperación económica sostenible enfocada hacia la economía baja en carbono le permitirá al Perú salir de esta emergencia mejor preparado frente a futuras pandemias y desastres climáticos, y aprovechar US $\$ 140.000$ millones en beneficios económicos netos para el año 2050, según se demuestra en el presente estudio. Este reporte es fruto de la cooperación entre la Universidad del Pacífico y la Universidad de Costa Rica, bajo la supervisión conjunta de la 2050 Pathways Platform y del Banco Interamericano de Desarrollo (BID) para el Ministerio del Ambiente del Perú.

Descarbonizar, o llegar a cero emisiones netas, significa reducir lo más posible las emisiones de gases de efecto invernadero (GEI), como las provenientes del uso de combustibles fósiles y de la deforestación, y compensar las emisiones restantes con reforestación a escala. La ciencia es clara en ese sentido: indica que solo así podremos, colectivamente, limitar el aumento de la temperatura mundial a $1,5^{\circ} \mathrm{C}$. Por esto, la Plataforma y el BID brindan su apoyo a Perú, así como a otros países del mundo, para formular estrategias que orienten la economía a cero emisiones netas hacia mitad de siglo y así cumplir con los objetivos del Acuerdo de París. 
Para este documento, nuestras instituciones han unido fuerzas a fin de apoyar a Perú en informar la actualización de la Estrategia Nacional ante el Cambio Climático a 2050 con un análisis de los beneficios y costos de descarbonizar su economía mediante una mayor penetración de energías renovables limpias y más baratas; un transporte privado, público y de carga limpio y eficiente; una importante reducción de la deforestación y una transición hacia sistemas agrícolas menos invasivos y más eficientes; menor generación de residuos sólidos, mayor reciclaje y tratamiento de aguas residuales, así como una industria cementera más eficiente.

Los beneficios socioeconómicos de la descarbonización están claros. La reducción del costo de la energía eléctrica y del transporte, los beneficios operativos de las redes eléctricas inteligentes, la disminución de costos en materia de salud asociados a enfermedades respiratorias debido a la combustión de fósiles, y el aumento de la productividad como resultado de un menor congestionamiento vehicular compensan con creces las inversiones necesarias para desplegar fuentes de energía renovables, vehículos eléctricos y mejor transporte público. Además, el bosque conservado provee servicios ecosistémicos, tales como la regulación del clima y del flujo de agua, la captura de carbono, el suministro de materias primas, la estabilización del suelo y la provisión de belleza escénica y paisajes recreativos. Asimismo, las actividades agroforestales y la modernización de las plantaciones comerciales generan ingresos adicionales; y el tratamiento de aguas residuales y el reciclaje de los residuos también producen ahorros.

Es técnicamente posible hacer la transición a cero emisiones netas a través de transformaciones en cada uno de los sectores de la economía peruana, propiciando la creación de empleos verdes que paguen bien y ayuden a lograr una recuperación sostenible e inclusiva. Estamos muy complacidos de compartir con ustedes este estudio y esperamos que contribuya a fortalecer las políticas climáticas y económicas del país a fin de construir una sociedad más limpia, resiliente y mejor preparada para enfrentar el futuro. 


\section{Resumen \\ ejecutivo}
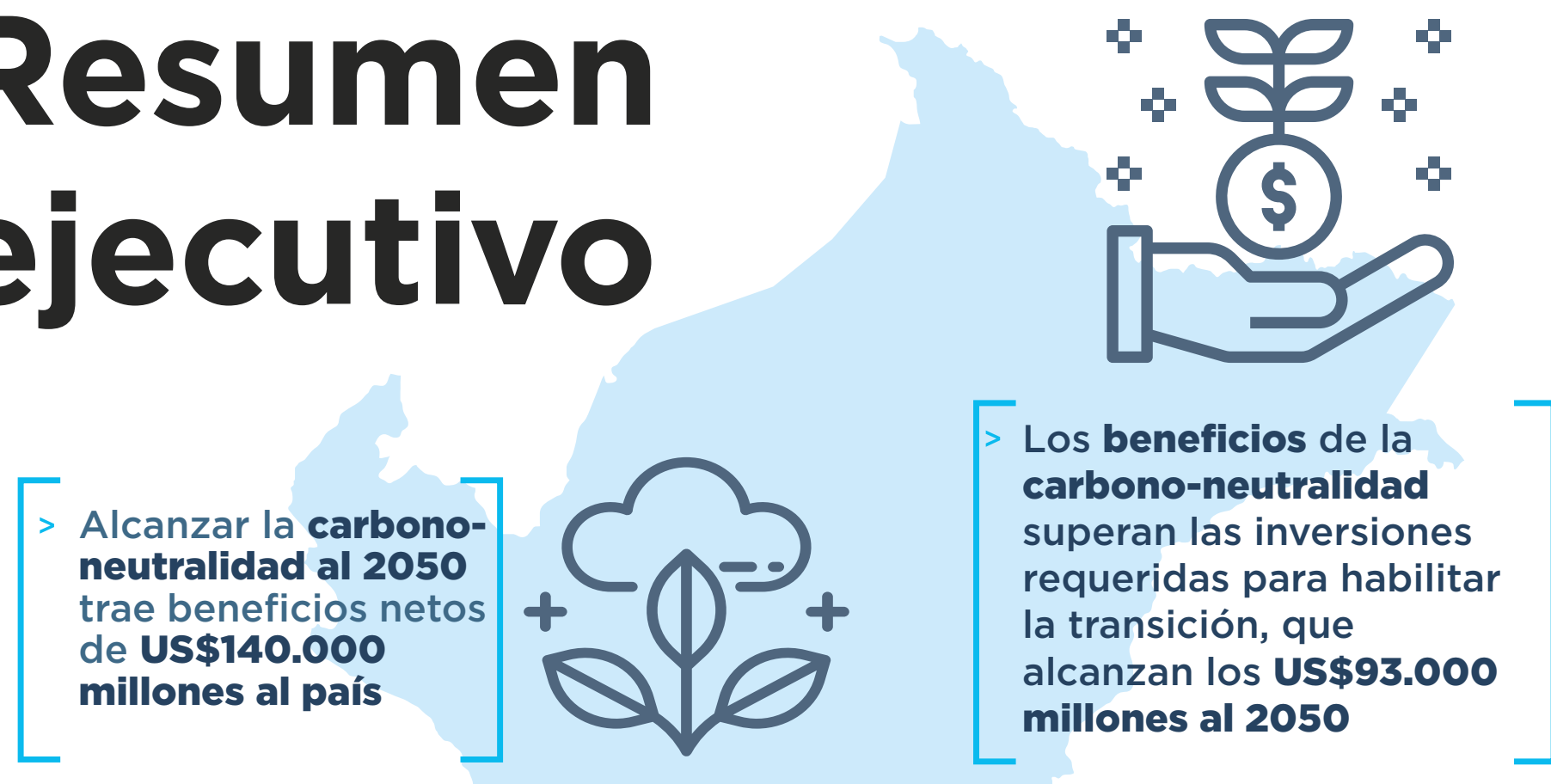

Las transformaciones

ocurren en los sectores
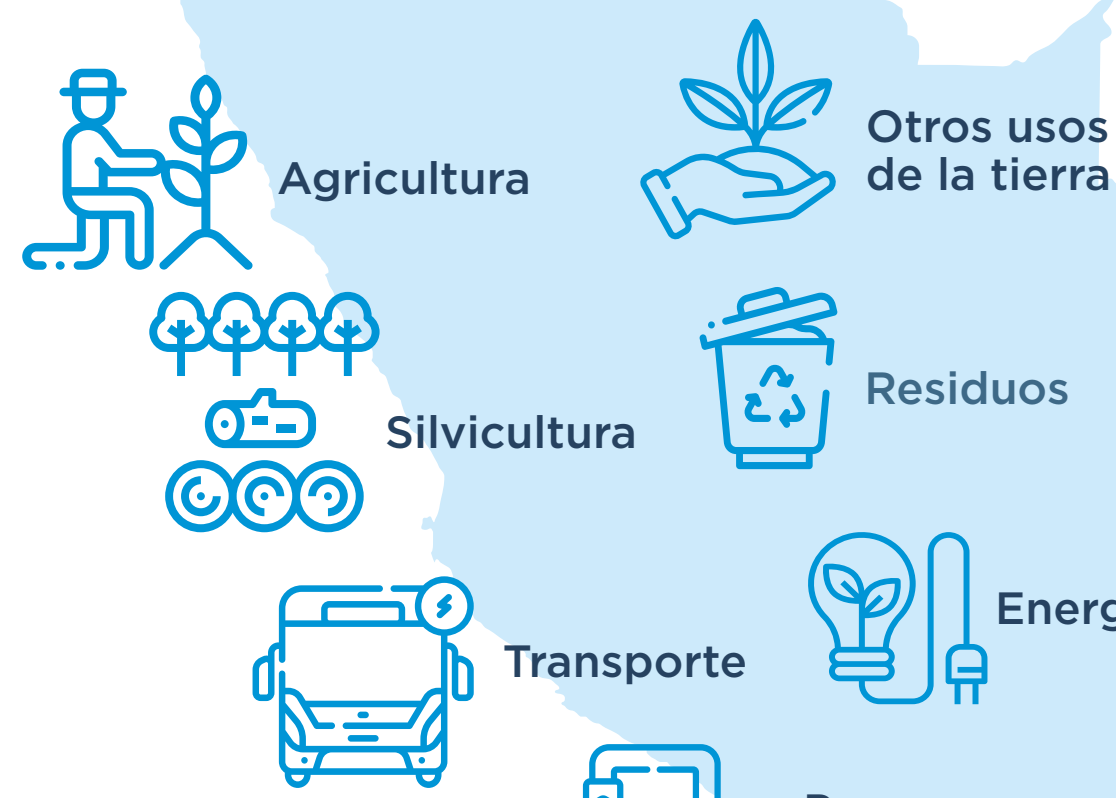

Transporte
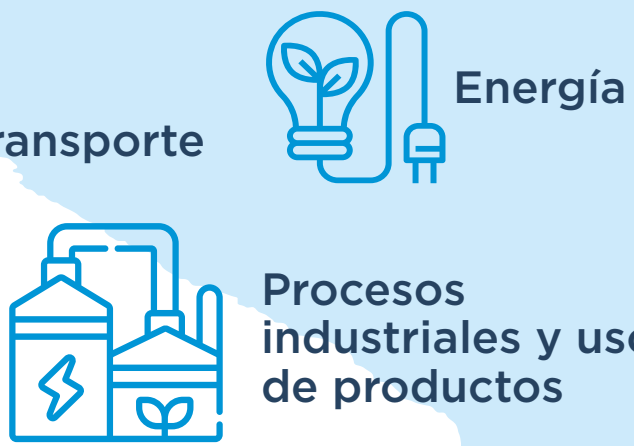

Procesos industriales y uso de productos 


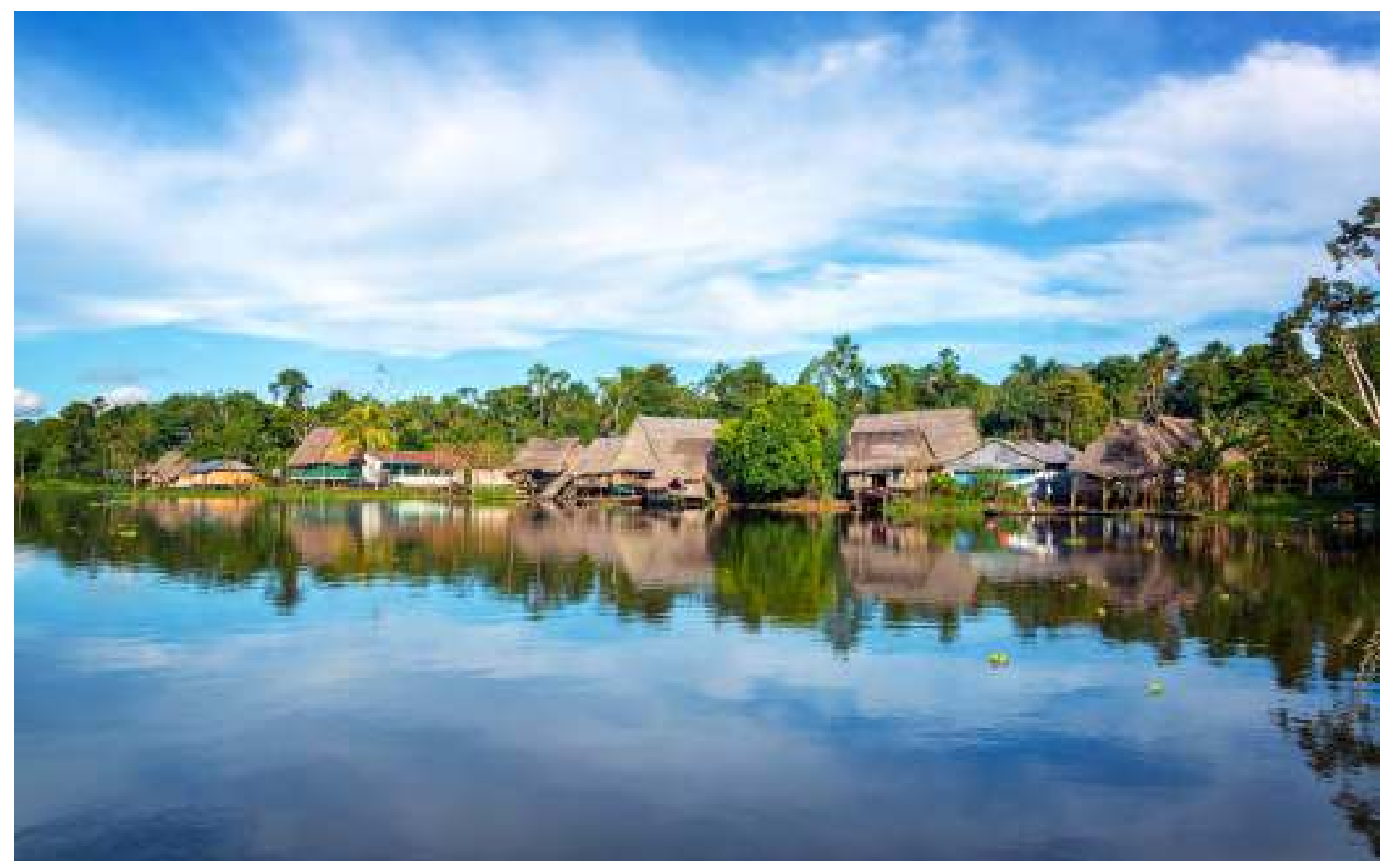

La República del Perú, a través del Ministerio del Ambiente (MINAM), está en proceso de actualizar su Estrategia Nacional ante el Cambio Climático (ENCC), la cual incluirá el objetivo de alcanzar la carbono-neutralidad del país para 2050. Así, el país alineará su política climática con los objetivos del Acuerdo de París: limitar el aumento de la temperatura global entre $1,5^{\circ} \mathrm{C}$ y $2^{\circ} \mathrm{C}$ con respecto a los niveles preindustriales (Naciones Unidas, 2015). En efecto, lograr dicho objetivo requiere reducir las emisiones netas de dióxido de carbono $\left(\mathrm{CO}_{2}\right)$ a cero para mitad de siglo, y limitar sustancialmente otras emisiones de gases de efecto invernadero (GEI) como el metano, el carbono negro y los óxidos nitrosos (IPCC, 2018). La evidencia internacional sugiere que estrategias climáticas como la ENCC permiten investigar acciones sectoriales en el corto, mediano y largo plazo para alcanzar la carbono-neutralidad y maximizar los beneficios sociales y económicos de la transición, incluidos el logro de 1 punto porcentual de crecimiento económico y la generación de 15 millones de empleos en América Latina y el Caribe (Vogt-Schilb, 2021).

Este estudio presenta un análisis de los costos y beneficios de alcanzar la carbono-neutralidad de Perú a mitad de siglo. Busca apoyar al Ministerio del Ambiente de la República del Perú en la actualización de la ENCC, especialmente en lo que atañe al componente de mitigación. Esta publicación sirvió de soporte técnico para el Estudio Técnico para la Carbono-Neutralidad elaborado por el MINAM y ha brindado insumos técnicos relevantes en la actualización de las Contribuciones Determinadas a Nivel Nacional (NDC, por sus siglas en inglés) de 2020, que representan el compromiso inicial de Perú según el Acuerdo de París. La ENCC será un instrumento clave en la implementación de las NDC con miras a 2050. 
El trabajo desarrolló un modelo de evaluación de rutas de descarbonización para Perú que combina modelos detallados de los sectores energía, transporte, y agricultura, silvicultura y otros usos de la tierra (AFOLU) con modelos simplificados de los sectores residuos, y procesos industriales y uso de productos (PIUP). El modelo permite estimar las emisiones de GEl, así como los beneficios y costos de rutas de descarbonización tanto a nivel total como por sector. La selección de los sectores y la calibración en emisiones de cada uno se basa en lo reportado en el Inventario Nacional de GEI de 2016 publicado en 2021 (MINAM, 2021). Dentro del estudio se desarrolló un escenario de carbono-neutralidad que presenta un proceso transformador en cada uno de los sectores, parte de y escala muchas de las intervenciones planteadas en las NDC de 2015 del país, y traza una ruta para llegar a cero emisiones netas de GEl en Perú para 2050. Este escenario de carbono-neutralidad se contrasta contra un escenario base en el que no se implementan acciones de mitigación más allá de las que se han ejecutado antes de 2018 y tiene una evolución tendencial. Los costos y los beneficios de la descarbonización se obtienen mediante el contraste de resultados de ambos escenarios. Tanto los beneficios como los costos en cada escenario se estiman multiplicando el nivel de actividad en cada sector por factores de beneficio o costo descritos en la literatura.

La metodología de evaluación se basa en el marco analítico de toma de decisiones robustas (RDM, por sus siglas en inglés) (Groves et al., 2020) y se ha beneficiado del involucramiento de múltiples actores clave del país mediante dos talleres consultivos y un taller de presentación de resultados. Además, se llevó a cabo una serie de reuniones bilaterales de profundización con expertos sectoriales de diferentes ministerios. Estas instancias permitieron identificar objetivos de desarrollo relevantes por sector para incluir en el análisis (por ejemplo, la necesidad de contar con un transporte público eficiente o una matriz eléctrica estable y renovable, o sistemas agrícolas igual o mayormente productivos); acciones concretas para lograr esos objetivos; modelos y datos disponibles para realizar los análisis; e incertidumbres que deben ser consideradas.

El método también permite estudiar el efecto de la incertidumbre del proceso de transformación mediante el análisis de múltiples rutas de implementación plausibles para cada escenario. Existe una ruta de implementación con supuestos estándar; esto es, con la información obtenida en los talleres e información de referencia disponible en la literatura nacional e internacional al día de la publicación del informe. Por ejemplo, los reportes internacionales indican que los costos de los vehículos eléctricos serán cada vez más bajos. Sin embargo, existe la posibilidad de que estas tendencias no se cumplan e incluso se debe de investigar qué ocurriría si el costo de los vehículos eléctricos no baja o si aumenta.

Para analizar la incertidumbre, se exploraron 1.000 rutas adicionales para cada escenario. Así, se examinaron y combinaron 201 variables inciertas distintas dentro de los modelos, entre ellas: el crecimiento poblacional y económico del país, los costos de las plantas renovables, los rendimientos de los cultivos o los costos de reciclar. En total, se han evaluado 1.001 rutas plausibles de implementación de cada escenario (2.002 en total) para obtener conclusiones robustas de los beneficios y costos de alcanzar la carbono-neutralidad de Perú en el largo plazo; es decir, para identificar de manera preliminar el efecto de diversas incertidumbres en el rango de costos y beneficios. Cada par de rutas, una para el escenario de carbono-neutralidad y una para el escenario base, considera las mismas variaciones de parámetros, lo cual otorga homogeneidad en el análisis y resultados comparables que permiten extraer conclusiones acerca de los costos y beneficios de cada ruta de implementación plausible del escenario de carbono-neutralidad. 


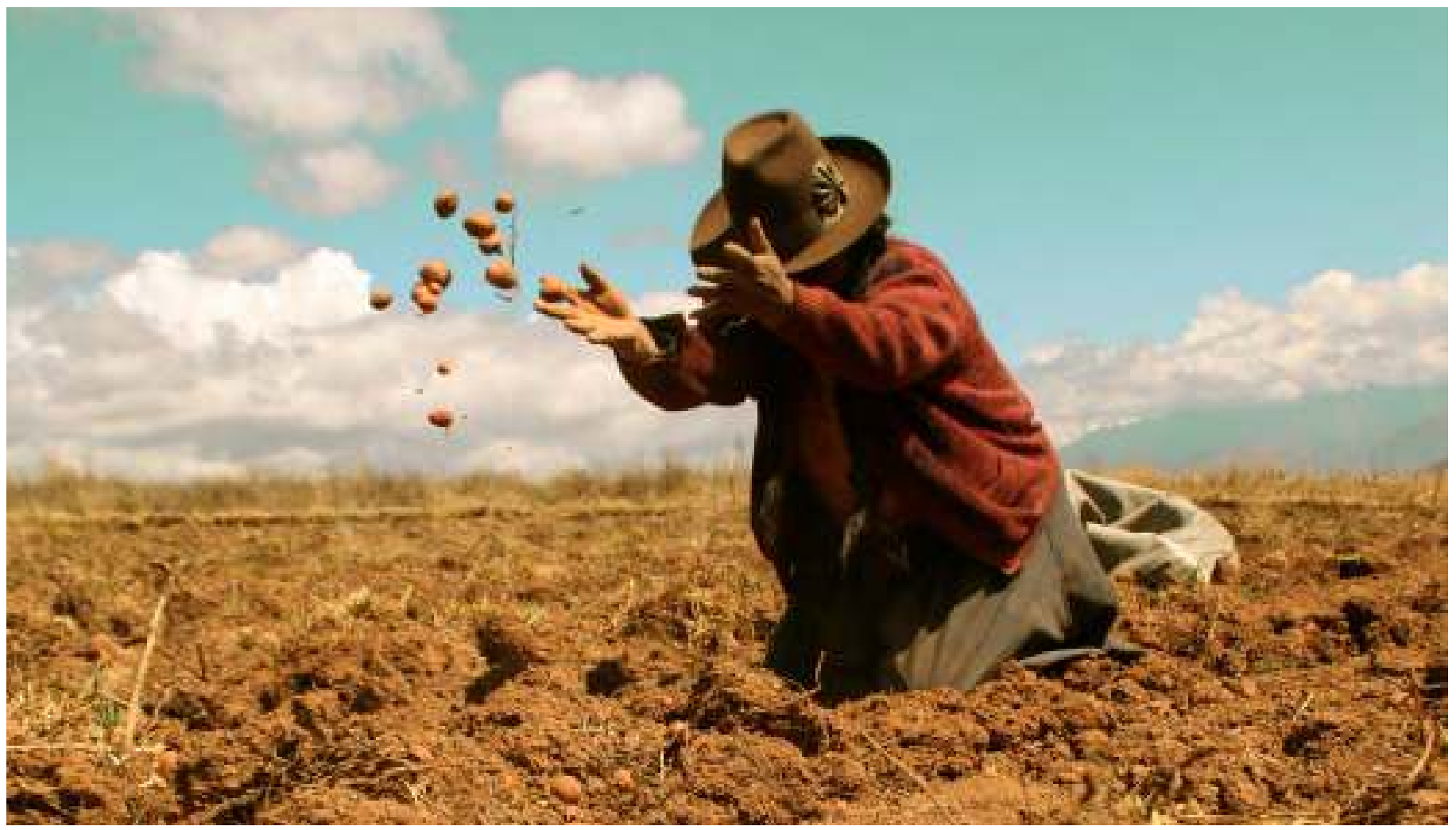

\section{Carbono-neutralidad en Perú bajo supuestos estándar}

Bajo supuestos estándar, y en virtud de las consideraciones efectuadas, este estudio ha demostrado que lograr la carbono-neutralidad es técnicamente posible con transformaciones en cada uno de los sectores de la economía. A continuación, se exponen las principales transformaciones para cada sector, ordenados de mayor a menor contribución en términos de la reducción de emisiones.

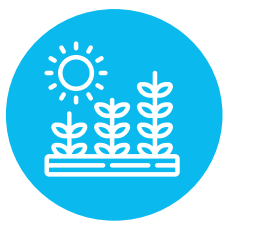

\section{Agricultura, silvicultura y otros usos de la tierra (AFOLU)}

Dichas revisiones son: reversión de la deforestación, con una disminución de las 120.000 $\mathrm{Ha}$ anuales en 2020 a tan solo $18.000 \mathrm{Ha}$ por año en 2050; aumento de la asignación de derechos del bosque primario no categorizado, que alcanzaría los 12,4 millones de Ha en 2050; escalamiento de los sistemas agroforestales y silvopastoriles, que en conjunto llegarían a poco más de 1 millón de Ha en 2050, además del desarrollo de plantaciones forestales para elevar el secuestro de carbono, que alcanzarían los 2 millones de $\mathrm{Ha}$ en el año 2050. Cabe destacar que no se considera la asignación de concesiones en el bosque primario para el desarrollo de estas plantaciones forestales. Las transformaciones en el sector AFOLU se complementan al promover la sustitución de la cobertura de arroz bajo el sistema de riego por secas intermitentes $(120.000 \mathrm{Ha}$ en 2050) y sustituciones modestas en el consumo de carne roja (reducción de un $23 \%$ en 2050 relativo al escenario base) por carne de cerdo (incremento de un 30\% en 2050 relativo al escenario base), así como por un aumento en el consumo de tubérculos con respecto a un escenario base. 


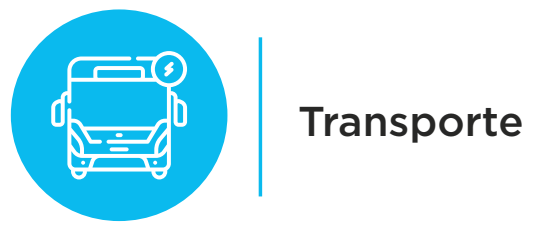

La transformación del sector transporte se habilita a 2050 con la electrificación total de la flota vehicular privada, pública y de carga, lo cual iría acompañado de un aumento del 5\% en la participación del transporte público en la movilidad total de pasajeros, que aumentaría el valor actual del 65\% y llegaría a 70\% a mediados de siglo. La transformación se complementa con un cambio modal al transporte no motorizado (transporte peatonal y en bicicleta) así como con un incremento del teletrabajo y de la digitalización de las actividades que permiten reducir la demanda del transporte de pasajeros en un 30\% total para 2050, es decir, un 15\% de reducción por transporte no motorizado y un $15 \%$ de reducción por teletrabajo y digitalización. De igual forma, las mejoras de logística posibilitarán una reducción del $20 \%$ en la demanda de carga del país para 2050.

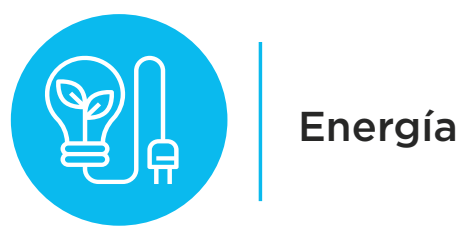

Se estima un aumento de la participación de las energías renovables en el sistema eléctrico, que pasarían del 65\%, valor estimado para 2020, a un $90 \%$ en 2050. La electrificación de las distintas actividades eleva la capacidad instalada existente de $12,8 \mathrm{GW}$ ( $46 \%$ de renovables) a casi $46 \mathrm{GW}$ (85\% de renovables). El escenario contempla un despliegue de las redes eléctricas inteligentes habilitadas con el almacenamiento de energía (principalmente por baterías que ayudan en la integración de las energías renovables intermitentes) que aumenta con el tiempo y podría facultar la participación de los clientes en la provisión de servicios auxiliares y esquemas de respuesta a la demanda. La eficiencia energética permite reducir un $35 \%$ el consumo de energía de los diferentes subsectores para 2050 con respecto

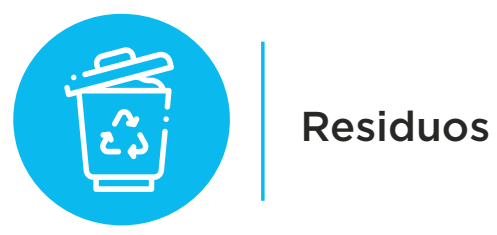

al escenario base.

El proceso transformador del sector residuos considera una reducción de la cantidad de residuos sólidos, producto de su segregación y el reciclaje, y de un mayor tratamiento de las aguas residuales y los efluentes industriales. La generación de residuos sólidos se reduce en un 25\% para 2050 en relación con el escenario base. El 50\% de las toneladas generadas restantes serán recicladas, lo que implica que aproximadamente el $37 \%$ de los residuos proyectados en un escenario base serán depositados en un relleno sanitario en 2050. La transformación se complementa con mayor cantidad de aguas residuales y efluentes industriales tratados; ambos alcanzarían el 50\% en 2050.

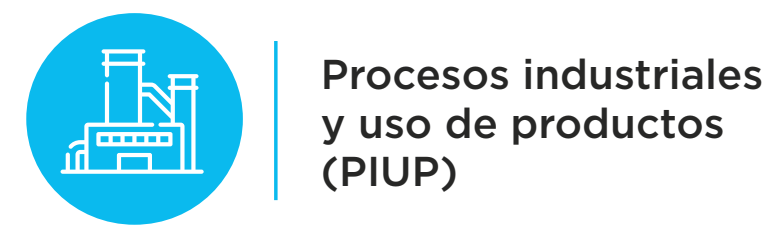

Se contempló únicamente una reducción del uso de clínker para la producción de cemento. 
Este es un sector que puede nutrirse de futuros estudios con la hoja de ruta que están delineando la industria peruana y la Federación Internacional del Cemento. El proceso transformador contempla que para 2050 el consumo de clínker se reduzca a 8,7 Mton, lo cual implica una disminución de 2,2 Mton con respecto al valor proyectado para 2050 en el escenario base.

\section{Gráfico RE1}

Trayectoria de las emisiones de GEI totales por año en Perú en el escenario base y el escenario de carbono-neutralidad bajo supuestos estándar

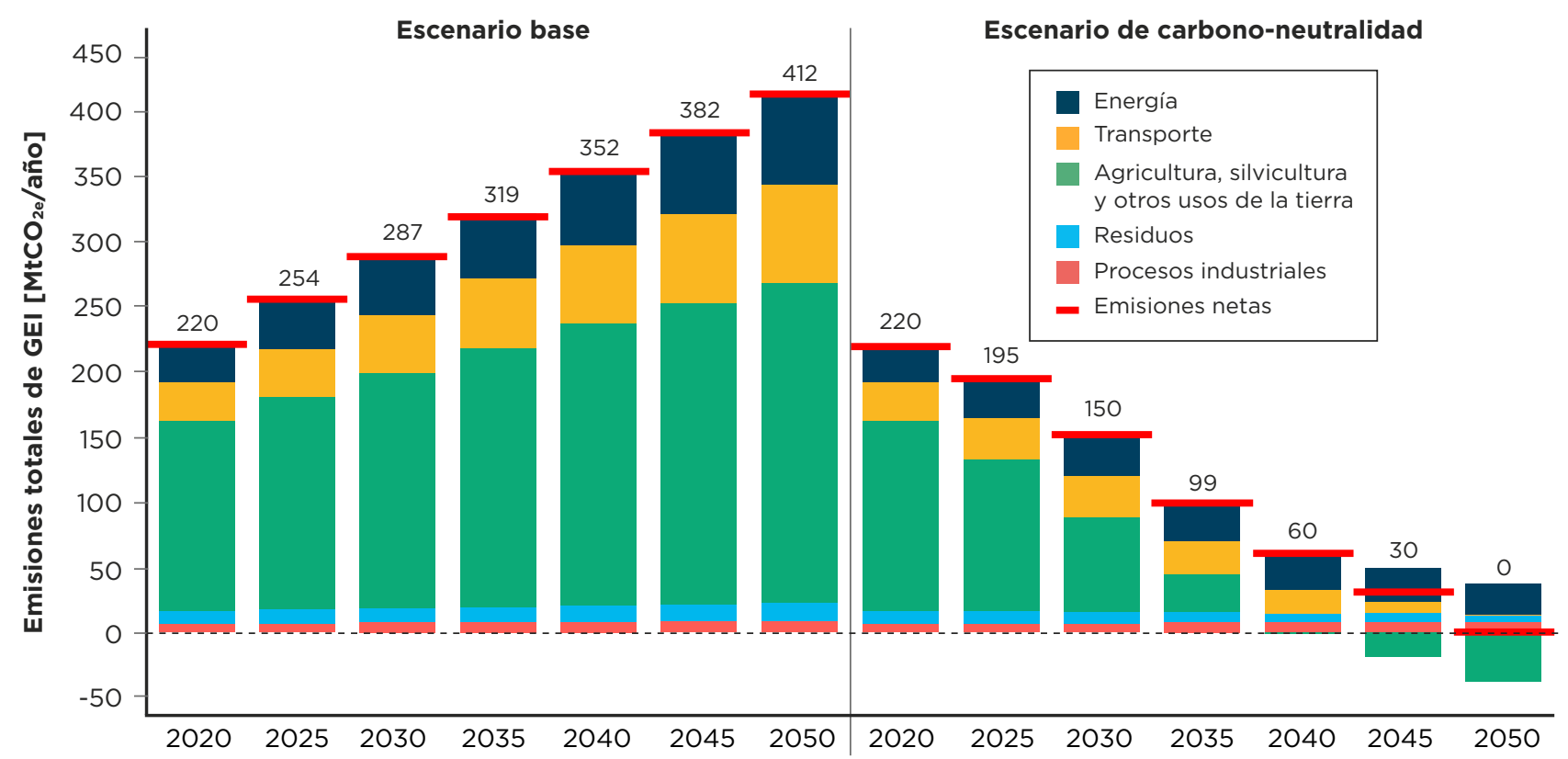

Fuente: Elaboración propia.

1) Nota: La trayectoria en el escenario base es sin acciones de política (izquierda) y en el escenario de carbono-neutralidad, con acciones de política (derecha). Los números sobre las barras corresponden al valor de las emisiones netas.

Implementar este proceso transformacional reduce las emisiones netas de $\mathrm{GEI}$ de $22 \mathrm{O} \mathrm{MtCO}_{2 \mathrm{e}}$ en 2020 a cero emisiones netas en 2050. Sin acciones de política, estas emisiones llegarían a $412 \mathrm{MtCO}_{2 e}$ en 2050. Con respecto a las emisiones proyectadas para 2050 en el escenario base, el sector AFOLU permite reducir casi $282 \mathrm{MtCO}_{2}$ (pasando de emitir $244 \mathrm{MtCO}_{2 \mathrm{e}}$ a secuestrar 38 $\mathrm{MtCO}_{2 \mathrm{e}}$ ), seguido del sector transporte, con 76 $\mathrm{MtCO}_{2 e}$; energía, con $46 \mathrm{MtCO}_{2 \mathrm{e}}$; residuos, con casi $8 \mathrm{MtCO}_{2 \mathrm{e}} ; \mathrm{y}$, por último, PIUP, con poco más de 1 $\mathrm{MtCO}_{2 \mathrm{e}}$. El gráfico RE1 muestra la evolución de las emisiones anuales de GEl en ambos escenarios para cada sector representado en diferentes colores y para el total. 
La descarbonización de la economía de Perú brinda un beneficio neto acumulado de US\$140.000 millones entre 2021 y 2050.? Alcanzar la carbononeutralidad del país para 2050 proporcionará un ahorro de casi US $\$ 233.000$ millones entre 2021 y 2050. El costo total descontado de este proceso transformador ascendería a unos US\$93.000 millones.

El gráfico RE2 presenta los beneficios y costos acumulados por periodo. En el corto plazo (entre 2021 y 2025), la transformación requiere una inversión de US\$18.000 millones, contra un beneficio total del periodo de US\$9.000 millones, lo cual se traduce en un beneficio neto negativo (un costo neto) de US\$9.000 millones. Estas inversiones habilitan múltiples beneficios en los demás periodos, como se detalla a continuación. En el mediano plazo (entre 2026 y 2035), los beneficios totales (US $\$ 65.000$ millones) compensan con creces los costos del periodo (US\$41.000 millones), brindando en dicho lapso un beneficio neto de US $\$ 24.000$ millones. El beneficio neto en el mediano plazo compensa el costo neto del corto plazo. En efecto, en el largo plazo (entre 2036 y 2050), el beneficio neto se estima en US $\$ 125.000$ millones, producto de beneficios totales (US\$159.000 millones) que sobrepasan por mucho a los costos del periodo (US\$34.000 millones).

\section{Gráfico RE2}

Beneficios y costos acumulados por periodo (corto, mediano y largo plazo) del escenario de carbono-neutralidad con respecto al escenario base bajo supuestos estándar

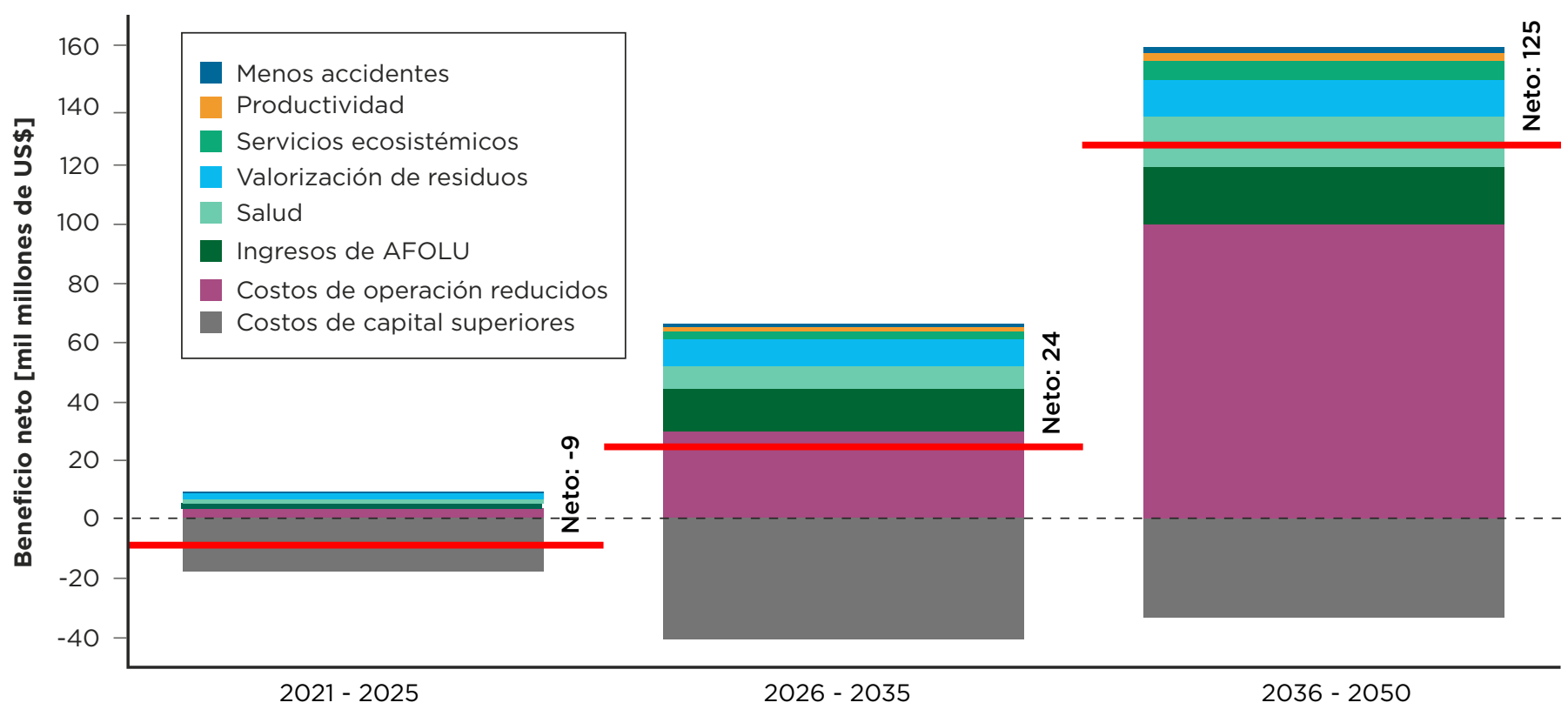

Fuente: Elaboración propia.

Nota: Valorización de residuos incluye el reciclaje y la reutilización de aguas residuales para otras actividades. Salud agrega los beneficios de una reducida combustión de derivados del petróleo (mejor calidad del aire) y los que resultan del tratamiento de residuos. Ingresos de AFOLU combina los beneficios de producción agrícola y comercialización maderera.

\footnotetext{
${ }^{1}$ Todos los costos y beneficios que se reflejan en este reporte han sido descontados al año 2021 utilizando una tasa de descuento del $8 \%$ según el Ministerio de Economía y Finanzas (2020). La tasa interna de retorno es del 29\%; es decir, cualquier tasa inferior brindaría un beneficio neto. Por ejemplo, usar la tasa de descuento que utiliza el MEF para proyectos de largo plazo (4\%) brindaría un beneficio neto de US\$300.000.
} 


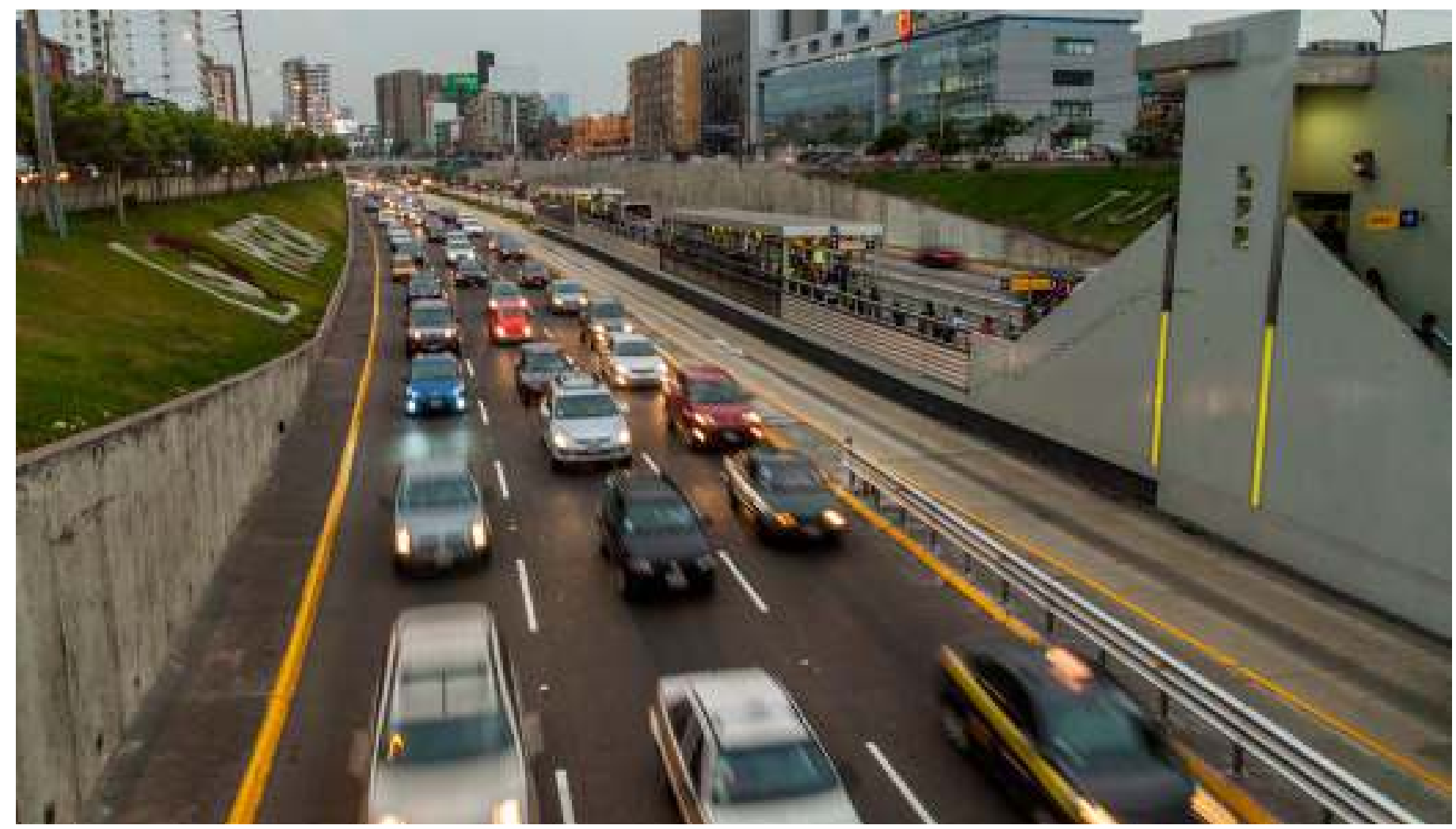

\section{Contribuciones sectoriales bajo supuestos estándar}

El reporte ha permitido analizar el proceso de transformación requerido por sector para alcanzar la carbono-neutralidad. Además, se ha logrado estimar los beneficios y costos para cada uno de los sectores examinados. Así, y ordenado de mayor a menor beneficio neto, se han obtenido las conclusiones que se exponen a continuación.

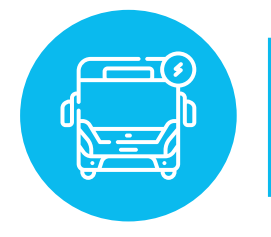

\section{Transporte}

La electrificación de la flota vehicular privada, pública y de carga, el aumento de la movilidad no motorizada, la digitalización de los servicios y el incremento del teletrabajo para reducir la demanda de pasajeros, sumados a la mejora de la logística de transporte de carga, permiten llevar las emisiones de GEI del sector a cero neto en 2050, lo cual representa una disminución de $76 \mathrm{MtCO}_{2 \mathrm{e}}$ con respecto al valor del escenario base estimado. La descarbonización del sector transporte beneficia a Perú con una reducción de los costos operativos (reducción de compra de combustibles fósiles) y de mantenimiento, mejoras en salud por una menor combustión, un aumento de la productividad, y menor cantidad de accidentes, todo lo cual representa un beneficio económico total de US\$139.000 millones acumulados para 2050. Estas ventajas sobrepasan por mucho las inversiones adicionales en términos de sustitución de la flota vehicular, así como las inversiones en infraestructura que en conjunto suman un costo total de US $\$ 47.000$ millones, y brindan un beneficio neto de US\$92.000 millones. 


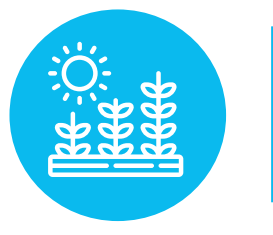

\section{Agricultura,} silvicultura y otros usos de la tierra
La introducción de intervenciones transformadoras permite que el sector pase de generar emisiones netas de $145 \mathrm{MtCO}_{2 \mathrm{e}}$ en 2020 a secuestrar $38 \mathrm{MtCO}_{2 e}$ en 2050. Las emisiones de GEI disminuyen gracias al descenso de la tasa de deforestación anual, que pasaría de $120.000 \mathrm{Ha}$ en 2020 a $18.000 \mathrm{Ha}$ en 2050. La expansión de los sistemas agroforestales, la plataforma de apoyo para el desarrollo agrícola y la asignación de derechos desempeñan un papel importante para lograr esta reducción. Por otro lado, el desarrollo de plantaciones con fines de restauración y de plantaciones con fines comerciales contribuye a que el sector se convierta en un sumidero neto de $\mathrm{CO}_{2}$. En cuanto a la actividad ganadera, se contemplan mejoras en el manejo de pastos naturales altoandinos y una mayor participación de la carne de cerdo en el creciente consumo de carnes. En el sector agrícola, los cambios en la técnica de producción de arroz, el uso de fertilizantes orgánicos y las modificaciones de los patrones de consumo en favor de los tubérculos frente al arroz permiten reducir las emisiones de GEI del sector. Las intervenciones en AFOLU generan para 2050 un beneficio acumulado de US $\$ 45.000$ millones en términos de ingresos derivados de las ventas de productos madereros y los servicios ecosistémicos. Estos beneficios compensan los costos totales de US\$16.000 millones provenientes de inversiones por agroforestería y plataforma de apoyo logístico para el desarrollo agrícola, asignación de derechos, aumento de las plantaciones forestales, y mayores costos de monitoreo y vigilancia para el cumplimiento de la asignación de derechos, así como para la implementación de prácticas forestales sostenibles en las nuevas concesiones forestales. En balance, el sector AFOLU tiene un beneficio neto de casi US $\$ 29.000$ millones para 2050.

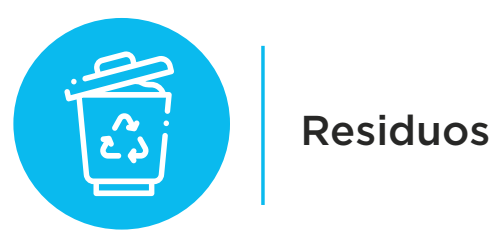

Menor cantidad de residuos, el aumento del reciclaje y el compostaje, y un mayor tratamiento de aguas residuales y efluentes industriales reducen las emisiones anuales de GEl para 2050 en 4,5 $\mathrm{MtCO}_{2 \mathrm{e}}$ con respecto al valor de 2020 y en 7,5 $\mathrm{MtCO}_{2 e}$ en relación con el valor del escenario base en el mismo año. La descarbonización del sector residuos brinda beneficios en términos de agua recuperada para otros usos, ventajas provenientes del reciclaje y de la reutilización de materiales sólidos, y beneficios en salud por el tratamiento de los residuos, todo lo cual implica un beneficio total de US $\$ 29.900$ millones para 2050 . Estas ganancias sobrepasan los costos de capital del periodo, estimados en US $\$ 12.900$ millones y contabilizan un beneficio neto de US\$17.000 millones para 2050. 


\section{Energía}

Aumentar la penetración de energías renovables para lograr una alta renovabilidad de la matriz eléctrica y energética, mejorar la eficiencia energética en las distintas actividades, y masificar las redes eléctricas inteligentes son acciones transformadoras que permiten reducir las emisiones anuales de GEl del sector energía a tan solo $24 \mathrm{MtCO}_{2}$ en 2050, lo cual implica una disminución de $46 \mathrm{MtCO}_{2 \mathrm{e}}$ con respecto a las emisiones que se obtendrían en el escenario base al mismo año. Esta transformación brinda beneficios totales por US $\$ 28.000$ millones cifrados en la reducción de costos operativos y mejoras en la salud gracias a una menor combustión. Estos beneficios sobrepasan los costos totales de US $\$ 26.000$ millones que implican la instalación de nuevas plantas renovables, la expansión de la red eléctrica para habilitar el despliegue de la generación distribuida y el desarrollo de redes eléctricas inteligentes. Todo esto representa un beneficio neto acumulado de US\$2.000 millones a 2050 para el sector que podrían aumentar si se consideran los potenciales beneficios de la implementación de las redes inteligentes.
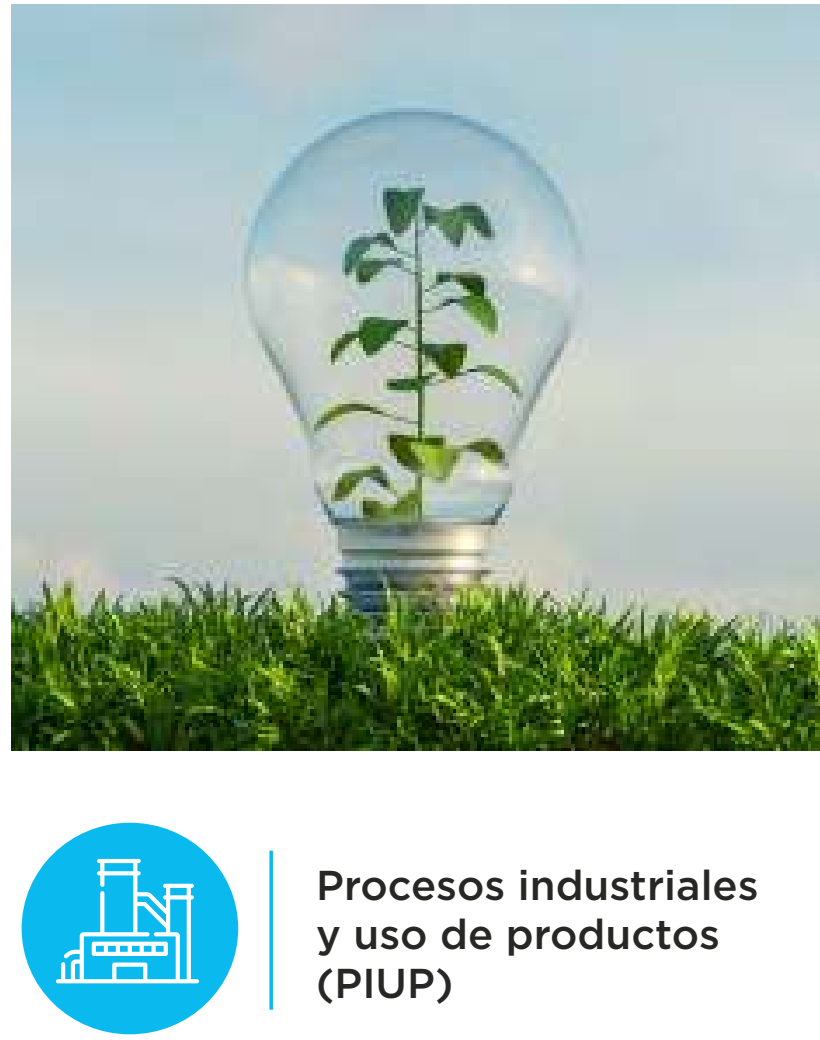

Este sector se ha estudiado de forma muy simplificada. Solo se considera una modesta reducción del clínker en la producción de cemento. La leve reducción de clínker permite disminuir las emisiones anuales de GEI del sector en 2050 de 8,8 $\mathrm{MtCO}_{2 \mathrm{e}}$ en el escenario base a 7,7 $\mathrm{MtCO}_{2 \mathrm{e}}$ en el escenario de carbononeutralidad. En este estudio, y por falta de información, no se han contemplado beneficios para el sector PIUP. Se estima una inversión acumulada a 2050 de US\$750 millones. 


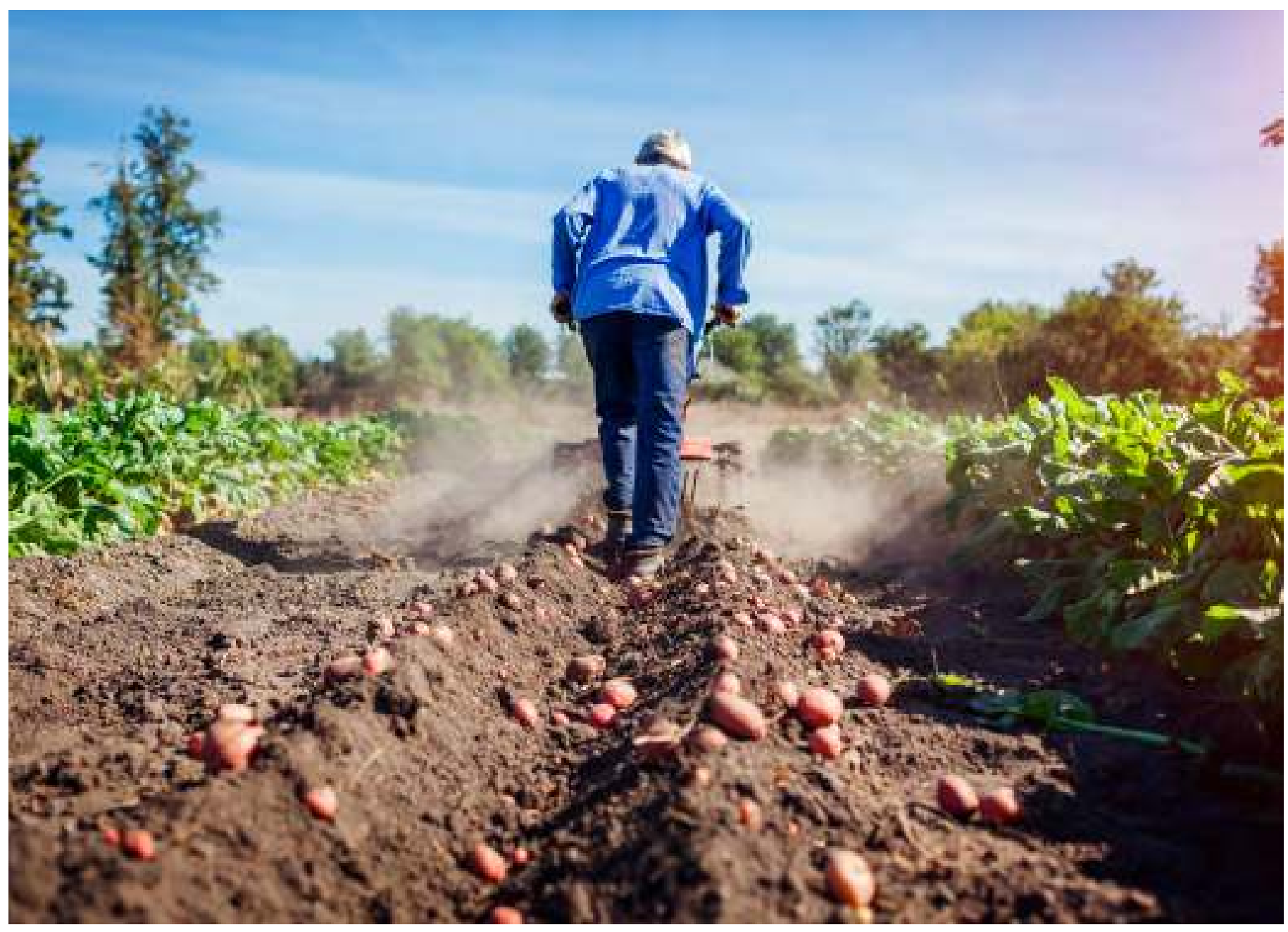

\section{Efecto de la incertidumbre}

La planificación de largo plazo está sujeta a incertidumbre profunda. Por ejemplo, la proyección de los costos tecnológicos podría variar, el crecimiento económico podría ser distinto al proyectadohoyen día, la población podría aumentar o disminuir. Este proyecto ha estudiado el efecto de 201 posibles factores de incertidumbre sobre la trayectoria de las emisiones, los beneficios y los costos de procurar la carbono-neutralidad. Estas trayectorias se han estimado para otras 1.000 rutas de implementación plausibles de cada escenario. Los resultados de esta evaluación indican que el $100 \%$ de las rutas de implementación plausibles del escenario de carbono-neutralidad examinadas brindan un beneficio neto positivo; esto es, todas las rutas exploradas tienen beneficios totales que compensan las inversiones (gráfico RE3). Todas estas rutas de implementación, excepto tres, implican un aumento de costos de capital que se extiende hasta US\$225.000 millones. Todas las rutas de implementación proporcionan una reducción de costos operativos, los cuales se suman a los diversos beneficios adicionales de la transformación, y en conjunto aportan un beneficio neto de la descarbonización acumulado a 2050 que es amplio y se encuentra entre US $\$ 20.000$ millones y US\$391.000 millones. 


\section{Gráfico RE3}

Beneficio neto acumulado a 2050 del escenario de carbono-neutralidad con respecto al escenario base por ruta de implementación plausible

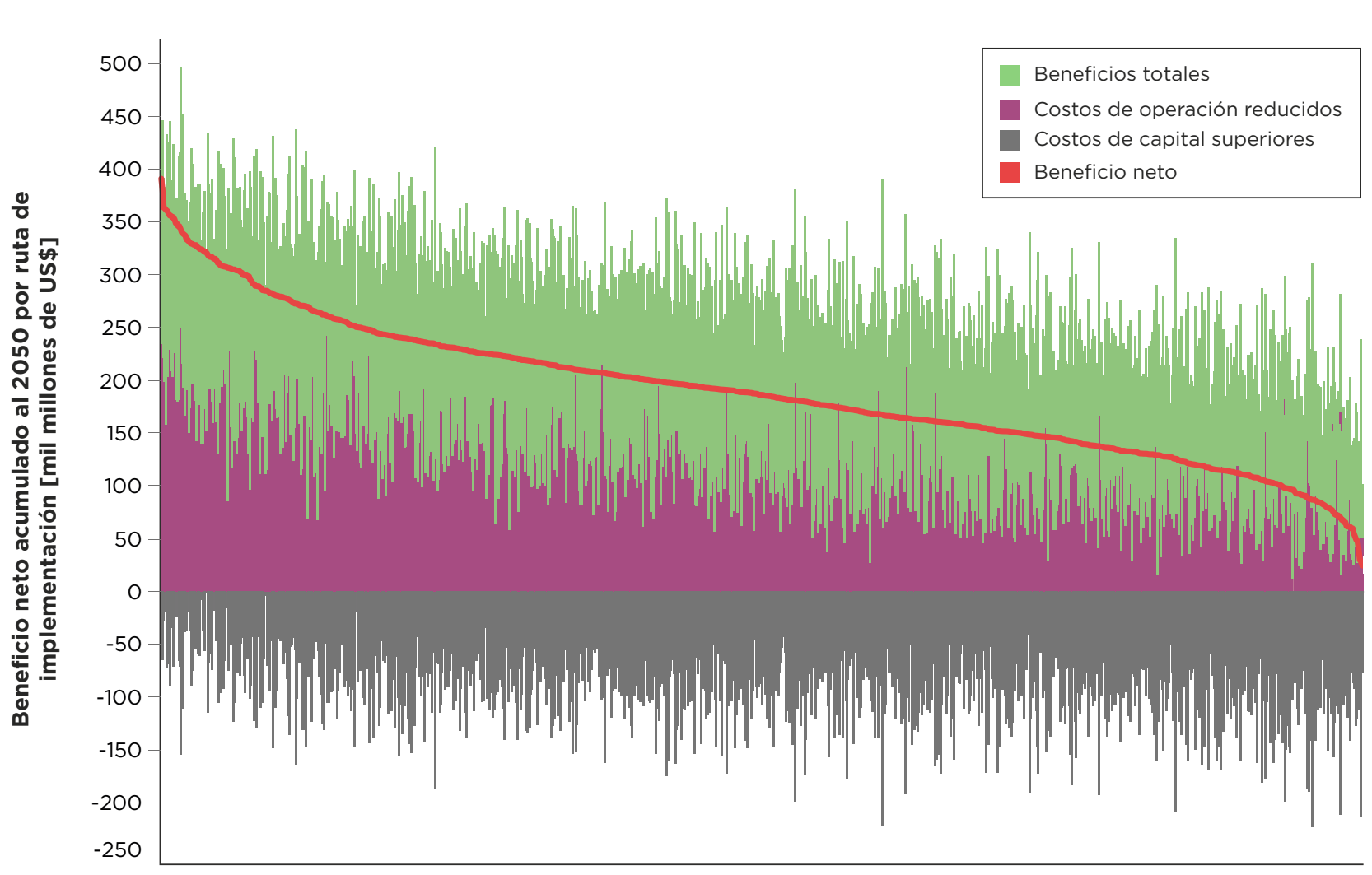

Fuente: Elaboración propia.

Nota: Beneficios totales incluye menos accidentes, productividad, servicios ecosistémicos, valorización de residuos, salud e ingresos de AFOLU.

\section{Apoyo a la estrategia de largo plazo en Perú}

Este estudio demuestra que lograr cero emisiones netas de GEl en Perú es técnicamente posible con intervenciones en cada uno de los sectores de la economía y bajo las consideraciones hechas. El proceso transformador no solo permite descarbonizar la economía, sino que además trae consigo beneficios para el país que sobrepasan por mucho los costos adicionales del proceso transformador y brindan un beneficio socioeconómico neto entre 2021 y 2050 . El análisis sirve de soporte técnico para el Estudio Técnico para la Carbono-Neutralidad elaborado por el MINAM de cara a la actualización de la ENCC y ha proporcionado insumos técnicos relevantes para la actualización de las NDC de 2020, que representan el compromiso inicial de Perú según el Acuerdo de París. 
Las conclusiones de este estudio pueden desempeñar un papel importante para asegurar una sólida implementación de la ENCC, logrando el alcance de sus objetivos en un futuro incierto. Igualmente, los resultados obtenidos pueden ser relevantes para informar inversiones que generen beneficios económicos que puedan servir al proceso de recuperación económica tras los impactos de la pandemia de COVID-19.

El análisis confirma que las acciones en los sectores de transporte y AFOLU son claves para lograr la meta de la carbono-neutralidad para 2050 y ambos implican amplios beneficios. Existen limitaciones importantes en este estudio que podrían mejorarse en los próximos meses y años; por ejemplo, los modelos desarrollados para representar a los sectores de residuos y PIUP, y la inclusión de muchos otros beneficios y costos no considerados en este análisis por falta de información durante su desarrollo.

Por último, este estudio se enmarca en un programa más amplio de investigación y política que informa acerca de la descarbonización a nivel mundial. Este trabajo muestra el valor de abordar el análisis de políticas públicas de manera que (1) sea participativo y aproveche la capacidad analítica y los conocimientos nacionales; (2) traduzca objetivos abstractos de cero emisiones netas para 2050 en acciones específicas a nivel sectorial y a lo largo del tiempo; (3) considere los costos y beneficios socioeconómicos más allá del impacto de las medidas sectoriales en las emisiones de GEl, y (4) analice la incertidumbre a través de la evaluación de rutas de implementación plausibles. El reporte ofrece ideas y modelos que son valiosos para otros países interesados en la descarbonización, y que pueden inspirar a instituciones de desarrollo a nivel mundial.

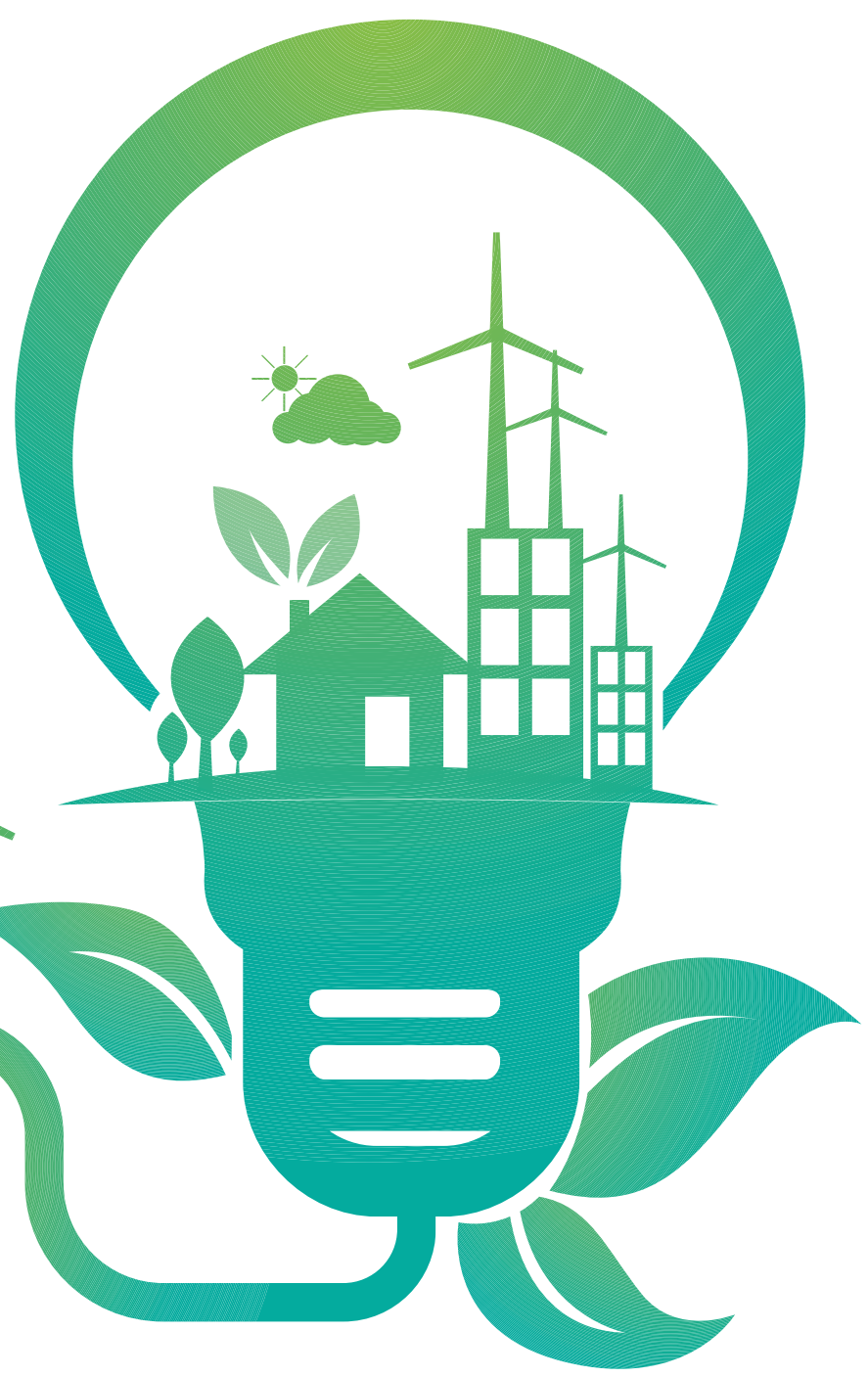




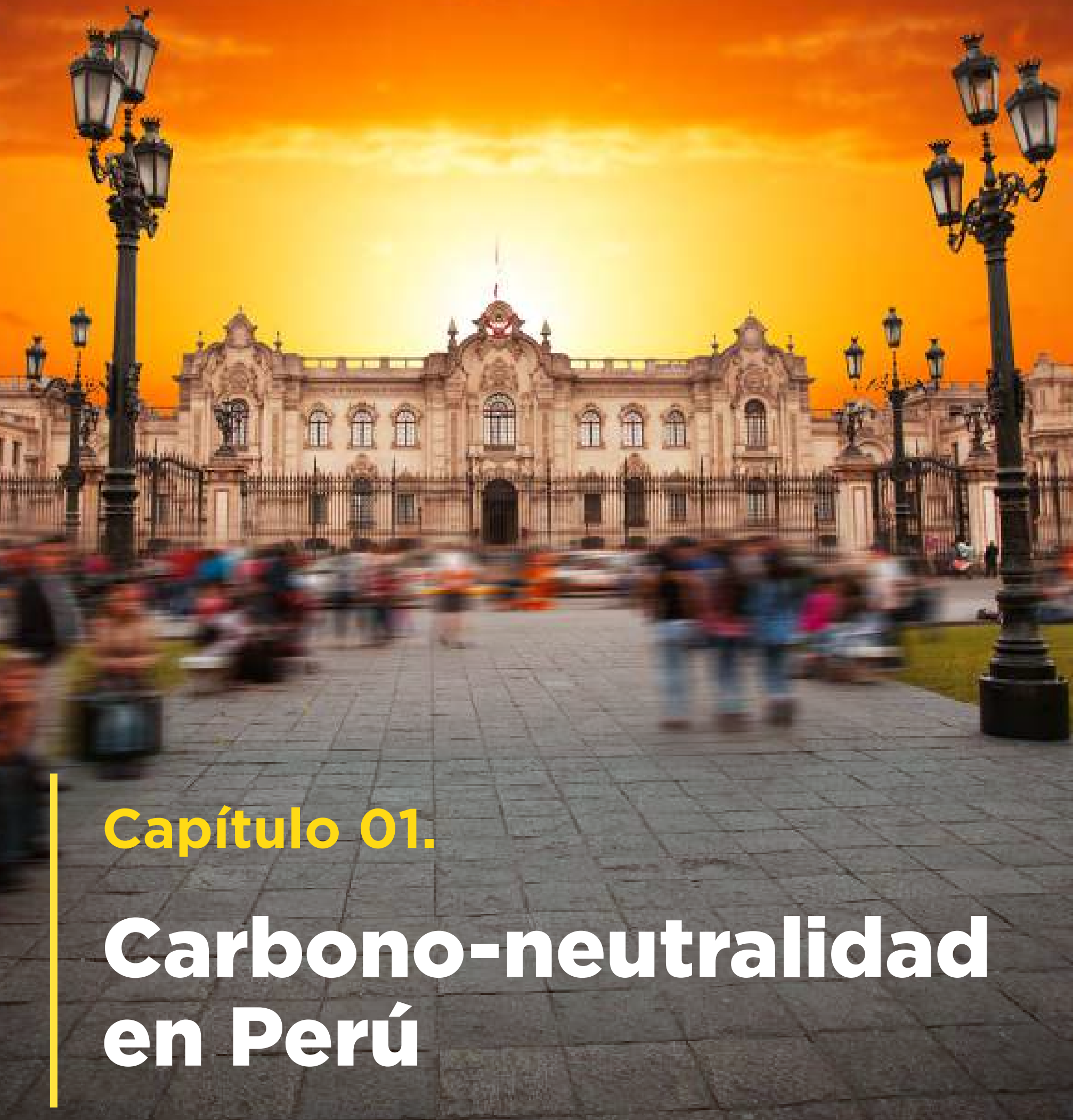


La República del Perú, a través del Ministerio del Ambiente (MINAM), está en proceso de actualizar su Estrategia Nacional ante el Cambio Climático (ENCC), la cual incluirá el objetivo de alcanzar la carbono-neutralidad del país para 2050, y de este modo su política climática se alineará con el Acuerdo de París (Naciones Unidas, 2015). El Banco Interamericano de Desarrollo (BID) y la 2050 Pathways Platform han apoyado al gobierno de Perú con este trabajo, que brinda insumos para el componente de mitigación. Han participado del estudio la Universidad del Pacífico y el Laboratorio de Investigación en Potencia y Energía de la Universidad de Costa Rica.

El objetivo principal ha sido realizar un análisis de costo-beneficio de una ruta de descarbonización que permite alcanzar cero emisiones netas de gases de efecto invernadero (GEI) a mitad de siglo. Para ello, se construyen modelos sectoriales que posibilitan estimar las emisiones de GEI sectoriales y totales de Perú hasta 2050. Los modelos se utilizan para crear una ruta de descarbonización que implementa distintas intervenciones sectoriales para reducir las emisiones de GEI hasta lograr la meta de cero emisiones netas a mitad de siglo. Este escenario, conocido como el escenario de carbono-neutralidad, se contrasta con un escenario de referencia en el cual no hay acciones de mitigación y las emisiones crecen tendencialmente, el cual se conoce como escenario base. Los costos y los beneficios de la descarbonización se obtienen mediante el contraste de resultados de ambos escenarios.

La metodología general del estudio parte de Groves et al. (2020) y usa el método de toma de decisiones robustas (RDM, por sus siglas en inglés) que incorpora los insumos de los actores claves en el análisis para reflejar los distintos objetivos e ideas (Lempert, 2013; 2019; Groves et al., 2020). Además, con inspiración en el método RDM, se estudia el efecto de la incertidumbre profunda ${ }^{2}$ del proceso de transformación a 2050 mediante el análisis de múltiples rutas de implementación plausibles de cada escenario.

Las siguientes secciones de este capítulo contextualizan el estudio bajo la actualización de la ENCC y se presenta el vínculo del proyecto regional de Rutas de Descarbonización Profunda de América Latina y el Caribe (Bataille et al., 2020; BID y DDPLAC, 2019; Waisman et al., 2019) con el apoyo al gobierno de Perú. Luego se detalla el proceso co-constructivo con los actores claves de los distintos sectores, parte del método RDM. El capítulo presenta además la metodología del estudio y una descripción breve de los modelos utilizados para estimar emisiones, beneficios y costos. Más adelante, se describe la exploración de incertidumbre. Finalmente, se enlistan los beneficios y costos que no han sido incluidos en el estudio, principalmente por falta de información, en aras de documentar potenciales mejoras para una futura actualización del análisis.

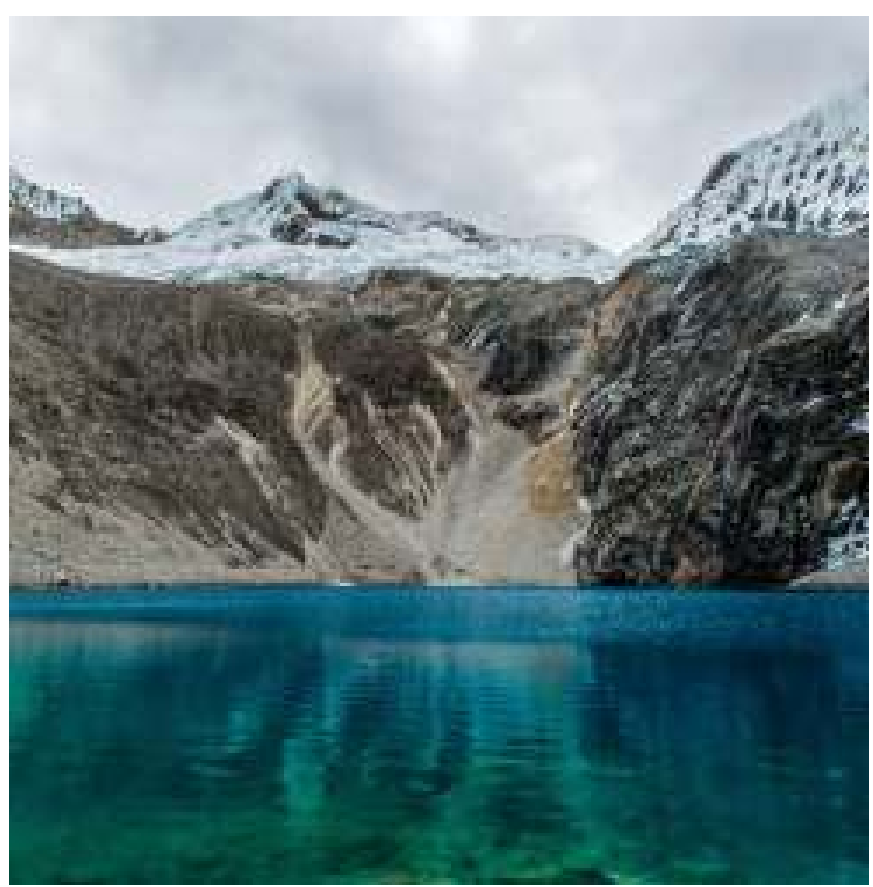

${ }^{1}$ En Perú, carbono-neutralidad, descarbonización y cero emisiones netas significa que todas las emisiones de GEI (no solo de CO 2 ) no excedan la captura natural de los bosques.

${ }^{2}$ En un contexto de toma de decisiones, la incertidumbre profunda tiene lugar cuando no existe consenso sobre las relaciones de las variables clave que afectan el futuro y sobre la función de probabilidad de las variables y parámetros de los modelos (Lempert, Popper y Bankes, 2003). 


\subsection{La actualización de la ENCC y la carbono-neutralidad en Perú}

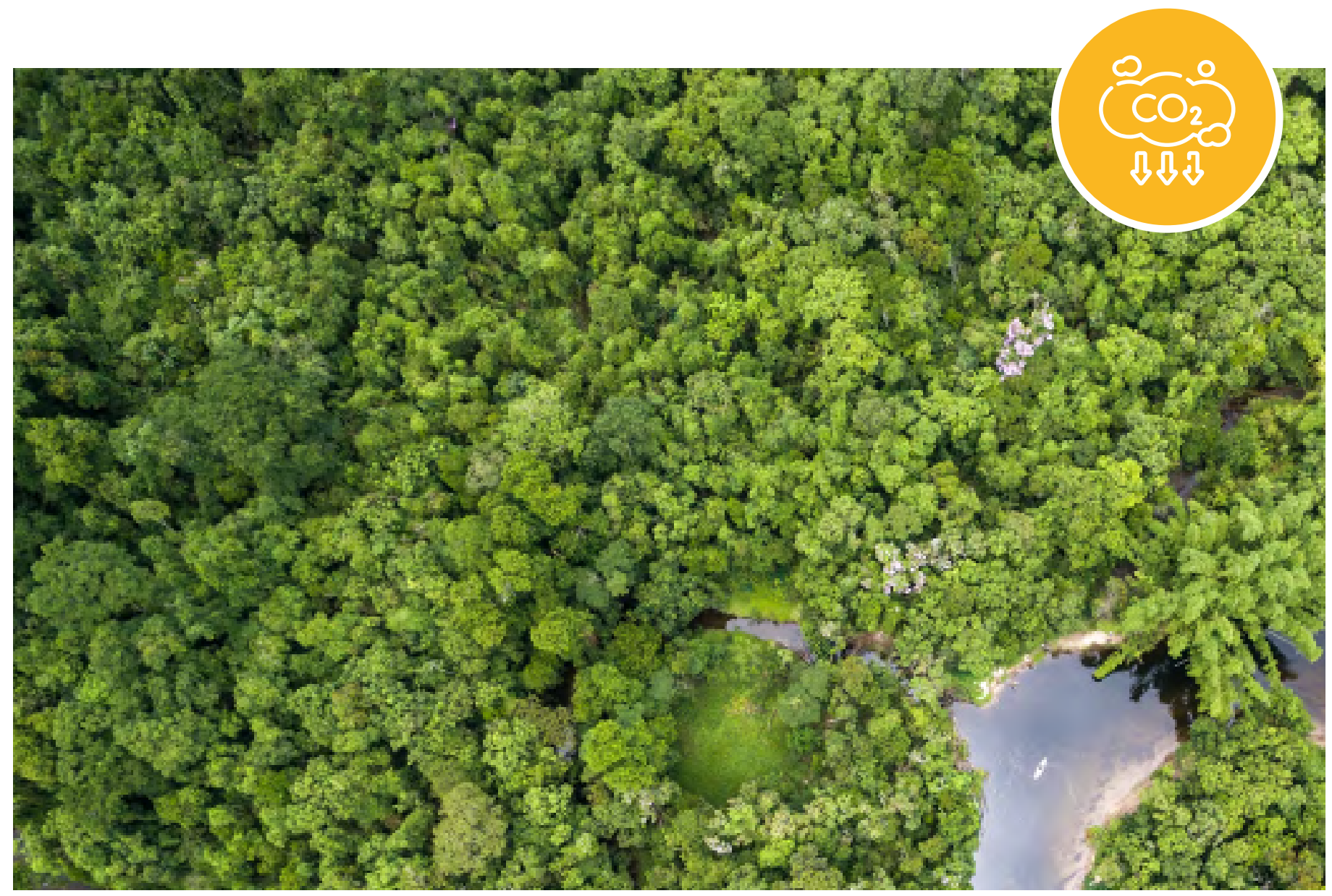

El Acuerdo de París (Naciones Unidas, 2015) compromete a las distintas partes a limitar sus emisiones para evitar un incremento muy por debajo de $2^{\circ} \mathrm{C}$ de la temperatura promedio global con respecto a los niveles preindustriales, y a realizar esfuerzos adicionales para limitar dicho aumento a $1,5^{\circ} \mathrm{C}$ para evitar los impactos negativos del cambio climático. Según el reporte especial del Panel Intergubernamental sobre Cambio Climático (IPCC, 2018), lograr esto último requiere reducir las emisiones netas de dióxido de carbono $\left(\mathrm{CO}_{2}\right)$ a cero a mitad de siglo y lograr una disminución sustantiva de otras emisiones de GEI como el metano, el carbono negro y los óxidos nitrosos. El Acuerdo de París invitó a los países a comunicar en 2020 sus estrategias de largo plazo, las cuales, de acuerdo al reporte especial del IPCC, deberían diseñarse con una visión transformadora en procura de la carbono-neutralidad para 2050 (Aguilar Jaber et al., 2020; BID y DDPLAC, 2019; Fay et al., 2015). 
Descarbonizar Perú requerirá acciones transformadoras en todos los sectores de la economía. Para que las estrategias climáticas de largo plazo sean exitosas, deberán diseñarse de manera tal que, además de alcanzar la carbononeutralidad, impulsen otros objetivos sociales y económicos sectoriales y nacionales. Así, también deberán ser adecuadamente integradas en las agendas de los diferentes sectores, que son los implementadores últimos. La mejor vía para lograr esta alineación sectorial y el alcance de objetivos de desarrollo más amplios es la co-construcción de las estrategias de largo plazo, entre ministerios de Medio Ambiente y ministerios y actores sectoriales, así como ministerios de Finanzas y Planificación, pues son los que mejor entienden los desafíos, oportunidades y posibles mecanismos para implementar las diferentes acciones requeridas para la transformación en cada una de sus áreas de trabajo (Jaramillo y Saavedra, 2021). En este sentido, tanto la actualización de la ENCC como este estudio en particular se centran en un diseño altamente participativo.

Lograr una economía con cero emisiones netas es técnicamente posible y, bien planeada y ejecutada, brindaría beneficios económicos para los países. Por ejemplo, la descarbonización acompañada de cambios estructurales podría aumentar el producto interno bruto (PIB) de los países del Grupo de los 20 (G-20) en un 2,8\% al 2050 (OCDE, 2017), y traería beneficios netos para Costa Rica que se estiman en US $\$ 41.000$ millones (Groves et al., 2020). La descarbonización incluye un mayor uso del transporte público y la electrificación de la flota vehicular; ambas acciones mejoran la calidad de vida de las personas, y brindan beneficios económicos gracias a la reducción del tiempo perdido en el congestionamiento de tránsito y a la disminución de la contaminación del aire; en Costa Rica, estas acciones implican un beneficio neto de US\$20.000 millones para 2050 (Godínez et al.,
2020). La descarbonización se beneficia de los costos decrecientes de las energías renovables, lo que permite una reducción de emisiones importante a un costo similar al planeado originalmente para las NDC de 2015. Esto mejora el acceso a la energía y reduce las facturas eléctricas (BID y DDPLAC, 2019). Una economía con cero emisiones netas también puede crear 15 millones de empleos netos en América Latina y el Caribe para 2030 (Saget, Vogt-Schilb y Luu, 2020). Comprender los beneficios de la descarbonización, así como la distribución de los mismos en el tiempo, puede ser un insumo relevante para Perú en un contexto en el cual la recuperación económica tras los impactos de la pandemia de COVID-19 se configura como una prioridad nacional.

En Perú la ENCC se aprobó en 2015 y rige hasta 2021, y responde al llamado de la Convención Marco de las Naciones Unidas sobre el Cambio Climático (CMNUCC) para que los países tomen acciones en mitigación y adaptación para hacer frente al cambio climático. El proceso de actualización de la ENCC inició en 2021 y contempla una planificación con un horizonte a 2050. En cuanto al componente de mitigación, la ENCC tiene como objetivo lograr la carbono-neutralidad del país a mitad de siglo. Para sustentar dicha meta, el MINAM se fijó como fin para 2020 desarrollar una propuesta técnica, llamada Estudio Técnico para la CarbonoNeutralidad, que se presentó a la Comisión de Alto Nivel de Cambio Climático del país. El presente trabajo ha constituido el insumo principal para la elaboración del mencionado Estudio y proporcionó insumos técnicos relevantes para la actualización de las actuales Contribuciones Determinadas a Nivel Nacional (NDC, por sus siglas en inglés), que representan el compromiso inicial de Perú según el Acuerdo de París. La ENCC será un instrumento clave en la implementación de las NDC con miras a 2050 . 


\subsection{DDPLAC y el apoyo al gobierno peruano}

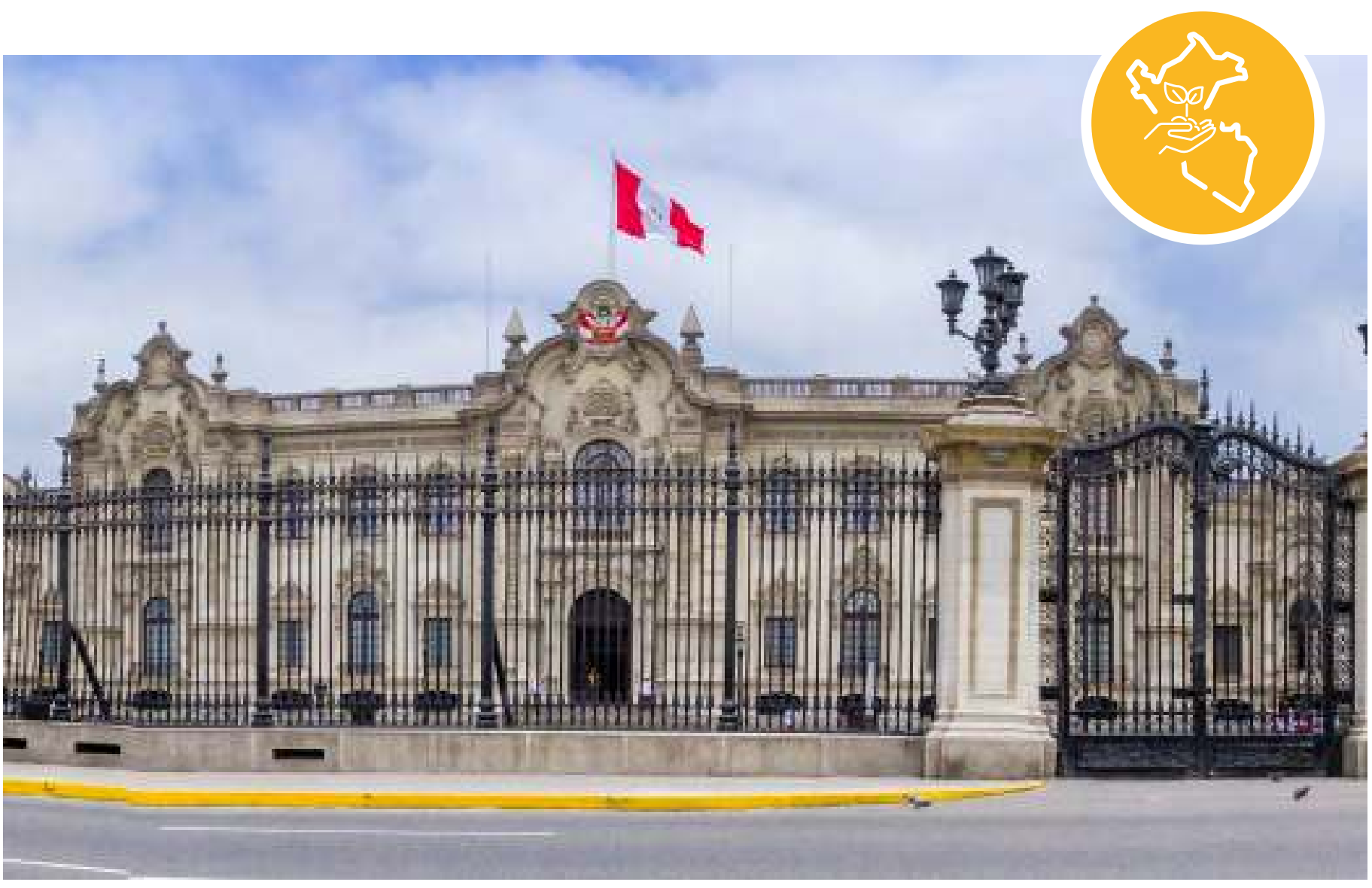

Este trabajo se desarrolla en el marco del segundo proyecto regional de Rutas de Descarbonización Profunda de América Latina y el Caribe (Bataille et al., 2020; BID y DDPLAC, 2019). Esta segunda versión utiliza las capacidades creadas y las alianzas producidas en su primera versión para apoyar a diferentes gobiernos de la región en el desarrollo de estudios técnicos que brinden insumos para crear y evaluar rutas de descarbonización consistentes con cero emisiones netas de dióxido de carbono para 2050 y con una reducción sustantiva de otras emisiones de GEl.
En el caso de Perú, la Universidad del Pacífico y la Universidad de Costa Rica se han aliado para apoyar al MINAM con este estudio, que utiliza un enfoque de toma de decisiones bajo incertidumbre profunda (Marchau et al., 2019), y en particular el método RDM (Lempert, 2013; Lempert, 2019) para estimar los costos y beneficios del escenario de carbononeutralidad mediante la captura de la incertidumbre tecnológica, económica e institucional que rodea su creación. 


\subsection{Proceso co-constructivo}

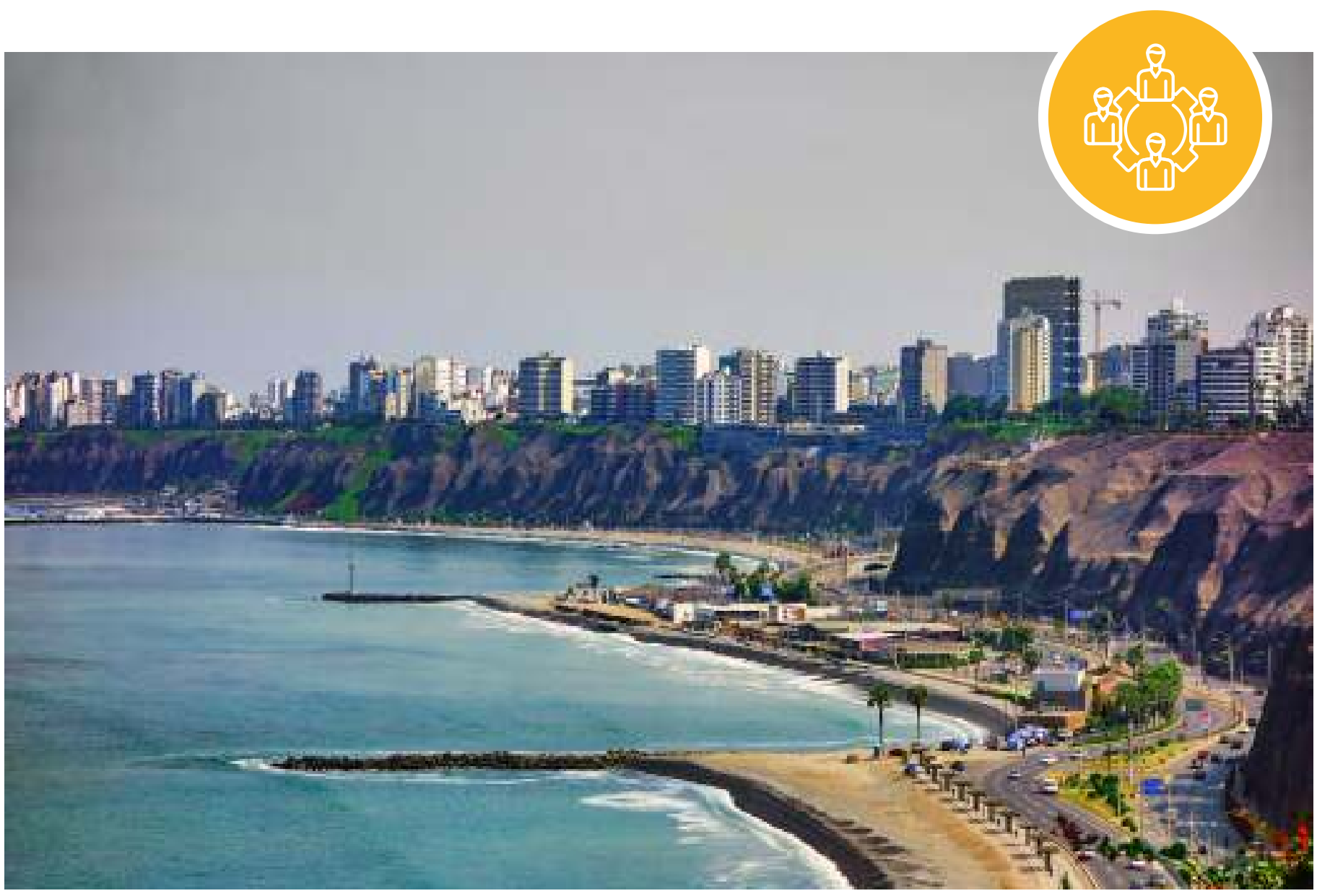

El estudio contempla los insumos de los actores claves de los diferentes sectores en Perú. Se realizaron dos series de talleres consultivos y una presentación de resultados.

La primera serie de talleres consultivos se llevó a cabo del 21 al 23 de abril de 2020 y en total hubo 109 participantes en representación de 45 instituciones diferentes. Se realizó un taller por sector, para un total de seis: energía; transporte; agricultura, silvicultura y otros usos de la tierra (AFOLU); residuos; y procesos industriales y uso de productos. Dentro de la metodología de RDM, el primer taller consultivo representa una oportunidad para exponer el enfoque del estudio y co-crear la matriz DAMI. Dicha matriz cumple con los siguientes objetivos: i) captura las diferentes métricas de desempeño sectorial y global para evaluar el éxito de las estrategias de descarbonización (D); ii) mapea las actuales NDC y las intervenciones planteadas por los participantes para producir un mapa de opciones de políticas que están a disposición para procurar el éxito de la estrategia de descarbonización (A); iii) permite identificar modelos y datos disponibles para estudiar el proceso transformador (M); y iv) 
enlista las incertidumbres que deben considerarse en el análisis en aras de producir un estudio robusto de beneficios y costos (I). Las acciones sirven para definir las metas de política que se contemplarán en los modelos, y las incertidumbres permiten identificar las variables dentro de los modelos que tendrían un efecto en las métricas de desempeño. Los detalles de los participantes, sus instituciones, y la matriz DAMI pueden consultarse en el anexo A.

La segunda serie de talleres consultivos se realizó del 25 al 27 de agosto de 2020, con un total de 159 participantes en representación de 53 instituciones distintas. Esta etapa arrojó resultados preliminares que mostraron la necesidad de contemplar opciones de políticas adicionales para alcanzar la carbononeutralidad. Por lo tanto, se incluyó una actividad para identificar opciones de políticas extra. Esto también sirvió para reforzar y reevaluar las demás variables de la matriz DAMI.

Finalmente, en un tercer taller, implementado el 14 y el 15 de octubre de 2020, se realizaron dos presentaciones de resultados finales con los actores claves. La primera presentación se enfocó en los sectores de energía, transporte, residuos y procesos, y contó con 116 participantes. La segunda se enfocó en AFOLU y contó con 81 participantes. En ambas presentaciones se mostraron los resultados totales del escenario de carbono-neutralidad y los correspondientes resultados sectoriales. Esta etapa promovió discusiones bilaterales con los expertos, permitió identificar mejoras en el estudio y definió los siguientes pasos.

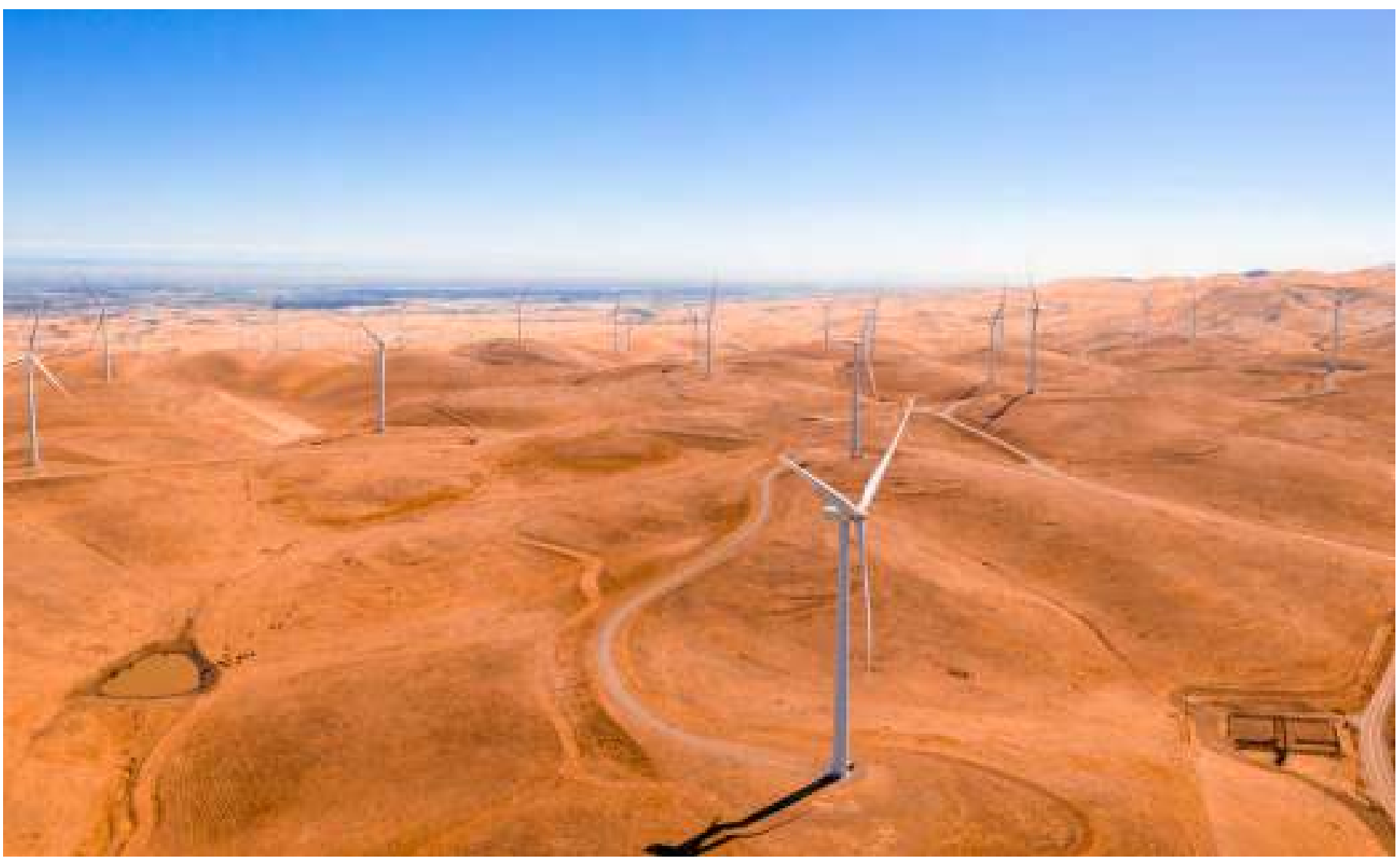




\subsection{Estimación de emisiones, beneficios y costos: metodología y modelos}

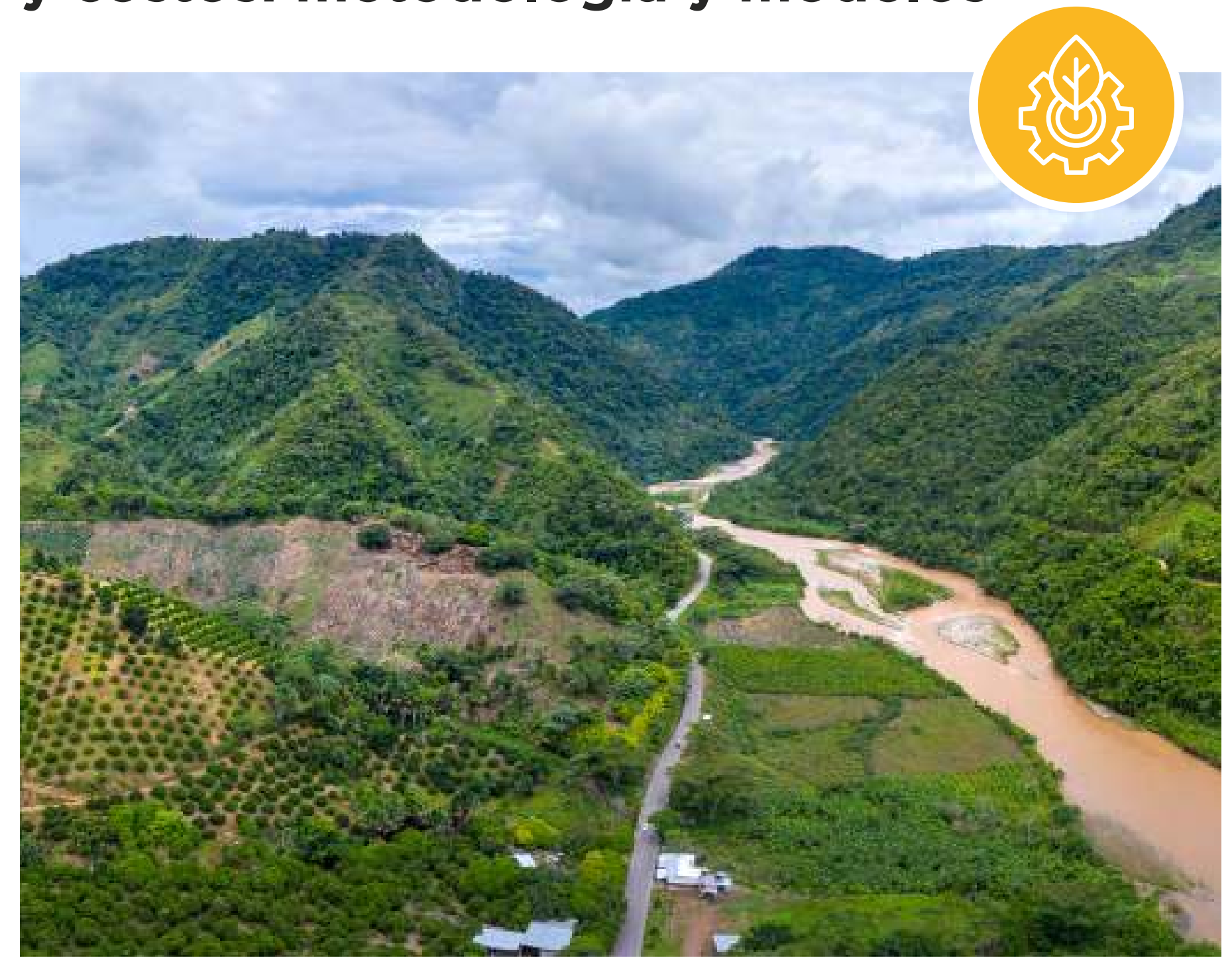

Este proyecto utilizó el marco metodológico de análisis que se exhibe en el diagrama 1.1. Los diversos insumos de los participantes de los talleres co-constructivos se utilizaron para mapear las distintas métricas de desempeño (Ds), las diferentes acciones de política que podrían ayudar a lograr la carbono-neutralidad (As), los modelos y datos con los cuales se puede estudiar el proceso transformador (Ms), más las principales incertidumbres que podrían tener un efecto en el mismo (Is). 
Estos son los insumos para llevar a cabo un ejercicio computacional que produce múltiples parametrizaciones sobre los modelos sectoriales para luego estimar las emisiones, los beneficios y los costos bajo incertidumbre. Los resultados del estudio se presentan en una visualización interactiva en la plataforma Tableau que se ha puesto a disposición de forma gratuita en Internet. ${ }^{3}$

Este proyecto desarrolló un modelo de evaluación de rutas de descarbonización para Perú que permite estimar las emisiones de GEI totales y por sector: energía; transporte; agricultura, silvicultura y uso del suelo; residuos; y procesos industriales y uso de productos. La selección de los sectores se basa en lo reportado en el Inventario Nacional de GEI (MINAM, 2021). El modelo permite además estudiar los beneficios y costos del proceso transformativo hacia la carbono-neutralidad del Perú para 2050. Estos resultados posibilitan cuantificar el beneficio neto; o sea, los beneficios menos los costos.

\section{Diagrama 1.1}

Marco metodológico desarrollado en el estudio

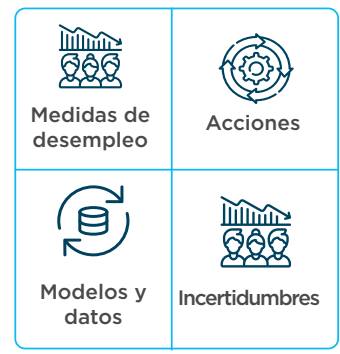

\section{Códigos Python}
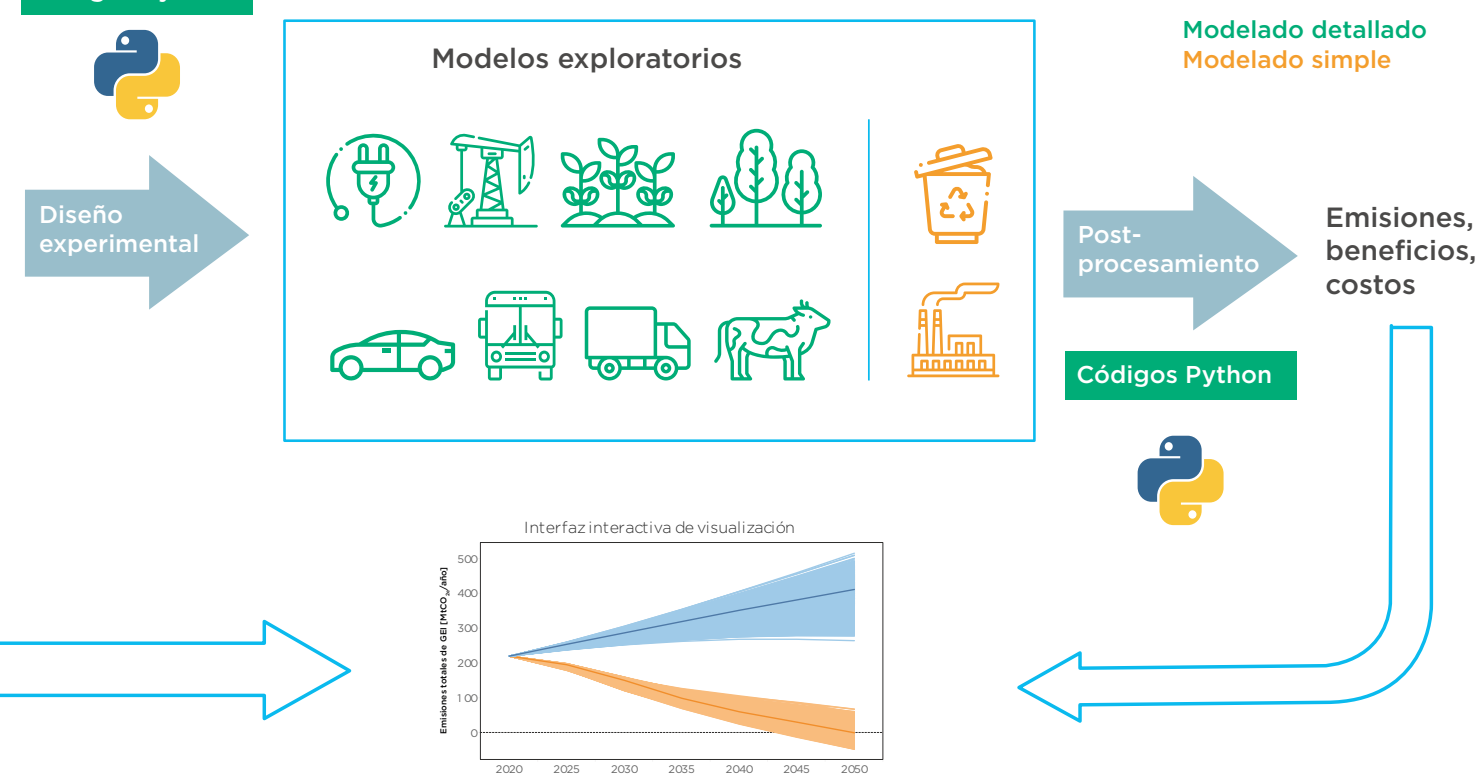

Fuente: Elaboración propia.

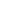

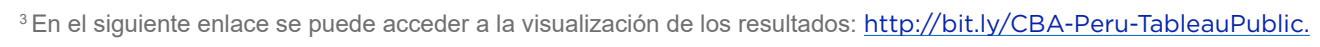


El modelo integrado combina el modelo existente del sector AFOLU (De la Torre Ugarte y ERay, 2000) con otros tres modelos desarrollados por el equipo de trabajo para los demás sectores. El modelo que caracteriza los sectores de energía y transporte se desarrolló utilizando el Sistema de Modelado de Código Abierto de Energía (OSeMOSYS, por sus siglas en inglés) (Howells et al., 2011). Por último, el equipo produjo modelos más simplificados para los sectores residuos y procesos industriales y uso de productos que fueron programados en Python. Los detalles técnicos de los modelos se presentan en el anexo B. El modelo desarrollado se diseñó para permitir la incorporación de otros modelos que pudieran surgir en el futuro para estimar las emisiones, los beneficios y los costos del proceso transformador de Perú y de cada uno de los sectores.

Con los modelos y la información de los talleres y fuentes secundarias, se proyectó un escenario de transformaciones sectoriales para la descarbonización que lleva a Perú a la carbononeutralidad en 2050. Este escenario se llama escenario de carbono-neutralidad. En cada uno de los sectores, los resultados de la reducción de emisiones, los beneficios y los costos del escenario de carbono-neutralidad se contrastan contra un escenario tendencial que se llama escenario base. Este escenario tendencial no implementa acciones de mitigación en ninguno de los sectores, más allá de las implementadas a 2018, y los hábitos se mantienen tendenciales a 2050. Los detalles del escenario de carbono-neutralidad y del escenario base se discuten con gran detalle tanto a nivel global como sectorial en el capítulo 2. Los costos y los beneficios de la descarbonización se obtienen mediante el contraste de resultados de ambos escenarios.

Cada modelo se ha calibrado con fuentes de información disponibles en el país y en la literatura

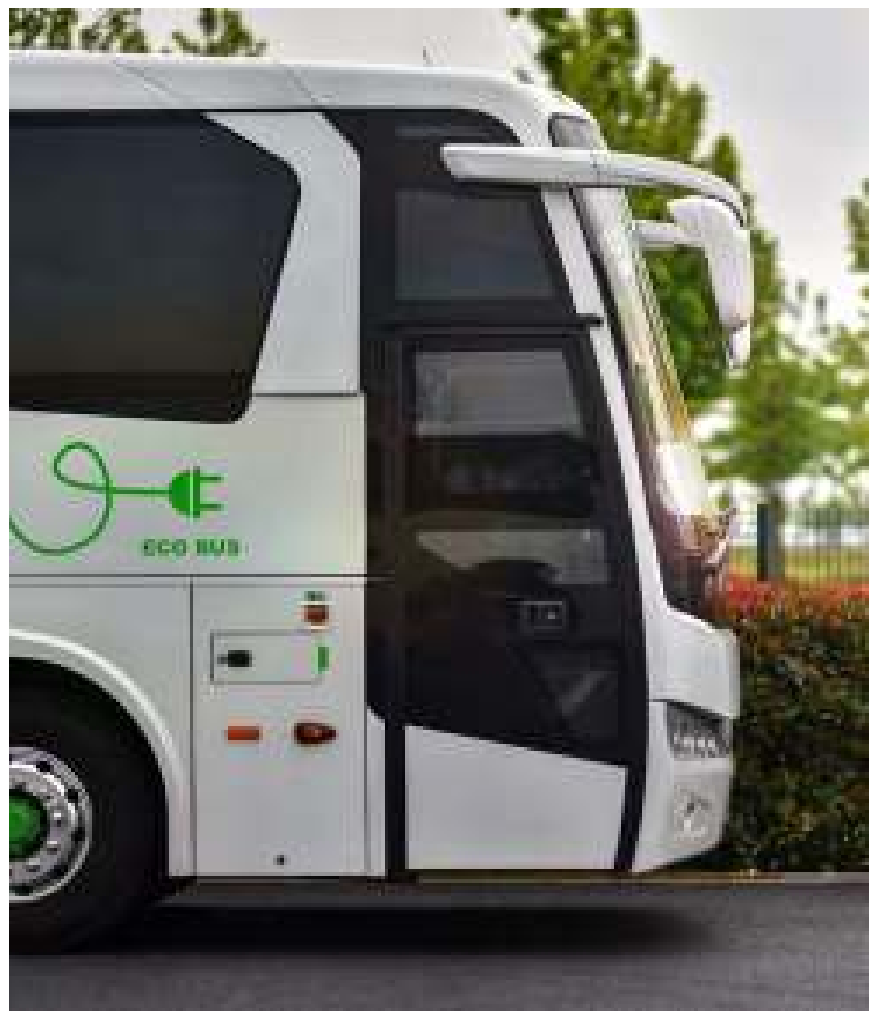

internacional en caso de no haber información nacional disponible. Los factores de emisión utilizan los resultados del último Inventario de GEI con información de 2016, de tal forma que las emisiones totales y sectoriales coincidan con lo reportado para ese año. Se llevan a cabo proyecciones de las diferentes actividades que permiten estimar las emisiones de cada escenario a 2050, dados los procesos transformacionales del escenario de carbono-neutralidad y las actividades tendenciales del escenario base.

Los beneficios de la descarbonización se estiman multiplicando el nivel de actividad en cada sector por factores de beneficio descritos en la literatura. Por ejemplo, el Fondo Monetario Internacional (FMI) estima para Perú el costo de los accidentes y del congestionamiento producto de la movilidad de pasajeros en función de los pasajeros-kilómetro (Coady et al., 2019). Por lo tanto, una reducción 
en la demanda de pasajeros conlleva a una disminución del costo correspondiente y por ende a un beneficio en el sector transporte. Desde la sección 1.4.1 hasta la sección 1.4.5 se describen los modelos usados y se enlistan los beneficios percibidos por sector. El anexo B detalla los factores de beneficio utilizados.

Los costos de implementar las acciones de mitigación se estiman multiplicando el nivel de inversión necesario por unidad de producción. Por ejemplo, la inversión necesaria para la incursión de energías renovables no convencionales se puede calcular con la cantidad de gigavatios necesarios para producir una cantidad de energía dada. El anexo B detalla los modelos y las fuentes para estimar los costos de la descarbonización.

Cada escenario se parametriza utilizando supuestos estándar; esto es, con las proyecciones de crecimiento económico y poblacional, los precios de las tecnologías y de los combustibles, eficiencias, rendimientos, factores de beneficios, y factores de emisión reportados en la literatura nacional e internacional existente al momento del estudio. Cada escenario con supuestos estándar representa una ruta plausible a 2050 y no debe entenderse como la ruta tendencial o de descarbonización más probable, ya que existen incertidumbres que afectarán las trayectorias de emisiones, beneficios y costos. Incertidumbres son, por ejemplo, el crecimiento económico y poblacional, el costo futuro de las energías renovables, 0 el precio internacional de los combustibles o del carbono.

La estimación con los supuestos estándar se presenta en el capítulo 2 para discutir en gran detalle el proceso transformacional y la evolución de los diferentes sectores para una ruta de implementación plausible de los escenarios. Posteriormente se aplica el método

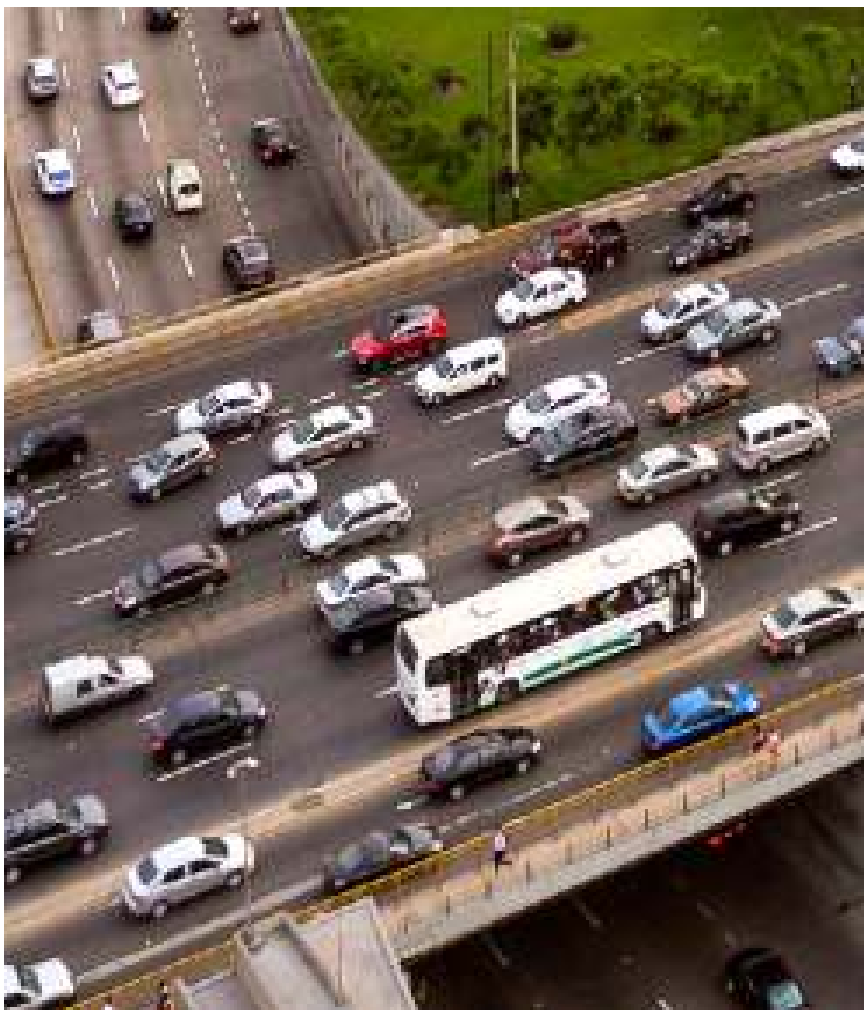

RDM para analizar el efecto de la incertidumbre profunda sobre las emisiones, los beneficios y los costos en diversas rutas de implementación de los escenarios. En este estudio se evalúan incertidumbres como crecimiento económico y poblacional, costos capitales de las tecnologías renovables y convencionales (en energía y transporte), costos operativos de las plantas renovables y convencionales (en energía y transporte), costos de infraestructura, precio internacional de los combustibles, factores de planta de las máquinas para producir electricidad, eficiencia de las tecnologías renovables y convencionales, precios de los cultivos, costos capitales y operativos en AFOLU, rendimiento de la tierra, coeficientes de beneficios, y coeficiente de emisión y absorción, entre otros. El anexo B detalla las variables inciertas y presenta el rango de variación explorado. Cada escenario (base y carbono-neutralidad) se parametriza de forma 
variada para evaluar su desempeño en 1.000 diferentes implementaciones adicionales; o sea, cada escenario se evalúa en 1.001 circunstancias futuras diferentes. Esto se presenta en detalle en el capítulo 3.

Incluir la incertidumbre en el estudio permite entender el rango de emisiones, beneficios y costos de la descarbonización de la economía y de los sectores. También posibilita evaluar el desempeño del escenario de carbono-neutralidad implementado en diversas rutas. En una etapa posterior del proyecto podría realizarse una evaluación de vulnerabilidad para entender las variables inciertas que podrían comprometer la meta de la carbono-neutralidad o conllevar costos inmanejables para los actores de la economía peruana.

Este estudio se centra en las transformaciones sectoriales que llevarían a Perú hacia la carbononeutralidad, no asíen las medidas de política pública que las habilitarán. Asimismo, evalúa los costos y beneficios de descarbonizar la economía del país, pero no examina en detalle la distribución de los mismos en hogares, grupos de ingresos, empresas - agencias gubernamentales. Se considera que la estructura económica permanece constante a 2050, ya que no se han analizado cambios en los nuevos servicios y modelos de negocio. No se ha evaluado la viabilidad legal o social de las acciones. Tampoco se estudia el efecto fiscal de la descarbonización producto del reducido consumo de combustibles fósiles, ni los potenciales impactos ambientales negativos y positivos de los procesos transformacionales de cada sector evaluado (externalidades ambientales). En general, tampoco se evalúan los instrumentos de política específicos ni los cambios institucionales requeridos para implementar las transformaciones evaluadas. Las proyecciones económicas se basan en información disponible antes de la pandemia; su impacto deberá estudiarse en siguientes análisis.

A continuación, se presenta una breve descripción de los modelos que permiten estimar emisiones, beneficios y costos por sector. En el anexo B se exponen más detalles técnicos de los modelos, las fuentes de datos para sus parametrizaciones, y los supuestos de modelación llevados a cabo por el equipo.

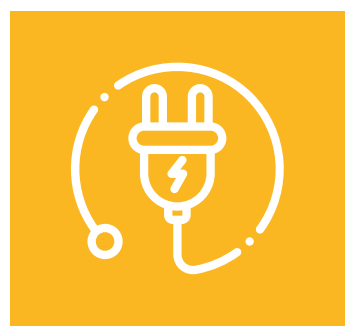

\subsubsection{Energía}

El sector energía se modela utilizando la herramienta OSeMOSYS (Howells et al., 2011). OSeMOSYSPerú fue desarrollado por el equipo de trabajo a lo largo de este proyecto, para lo cual se utilizaron fuentes de información disponibles y proyecciones de costos nacionales e internacionales, partiendo del modelo que se encuentra en Godínez et al. (2020). OSeMOSYSPerú no solo caracteriza al sector energético, sino que además describe el sector transporte (véase la sección 1.4.2) y su vínculo con el sector energía. El modelo permite buscar la combinación tecnológica de menor costo total que satisfaga las diferentes demandas de energía, dadas las fuentes de energía primaria y secundaria, considerando restricciones de uso, capacidad, cantidad, entre otros. También puede emplearse para simular múltiples escenarios o rutas de implementación bajo consideraciones políticas e incertidumbres.

En su módulo correspondiente a energía, el modelo OSeMOSYS-Perú caracteriza los consumos de los diferentes sectores productivos: residencial, comercial, público, industrial, minero, pesca, agricultura y transporte. Los consumos 
se abastecen con diversas fuentes de energía, que abarcan la producción eléctrica (plantas hidroeléctricas, de gas natural, térmicas, renovables eólicas, renovables solares) y la distribución de productos energéticos adicionales (gas natural, biomasa, fueloil, diésel, etc.). Las fuentes de energía se procesan para producir derivados del petróleo, gas natural y electricidad, mediante diversas plantas transformadoras; por ejemplo, una planta hidroeléctrica. Luego, la energía secundaria es transportada hasta los usos finales mediante infraestructura: un oleoducto, un gasoducto o la red eléctrica de transmisión y distribución. El modelo también caracteriza las importaciones y exportaciones de energía y electricidad. El diagrama 1.2 muestra de forma simplificada las fuentes, los procesos y las demandas incluidas en el modelo.

\section{Diagrama 1.2}

Esquema simplificado del modelo del sector energía desarrollado

Fuentes

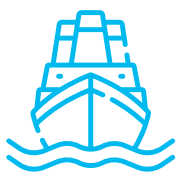

Importaciones de crudo y producto refinado

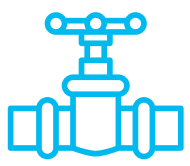

Extracción de gas natural y crudo

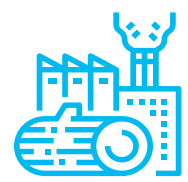

Biomasa

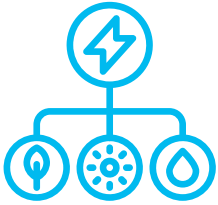

Renovables
Procesos

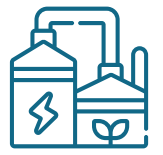

Plantas de gas natural

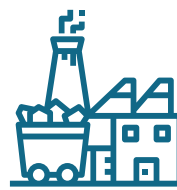

Carboneras

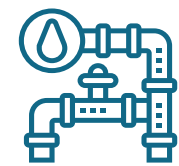

Oleoductos y gasoductos

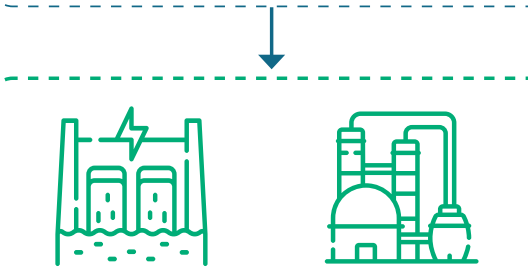

Hidroeléctricas

Plantas de gas natural y térmicas

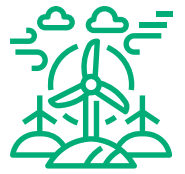

Plantas eólicas

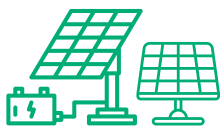

Sistemas fotovoltaicos

'También incluye biomasa y de carbón
Demandas

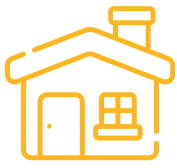

Residencial

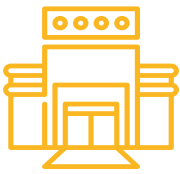

Comercial y pública

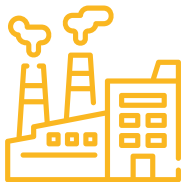

Industrias, minas, pesca y agricultura

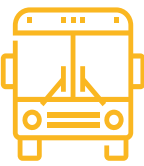

Transporte de pasajeros

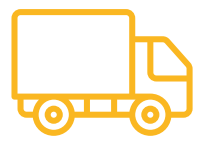

Transporte de carga

Fuente: Elaboración propia. 
En el escenario de carbononeutralidad se evalúan cuatro procesos transformacionales para el sector energía:

$>$ Aumento de la renovabilidad de la matriz eléctrica y energética producto de una mayor inserción de las fuentes de energía renovable y de un menor uso de los combustibles fósiles para producir energía primaria. Se considera una fuerte penetración de plantas renovables no convencionales, es decir plantas eólicas y solares, para la producción de energía eléctrica limpia que a su vez habilita un transporte limpio y de bajas emisiones. Este proceso transformador parte de la planificación indicada por el Comité de Operación Económica del Sistema Interconectado Nacional (COES) (COES, 2020) que se escalan producto de los costos decrecientes de las renovables no convencionales. Se fomenta también la incursión de plantas geotérmicas para aprovechar el calor de la tierra y producir energía limpia.

> Para habilitar este tipo de tecnologías, se integra el concepto de redes inteligentes, almacenamiento y cargadores eléctricos de recarga rápida para el transporte eléctrico. Estos elementos se incorporan mediante costos de capital, y en el alcance actual no se incluye la dinámica operativa, como el predespacho económico o los sistemas de control. Hay un despliegue de las redes eléctricas inteligentes que aumenta la flexibilidad del sistema y permite la implementación de esquemas de respuesta de la demanda y servicios auxiliares, así como una gestión inteligente de las nuevas tecnologías, lo cual podría brindar beneficios a los clientes por participación activa en un mercado, pero que no son estimados en este estudio.
> Para este escenario se considera que la base de la generación eléctrica con plantas térmicas tracción a diésel o fuel oil se mantiene constante. Se da una reducción en la producción de electricidad con plantas que utilizan gas natural de $25 \%$ a 2050 con respecto a los valores de 2020 . Actualmente existe una capacidad de $6,9 \mathrm{GW}$ instalados de plantas térmicas (mayor que los 5,1 GW de hidroelectricidad); no obstante, su uso no es el predominante y responde principalmente a criterios operativos; problemas de estabilidad o de control de frecuencia. En este sentido, a futuro se deberán estudiar esquemas de retiro de estas plantas que contribuyan con el proceso de descarbonización profunda del sector energético del país.

$>$ Finalmente, se considera que existirá una reducción del consumo de energía en los diferentes sectores productivos, como industria, agricultura, minería, comercio, y en residencias, como resultado de la eficiencia energética. El gobierno de Perú impulsa este proceso mediante la Ley 27.345-Ley de Promoción del Uso Eficiente de la Energía; el Decreto Supremo 053-2007-EM, que aprueba el Reglamento de la Ley 27.345; el Decreto Supremo 034-2008-EM, que dicta medidas para el ahorro de energía en el sector público; la Resolución Ministerial 038-2009-MEM/ $\mathrm{DM}$, con Indicadores de consumo energético y metodología de monitoreo; el Decreto Supremo 009-2009-MINAM, con medidas de ecoeficiencia para el sector público; la Resolución Ministerial 469-2009-MEM/ DM, que aprueba el Plan Referencial del Uso Eficiente de la Energía 2009-2018; el Decreto Supremo 026-2010-EM, para la creación de la Dirección General de Eficiencia Energética; el Decreto Supremo 064-2010-EM, que aprueba la Política Energética Nacional del Perú 2010- 
2040, y el Decreto Supremo 004-2016-EM, que aprueba medidas para el uso eficiente de la energía. Con fines de reflejar este cambio, se ha considerado un costo capital proporcional al producto interno bruto (PIB), tomando en cuenta que el sector industrial será el de mayor crecimiento.

\section{El modelo de energía evalúa} varios beneficios producto de la descarbonización:

$>$ Reducción de los costos de operación y de mantenimiento del sistema de energía producto de un sistema renovable con baja participación de derivados del petróleo y una disminución del consumo de energía por eficiencia energética. Estas estimaciones utilizan tendencias de costos de PROSEMER (BID, 2019) y fuentes de información internacional que incluye reportes del BID (García de Fonseca, Parikh y Manghani, 2019) y de la Agencia Internacional de Energía (AIE, 2018).

$>$ Disminución de los costos en salud asociados a enfermedades respiratorias generadas por la combustión según datos del Fondo Monetario Internacional (FMI) para Perú (Coady et al., 2019).

El modelo de energía contempla una serie de costos, entre los cuales se incluyen los siguientes:

$>$ Los provenientes de la instalación de plantas de energía renovable y del almacenamiento de energía según datos de (García de Fonseca, Parikh y Manghani, 2019).

$>$ Los derivados de la implementación de redes eléctricas inteligentes según datos del Instituto de Investigación en Sistemas Eléctricos (EPRI, 2011).
$>$ Los correspondientes al cambio de la infraestructura del sector eléctrico para que soporte la generación distribuida al incorporar energías renovables. La inversión no varía con el tipo de planta, sino con las capacidades. Los costos se basan en valores obtenidos del operador de red en Costa Rica y disponibles en EPERLab-UCR.

$>$ Los derivados de la instalación de estaciones de recarga para movilidad eléctrica. Su contabilidad se hace en el segmento de infraestructura. Los costos se basan en valores de comercializadoras de cargadores y oferentes para la compra de 28 cargadores en Costa Rica y disponibles en EPERLab-UCR.

$>$ Los provenientes de la implementación de los programas de eficiencia energética según datos de la AIE (2018).

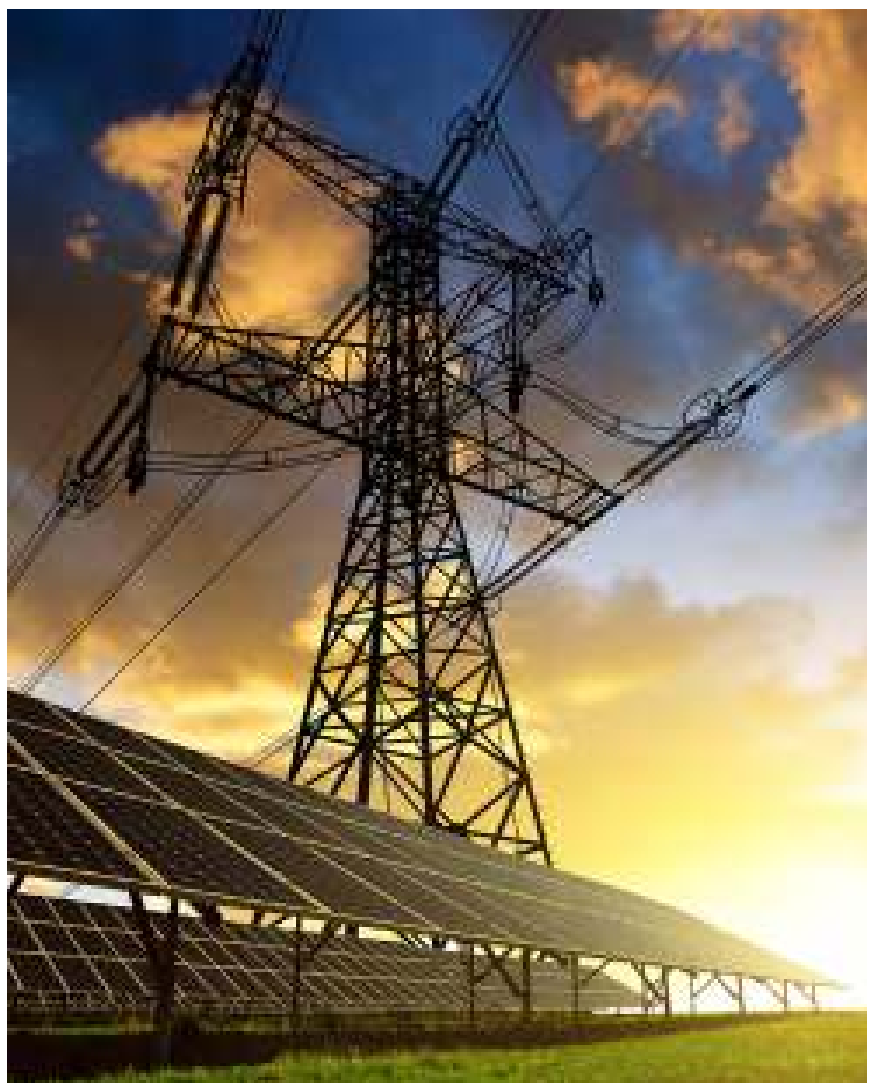




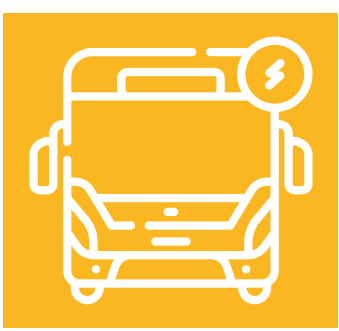

\subsubsection{Transporte}

El sector transporte también se modela en OSeMOSYS-Perú, el cual permite capturar el vínculo entre el sistema de energía y el sistema de transporte. La mitad de la energía neta de Perú es consumida por el sector transporte (MINEM, 2020b), el cual utiliza la mayor cantidad de combustibles fósiles del país. Los principales productos energéticos usados son la gasolina, el diésel y el gas licuado de petróleo (GLP), con una ligera tendencia a los biocombustibles, debido a las regulaciones ambientales que se han implementado desde la creación de la Ley 28.054 (Ley de Promoción del Mercado de Biocombustibles). Los periodos de renovación de la flota vehicular existente se basan en insumos durante los talleres co-constructivos y reuniones bilaterales. Se utilizaron fuentes internacionales para estos periodos en las tecnologías eléctricas ante la escasez de información local. Su descarbonización se lograría en gran medida con la electrificación de la flota vehicular y al cambio modal, lo cual trae aparejados grandes beneficios para la sociedad, gracias a los costos reducidos de contar con vehículos eléctricos, a mejoras en la calidad del aire, al aumento de la productividad y a la reducción de la accidentabilidad.

El modelo caracteriza la totalidad de la flota vehicular terrestre, la cual hoy en día está constituida por vehículos de combustión interna y consume diversos combustibles fósiles, y permite estudiar los cambios modales de transporte privado a transporte público y a transporte no motorizado o movilidad activa (peatonal y en bicicleta). El transporte ferroviario del país se caracteriza por una sola tecnología en el modelo, que tiene una dinámica similar a la del transporte público. OSeMOSYS-Perú analiza la cadena de suministro de energía (desde los derivados del petróleo hasta la electricidad). El modelo contempla diversas tecnologías (e.g., automóviles, motocicletas, buses, camiones) para la movilidad de pasajeros y de carga. El diagrama 1.3 muestra de forma simplificada las fuentes de energía para transporte, las tecnologías, las actividades consideradas, y las demandas de movilidad terrestre contempladas.

En el escenario de carbononeutralidad se evalúan cinco procesos transformacionales para el sector transporte:

$>$ Electrificación de la flota vehicular (con vehículos que usan baterías o celdas de hidrógeno) tanto de pasajeros como de carga.

> Reducción de la demanda del transporte de pasajeros gracias a: i) inversiones en infraestructura para acortar los recorridos en carreteras; ii) aumento del teletrabajo; iii) incremento de la digitalización de los trámites.

$>$ Disminución de la demanda de transporte de carga producto de mejoras en la logística e infraestructura vial que permiten una reducción de las toneladas-kilómetro.

$>$ Modesto cambio modal del transporte privado al transporte público. Aunque el uso del transporte público es alto en Perú (MINEM, 2020b), se considera una ligera reducción de la demanda de transporte privado que se suple con transporte público.

$>$ Cambio modal del transporte motorizado al no motorizado. Se considera un aumento de la movilidad activa basada en la bicicleta - peatonal para trasladarse, habilitado por inversiones en aceras, ciclovías y densificación de las ciudades. 


\section{Diagrama 1.3}

Esquema simplificado del modelo del sector transporte desarrollado

Fuentes

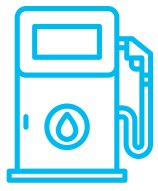

Estaciones de servicio

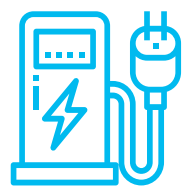

Cargadores eléctricos

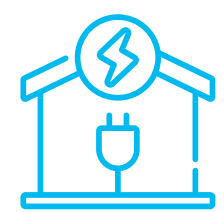

Electricidad en los hogares
Tecnologías

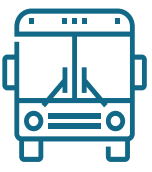

Autobuses

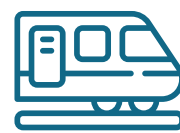

Trenes

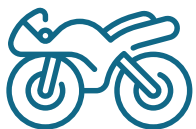

Motocicletas

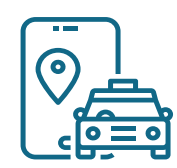

Taxis - Apps

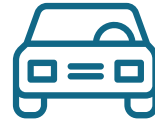

Vehículos livianos

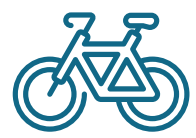

No motorizadas

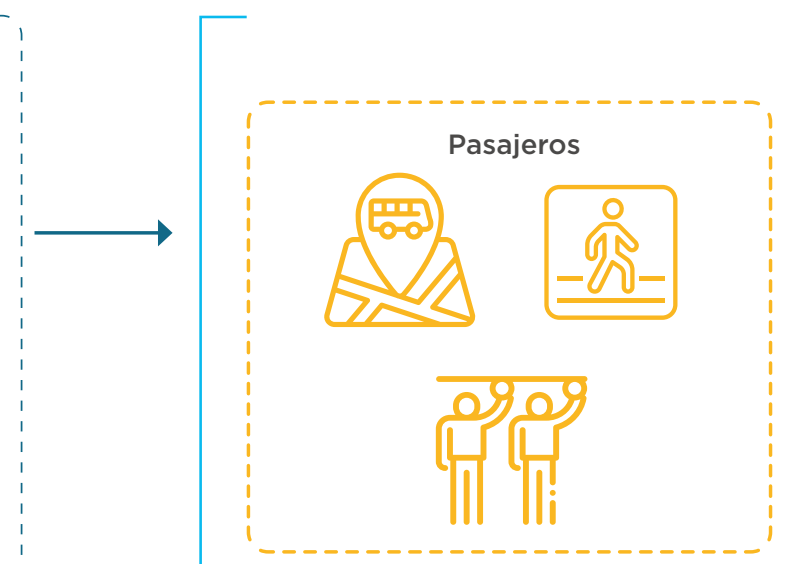

Carga
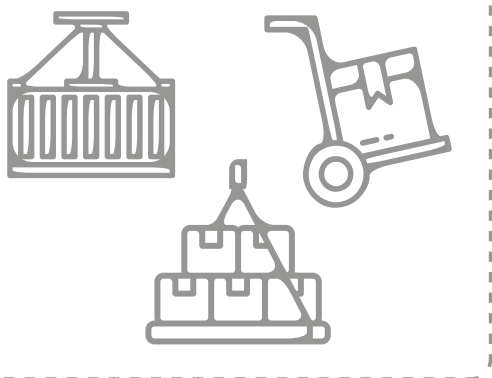


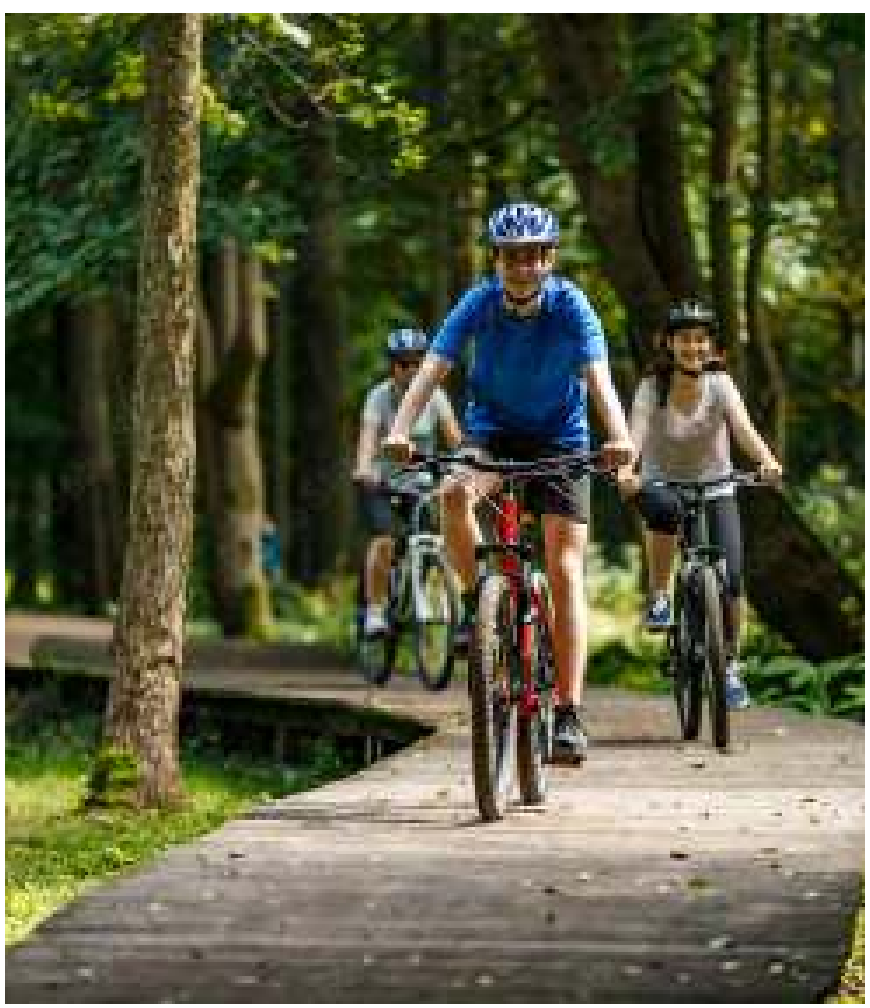

El modelo del sector transporte evalúa varios beneficios producto de la descarbonización:

$>$ Reducción del costo de operación y mantenimiento de la flota vehicular producto en gran medida de su electrificación y de la eficiencia energética que disminuye los consumos. Estas estimaciones utilizan tendencias de costos de la AIE (2018).

$>$ Disminución de los costos en salud asociados a enfermedades respiratorias generadas por la combustión según datos del FMI para Perú (Coady et al., 2019).

$>$ Aumento dela productividad como resultado de un menor congestionamiento y la subsecuente disminución del tiempo productivo pasado en el tráfico según datos del FMI para Perú (Coady et al., 2019).
$>$ Reducción del costo por accidentes en las carreteras, gracias a una menor utilización del transporte privado y a un aumento del uso del transporte público, del transporte no motorizado, de la digitalización y del teletrabajo según datos del FMI para Perú (Coady et al., 2019).

\section{El modelo del sector transporte} contempla una serie de costos, entre los cuales se incluyen los siguientes:

$>$ Costos de la renovación o sustitución de la flotilla vehicular para el traslado de pasajeros y el transporte de carga según datos de la AIE (2018) y (ETSAP-IEA, 2020).

$>$ Costos en la infraestructura del sector transporte tanto de pasajeros como de carga según estudios recientes (Broin y Guivarch, 2016; Schroten. et al., 2019).

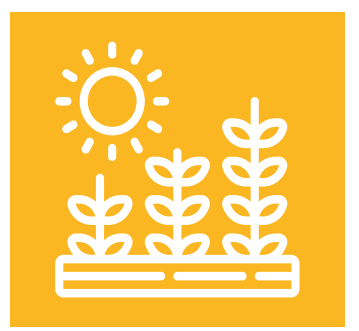

\subsubsection{Agricultura, silvicultura y otros usos de la tierra (AFOLU)}

El sector AFOLU se modela en forma integrada en POLYSYS-Perú, un modelo integrado de asignación del uso de la tierra que permite capturar la relación entre las actividades agrícolas y ganaderas, y el cambio de uso del suelo. El modelo incorpora el manejo de inventario de suelos de bosque primario y bosque secundario, así como la relación de estos bosques con las fuentes de deforestación, la pérdida de productividad del suelo, la expansión agrícola y ganadera, la minería, los incendios forestales y la expansión urbana. 
Para el sector agrícola se consideran siete regiones (Costa Norte, Costa Centro, Costa Sur, Sierra Norte, Sierra Centro, Sierra Sur y Amazonía) y 14 categorías de cultivos (alfalfa, maíz, legumbres, tubérculos, frutas de consumo doméstico, vegetales de consumo doméstico, frutas de exportación, vegetales de exportación, café y cacao, maíz amarillo duro, caña de azúcar, arroz, algodón, y granos y cereales). Para el sector ganadero, se han considerado las mismas siete regiones y seis categorías de ganado (vacuno, porcino, avícola, ovino, caprino y auquénido). La interacción del sector agricultura con el sector de uso de la tierra, cambio de uso de la tierra y silvicultura (UTCUTS) o con el manejo del paisaje se da exclusivamente en la Amazonía, ya que en el modelo POLYSYS-Perú solo se han considerado bosques tropicales amazónicos. El diagrama 1.4 muestra el esquema del modelo POLYSYS.

\section{Diagrama 1.4}

Esquema simplificado del modelo del sector AFOLU utilizado

\section{UTCUTS}
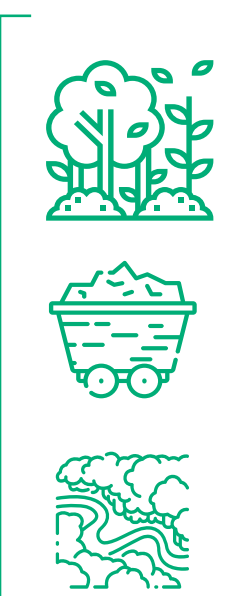

Cobertura de bosques, agricultura, ganadería, minería

y Amazonía
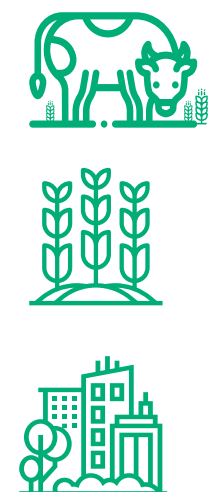

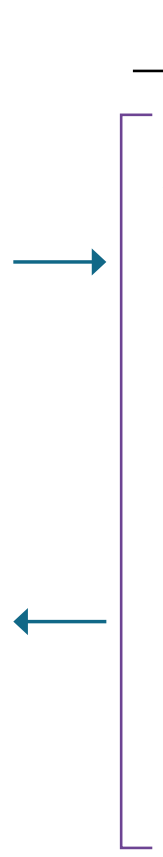

Agrícola

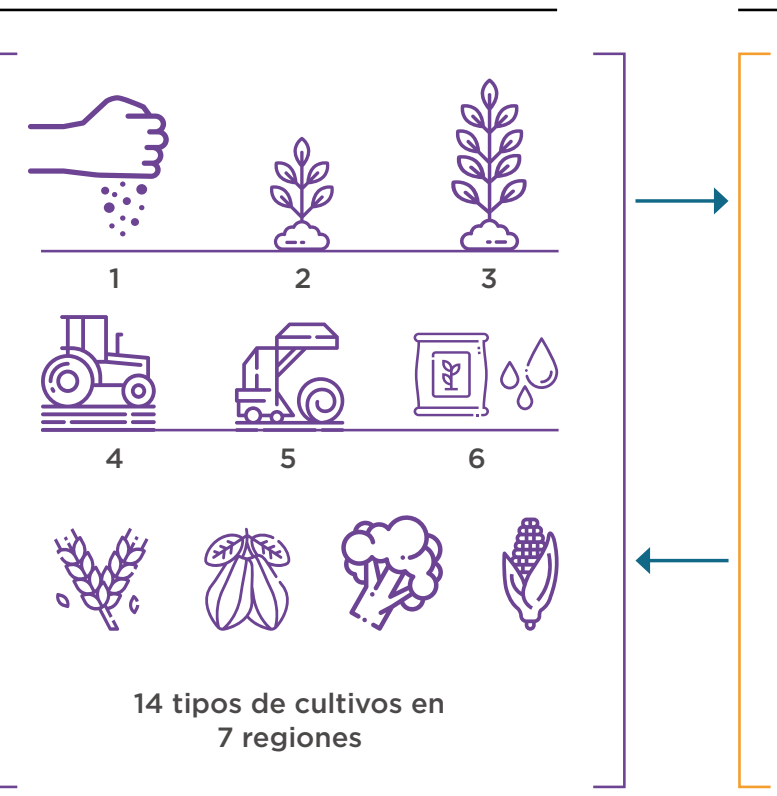

\section{Ganadería}

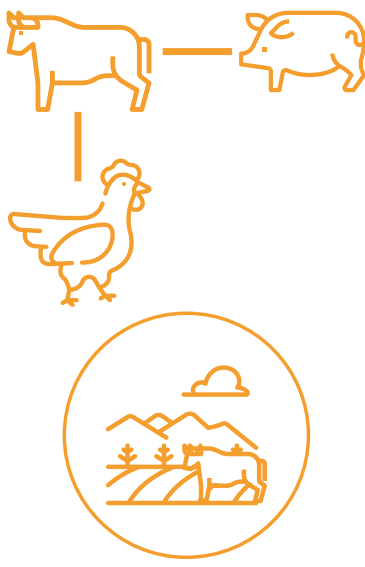

6 categorías de ganado en 7 regiones
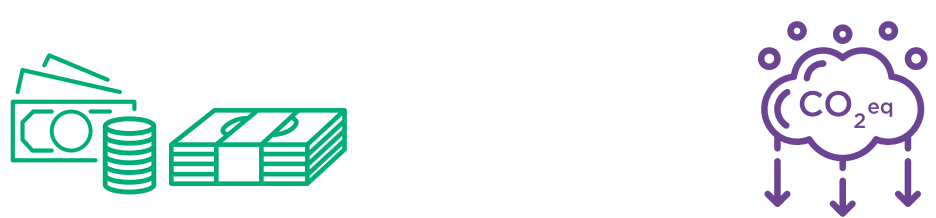

Dinámica: variables macroeconómicas

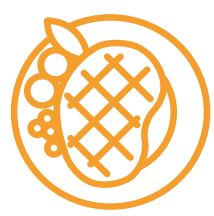

Fuente: Elaboración propia. 


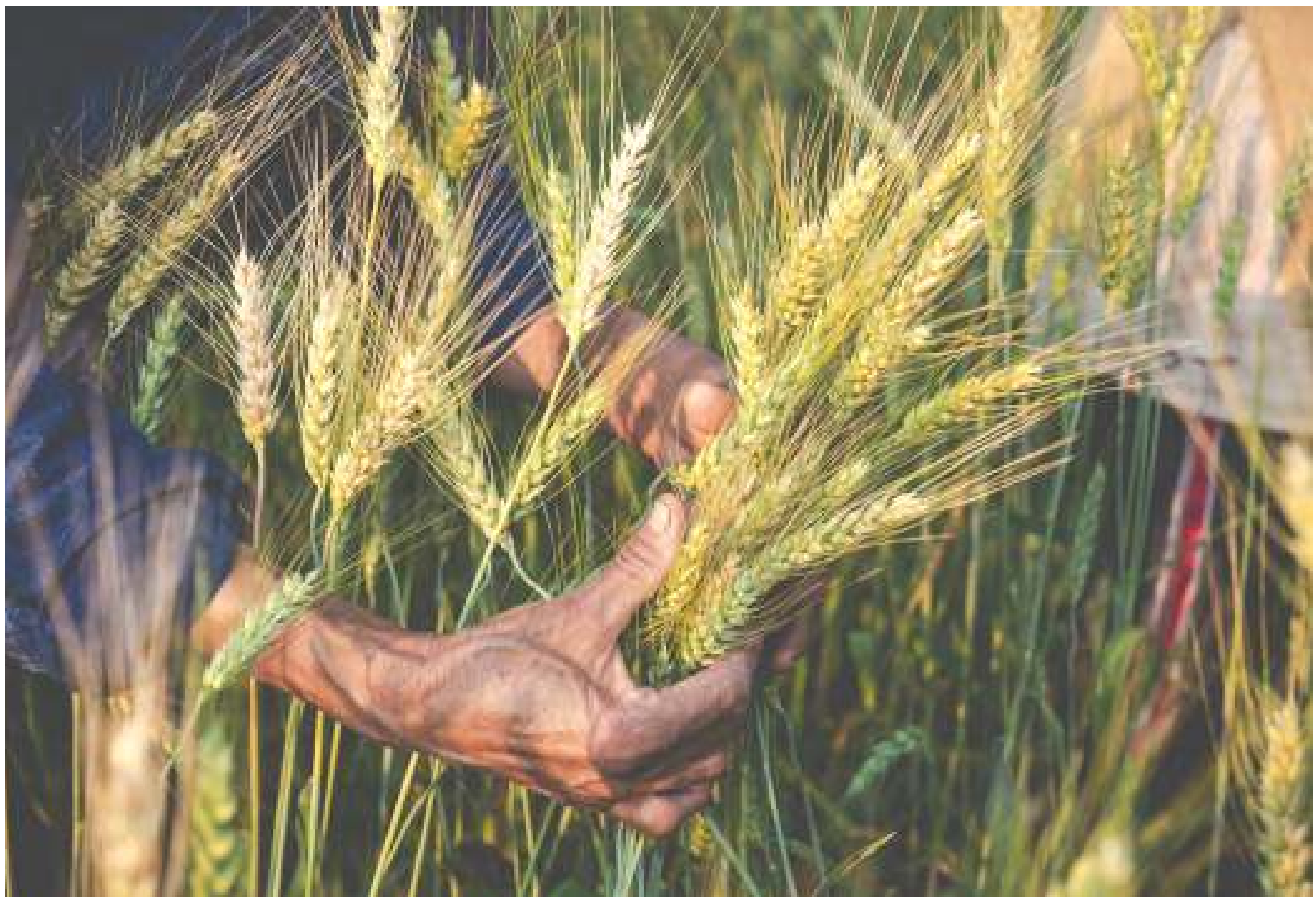

El eje de la interacción del modelo es el uso de la tierra. Los cultivos y pastos compiten por el uso del suelo en función de la rentabilidad que cada actividad proporciona en términos de hectárea. En el caso de la región amazónica, esta competencia por el suelo incide sobre el paisaje boscoso, ya que la deforestación del bosque se convierte en una respuesta a las presiones agrícolas y ganaderas. Cabe indicar que la mayor presión de las actividades agrícolas y ganaderas sobre el bosque se debe a que los pequeños productores carecen de recursos para conservar la productividad del suelo y a esta pérdida de productividad la reemplazan con capital natural en la forma de deforestación. Según investigaciones iniciales (Dourejeanni, 1987) recientemente reconfirmadas
(Bedoya Garland, Aramburú Burneo, 2017; Ravikumar et al., 2017), aproximadamente el $80 \%$ de la deforestación se produce para reemplazar la pérdida de productividad del suelo, según lo descrito anteriormente.

El modelo captura esta competencia por el suelo y la dinámica de la gestión del bosque. A esta dinámica, le integra otros factores de oferta y demanda para determinarlos precios, las cantidades producidas, las cantidades demandadas por el mercado doméstico, las exportaciones, los costos operativos, los ingresos y las inversiones, así como los impactos ambientales, como las emisiones, y los servicios ecosistémicos. 
El escenario de carbononeutralidad evalúa tres grandes transformaciones para el sector AFOLU; cada una se segmenta en subprocesos de cambio para el sector:

$>$ En el caso de UTCUTS, se han considerado las siguientes transformaciones:

- Reducción de la deforestación del bosque primario impulsada por la asignación de derechos del bosque y por inversiones para la conservación, recuperación y el incremento de la productividad de los suelos agrícolas en la Amazonía mediante la introducción de sistemas agroforestales (café y cacao), la implementación de una plataforma de apoyo logístico para el desarrollo agrícola y el desarrollo de sistemas silvopastoriles que en conjunto permiten reducir la presión de la agricultura sobre el bosque. Adicionalmente, los sistemas agroforestales y silvopastoriles contribuyen con la captura de carbono y se incrementa la productividad de los cultivos bajo sistemas agroforestales. En ningún caso la asignación de derechos contempla concesiones en el bosque primario para el desarrollo de plantaciones forestales.

- Impulso para aprovechar los recursos forestales a través de la promoción de concesiones bajo un manejo forestal sostenible y de plantaciones forestales para la comercialización.

- Fomento importante de las inversiones en plantaciones con fines de restauración que en ningún caso considera el desarrollo de plantaciones forestales en el bosque primario.
$>$ En el sector agricultura se consideran las siguientes transformaciones:

- Recuperación y manejo de pastos naturales altoandinos, lo que resulta en un incremento de la eficiencia del ganado y logra reducir las emisiones por kilo de carne vacuna producida en la región Sierra.

- Desarrollo de sistemas silvopastoriles en la Amazonía, lo que trae aparejada una mayor eficiencia del ganado, logrando reducir las emisiones por kilo de carne vacuna producida en la región Amazonía, y adicionalmente contribuye a la captura de carbono.

- Aprovechamiento de los residuos agrícolas a través de la producción de fertilizantes orgánicos en sustitución de fertilizantes inorgánicos, principalmente en los cultivos de frutas, cereales y granos, y arroz.

- Adopción del sistema de secas intermitentes para los cultivos de arroz en la Costa en sustitución del sistema tradicional de cultivo de arroz; esto contribuye a reducir las emisiones e incrementa la productividad del cultivo.

$>$ Un elemento transformador adicional es la promoción de cambios en la dieta alimentaria, a saber:

- Por el lado de los carbohidratos, se impulsa una transición del consumo de arroz al consumo de tubérculos, cereales y granos, y legumbres, manteniendo un nivel de consumo de calorías similar. Esto contribuye a reducir la presión de la expansión de los cultivos de arroz y redirige la demanda hacia cultivos que generan menores emisiones. 
- Por el lado del consumo cárnico, se fomenta una transición del consumo de carne vacuna al consumo de carne de cerdo, con lo cual se mantiene el crecimiento tendencial del consumo cárnico, pero con una mayor participación de la carne de cerdo en relación con la carne vacuna. Esto contribuye a reducir la presión de la deforestación por expansión ganadera sobre el bosque y redirige la demanda hacia un consumo cárnico con menores emisiones.

\section{El modelo del sector AFOLU evalúa varios beneficios producto de la descarbonización:}

$>$ Ingresos financieros netos, resultado de una mayor actividad forestal, y de cambios en los precios y productividades de las actividades agrícolas y ganaderas según datos del Instituto Nacional de Estadística e Informática (INEI, 2020a; 2020b), el Ministerio de Desarrollo Agrario y Riego (MIDAGRI, 2020a) y el Servicio Nacional Forestal y de Fauna Silvestre (SERFOR, 2020), así como entrevistas con especialistas de Reforesta Perú, ${ }^{4}$ MIDAGRI, SERFOR y el Organismo de Supervisión de los Recursos Forestales y de Fauna Silvestre (OSINFOR).

$>$ Incremento del valor de los servicios ecosistémicos del bosque primario, del bosque secundario y de las plantaciones de restauración según estimaciones realizadas por Carrasco et al. (2014).

$>$ Ingresos por mercado de carbono. ${ }^{5}$

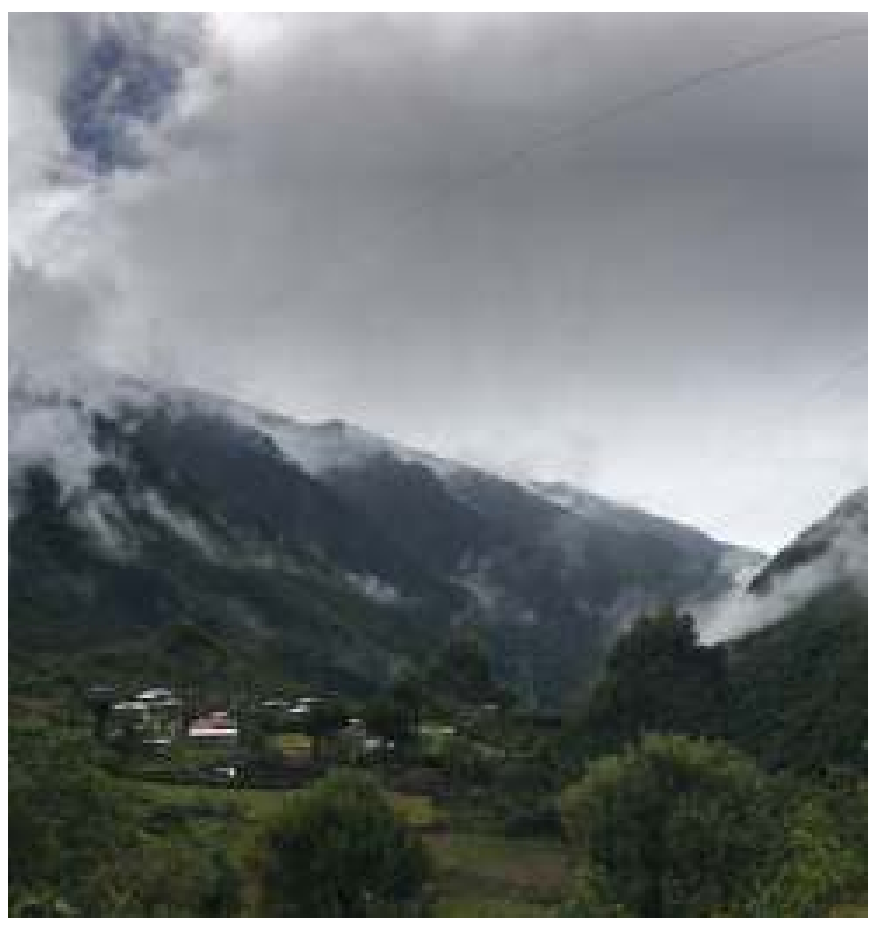

El modelo del sector AFOLU contempla una serie de inversiones, entre las cuales se incluyen las siguientes:

$>$ Las provenientes de las plantaciones de restauración y comerciales según estudios recientes (OSINFOR, 2018; Quintanilla et al., 2018), y entrevistas con especialistas de Reforesta Perú, SERFOR y OSINFOR.

$>$ Las derivadas de la implementación de sistemas agroforestales y plataformas de apoyo logístico para el desarrollo agrícola según entrevistas con especialistas de Alianza Perú Cacao, ${ }^{6}$ MIDAGRI, MINAM y el Centro Internacional de Investigación en Agroforestería (ICRAF).

\footnotetext{
${ }^{4}$ Empresa peruana especializada en plantaciones forestales.

${ }^{5}$ Como dicho mercado aún no existe en Perú, se considera como supuesto estándar del escenario de carbono-neutralidad un precio igual a cero en el mercado de carbono. Posteriormente se exploran valores que pueden llegar a ser de hasta US $\$ 200$ por tonelada de $\mathrm{CO}_{2 \mathrm{e}}$

6 Iniciativa público-privada integrada por múltiples empresas y cooperativas vinculadas al sector cacaotero/chocolatero que buscan hacer más competitiva la cadena de valor del cacao peruano.
} 
$>$ Las correspondientes a la puesta en marcha de concesiones bajo manejo forestal sostenible según estudios recientes (Quintanilla et al., 2018) y entrevistas realizadas con especialistas de Reforesta Perú, SERFOR y OSINFOR.

$>$ Las propias de la asignación de derechos forestales y títulos habilitantes según lo estimado en el proyecto Planificación Ante el Cambio Climático, Plan CC (2013).
$>$ Las provenientes de la actividad agraria y ganadera según datos de INEI (2020a, 202Ob) y MIDAGRI (2020a, 2020b).

$>$ Las derivadas de la implementación de sistemas silvopastoriles según información de ProNaturaleza (2007), estudios recientes (Echeverria, Pizarro y Gómez, 2019) y entrevistas con especialistas de SERFOR, MINAM y MIDAGRI.

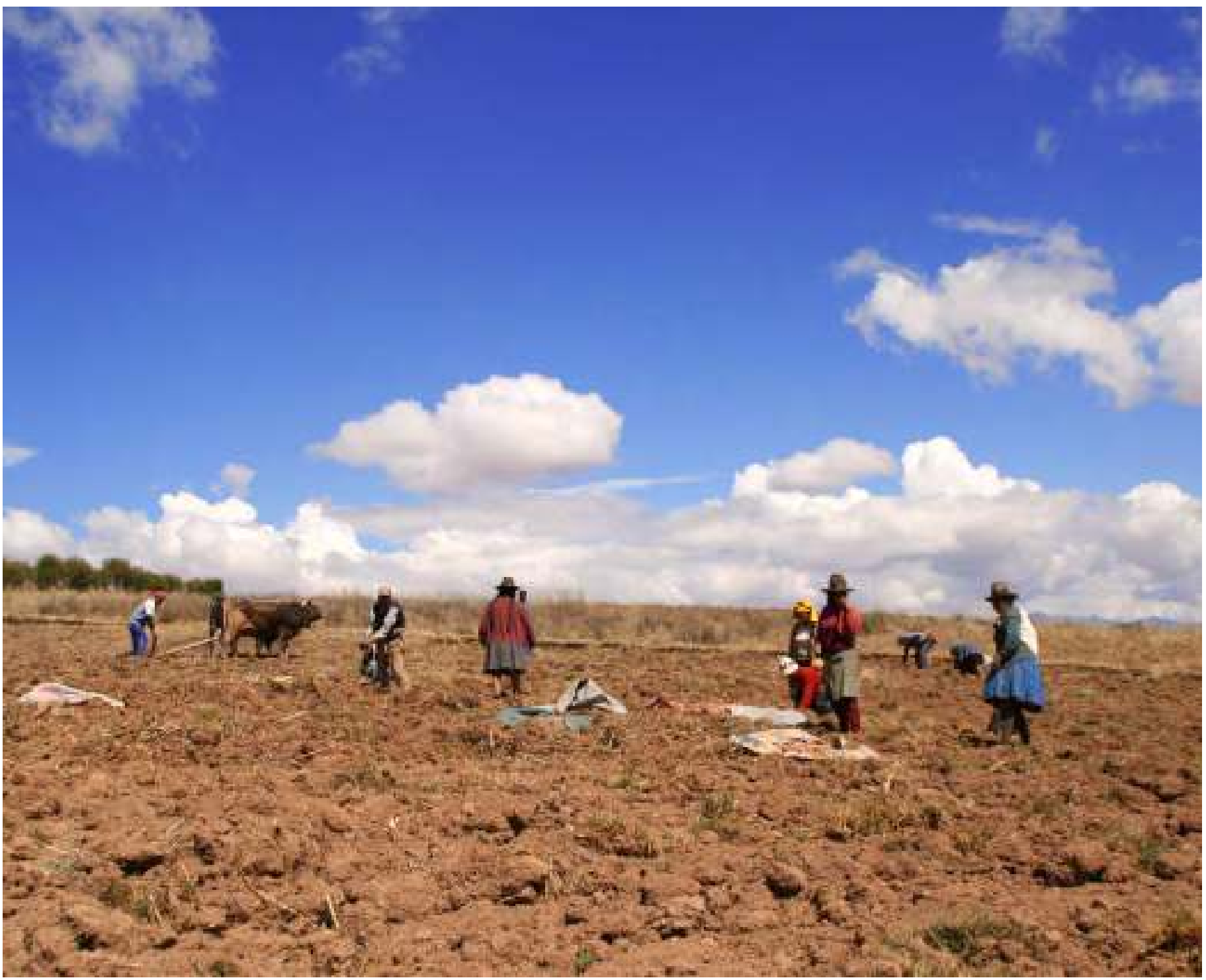




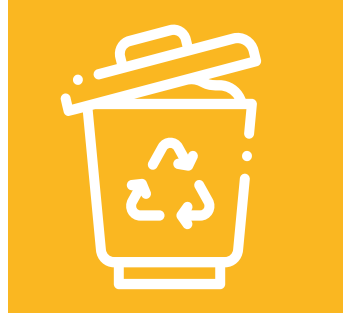

\subsubsection{Residuos}

El modelado del sector residuos se basa en la metodología propuesta por el IPCC (IPCC, 2006) y ha sido construido en base a los informes efectuados por INFOCARBONO (MINAM, 2021) para reportar emisiones anuales de GEI. El modelado del sector residuos es mucho más simplificado que el de energía, transporte y AFOLU, que procura dar un primer paso hacia la evaluación de costos y beneficios del proceso transformador del sector. Los próximos proyectos deberán ahondar en la dinámica del sector y su vínculo con otros (e.g., con energía). El modelado se divide en tres categorías: i) disposición de residuos sólidos en tierra; ii) tratamiento de aguas residuales (domésticas y municipales); iii) tratamiento de efluentes industriales. En general, el modelado parte de los valores base de 2014 y proyecta niveles de actividad en función del crecimiento de la población o el PIB como toneladas de material sólido generado o demanda bioquímica de oxígeno de los vertidos. El modelo utiliza un factor de emisiones promedio según el inventario (MINAM, 2021).
En el diagrama 1.5 se muestra un esquema simplificado del modelo. A la izquierda se representan las fuentes generadoras de residuos sólidos y líquidos, mientras que a la derecha se exponen las opciones para la disposición final. En el caso de los residuos sólidos, se debe impulsar un proceso de segregación de residuos que permitirá la reutilización de cierto material basado en un proceso de reciclaje o compostaje (lo cual reduce directamente las emisiones) o bien se les podría depositar en rellenos sanitarios, lo que genera emisiones. No se considera el uso de los residuos sólidos para la producción de energía. Para el caso de aguas residuales domésticas y municipales, el modelo contempla la posibilidad de reutilización de dichas aguas para procesos extractivos. En cuanto a los vertidos, se consideran dos opciones: con tratamiento y sin él. El primer caso es generalizado y no se detalla de manera específica el tipo de tecnología; está basado en costos y se considera una reducción directa de las emisiones. Para el caso de vertidos sin tratamiento, se siguen utilizando los coeficientes de emisiones promedio. Esta consideración aplica para aguas residuales residenciales, comerciales e industriales.

\section{Diagrama 1.5}

Esquema simplificado del modelo del sector residuos desarrollado

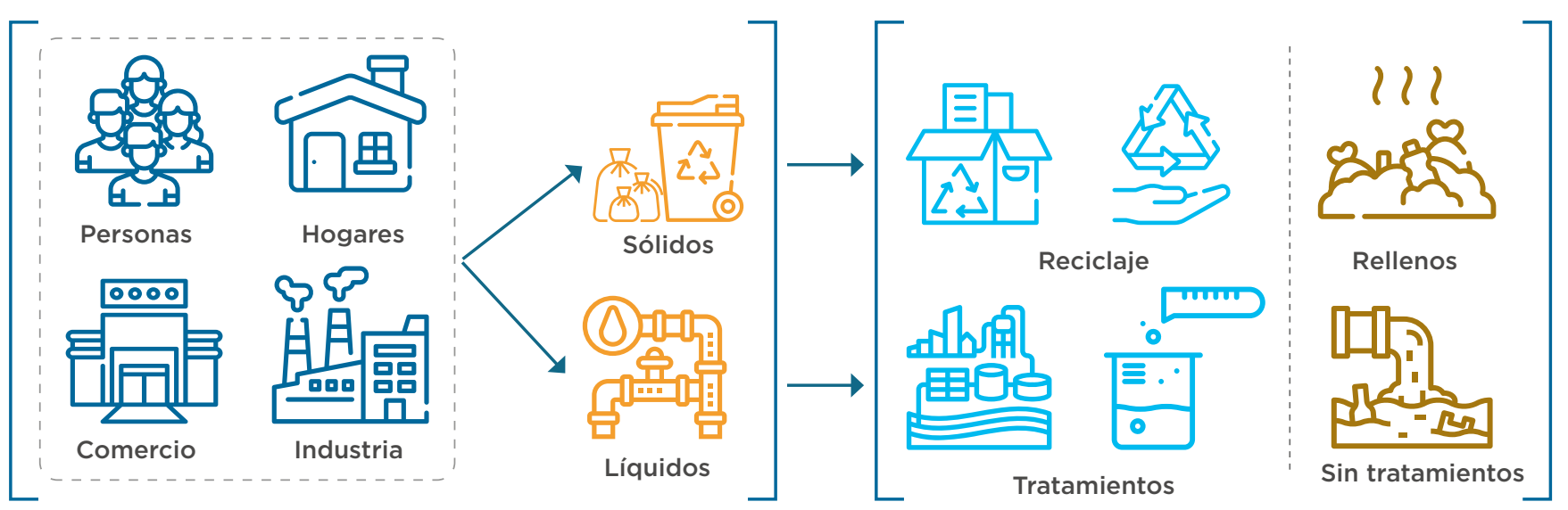

Fuente: Elaboración propia. 
En el escenario de carbononeutralidad se evalúan tres procesos transformacionales para el sector residuos:

$>$ Reducción de la cantidad de residuos sólidos generados.

$>$ Aumento de la fracción de residuos reciclados. Este proceso sugiere la revalorización de residuos sólidos bajo un concepto de economía circular.

$>$ Aumento del tratamiento de vertidos de origen residencial, comercial e industrial.

El modelo de residuos evalúa varios beneficios producto de la descarbonización:

$>$ Ingresos por material reciclado según estudios del BID (Lobo et al., 2016).

$>$ Ingresos por agua recuperada que se utiliza para otros fines según SEDAPAL (2019).

$>$ Beneficios para las comunidades en términos de salud y porque se evita construir sistemas de tanques sépticos (que adicionalmente promueven la contaminación difusa) según estudios del BID (Dixon, 2012).

\section{Los costos que contempla el modelo} de residuos son los siguientes:

$>$ Los derivados de segregar, reciclar y del tratamiento de aguas residuales según datos internacionales y nacionales (COVEC, 2017; León, 2020).
$>$ Los provenientes de la inversión para los procesos de recolección según datos del Banco Mundial (2012).

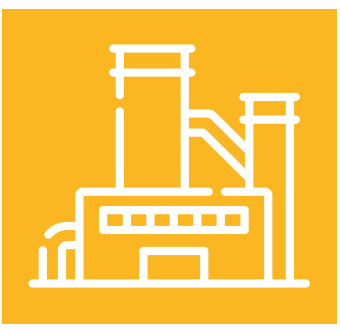

\subsubsection{Procesos industriales y uso de productos (PIUP)}

El sector de procesos industriales y uso de productos ha sido modelado en base a la metodología de la IPCC, y se ha construido a partir de los informes realizados por INFOCARBONO (MINAM, 2021). El enfoque principal vigente en la actualidad ha sido desarrollado para la producción de cemento, ámbito que representa cerca del $75 \%$ de las emisiones del sector (MINAM, 2021). Actualmente, para este subsector se cuenta con un enfoque inicial basado en TIER 2, en el cual se contempla el efecto del clínker sobre la producción de cemento. El modelado del sector PIUP es el más simplificado de todos que procura dar un primer paso hacia la evaluación de costos y beneficios del proceso transformador del sector. Los proyectos por venir deberán ahondar en la dinámica del sector y su vínculo con otros (e.g., con energía y residuos).

El diagrama 1.6 muestra un esquema simple del modelo, en el cual resalta el efecto del clínker sobre la producción de cemento. Para este efecto, se utilizan proyecciones de producción de cemento basadas en tendencias internacionales y en los últimos registros de Perú (FICEM, 2016; AIE, 2018), valores promedio de factor clínker y un coeficiente de emisiones. En esta etapa no se han contemplado aspectos adicionales como mejoras 
en la eficiencia energética del proceso o captura de carbono, los cuales constituyen el enfoque moderno del sector. Actualmente, la industria cementera de Perú y la Federación Internacional de Cemento (FICEM) trabajan en la generación de este tipo de análisis (TIER3), los cuales podrán ser incorporados en una etapa posterior. Para el resto de los sectores productivos se generan proyecciones de emisiones a largo plazo, utilizando las series históricas reportadas a nivel nacional.

\section{Diagrama 1.6}

Esquema simplificado del modelo del sector procesos industriales desarrollado

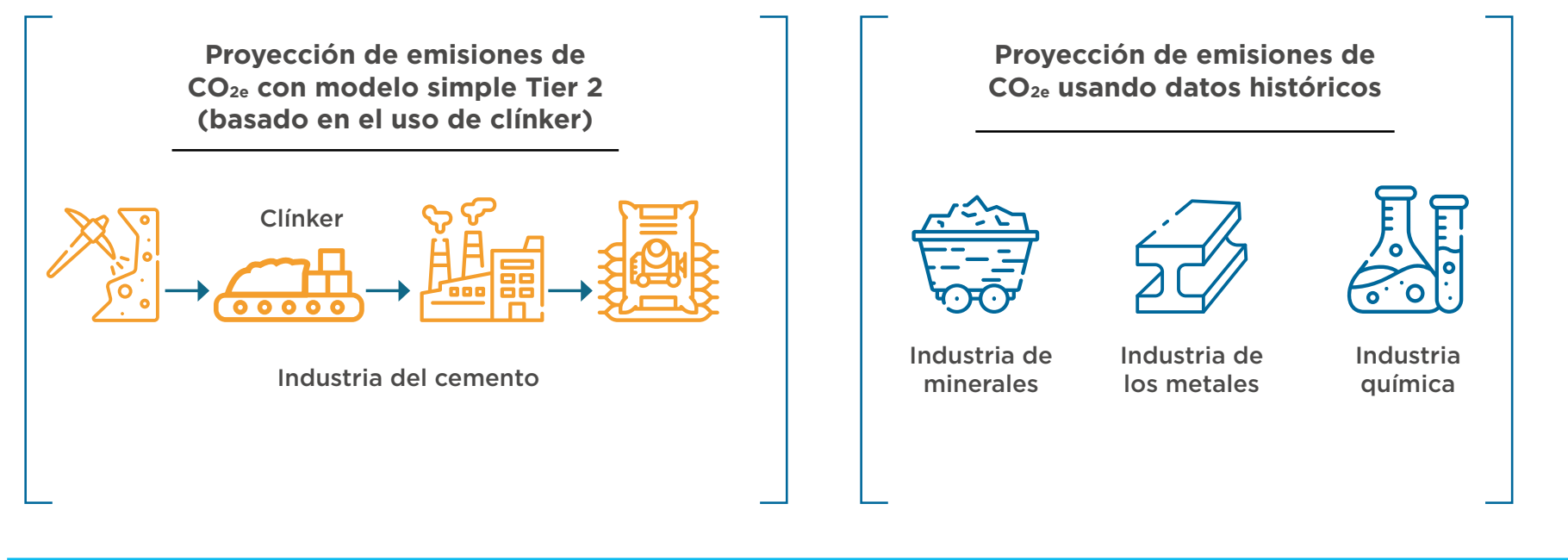

Fuente: Elaboración propia.

En el escenario de carbononeutralidad se evalúa un único proceso transformacional para el sector PIUP, a saber:

$>$ La reducción de la cantidad de clínker en la producción de cemento. Se reconoce que esta acción tiene una limitación técnica de reducción (factor clínker).
Al día de hoy el modelo PIUP no evalúa beneficios de la descarbonización. Se contempla un único costo de capital:

> Los costos de inversión para la reducción de clínker según FICEM (2016) y Hills, Florin y Fennell (2016). 


\subsection{Exploración de la incertidumbre}

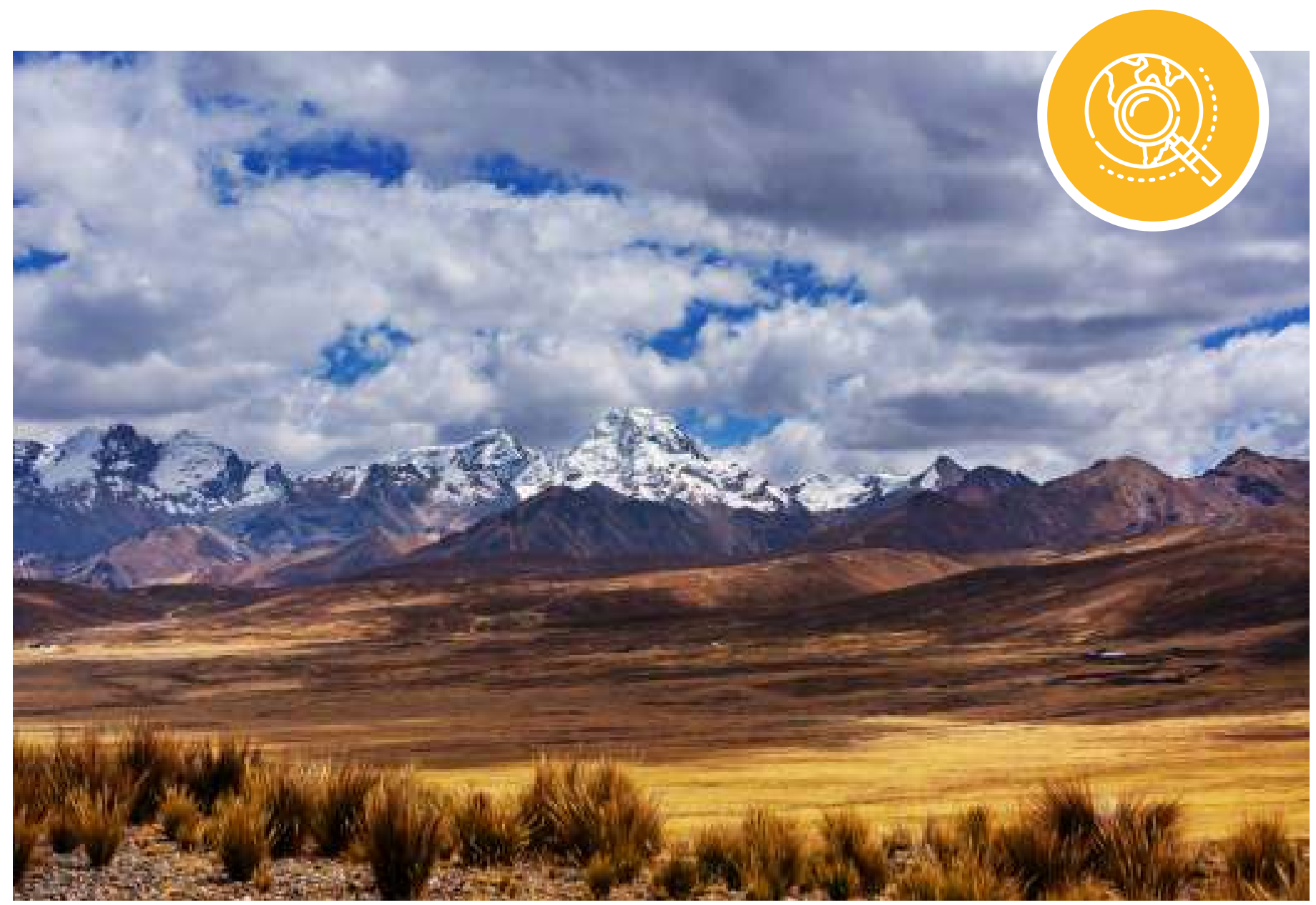

La planificación de largo plazo está sujeta a incertidumbre. Los supuestos estándar han servido para calibrar los modelos y realizar una estimación de una ruta plausible de implementación del escenario de carbono-neutralidad. Sin embargo, los costos tecnológicos, los precios de los combustibles, el precio internacional del carbono, entre otros parámetros que se han asumido en las trayectorias estándar, podrían tomar distintas rutas al 2050.
A fin de estudiar el efecto de la incertidumbre, se ha utilizado el método de toma de decisiones robustas para parametrizar los modelos con 1.000 conjuntos únicos de valores que conforman rutas plausibles de implementación de los escenarios estudiados. Analizar las distintas rutas de implementación permite comprender los rangos de las emisiones en 2050, de los beneficios netos de la descarbonización y de sus costos. ${ }^{7}$ Hay más de 201 incertidumbres definidas en el modelo de evaluación de rutas de descarbonización.

7 También permitiría identificar acciones de política robustas, es decir, que cumplan sus objetivos en una gran cantidad de futuros plausibles, que fortalezcan las decisiones de los formuladores de políticas; sin embargo, este análisis no fue incluido en este estudio. 
La incertidumbre para 2050 puede categorizarse en seis bloques:

Imprecisión en la formulación de los modelos para estimar las emisiones.

Información incompleta o inadecuada para estimar las emisiones actuales; por ejemplo, acerca de la producción de cemento y de las aguas residuales.

Incertidumbre sobre los precios internacionales de las tecnologías futuras, del carbono, de la madera de las plantaciones forestales, así como acerca de los precios internacionales de los productos agrícolas, entre otros que pueden afectar las estimaciones futuras.

Incertidumbre sobre la evolución futura del rendimiento de los cultivos, que podría causar cambios en la estructura productiva agrícola nacional.
Imprecisiones en la creación del modelo que usa valores promedio de múltiples actividades en el país. Por ejemplo, el modelo utiliza las distancias promedio recorridas por los diferentes vehículos y no distingue por regiones.

Incertidumbre acerca de los coeficientes de beneficios y costos utilizados para estimar los beneficios netos, los cuales en muchos casos son valores internacionales.

A fin de examinar estas incertidumbres, se han realizado 1.000 simulaciones adicionales para cada escenario estudiado. Cada simulación, llamada también un futuro plausible, refleja un conjunto de supuestos sobre parámetros inciertos. Después de parametrizar cada futuro, se usa el modelo de evaluación de rutas de descarbonización para estimar las emisiones, los beneficios y los costos de ese futuro correspondiente. 


\subsection{Otros beneficios y costos no estimados}

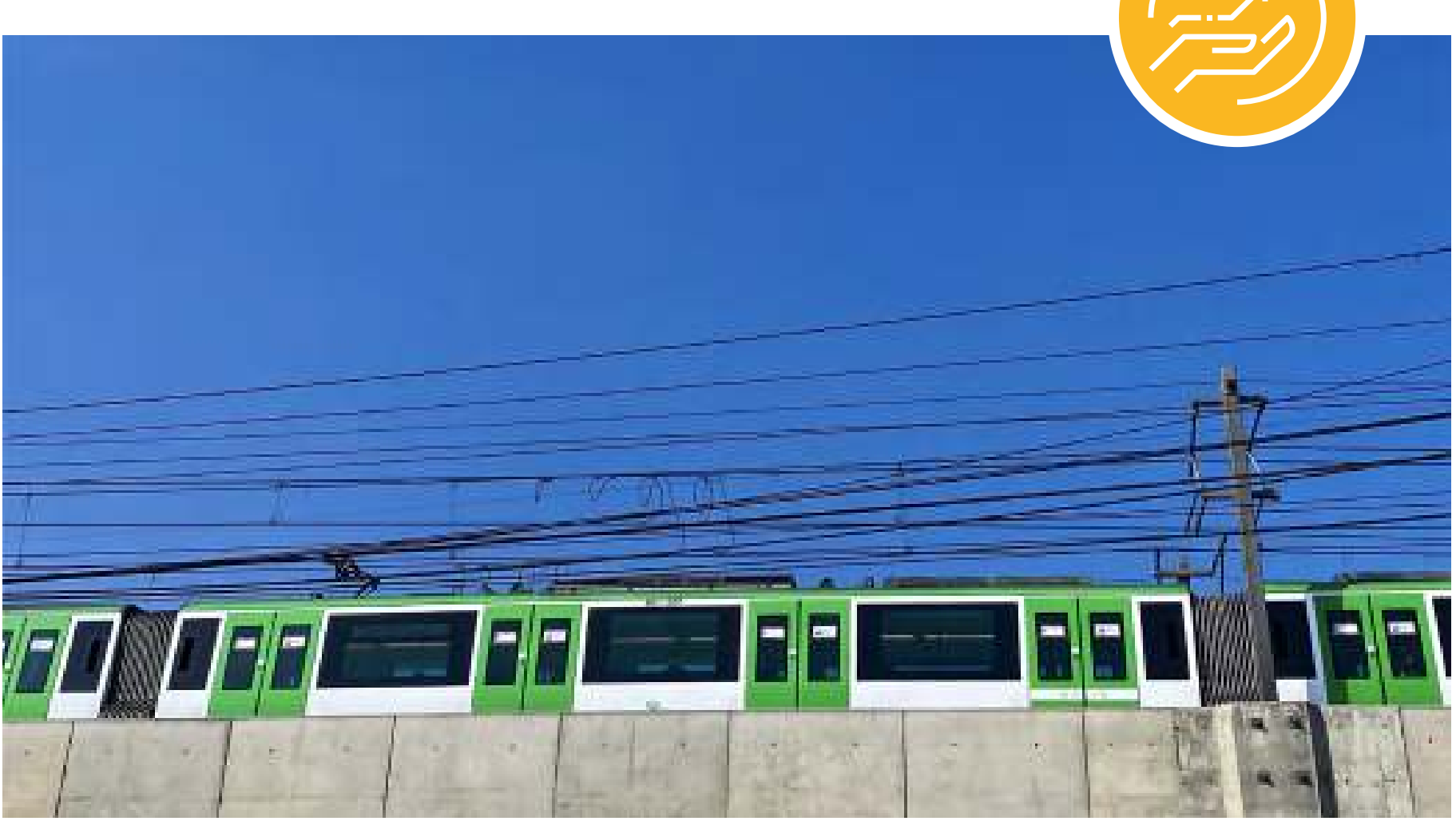

Por limitaciones de disponibilidad de información, existen beneficios que no se han incluido en este estudio. Esto sugiere que los beneficios discutidos en el reporte han sido subestimados. Entre ellos, cabe citar los siguientes:

$>$ Los derivados de la continuidad del servicio eléctrico producto del aumento de la renovabilidad integrada con el almacenamiento de energía.

$>$ El bienestar social de tarifas eléctricas reducidas gracias a inversiones en renovables de menor costo.
$>$ Aquellos de las redes inteligentes, que permiten que múltiples clientes perciban ingresos gracias a su participación en la venta de servicios auxiliares y esquemas de respuesta de la demanda.

$>$ Los provenientes de los vehículos eléctricos, que pueden inyectar energía a la red eléctrica y brindar servicios auxiliares mediante la tecnología vehículo-a-la-red.

$>$ La reducción de los niveles de estrés producto de un transporte más silencioso y con menos vibraciones. 
$>$ Los beneficios de la movilidad activa, que brinda beneficios para la salud y favorece la disminución de la obesidad.

Los beneficios para la salud como resultado de una dieta más equilibrada.

$>$ Los provenientes de una menor incidencia de la malaria gracias a la reversión de la deforestación y la reducción de la producción de arroz por medio del riego por inundación. Esto significa una disminución de los costos de atención de la salud y un incremento de la productividad de la población, que no se vería afectada por la enfermedad mencionada, y también redundaría en una reducción significativa del consumo hídrico agrícola (Caldas Cueva y Lizárraga Travaglini, 2020; Escobedo, 2010; Vittor et al., 2006).

> Los beneficios potenciales de la utilización de los residuos de la crianza de cerdos para la producción de biogás.

> Los beneficios que una mayor producción forestal suscita en la industrialización.

$>$ Las mejoras de la productividad agrícola gracias al incremento de la oferta de fertilizantes orgánicos.

> La generación de empleo producto de las transformaciones para la descarbonización.

$>$ Los que resultan de un cemento mejorado.

$>$ Aquellos que se derivan de la reducción del impacto económico del cambio climático sobre Perú, producto de la reducción de las emisiones de GEI globales.
$>$ Los que resultan de la descarbonización del sector industrial, especialmente aquellos que se obtendrían sobre las ciudades aledañas a actividades mineras.

De igual forma, existen costos que no se han incluido por falta de información; y, por ende, los costos podrían ser mayores a los estimados en este estudio. Entre ellos se pueden mencionar los siguientes:

$>$ Los derivados de la electrificación del sector industrial para los procesos que pueden ser electrificados, incluyendo el uso del hidrógeno verde como sustituto de los derivados del petróleo, especialmente en actividades mineras.

$>$ Los provenientes de la electrificación requerida para el desarrollo y la logística de las plantaciones forestales con fines comerciales.

$>$ Los costos adicionales generados por un mayor requerimiento de mano de obra y maquinaria debido al incremento de la productividad en los cultivos.

$>$ Los costos de monitoreo y vigilancia para el cumplimiento de la asignación de derechos, así como para la constatación de prácticas forestales sostenibles.

> Los correspondientes a capacitación y creación de capacidades para un manejo sostenible de los pastos altoandinos, así como para mejores prácticas ganaderas que permitan el incremento de la productividad del ganado vacuno. 


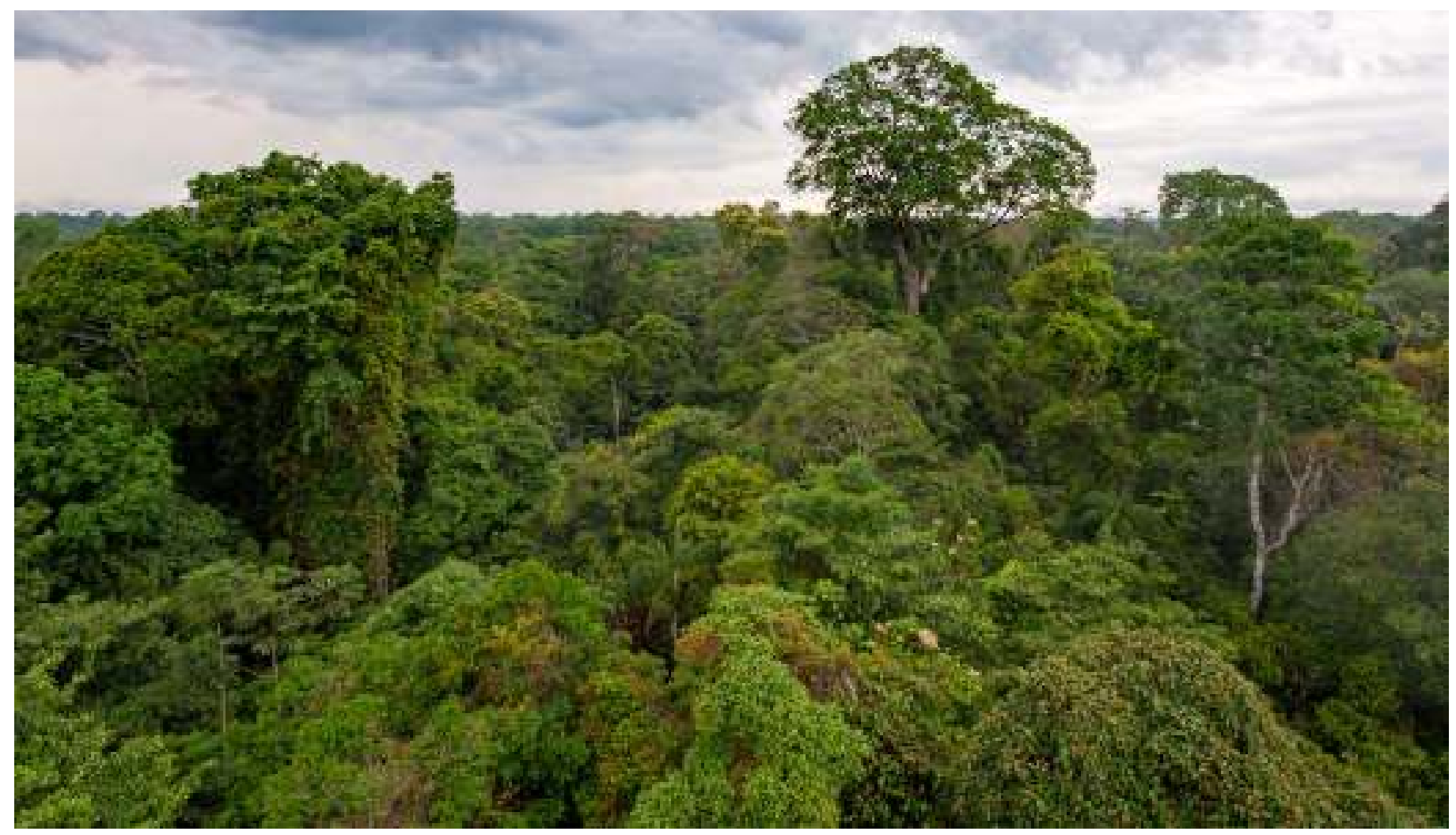

$>$ Los que surgen de la generación de capacidades locales para el desarrollo de las concesiones forestales manejadas de manera sostenible, así como para las concesiones forestales en transición a la sostenibilidad.

$>$ Los costos para la concertación y elaboración de un plan de gestión y ordenamiento territorial.

$>$ Los costos para la creación de capacidades de parte de los productores, relacionadas con la implementación de sistemas agroforestales.

$>$ Los costos de la creación de capacidades de parte de los productores, vinculadas al mantenimiento y al manejo de los pastos naturales altoandinos.

$>$ Los referidos a la capacitación y la creación de capacidades para la elaboración de fertilizantes orgánicos a partir del aprovechamiento de los residuos provenientes de las cosechas.

$>$ Los costos de promover el cambio de patrones de consumo.

$>$ Los costos del tratamiento de aguas residuales para disposición en cuerpos de agua y para la reutilización, que podrá requerir tratamiento adicional al previsto para su vertimiento.

$>$ Los costos ambientales de las acciones transformadoras que podrían imponer un riesgo ambiental y los costos asociados con la creación de políticas o normas para mitigar estos riesgos.

$>$ Aquellos que se requerirían para la construcción de una o varias líneas de metro para la movilidad de pasajeros. 


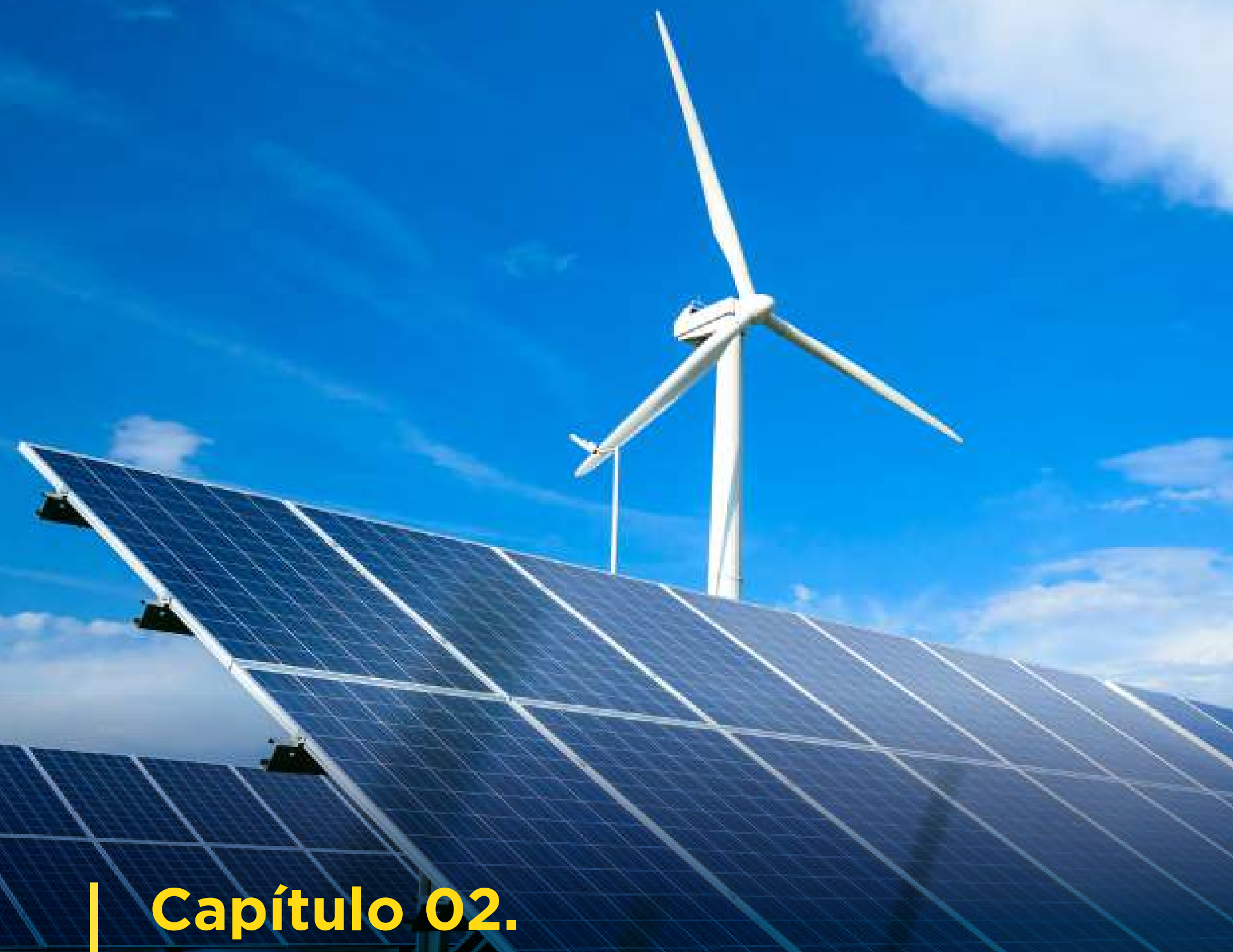

La ruta de la descarbonización y su efecto en emisiones, benefficios y costos 
Este capítulo presenta el efecto del escenario de carbono-neutralidad contrastado con el escenario base en términos de emisiones, beneficios y costos, considerando los supuestos estándar; es decir, con la información obtenida en los talleres y datos de referencia disponibles en la literatura al día de la publicación del informe. Cabe mencionar que para la construcción de ambos escenarios se utilizaron las proyecciones de crecimiento poblacional y económico (producto interno bruto, PIB) que se presentan en el gráfico 2.1. Estas proyecciones estiman la evolución de estas variables previas a la COVID y futuras actualizaciones deberán estudiar el efecto de la pandemia en el largo plazo.

\section{Gráfico 2.1}

Supuesto estándar en cuanto a la proyección de población y el PIB en ambos escenarios estudiados
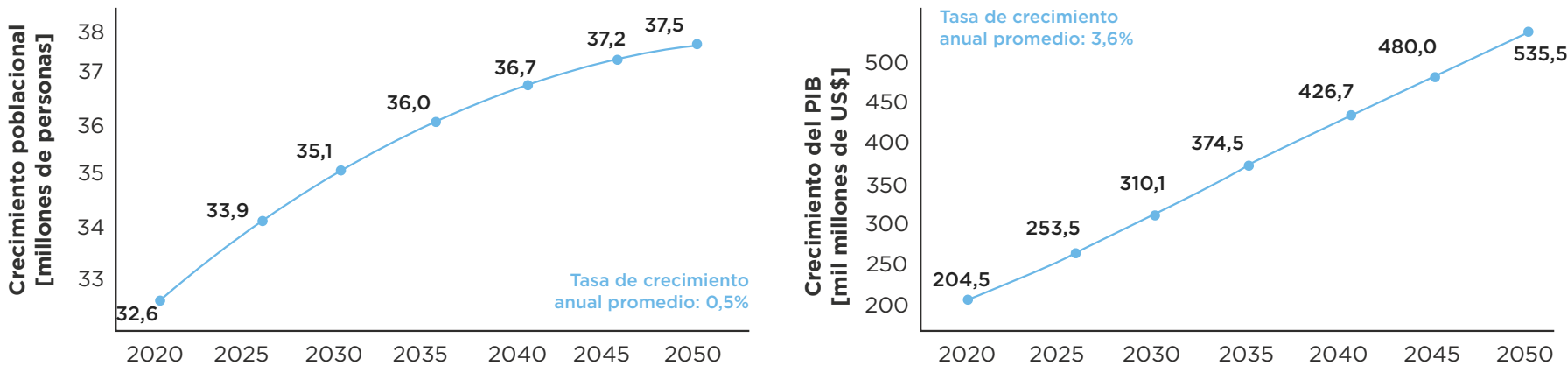

Fuente: UN PAGE (2017).

En las siguientes secciones se exponen los resultados referentes a emisiones, beneficios y costos sobre toda la economía de Perú, seguidos de un detallado análisis sectorial del proceso transformador, los supuestos, las emisiones, los beneficios y los costos correspondientes. Los resultados de beneficios y costos se presentan descontados a 2021, considerando una tasa de descuento del 8\% según el Ministerio de Economía y Finanzas (MEF, 2020); esta es la tasa social de descuento que usa Perú y representa el costo de oportunidad en que incurre el país cuando utiliza recursos para financiar sus proyectos. 


\subsection{Análisis total de emisiones, beneficios y costos}

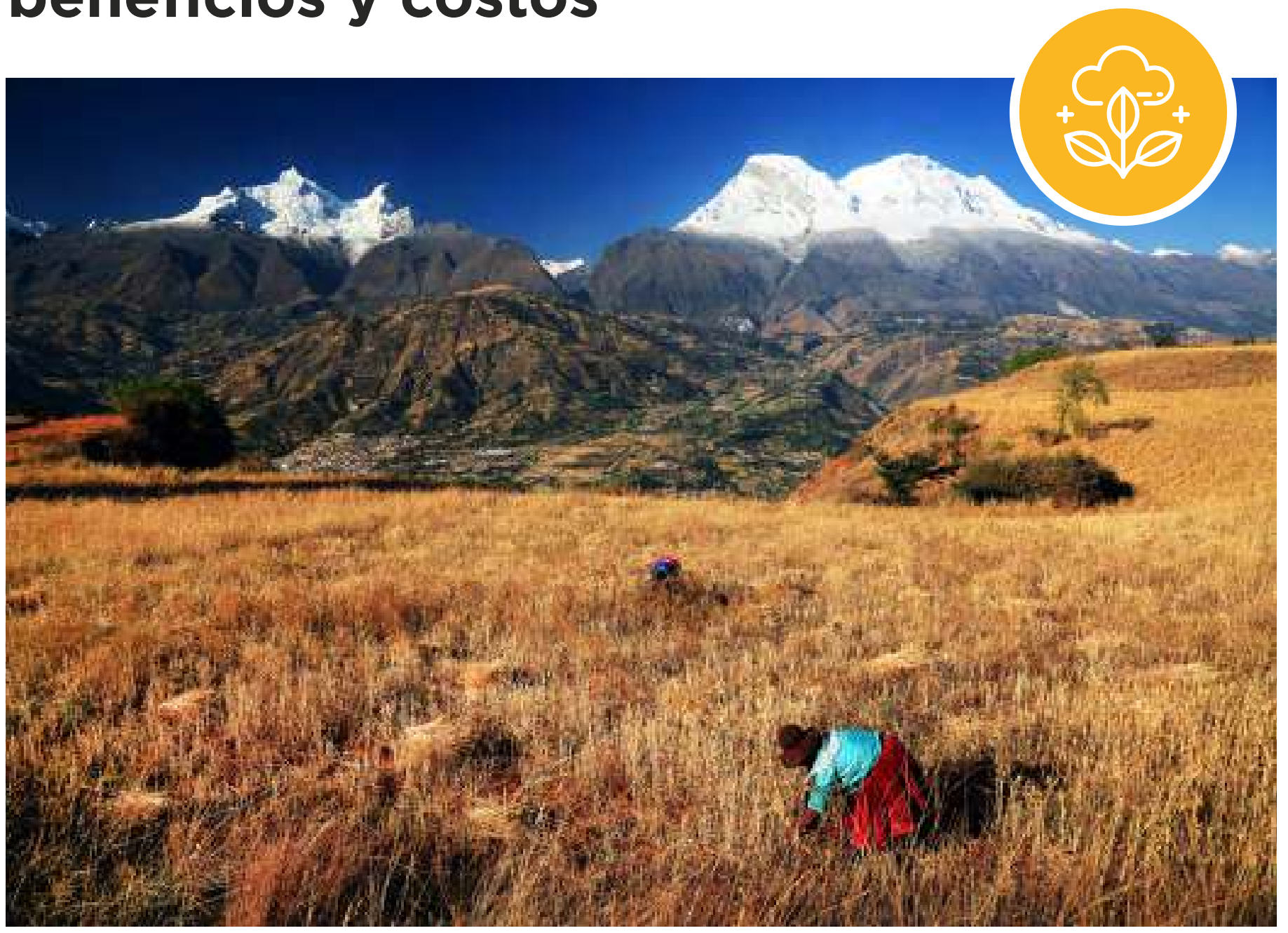

Este estudio ha delineado un escenario de descarbonización que logra la carbono-neutralidad de Perú para 2050; es decir, un escenario en el que se reducen las emisiones de sectores relevantes de la economía del país de manera considerable, y las remanentes son absorbidas por los bosques, el único sumidero considerado. Este escenario se denomina "escenario de carbononeutralidad", y toma en cuenta el escalamiento de las Contribuciones Determinadas a Nivel Nacional
(NDC, por sus siglas en inglés) de 2015. El proceso transformacional en cada sector se aborda de manera detallada en la sección 2.2, considerando tres plazos: corto (2021-25), mediano (2026-35) y largo (2036-50). Sobre la base de los insumos recibidos durante los talleres co-constructivos y las reuniones bilaterales con expertos sectoriales, la transformación por sector de mayor a menor contribución en términos de la reducción de emisiones se detalla a continuación. 


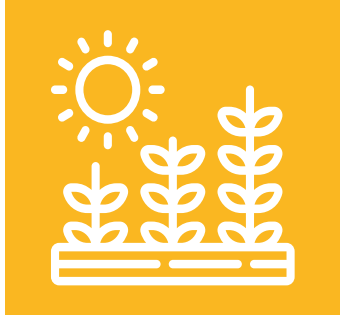

\section{Agricultura, silvicultura y otros usos de la tierra (AFOLU)}

\author{
Reversión de la \\ deforestación, con \\ una disminución de las
} actuales $123.000 \mathrm{Ha}$ anuales a tan solo $18.000 \mathrm{Ha}$ por año en 2050; aumento de la asignación de derechos del bosque primario, que alcanzaría los 12,4 millones de Ha en 2050; escalamiento de los sistemas agroforestales y silvopastoriles, que en conjunto llegarían a poco más de 1 millón de Ha en 2050, además del desarrollo de plantaciones forestales para elevar el secuestro de carbono, que alcanzarían los 2 millones de $\mathrm{Ha}$ en el año 2050. Cabe destacar que no se considera la asignación de concesiones en el bosque primario para el desarrollo de estas plantaciones forestales. Las transformaciones en el sector AFOLU se complementan al promover la sustitución de la cobertura de arroz bajo el sistema de riego por secas intermitentes (120.000 Ha en 2050) y sustituciones modestas en el consumo de carne roja (reducción de un 23\%) por carne de cerdo (incremento de un $30 \%$ en 2050), así como por un aumento en el consumo de tubérculos con respecto a un escenario base.

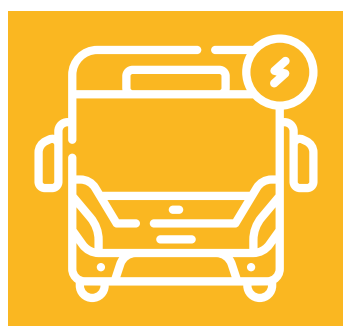

\section{Transporte}

La transformación del sector transporte se habilita a 2050 con la electrificación total de la flota vehicular privada, pública y de carga, lo cual iría acompañado de un aumento en la participación del transporte público en la movilidad total de pasajeros del 5\%, que llegaría al 70\% a mediados de siglo. La transformación se complementa con un cambio modal al transporte no motorizado (transporte peatonal y en bicicleta), así como con un incremento del teletrabajo y de la digitalización de las actividades, lo que permite reducir la demanda del transporte de pasajeros en un 30\% total para 2050, es decir, un 15\% cada intervención. De igual forma, las mejoras de logística posibilitarán una reducción importante del $20 \%$ en la demanda de carga del país para 2050.

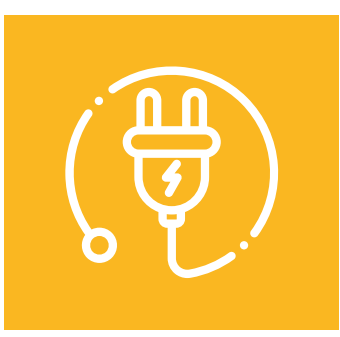

\section{Energía}

Se estima un aumento de la participación de las energías renovables en el sistema eléctrico, que pasarían del 65\%, valor estimado para

2020, a un $90 \%$ en 2050. La electrificación de las distintas actividades eleva la capacidad instalada existente de 12,8 GW (46\% de renovables) a casi 46 GW (85\% de renovabilidad). El escenario contempla un despliegue de las redes eléctricas inteligentes habilitadas con el almacenamiento de energía (principalmente por baterías que habilitan las energías renovables intermitentes), que aumenta con el tiempo y que podría habilitar la participación de los clientes en la provisión de servicios auxiliares y esquemas de respuesta a la demanda. La eficiencia energética permite reducir un 35\% el consumo de energía de los diferentes subsectores para 2050 con respecto al escenario base. La participación del gas natural, el carbón y el petróleo para producir energía en el país disminuye en el tiempo y pasa del actual $84 \%$ a un $67 \%$ en 2050 . Se considera que este alto porcentaje se utiliza en el sector industrial que no ha sido estudiado en detalle en este proyecto y 
para exportación de energía a la región, ya que se ha considerado que el resto de los países continúa consumiendo derivados de petróleo. A futuro, se deberán revisar estos consumos y analizar el efecto de una reducción de su consumo aún mayor, producto de la descarbonización del consumo de energía en la industria y de los países vecinos.

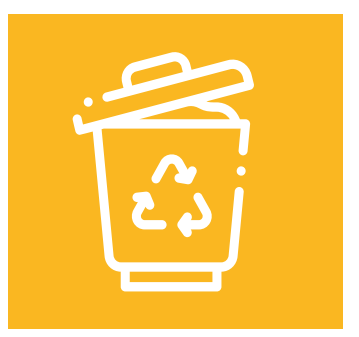

\section{Residuos}

El proceso transformador del sector residuos considera una reducción de la cantidad de residuos sólidos, producto de la segregación de residuos

y el reciclaje, y de un mayor tratamiento de las aguas residuales y los efluentes industriales. La generación de residuos sólidos se reduce en un 25\% para 2050 en relación con el escenario base. El 50\% de las toneladas generadas restantes serán recicladas, lo que implica que aproximadamente el $37 \%$ de los residuos proyectados en un escenario base serán depositados en un relleno sanitario en 2050. La transformación se complementa con mayor cantidad de aguas residuales y efluentes industriales tratados; ambos alcanzarían el 50\% en 2050.

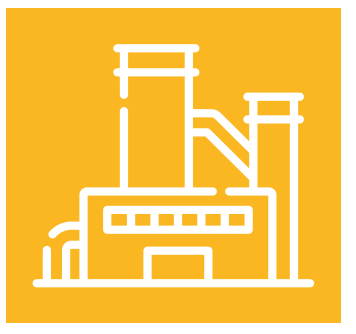

\section{Procesos industriales y uso de productos (PIUP)}

Se contempló únicamente una reducción del uso de clínker para la producción de cemento. Este es un sector que puede nutrirse de futuros estudios con la hoja de ruta que están delineando la industria peruana y la Federación Internacional del Cemento. El proceso transformador contempla que para 2050 el consumo de clínker se reduzca a 8,7 Mton, lo cual implica una disminución de 2,2 Mton con respecto al valor proyectado para 2050 en el escenario base.

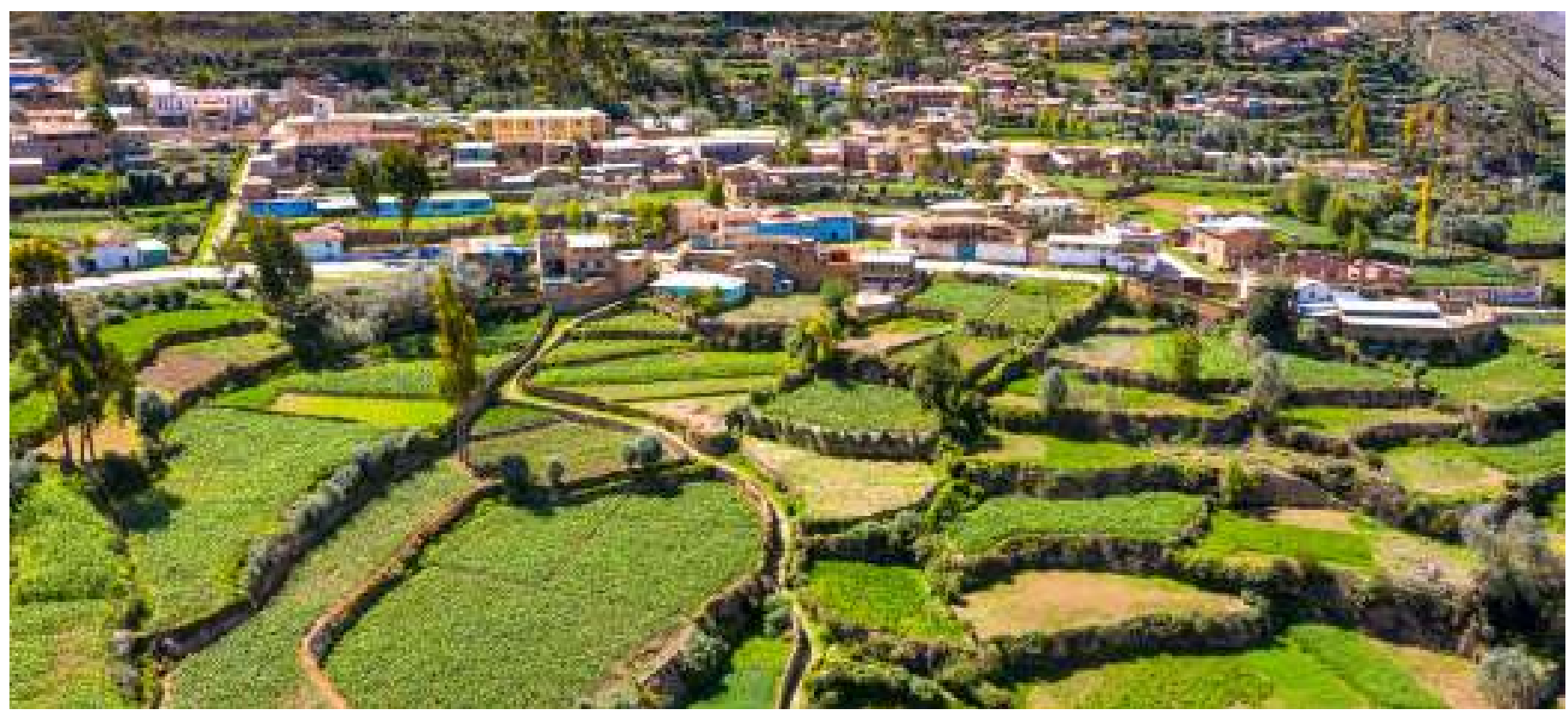


Como ya se ha adelantado, los resultados del escenario de carbono-neutralidad se contrastan con un escenario tendencial que se llama escenario base. Este escenario no contempla la implementación de las NDC de 2015 ni acciones adicionales de mitigación en ninguno de los sectores, más allá de las que se habían implementado antes de 2018, y tiene una evolución tendencial. Además, los consumos y el uso de los bienes y servicios se proyectan en función del PIB y el crecimiento poblacional a 2050. Este escenario plantea los siguientes supuestos para los sectores (la sección 2.2 también presenta con mayor detalle las consideraciones efectuadas en este escenario por cada sector):

> La producción de energía eléctrica renovable no convencional en el país mantiene porcentajes bajos de penetración. Se complementa con plantas hidroeléctricas y plantas a base de combustibles fósiles. La penetración de plantas eólicas y solares es escasa para la producción de electricidad en todo el horizonte de planificación.

$>$ Se mantiene el consumo de combustibles fósiles para la movilidad en el sector transporte, que en 2018 abarcó un 43\% del consumo total de energía del país (MINEM, 2020b). Además, el sector transporte conserva su flotilla basada en vehículos de combustión interna y no se fomenta la movilidad no motorizada.

$>$ En agricultura, silvicultura y otros usos de la tierra (AFOLU), la deforestación continúa aumentando. La expansión de la frontera agrícola nacional está circunscripta al crecimiento neto de tierras cultivables en la Amazonía. La ganadería se expande en función del crecimiento poblacional y del ingreso per cápita. De igual forma, la demanda de arroz y otros cultivos aumenta producto del crecimiento económico y poblacional. El riego por inundación sigue siendo la práctica común para la producción de arroz, y los residuos agrícolas se desechan y/o queman. No se fomenta la transición de las concesiones forestales tradicionales hacia concesiones forestales bajo manejo forestal sostenible ni se incrementan las concesiones otorgadas. No se fomentan plantaciones forestales con fines comerciales, plantaciones comerciales con fines de restauración, sistemas silvopastoriles, sistemas agroforestales ni se brinda apoyo logístico a los productores agrícolas.

$>$ El volumen de residuos sólidos no tratados se incrementa en función de la población del país y no se realizan acciones para aumentar el tratamiento de las aguas residuales, las cuales aumentan con el crecimiento poblacional. Los efluentes industriales también ascienden como producto del crecimiento económico del país y esto causa un aumento de las emisiones del sector.

$>$ En el sector de procesos industriales y uso de productos (PIUP), la industria de minerales, química y metales mantiene su tendencia y las limitadas acciones conllevan a un aumento de las emisiones de gases de efecto invernadero (GEI).

Bajo supuestos estándar, se estima que la implementación del escenario de carbononeutralidad reduce las emisiones netas de GEI de unas $220 \mathrm{MtCO}_{2 \mathrm{e}}$ en 2020 a cero emisiones netas para 2050 (gráfico 2.2). Sin acciones de políticas y bajo un comportamiento tendencial como lo plantea el escenario base, las emisiones de GEI aumentarán a casi $412 \mathrm{MtCO}_{2 e}$ en 2050. El gráfico 2.2 muestra este comportamiento por sector. Los cambios más marcados se observan en AFOLU, donde se pasa de emisiones netas de $145 \mathrm{MtCO}_{2 \mathrm{e}}$ a 
una absorción neta de casi $38 \mathrm{MtCO}_{2 \mathrm{e}}$ (negativas), y en transporte, donde se pasa de una emisión de poco más de $29 \mathrm{MtCO}_{2 \mathrm{e}}$ a cero emisiones en 2050.
Los sectores de energía, residuos y PIUP terminan de contribuir a la reducción de emisiones de GEI en Perú de cara a la carbono-neutralidad.

\section{Gráfico 2.2}

Trayectoria de emisiones de GEI totales por año en Perú bajo el escenario base y el escenario de carbono-neutralidad bajo supuestos estándar

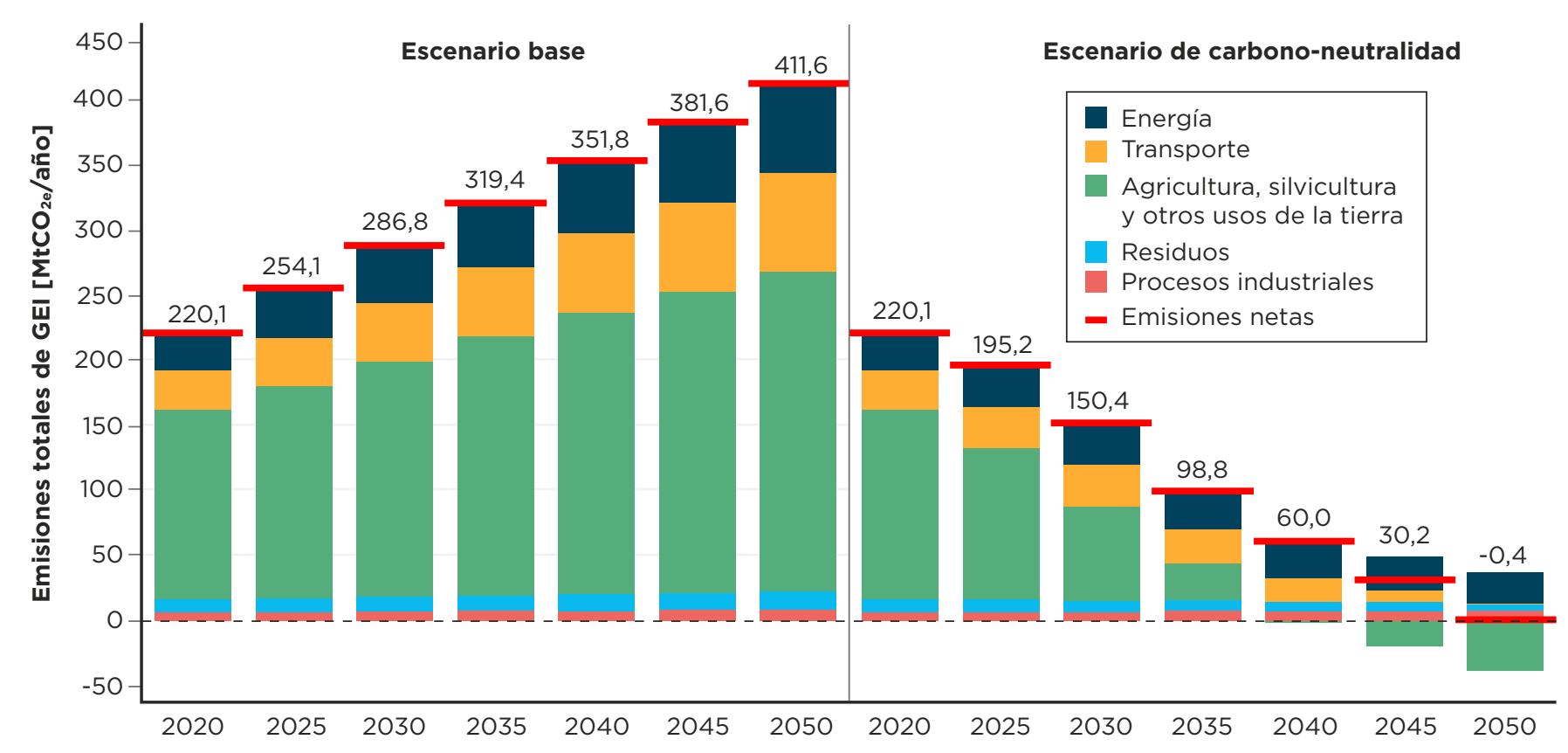

Fuente: Elaboración propia.

$\gg$ Nota: Los números sobre las barras corresponden al valor de las emisiones netas.

Bajo supuestos estándar, la mayor reducción de emisiones netas anuales de GEl en 2050 en el escenario de carbono-neutralidad y relativas al escenario base proviene del sector AFOLU, con un valor de casi $282 \mathrm{MtCO}_{2 \mathrm{e}}$ (gráfico 2.3), y es producto de evitar $244 \mathrm{MtCO}_{2 \mathrm{e}}$ y de absorber 38 $\mathrm{MtCO}_{2 \mathrm{e}}$ (véase el gráfico 2.2 para complementar). En este estudio el sector AFOLU es el único con una absorción de emisiones de GEl para 2050, lo que permite compensar otras emisiones no evitadas provenientes de otros sectores, como el de energía. Las acciones en transporte logran la segunda mayor reducción de emisiones de GEI en 2050 con respecto al escenario base, emisiones que corresponden a casi $76 \mathrm{MtCO}_{2 \mathrm{e}}$. Los sectores de energía, residuos y PIUP completan los esfuerzos para lograr la carbono-neutralidad y reducen unas $46 \mathrm{MtCO}_{2 \mathrm{e}}, 8 \mathrm{MtCO}_{2 \mathrm{e}}$ y $1 \mathrm{MtCO}_{2 \mathrm{e}}$, respectivamente, para 2050. 


\section{Gráfico 2.3}

Reducción de emisiones de GEI por sector en Perú, escenario de carbono-neutralidad versus escenario base bajo supuestos estándar, 2050

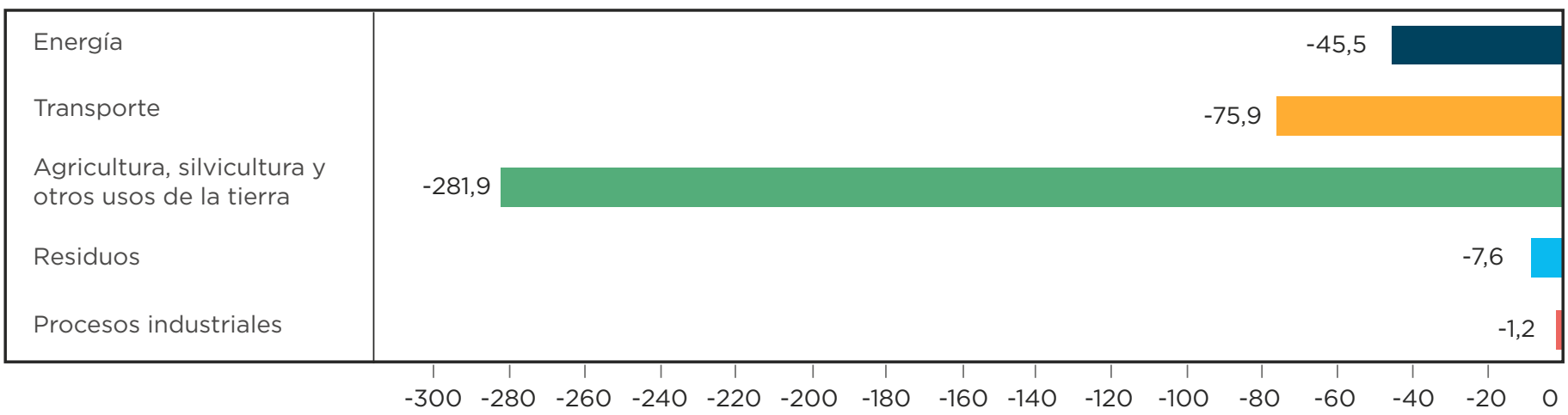

Reducción de emisiones de GEI en el 2050 (relativas al escenario base) [MtCO 2 ]

Fuente: Elaboración propia.

Bajo supuestos estándar, alcanzar la carbononeutralidad de Perú para 2050 brindará un ahorro de unos de US\$233.000 millones entre 2021 y 2050. El costo descontado sería de casi US $\$ 93.000$ millones en el mismo periodo. Alcanzar la carbononeutralidad le proporcionará a Perú un beneficio neto acumulado (beneficios menos costos) de aproximadamente US\$140.000 millones entre 2021 y 2050. Lo anterior se obtiene con una tasa de descuento del 8\%. La tasa interna de retorno es del 29\%; es decir, cualquier tasa por debajo de esta brindará un beneficio neto. Por ejemplo, utilizar una tasa del $4 \%$, según la recomendación del MEF para proyectos de largo plazo con hasta 50 años, resultaría en un beneficio neto de US\$300.000 millones entre 2021 y 2050.

El gráfico 2.4 muestra los beneficios y costos incurridos en las tres franjas de tiempo estudiadas. En el corto plazo, se estima un beneficio neto negativo, es decir un costo, de poco más de US\$9.000 millones, debido a las inversiones necesarias para habilitar la transformación (US\$18.000 millones), que sobrepasan los beneficios totales percibidos en el mismo periodo (US\$9.000 millones). Sin embargo, en el mediano plazo los beneficios totales (de US $\$ 65.000$ millones) compensan con creces los costos del periodo (cerca de US\$41.000 millones) y así la carbono-neutralidad en el mediano plazo brinda un beneficio neto de US\$24.000 millones. En el largo plazo, el beneficio neto se estima en unos US $\$ 125.000$ millones, producto de beneficios totales (de casi US\$159.000 millones) que sobrepasan por mucho los costos del periodo (cerca de US\$34.000 millones). A continuación, se describe cada beneficio estimado de mayor a menor, y se indican los sectores que contribuyen al beneficio. 


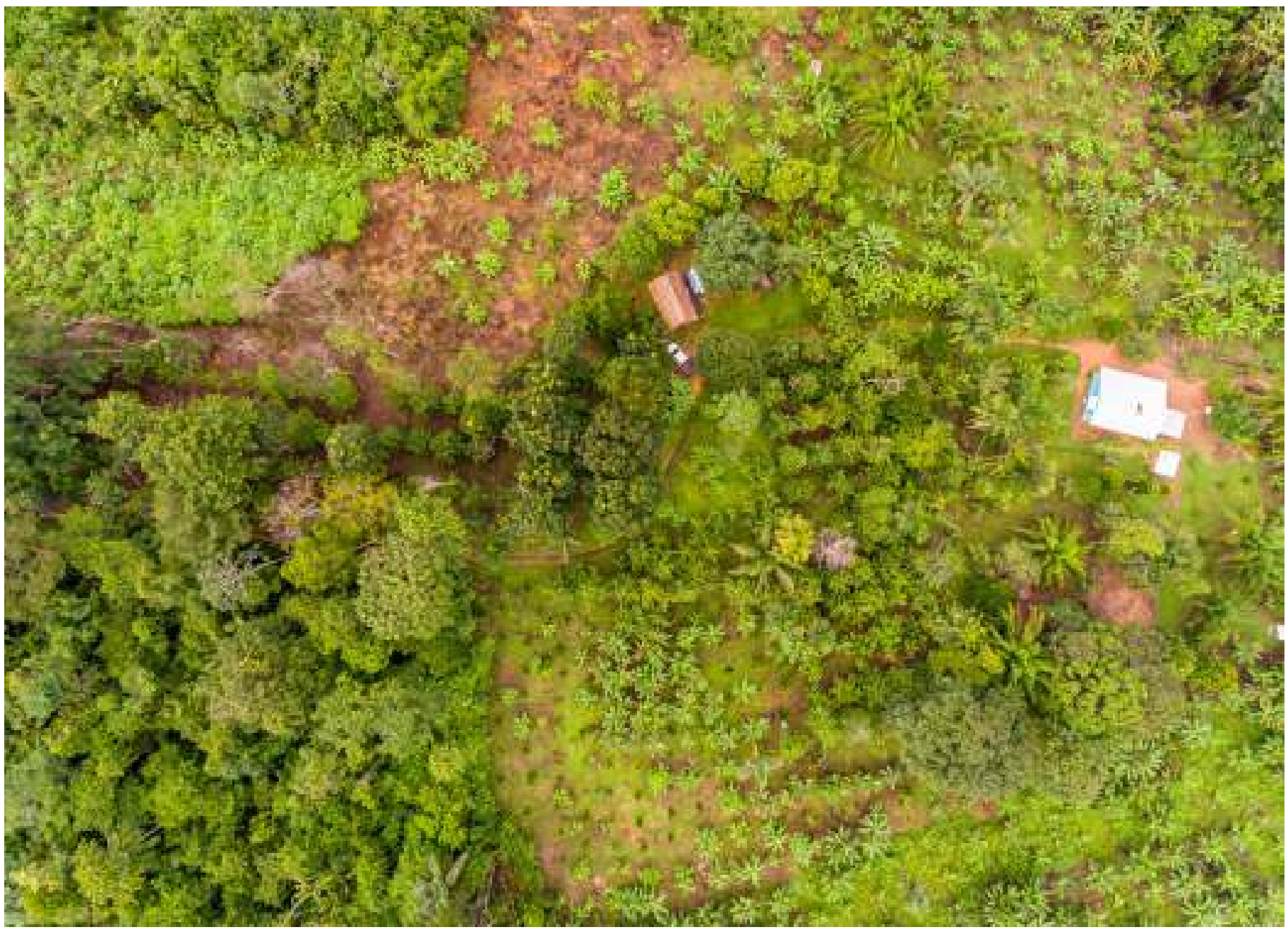

$>$ El mayor beneficio se logra por una operación y un mantenimiento más económicos del sistema de energía y transporte, el cual crece conforme la transformación se consolida. Entre 2021 y 2050 el beneficio acumula US\$131.000 millones (US\$3.000 millones; US\$29.100 millones y US\$98.700 millones en cada periodo).

$>$ El segundo mayor beneficio se obtiene por ingresos provenientes de las ventas de madera de las plantaciones forestales para comercialización, las concesiones forestales bajo manejo forestal sostenible y de los sistemas agroforestales (denominado ingresos en AFOLU). Estos beneficios aumentan en el tiempo (US\$1.800 millones, US\$14.300 millones y US\$ 19.600 millones en cada periodo) y llegan a acumular US\$35.700 millones.

$>$ Reducir la quema de derivados del petróleo en los sectores energía y transporte disminuye los costos de tratar enfermedades respiratorias generadas por la combustión y suma un beneficio total de aproximadamente US $\$ 20.000$ millones para 2050 (US\$800 millones, US $\$ 5.600$ millones y US $\$ 14.000$ millones en cada periodo de análisis, respectivamente).

$>$ Las acciones en materia de residuos, lo cual incluye reciclaje, la reutilización del agua tratada para otras actividades y los beneficios en salud producto del tratamiento de aguas 
residuales, brindan un beneficio adicional de casi US $\$ 30.000$ millones para 2050 (US $\$ 2.800$ millones, US\$11.500 millones y US\$15.600 millones en cada periodo).

$>$ Los servicios ecosistémicos -de regulación del clima y precipitaciones y de suministro de materias y de recreo- por el bosque primario, el bosque secundario y las plantaciones de restauración aumentan en proporción a la cobertura producto de la asignación de derechos (US $\$ 200$ millones, US $\$ 2.400$ millones y US $\$ 6.600$ millones en cada periodo de análisis) y agregan un beneficio total de poco más de US\$9.000 millones; estudios recientes han encontrado que este beneficio podría multiplicarse por siete (HernándezBlanco et al., 2020).

$>$ El cambio modal a transporte público y al transporte no motorizado o a la movilidad activa (peatonal y en bicicleta), así como el aumento del teletrabajo y la digitalización de los servicios, brinda un beneficio adicional por productividad y reducción de accidentes que a 2050 acumula más de US\$6.000 millones (US\$300 millones, US\$2.100 millones y US $\$ 4.100$ millones en cada periodo).

\section{Gráfico 2.4}

Beneficios y costos por periodo del escenario de carbono-neutralidad versus el escenario base bajo supuestos estándar

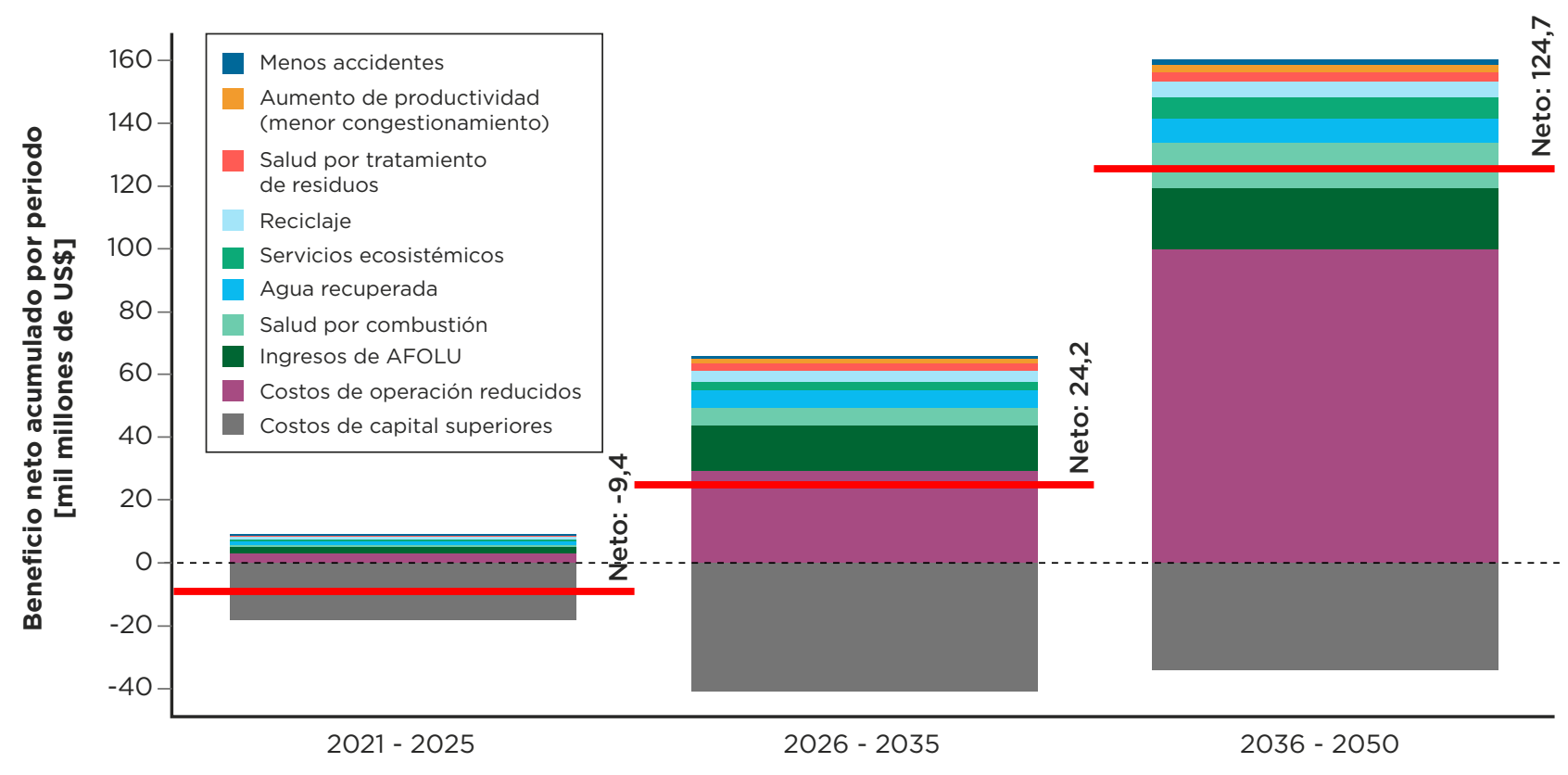

Fuente: Elaboración propia. 


\section{Gráfico 2.5}

Beneficio neto por sector al implementar el escenario de carbono-neutralidad versus el escenario base bajo supuestos estándar

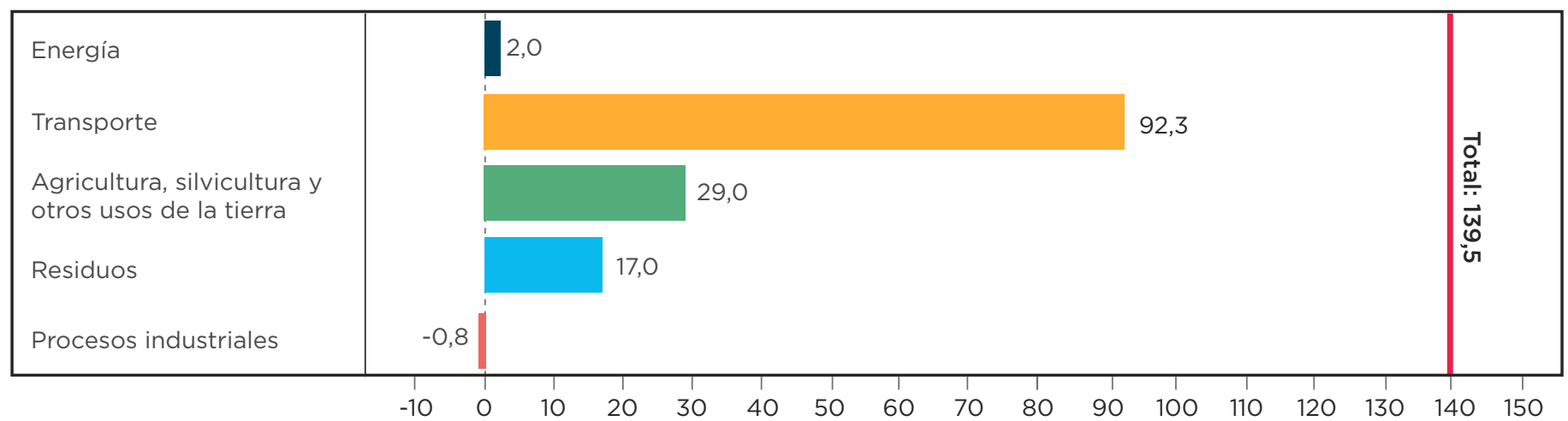

Beneficio neto acumulado al 2050 por sector [mil millones de US\$]

Fuente: Elaboración propia.

Estos beneficios podrían ser superiores si se consideraran aquellos que resultan de las redes eléctricas inteligentes, si se estimaran los beneficios por reducción del estrés en las carreteras, los de la movilidad activa que favorece la disminución de la obesidad, los que atañen una dieta más equilibrada, aquellos que resultan de la reducción del impacto económico del cambio climático sobre Perú gracias a la reducción de emisiones, entre otros.

Bajo supuestos estándar, el sector transporte brinda el mayor beneficio, seguido de AFOLU, residuos, energía y PIUP. El gráfico 2.5 muestra el beneficio neto por sector. En la sección 2.2 se detallan los beneficios y costos para cada uno de los diferentes sectores estudiados.

El mayor beneficio de la transformación se obtiene de la reducción de costos operativos (gráfico 2.6). Por falta de información, los costos operativos de los sectores de residuos y PIUP no se han incluido. Los ahorros por operación y mantenimiento del nuevo sistema de energía y transporte crecen considerablemente en el tiempo, de acuerdo con los detalles que se exponen a continuación.

$>$ La reducción del creciente uso de refinerías y plantas térmicas para la producción de electricidad, la reducción de importaciones de energía gracias al aumento del recurso renovable local, y una relativa disminución de la participación del gas natural en la matriz energética permiten bajar los costos operativos del sistema de energía. Estas acciones cobran cada vez más fuerza con el tiempo y brindan un ahorro de US\$1.200 millones en el corto plazo, que aumenta a US\$7.900 millones en el mediano plazo, y alcanza los US\$12.600 millones en el largo plazo, para conformar un total de poco más de US\$21.000 millones a 2050. 
$>$ La paulatina electrificación de la flota vehicular reduce la factura petrolera y proporciona un ahorro operativo de US $\$ 2.900$ millones en el corto plazo, que se multiplica por nueve en el mediano plazo (US $\$ 25.400$ millones) y alcanza los US $\$ 90.300$ millones en el largo plazo; para poco más de US $\$ 118.000$ millones acumulados a 2050.

$>$ La intensificación del monitoreo y de las actividades para el resguardo de los bosques causa un aumento de los costos operativos en el sector AFOLU, los cuales llegan a US\$1.000 millones en el corto plazo. Los costos operativos del sector ascienden a US $\$ 4.300$ millones en el mediano plazo, debido a una fuerte expansión de las plantaciones con fines de restauración y de las plantaciones con fines comerciales, el escalamiento del uso de sistemas agroforestales y silvopastoriles, y una mayor supervisión y un mayor monitoreo de los bosques asignados. En el largo plazo, las actividades de resguardo aumentan y requieren mayores costos operativos, que alcanzan los US $\$ 4.200$ millones. En total, el sector AFOLU aumentaría los costos operativos en poco más de US\$9.000 millones a 2050.

\section{Gráfico 2.6}

Reducción de costos operativos del escenario de carbono-neutralidad versus el escenario base bajo supuestos estándar

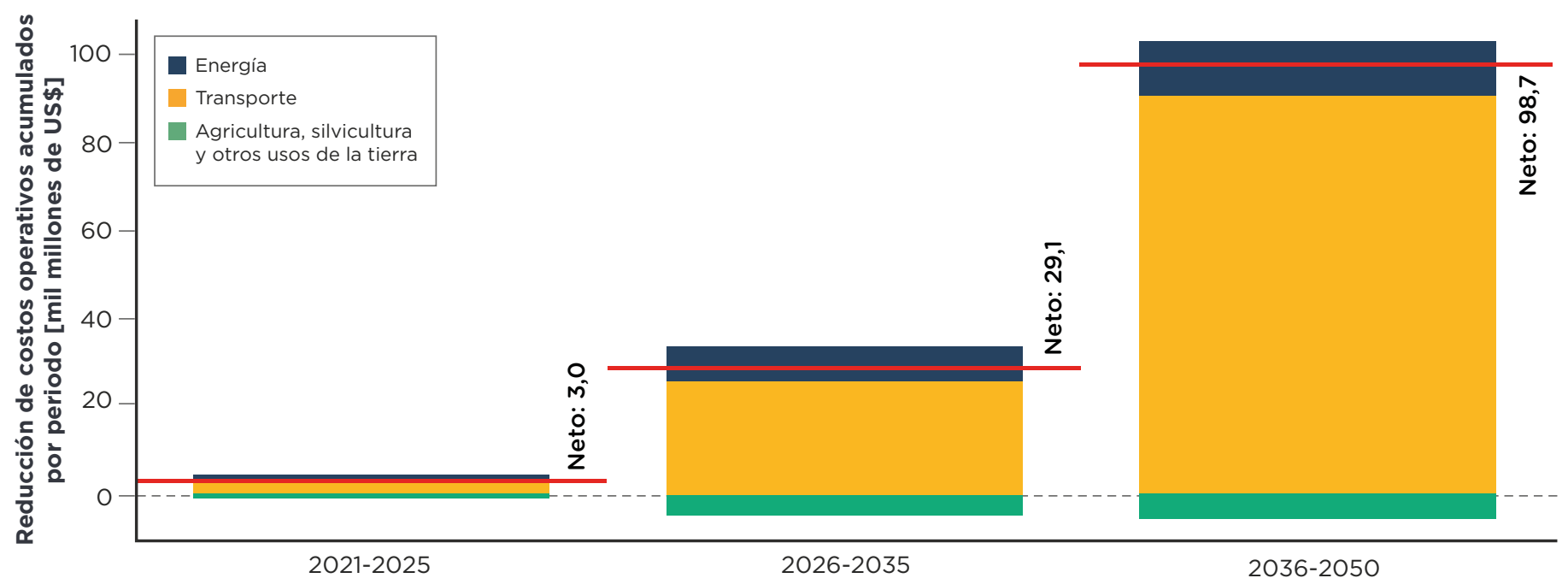

Fuente: Elaboración propia.

Nota: El estudio no captura costos operativos en los sectores residuos y PIUP, ya que no se contó con información durante su desarrollo. 
Bajo supuestos estándar, implementar el escenario de carbono-neutralidad requiere inversiones adicionales con respecto al escenario base, las cuales acumulan cerca de US\$93.000 millones para 2050 (gráfico 2.7):

$>$ El sector energía demanda inversiones que aumentan en el tiempo. En el corto plazo se estima una inversión adicional de US\$6.900 millones para la construcción de plantas eléctricas a base de geotermia, plantas hidroeléctricas de filo de agua de máximo $100 \mathrm{MW}$, plantas eléctricas renovables no convencionales (eólicas y solares) e inversiones en el despliegue de las redes eléctricas inteligentes. En el corto plazo se evitan también inversiones en plantas de gas natural y plantas térmicas que se hubieran producido bajo un escenario tendencial. Las inversiones ascienden a US\$8.900 millones en el mediano plazo y se realizan en infraestructura eléctrica para habilitar la electrificación de las actividades económicas, especialmente el transporte, así como también se observa un mayor impulso de las inversiones efectuadas en el plazo anterior. El sector energía requiere inversiones de US\$10.100 millones en el largo plazo, las cuales obedecen al aumento de la infraestructura eléctrica, la construcción de plantas renovables no convencionales, plantas hidroeléctricas de pequeña escala, y un mayor despliegue de inversiones para implementar más redes eléctricas inteligentes.

$>$ El sector transporte requiere inversiones que se estiman en US\$8.300 millones en el corto plazo; US $\$ 24.300$ millones en el mediano plazo y US\$14.400 millones en el largo plazo. Las inversiones en este sector se relacionan principalmente con la electrificación de la flota vehicular que sustituye a la flota de combustión interna existente; a inversiones en infraestructura (aceras, ciclovías, nuevas rutas) que habilitan la reducción de la demanda, y a infraestructura para la recarga de automóviles, buses y camiones eléctricos.

$>$ Las inversiones en el sector AFOLU se estiman en US\$2.200 millones en el corto plazo, US $\$ 2.800$ millones en el mediano plazo y US $\$ 1.400$ millones en el largo plazo; US $\$ 6.400$ millones en total. Tienen lugar principalmente en el subsector de uso de la tierra, cambio de uso de la tierra y silvicultura (UTCUTS). Gran parte de las mismas en cada periodo, aproximadamente el $40 \%$, se producen para la creación de plantaciones forestales con fines de restauración. Las inversiones en cada plazo se complementan con costos para la asignación de derechos, la agroforestería y plataformas de apoyo logístico para el desarrollo agrícola, la creación de concesiones forestales bajo manejo forestal sostenible y las plantaciones forestales con fines de comercialización de productos madereros.

$>$ Las inversiones en el sector residuos aumentan en cada periodo: US\$900 millones en el corto plazo, US\$4.500 millones en el mediano plazo y US\$7.500 millones en el largo plazo. Su objetivo principal se centra en la construcción de plantas de tratamiento de aguas residuales y efluentes industriales y en infraestructura para el reciclado de material sólido, lo que incluye maquinaria y camiones de transporte.

> La reducción paulatina del uso del clínker requiere una inversión de US\$100 millones en el corto plazo, US\$300 millones en el mediano plazo y US $\$ 400$ millones en el largo plazo. 


\section{Gráfico 2.7}

Costos de capital adicionales por sector para implementar el escenario de carbono-neutralidad versus el escenario base bajo supuestos estándar

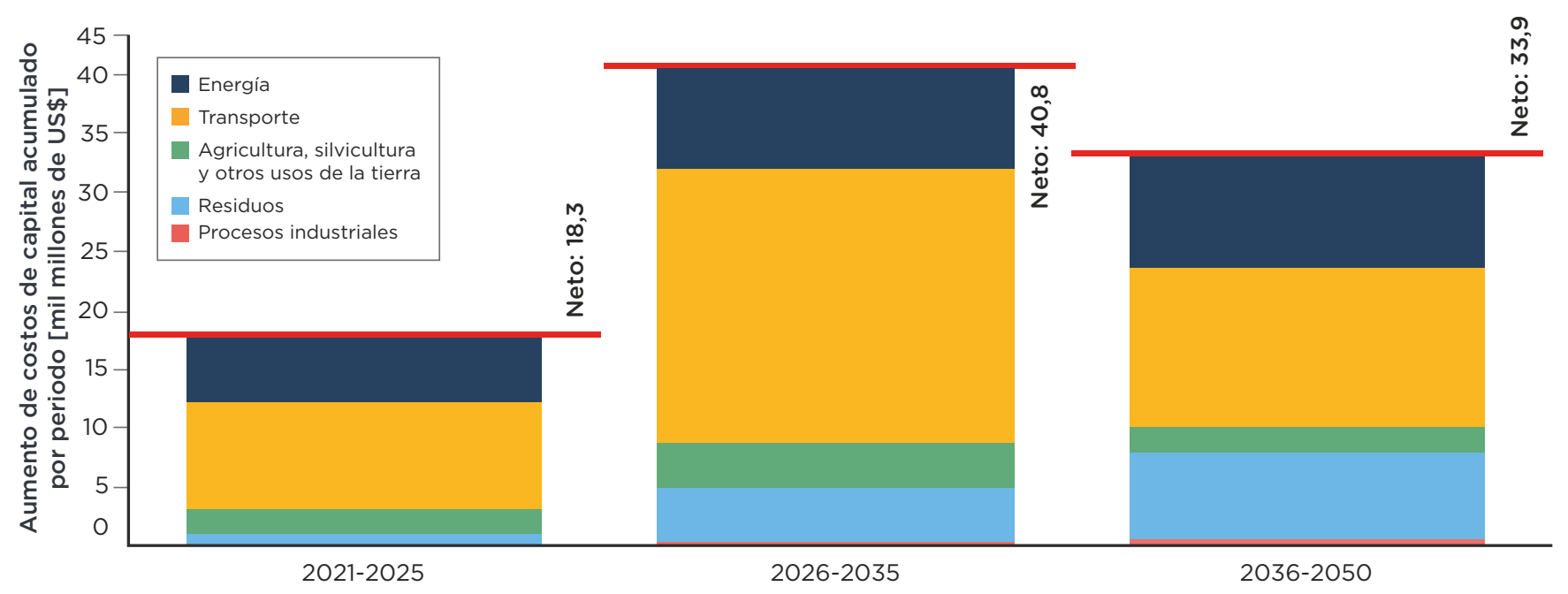

Fuente: Elaboración propia.

Hay costos que no se han cuantificado, entre ellos: los derivados de la electrificación de la industria, los necesarios en mano de obra por el incremento en la producción agrícola, aquellos para el monitoreo y vigilancia necesarios para cumplir con la asignación de derechos y los que se precisan para la constatación de prácticas forestales sostenibles, los costos para la concertación y elaboración de un plan de gestión y ordenamiento territorial, aquellos para promover cambios de patrones de consumo, los necesarios para el tratamiento de aguas residuales para disposición en cuerpos de agua y para la reutilización que podría requerir tratamiento adicional antes de su vertimiento, entre otros. Por ende, la estimación de los costos podría ser superior si se consideran los anteriores.
Al analizar las emisiones y los beneficios netos de manera conjunta, se observa que el mayor beneficio neto acumulado a 2050 proviene de la descarbonización del transporte, con una importante reducción de emisiones anuales de GEl a mitad de siglo (gráfico 2.8). La mayor reducción de emisiones anuales de GEI se logra en el sector AFOLU, con el segundo mayor beneficio neto acumulado a 2050. La descarbonización del sector energía permite obtener la tercera mayor reducción y el cuarto mayor beneficio neto. El sector residuos se ubica en la cuarta posición en términos de reducción de emisiones y tercero en obtención de beneficios netos. Según la información utilizada para este estudio, la menor reducción se logra en el sector PIUP, con un costo modesto. 


\section{Gráfico 2.8}

Beneficio neto acumulado a 2050 frente a la reducción de emisiones anuales de GEI en 2050 del escenario de carbono-neutralidad versus el escenario base bajo supuestos estándar

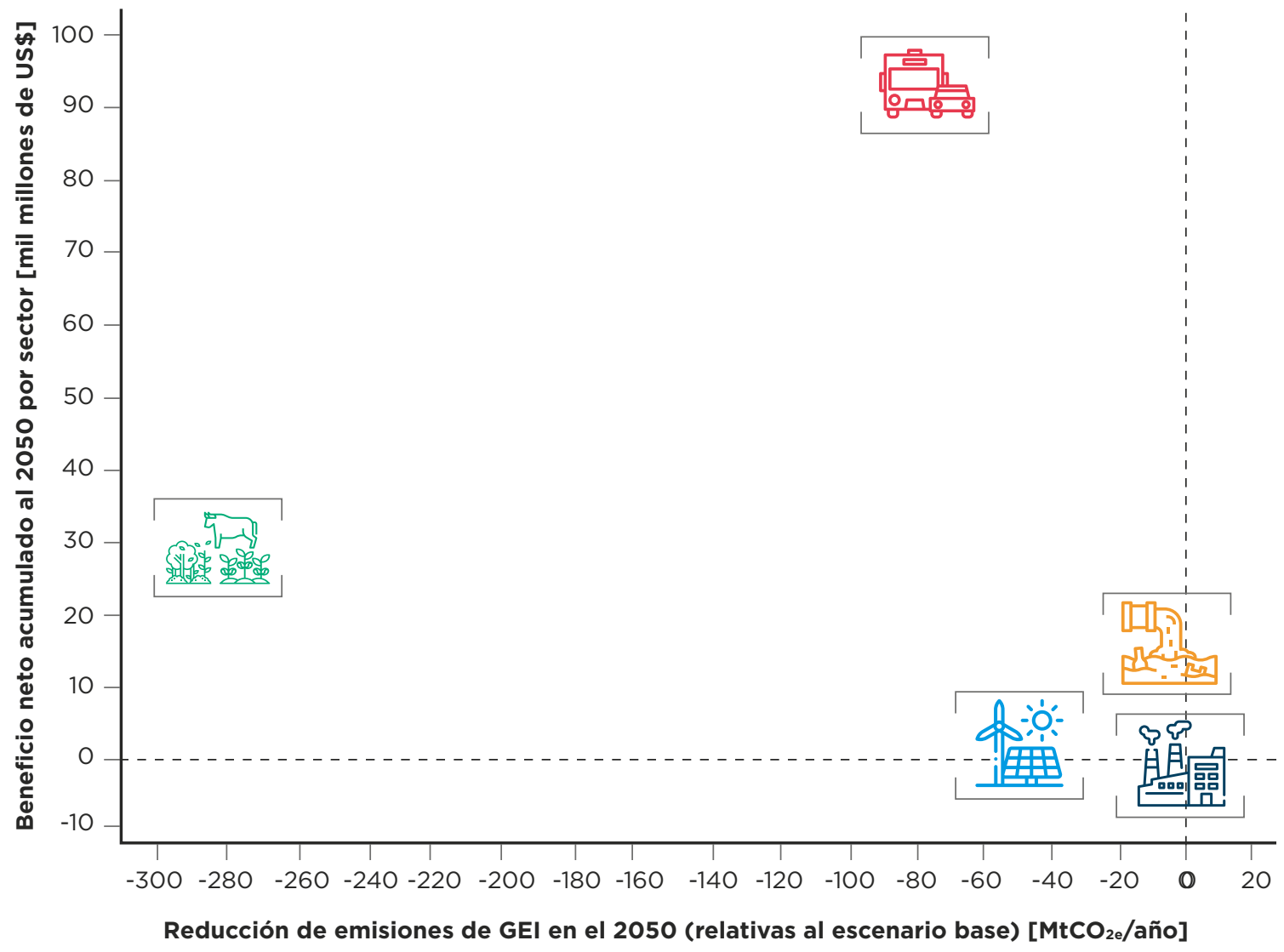




\subsection{Análisis sectorial: transformaciones, emisiones, beneficios y costos}

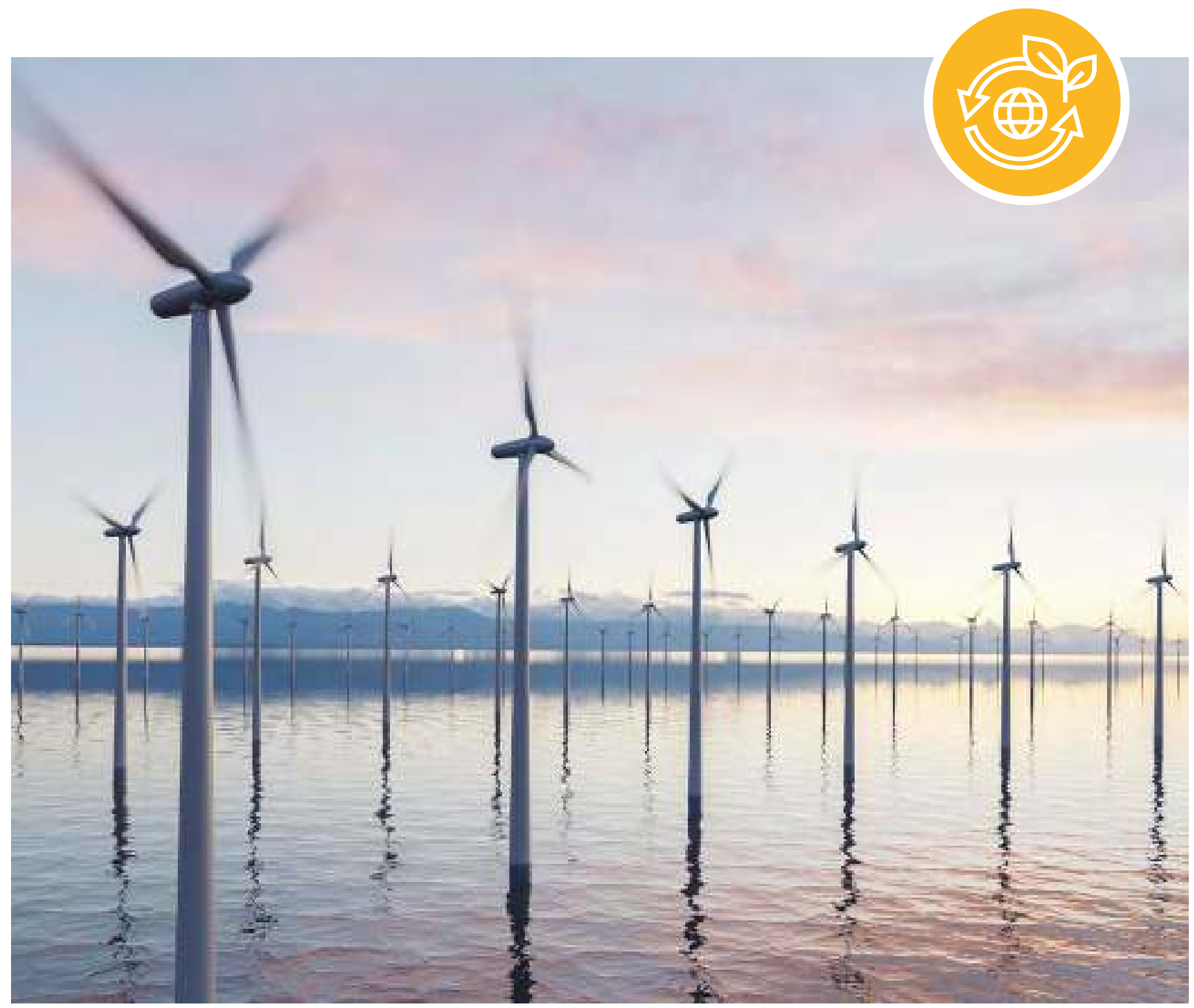

Las siguientes secciones presentan el proceso de transformación, la trayectoria de emisiones, los beneficios netos percibidos y los costos de dicha transformación para cada sector. Estos resultados aún consideran los supuestos estándar. 


\subsubsection{Energía}

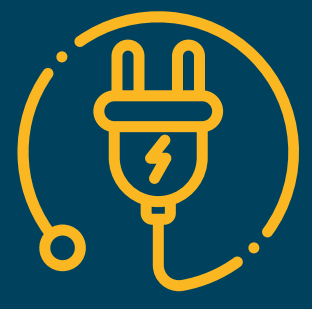

El escenario de carbono-neutralidad evita un crecimiento desmedido de las emisiones anuales de GEI a 2050. Estas suben en el corto plazo, pero a 2050 se logra una reducción de $5 \mathrm{MtCO}_{2 \mathrm{e}}$ con respecto al valor estimado en 2020. Para 2050 la transformación de la matriz eléctrica y energética de Perú permite una reducción de casi $46 \mathrm{MtCO}_{2 e}$ de emisiones anuales de GEI con respecto a aquellas que resultarían en el escenario base. La descarbonización del sector energía en Perú brinda un beneficio neto de US $\$ 2.000$ millones entre 2021 y $2050 .^{2}$

\section{Escenario base}

Se asume que el sector energía evoluciona de manera tendencial, como se señala a continuación:

$>$ La demanda de energía eléctrica crece según las proyecciones realizadas por el Comité de Operación Económica del Sistema Interconectado Nacional (COES) (COES, 2020). Dado que el COES proyecta la demanda hasta 2030, en este estudio se utiliza la tasa de crecimiento del último año (2,8\%) para calcular la demanda a 2050. En cuanto a la eficiencia energética, se asume que no hay despliegue alguno en los diferentes sectores del sistema, lo que causa un aumento del consumo.

> La participación relativa de cada tipo de planta se define en base a los datos históricos de producción de energía eléctrica de los últimos cinco años (MINEM, 2020b). La producción de todas las plantas eléctricas para suplir la demanda creciente de electricidad producto del aumento económico y poblacional se define a partir de las tendencias actuales (COES, 2020).
$>$ Se considera la entrada en vigencia de los proyectos de plantas eléctricas ya contempladas en la planificación nacional y comprometidas en el corto plazo según información del COES (COES, 2020). No se ha podido incluir el efecto de la potencial interconexión con los países vecinos por falta de información al momento de ejecutar el estudio. Futuros proyectos podrán evaluar los beneficios económicos de la participación del país en el mercado regional.

$>$ En este sentido, se considera una penetración limitada de energías renovables no convencionales para la producción de electricidad. Partiendo de la información de COES (2020), se considera que la generación eólica y la solar suplen en conjunto el $4,6 \%$ del total de la energía eléctrica durante todo el periodo.

$>$ Se asume que la producción de electricidad con plantas hidroeléctricas aumentará, pasando de 106 PJ en el 2020 a 147 PJ, 197 PJ y 285 PJ en el 
corto, mediano y largo plazo, respectivamente. Sin embargo, su participación relativa sufre una leve reducción, de un existente $59,5 \%$ a un $49,3 \%$ a mitad de siglo.

$>$ En este escenario el uso de la biomasa para producir electricidad crece como resultado de una mayor disponibilidad de este producto energético (madera, bagazo, entre otros). Esta fuente produce 12 PJ, 24 PJ y 43 PJ en el corto, mediano y largo plazo, respectivamente.

> La producción de electricidad a partir de plantas térmicas también aumenta, con lo cual se pasa de una participación del 0,6\% (1 PJ) a una del 7,0\% (41 PJ) en 2050.

$>$ La producción de electricidad a partir del gas natural también se incrementa, desde $61 \mathrm{PJ}$ en 2020 hasta 181 PJ en 2050; de igual forma, su participación relativa se reduce del $34,3 \%$ al $31,2 \%$.

El crecimiento económico y poblacional conlleva a un aumento del consumo de electricidad de los diferentes sectores, lo que requiere la instalación de nuevas plantas eléctricas a 2050. El sistema parte de una capacidad instalada efectiva en el sistema interconectado que se estima para 2020 en 12,8 GW con base en proyecciones de MINEM (2020a): un 54\% termoeléctrica (de gas, vapor, ciclo combinado o combustión), un 40\% hidroeléctrica y un $6 \%$ solar, eólica y biomasa. De este modo:

$>$ El crecimiento de la biomasa como resultado de la oferta del producto conlleva a un incremento de las plantas de biomasa que se instalan en el sistema, de modo que se pasa de una instalación prácticamente nula hoy en día a 0,5 GW en el corto plazo; a 1,0 GW en el mediano plazo y a 1,8 GW en el largo plazo.
$>$ Se asume un despliegue modesto de las energías renovables no convencionales (eólica, solar de gran escala y solar de techo) que aumentan la capacidad instalada actual (0,7 GW) a 2,5 GW en 2050, con valores intermedios de 1,1 GW y 1,6 GW en el corto y mediano plazo, respectivamente.

$>$ Las plantas hidroeléctricas exhiben el mayor aumento y la capacidad instalada prácticamente se triplica para 2050, pasando de los actuales $5,1 \mathrm{GW}$ a $7,3 \mathrm{GW}$ en el corto plazo; a 9,9 GW en el mediano plazo y a 14,6 GW a mitad de siglo.

> La capacidad instalada se complementa con plantas térmicas y de gas natural, las cuales en conjunto suman a mitad de siglo 15,2 GW (un $45 \%$ del total).

El consumo de energía en el sector también aumenta como producto del crecimiento poblacional y económico. Debido a la falta de información sobre el crecimiento de la producción de energía del país, se asume que el crecimiento se suple de forma proporcional al actual:

$>$ Durante todo el periodo de estudio los derivados del petróleo suplen el $23 \%$ de la producción total de energía del país y el gas natural suple aproximadamente el 60\%, de los cuales el $10 \%$ se usa para la producción de electricidad. Se considera que existirán las reservas para suplir esta producción y que se hacen inversiones para habilitar su transporte. Dicha inversión en infraestructura es proporcional a la producción y se basa en datos históricos.

> Únicamente el 16\% de la producción de energía se hace con electricidad renovable. 


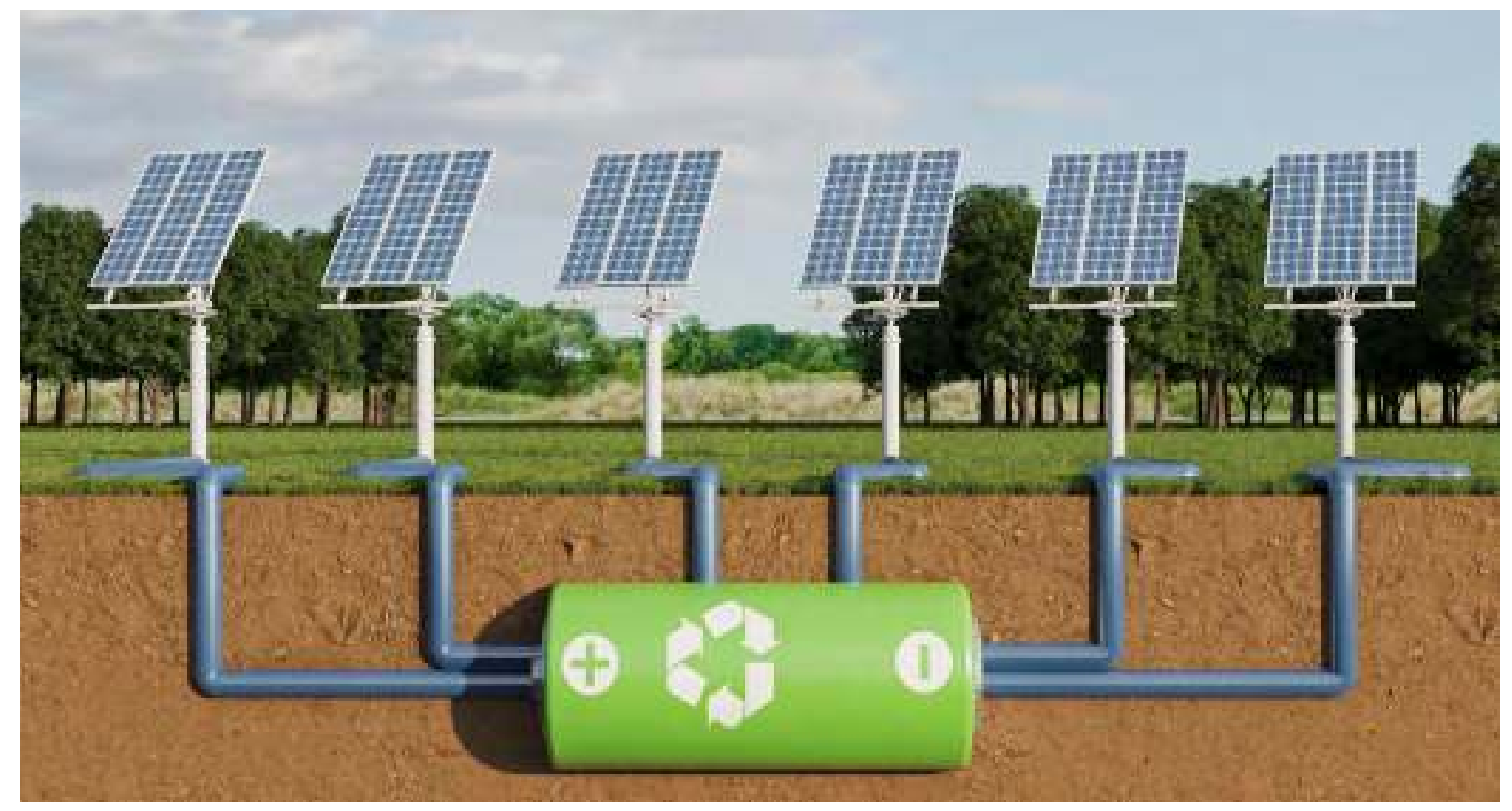

\section{Escenario de carbono-neutralidad}

Este escenario caracteriza un proceso transformacional que permite reducir con respecto a un escenario tendencial las emisiones anuales de GEI del sector energía y contribuir hacia la carbono-neutralidad de Perú (gráfico 2.9). La transformación de la matriz eléctrica considera lo siguiente:

$>$ En el corto plazo, la producción de energía eléctrica a partir de fuentes renovables (geotermia, eólica, hidroeléctrica y solar) aumenta del estimado 65\% en 2020 a un $77 \%$ en 2025. La producción de electricidad con biomasa se mantiene constante, ya que hay poca información de la demanda de suelo que este recurso podría imponer en otros sectores. La participación mixta de plantas hidroeléctricas, renovables no convencionales, gas natural y quema de combustibles fósiles que existe hoy en día se modifica, a fin de aumentar la producción de electricidad con plantas eólicas y solares, mientras que se mantiene una participación importante de plantas hidroeléctricas. La producción de electricidad con plantas termoeléctricas se reduce $3 \mathrm{PJ}$ con respecto a los valores estimados para 2020. A raíz de la reducción del consumo interno, se considera que las exportaciones de petróleo y gas aumentan ligeramente en el tiempo.

$>$ En el mediano plazo, se contempla un incremento de la producción de electricidad a partir de fuentes renovables, de modo que se pasa a un $84 \%$ con una mayor generación de electricidad a partir de renovables no convencionales (principalmente plantas eólicas 
y solares) y producción de hidroeléctricas de pequeña escala ya planificadas (hasta 100 MW y de filo de agua para evitar grandes embalses). La instalación de plantas renovables no convencionales se realiza de la mano del almacenamiento de energía por baterías, por ejemplo, de iones de litio, ya que el costo de esta tecnología ha alcanzado valores competitivos y permite una operación del sistema eléctrico más estable (Zare y Nojavan, 2018). El 100\% de las renovables no convencionales de gran escala se considera con almacenamiento de energía y el $50 \%$ de las plantas solares de techo lo posee. Se considera que la producción con térmicas es igual a los valores actuales y hay una leve reducción de 8 PJ en la producción de electricidad con gas natural. Se considera que ambos ajustes son posibles con acciones de mantenimiento sobre las correspondientes unidades.

$>$ En el largo plazo, la proporción de producción de electricidad a partir de renovables logra un $90 \%$, como resultado de la implementación de energía eólica y solar. Se asume que la energía solar instalada en los techos aumenta en mayor proporción que la solar de gran escala, gracias a los costos decrecientes de la tecnología y la reducida necesidad de espacio para su instalación, lo que promovería su instalación.

\section{Gráfico 2.9}

Evolución de la matriz eléctrica de Perú en el escenario base versus el escenario de carbono-neutralidad bajo supuestos estándar

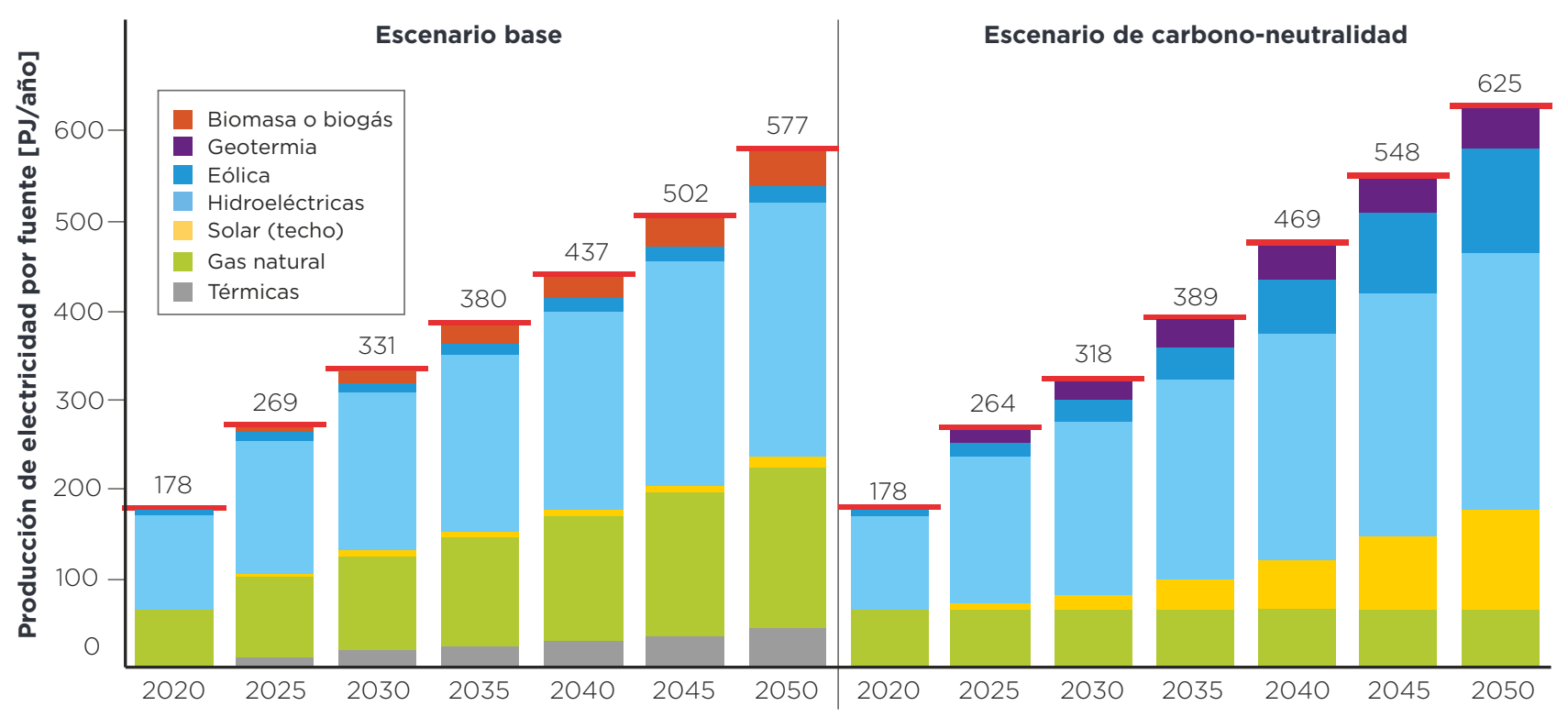


El aumento de la electrificación de las actividades, principalmente del sector transporte (véase la sección 2.2.2), requiere la instalación de plantas eléctricas renovables no convencionales. En general, se considera la entrada en vigencia de plantas eléctricas renovables ya planificadas. Las plantas hidroeléctricas ya planificadas complementan el parque de plantas para abastecer el creciente consumo de energía (gráfico 2.10):

$>$ En el corto plazo, la transformación de la capacidad instalada es limitada. Dicha capacidad de las plantas térmicas y de gas natural se mantiene con respecto al valor actual. Se asume para 2025 un aumento de 5,1 GW proveniente de plantas eléctricas renovables: 3,1 GW de hidroeléctricas, 1,4 GW de renovables no convencionales y $0,6 \mathrm{GW}$ de geotermia.

$>$ En el mediano plazo, la instalación de plantas hidroeléctricas y renovables no convencionales aumenta en $8,7 \mathrm{GW}$ adicionales con respecto a 2025: 3,4 GW hidroeléctricos, 4,7 GW de renovables no convencionales y $0,6 \mathrm{GW}$ de geotermia.

$>$ En el largo plazo, y producto de los costos cada vez más bajos de las renovables, el sistema eléctrico alcanza una capacidad instalada total de 45,8 GW entre plantas hidroeléctricas y renovables no convencionales, con lo cual supera en 11,6 GW al escenario base. Para 2050, las plantas renovables (convencionales y no convencionales) ocupan el $85 \%$ de la capacidad total del sistema eléctrico.

La incorporación de nuevas plantas eléctricas no convencionales, el surgimiento del almacenamiento de energía y el crecimiento tecnológico del sector fomentan una transformación y aumentan la capacidad del sistema eléctrico. De este modo:

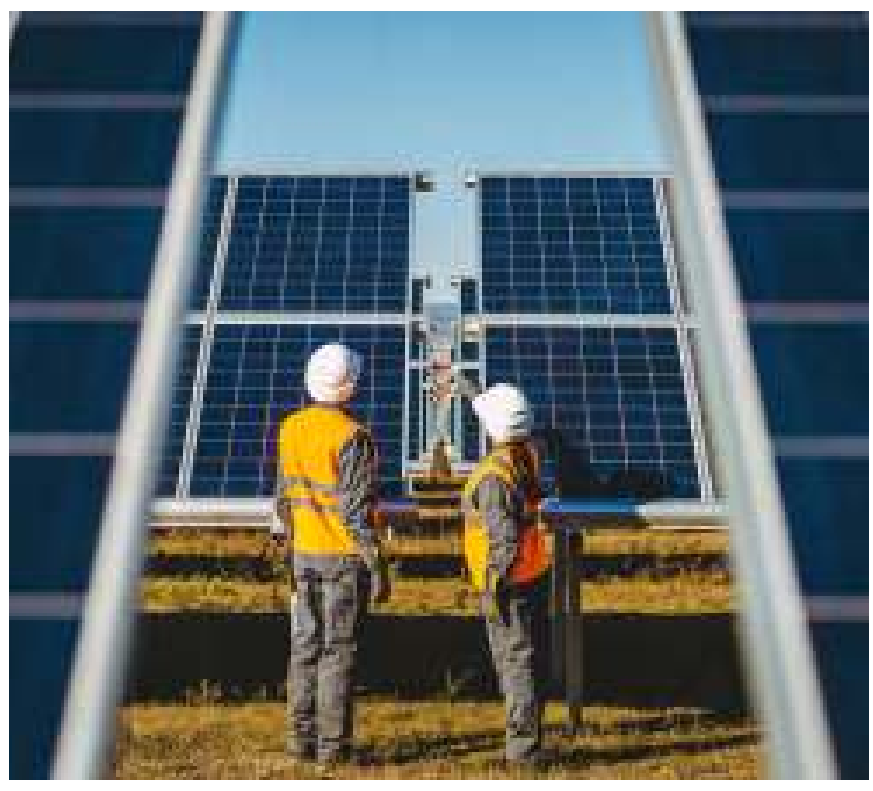

$>$ En el corto plazo se inicia el despliegue de redes eléctricas inteligentes. En esta primera etapa se considera la instalación de medidores inteligentes para la gestión oportuna de la demanda y el aumento de la eficiencia energética del sector eléctrico, que también se apoya de la sustitución de materiales para la construcción.

$>$ En el mediano plazo, el despliegue de redes eléctricas inteligentes se incrementa (más medidores inteligentes y su correspondiente infraestructura de medición avanzada) y se habilita una participación activa de los usuarios en un mercado dinámico del sector eléctrico. Este plazo considera también un aumento de la capacidad del sistema eléctrico que permite la interconexión de las energías renovables no convencionales sin afectar la calidad del suministro de electricidad.

La tendencia se mantiene en el largo plazo, con una mayor penetración de las redes eléctricas inteligentes y una mayor capacidad del sistema eléctrico. 


\section{Gráfico 2.10}

Capacidad instalada del sistema eléctrico de Perú en el escenario base versus el escenario de carbononeutralidad bajo supuestos estándar

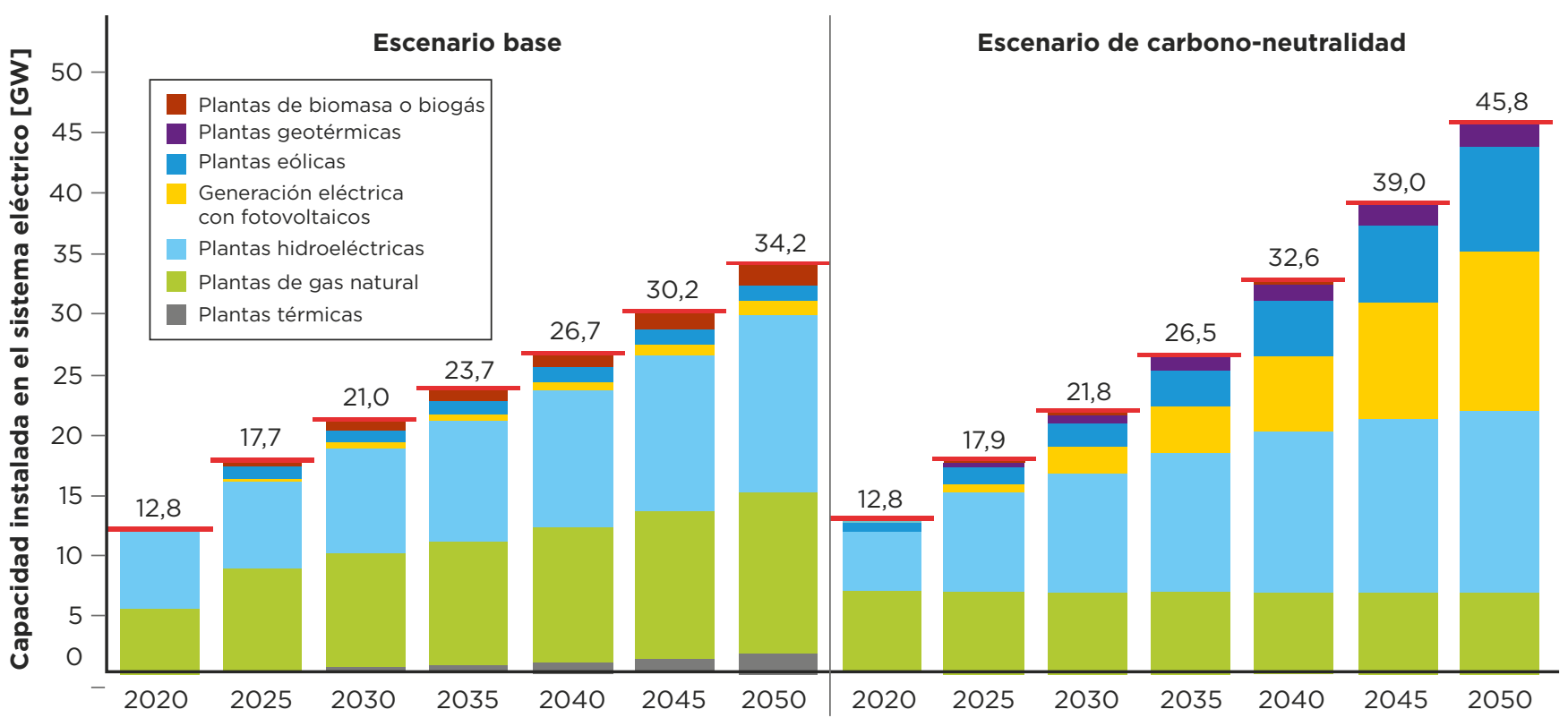

Fuente: Elaboración propia.

Más allá de los cambios en el sector eléctrico, la transformación del sector energía considera un aumento de la eficiencia energética y de la participación de las energías renovables en la matriz energética. La matriz está conformada por todas las fuentes primarias de energía (extracción e importación) de las cuales se derivan los procesos de transformación y sus pérdidas hasta su uso final y las exportaciones. Casi una tercera parte de la energía primaria de Perú se exporta como un producto con valor agregado, con preponderancia del gas natural (gráfico 2.11):

$>$ El corto plazo se caracteriza por la presencia de pocos cambios. A su término, predomina el gas natural, con un 57\%, seguido por el petróleo, con un $22 \%$, y por las fuentes renovables o aquellas que producen emisiones biogénicas, que complementan con un $21 \%$.

$>$ Para el mediano plazo, el proceso de transformación permite aumentar el uso de renovables y leña al $25 \%$. La producción con biomasa se mantiene constante en todo el horizonte, ya que su demanda de suelo no se estudia de forma integrada. Este proceso incluye un mayor uso de renovables en el sector eléctrico, lo que potencia la electrificación del transporte. Adicionalmente, se denota una disminución de energía de un $20 \%$ con respecto al escenario base, gracias a acciones de eficiencia en los usos finales y el empleo de nuevos materiales para la construcción y a una restricción de las exportaciones. En 
este último caso, se consideró como premisa del escenario que la capacidad instalada en plantas de procesamiento de gas y refinerías se mantendría limitada a la actual.

> Para el largo plazo, se proyecta una reducción del consumo de energía de casi un $35 \%$ gracias en parte a la sustitución de materiales. Se consolida la penetración de nuevas tecnologías más eficientes y el cambio de hábitos inducidos (por ejemplo, mediante tarifas horarias) o naturales (por ejemplo, mediante campañas de concientización ambiental) de los consumidores finales. El cambio también responde a procesos como una planificación urbana más sostenible y al uso de tecnologías amigables con el ambiente. Para 2050, el 34\% de la energía en Perú se produce a partir de fuentes renovables (biomasa, eólica, solar, hidroenergía, leña y geotermia). De esta, la hidroelectricidad representa un $14 \%$. La producción de energía con gas natural, carbón y petróleo se mantiene constante con respecto a los valores actuales y su participación pasa de un $84 \%$ en 2020 a un $67 \%$ en 2050 . Se considera que este alto porcentaje se utiliza en el sector industrial que no ha sido estudiado en detalle en este proyecto y para exportación de energía a la región, ya que se ha asumido que el resto de los países continúa consumiendo derivados de petróleo. A futuro, se deberán revisar estos consumos y analizar el efecto de una reducción de su consumo aún mayor, producto de la descarbonización del consumo de energía en la industria y de los países vecinos.

\section{Gráfico 2.11}

Evolución de la matriz energética de Perú en el escenario base versus el escenario de carbononeutralidad bajo supuestos estándar

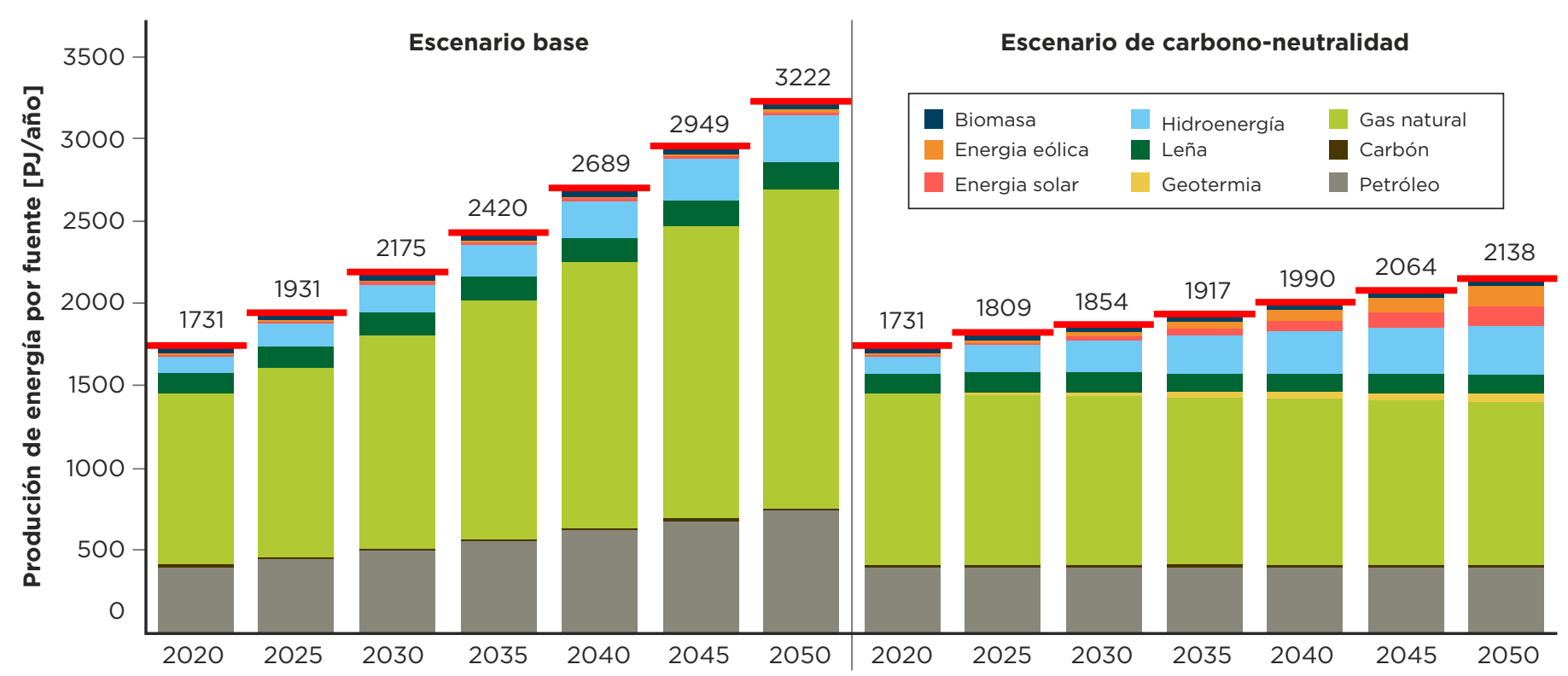

Fuente: Elaboración propia. 


\section{Emisiones}

Implementar el proceso transformador descrito anteriormente permite reducir las emisiones de GEI del sector energético (gráfico 2.12). Bajo supuestos estándar, al año 2050, el sector energía proyecta emisiones anuales de $\mathrm{GEI}$ de unas $24 \mathrm{MtCO}$. Comparadas con las $70 \mathrm{MtCO}_{2 e}$ del escenario base al mismo año, el escenario de carbono-neutralidad permite una disminución de cerca de $46 \mathrm{MtCO}_{2 e}$ a mitad de siglo. El proceso de transformación evita un aumento significativo de las emisiones anuales de GEI. Con respecto a los valores estimados de 2020, la disminución a 2050 es de $5 \mathrm{MtCO}_{2 \mathrm{e}}$, a pesar del creciente consumo de energía resultante de la electrificación de las diferentes actividades económicas.

\section{Gráfico 2.12}

Emisiones anuales del sector energético en el escenario base versus el escenario de carbono-neutralidad bajo supuestos estándar

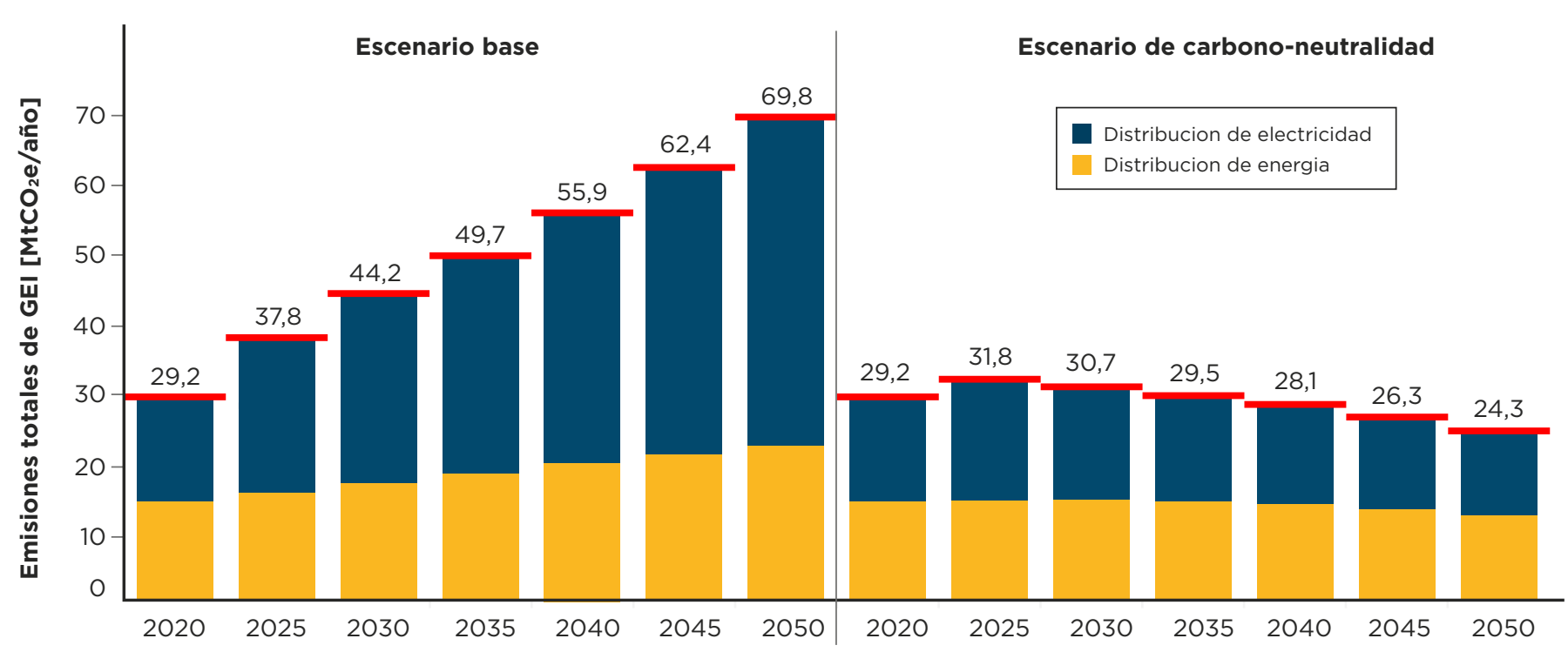




\section{Beneficios y costos}

Bajo supuestos estándar, la descarbonización del sector energía brinda beneficios totales (US\$28.000 millones) que sobrepasan los costos (US $\$ 26.000$ millones), con lo cual se obtiene un beneficio neto acumulado de US $\$ 2.000$ millones para 2050 (gráfico 2.13). Para ello:

$>$ En el corto plazo, se requieren inversiones estimadas en US $\$ 6.900$ millones. Se obtiene un beneficio por reducción de costos operativos y de mantenimiento de US $\$ 1.200$ millones. Los beneficios en materia de salud producto de la reducida quema de combustible suman US\$400 millones en el corto plazo. Sin embargo, los beneficios totales en dicho plazo no compensan los costos y el resultado es un beneficio neto negativo (un costo) de US $\$ 5.300$ millones en este periodo.

$>$ En el mediano plazo, el beneficio neto es de US\$1.200 millones. A pesar de la existencia de inversiones adicionales por US $\$ 8.900$ millones, los beneficios provenientes de la reducción de costos operativos (US $\$ 7.900$ millones) y de las mejoras en salud por una menor quema de combustibles (US $\$ 2.200$ millones) son mayores.

$>$ El beneficio neto en el largo plazo se estima en US $\$ 6.100$ millones. Las inversiones adicionales de US $\$ 10.100$ millones se compensan con beneficios totales por US $\$ 16.200$ millones.

\section{Gráfico 2.13}

Beneficio neto del escenario de carbono-neutralidad versus el escenario base en el sector energético bajo supuestos estándar

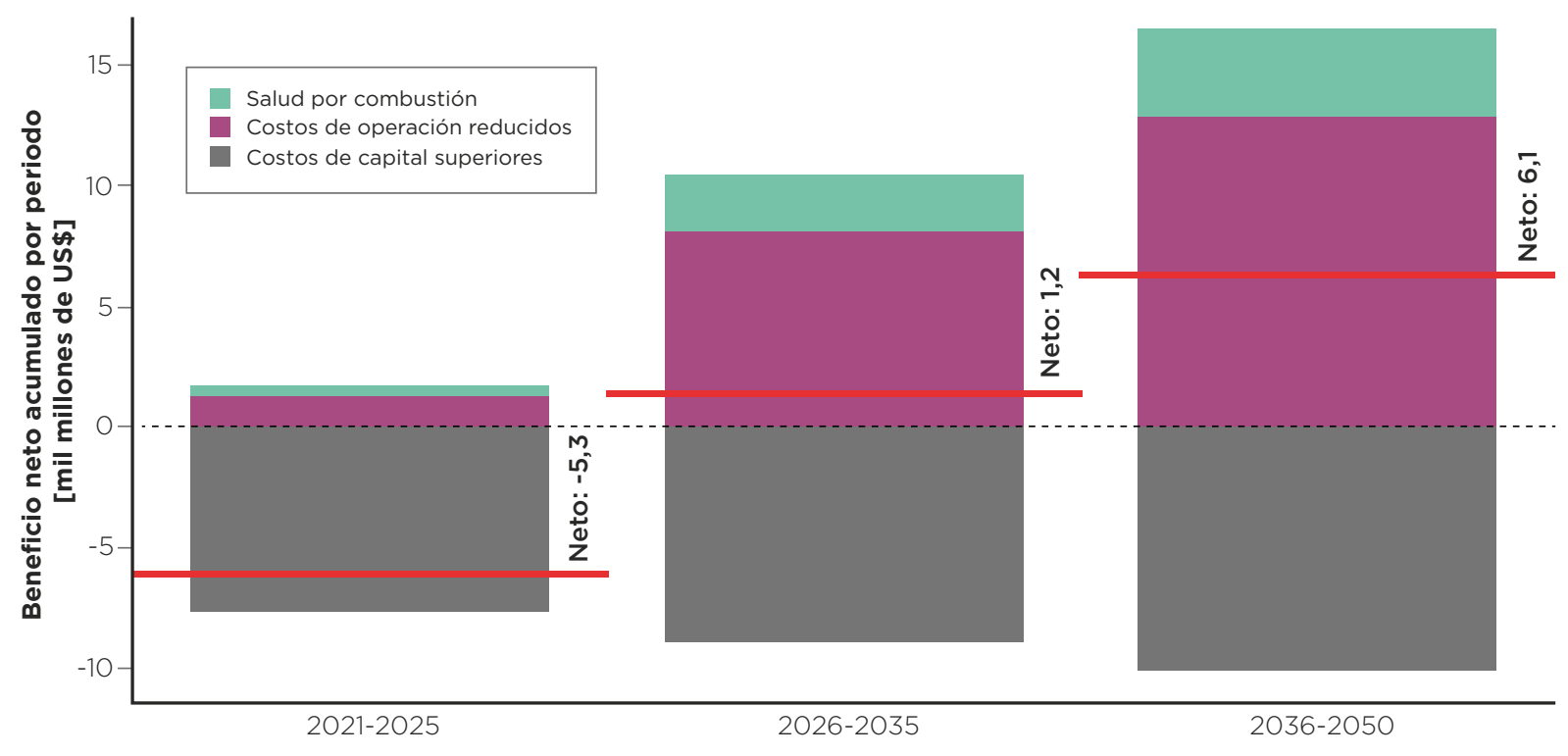


Un sistema más eficiente de energía renovable reduce los costos operativos que se estiman bajo los supuestos estándar en US\$21.700 millones (gráfico 2.14). A continuación. se describe la desagregación de costos operativos reducidos por periodo:

$>$ En el corto plazo, disminuir la participación relativa de las plantas de gas natural y de refinería para producir energía conlleva a un ahorro cercano a US $\$ 1,2$ millones.

$>$ En el mediano plazo, se obtienen ahorros que alcanzan los US\$7.900 millones. Estos ahorros se logran principalmente gracias a un menor uso relativo al total de las plantas de gas natural y las refinerías, que combinadas permiten ahorrar US\$9.500 millones, con lo cual se compensa el aumento de US\$1.600 millones que tiene lugar en el resto del sistema energético.

$>$ Reducir el uso relativo de las plantas de gas natural y de las refinerías trae aparejados mayores ahorros en el largo plazo, los cuales se estiman en US\$13.900 millones. Producto de la expansión de la red eléctrica, los costos operativos y de mantenimiento de la infraestructura aumentan US\$1.000 millones. Este último periodo brinda un ahorro por operación y mantenimiento de US\$12.600 millones.

\section{Gráfico 2.14}

Costos operativos y de mantenimiento del sector energía en el escenario base versus el escenario de carbono-neutralidad bajo supuestos estándar

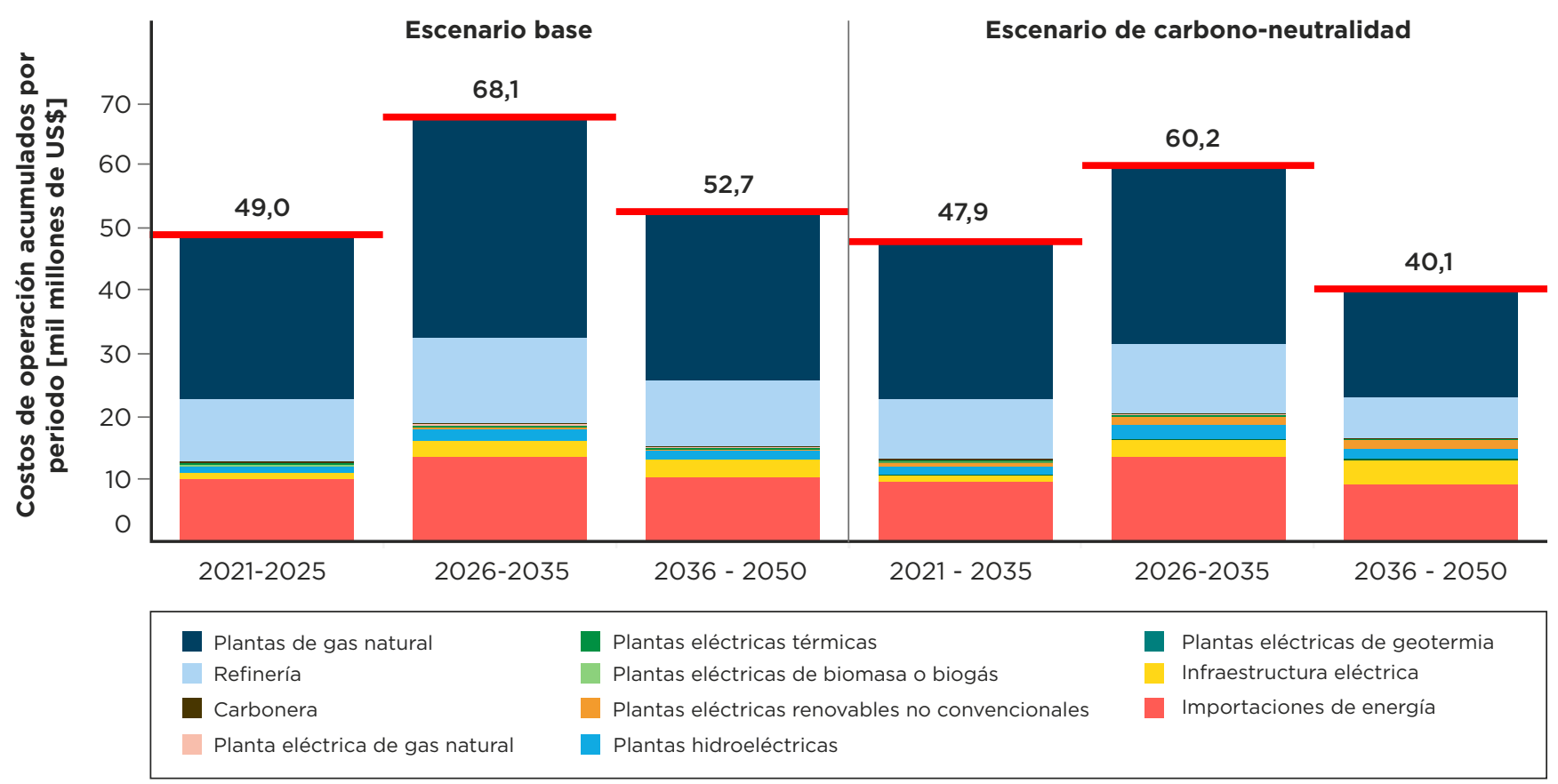

Fuente: Elaboración propia. 


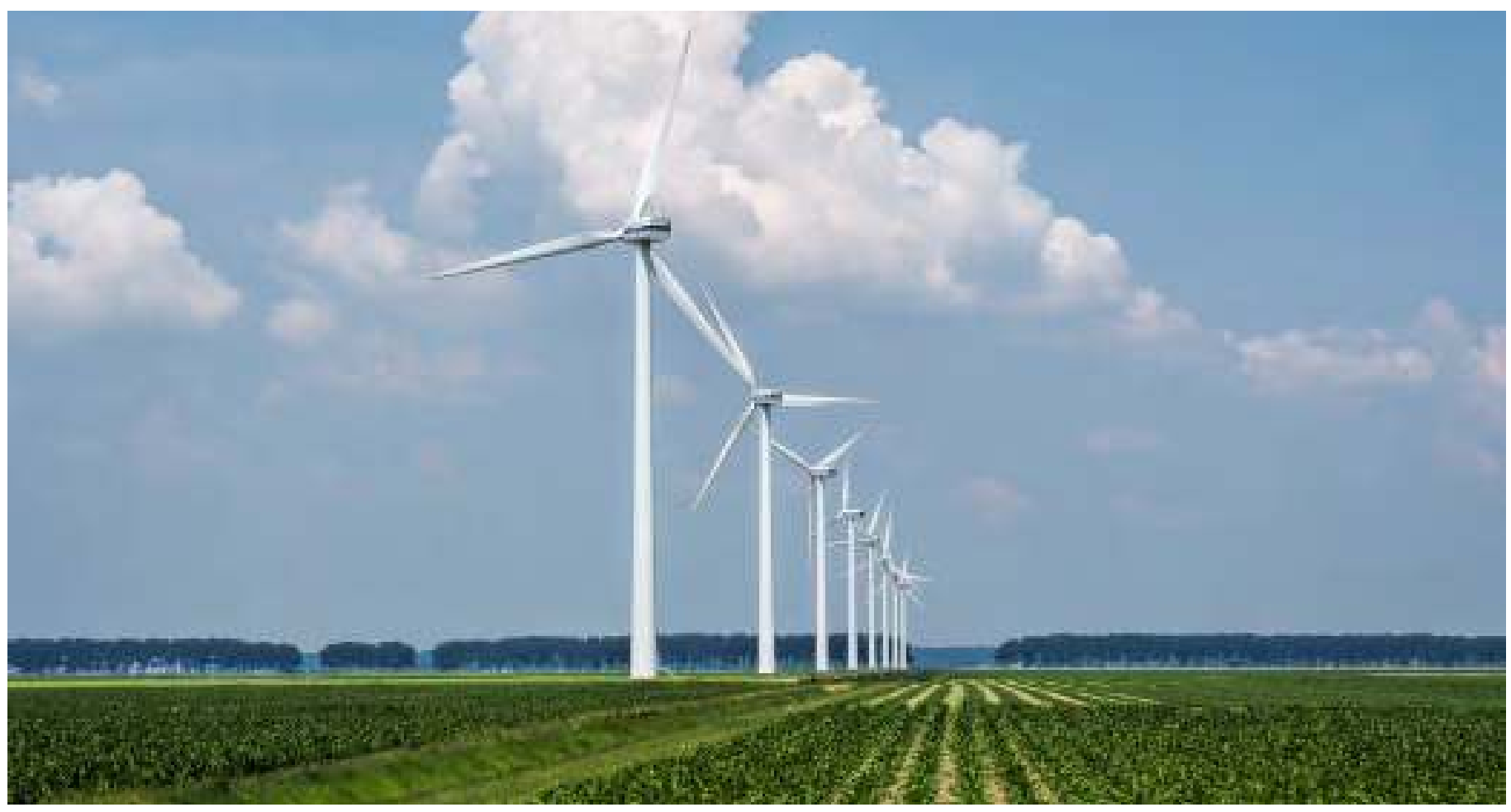

Alcanzar la carbono-neutralidad requiere inversiones adicionales estimadas en unos US\$26.000 millones bajo supuestos estándar (gráfico 2.15). A continuación, se describen las inversiones adicionales por periodo:

$>$ En el corto plazo, se requieren inversiones adicionales de US\$6.900 millones. Se evitan las inversiones en plantas térmicas y de gas natural destinadas en el escenario base para la producción de energía eléctrica como resultado del proceso de descarbonización del escenario de carbono-neutralidad, con lo cual se logran ahorros de US\$3.400 millones. Las inversiones evitadas en refinerías permiten un ahorro de US\$300 millones. Tampoco se realizan inversiones de US $\$ 400$ millones en plantas de biomasa. En este periodo, las inversiones en energía renovable no convencional aumentan en US\$800 millones, mientras que se invierten US\$3.900 millones en plantas hidroeléctricas. Las inversiones en el corto plazo se complementan con US $\$ 2.100$ millones para habilitar las primeras fases de las redes eléctricas inteligentes, US\$200 millones adicionales en infraestructura eléctrica, y con US\$4.000 millones en plantas eléctricas de geotermia.

$>$ En el mediano plazo, las inversiones con respecto al escenario base aumentan en US\$8.900 millones. Reducir el creciente uso de plantas de gas natural, plantas térmicas y refinerías disminuye las inversiones en US\$3.000 millones. Se evitan también inversiones de US\$300 millones en plantas eléctricas a base de biomasa. Las inversiones en plantas renovables no convencionales (eólicas y solares) se incrementan en US\$1.600 millones. Las inversiones en plantas 
hidroeléctricas para aprovechar la capacidad del país aumentan en US\$1.400 millones en este periodo. Las inversiones adicionales se complementan con una mayor penetración de las redes eléctricas inteligentes, que requieren inversiones de alrededor de US $\$ 5.000$ millones. También se realizan inversiones adicionales de US $\$ 1.900$ millones en infraestructura eléctrica para habilitar la inserción de la generación distribuida, especialmente en las redes eléctricas de distribución. La instalación de plantas de geotermia requiere una inversión de US\$2.300 millones.
$>$ En el largo plazo, se mantiene la tendencia a ahorrar en plantas que producen emisiones de GEI (-US $\$ 1.900$ millones) y plantas de biomasa (-US $\$ 200$ millones), y a invertir en renovables no convencionales (+US\$1.400 millones, redes inteligentes (+US\$6.900 millones), infraestructura (+US\$3.600 millones) y geotermia (+US 1.000 millones). Las inversiones en plantas hidroeléctricas se reducen en este periodo en US\$600 millones. Este último periodo del horizonte de planificación requiere una inversión adicional estimada en US\$10.100 millones.

\section{Gráfico 2.15}

Inversiones en el sector energía en el escenario base versus el escenario de carbono-neutralidad bajo supuestos estándar

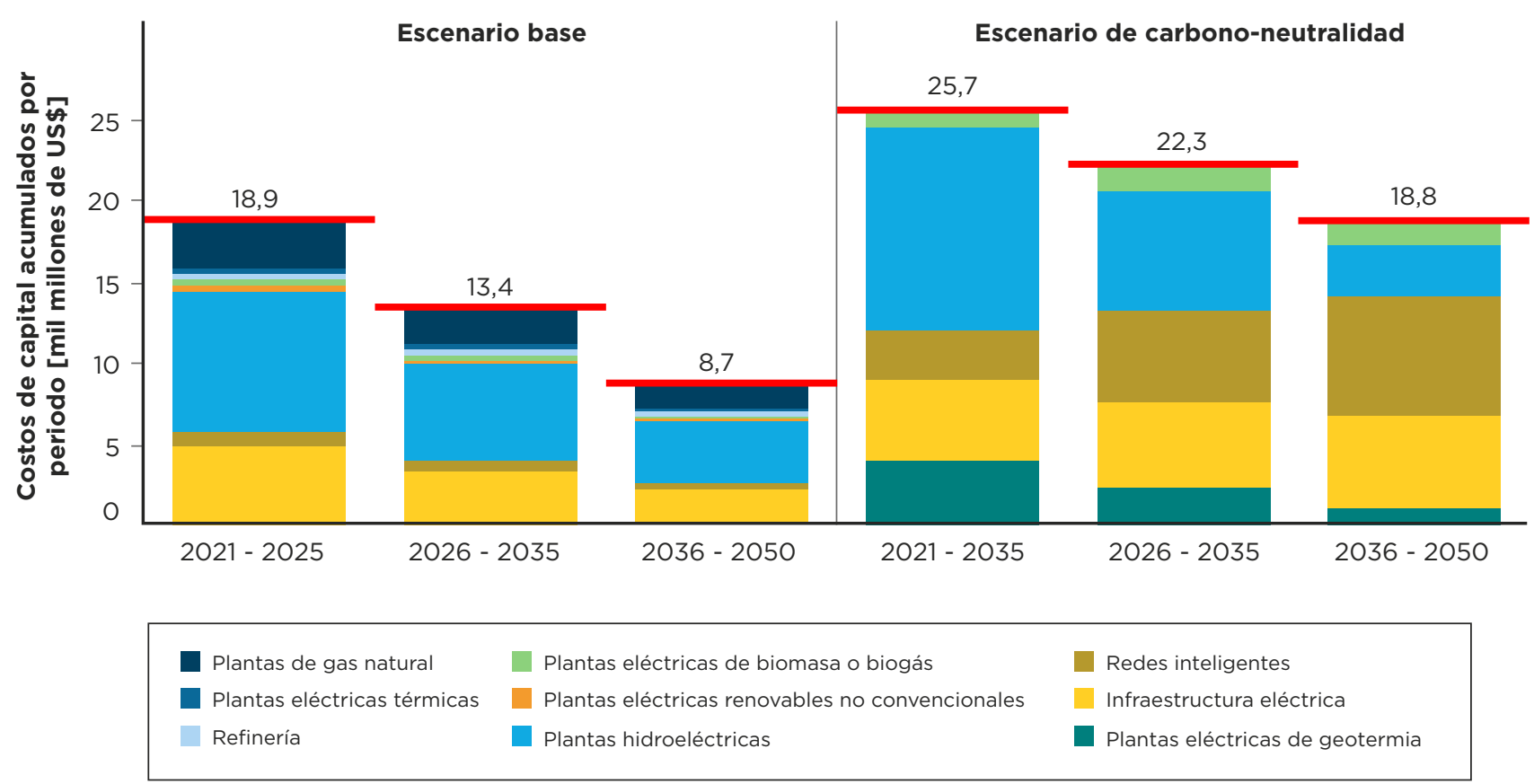




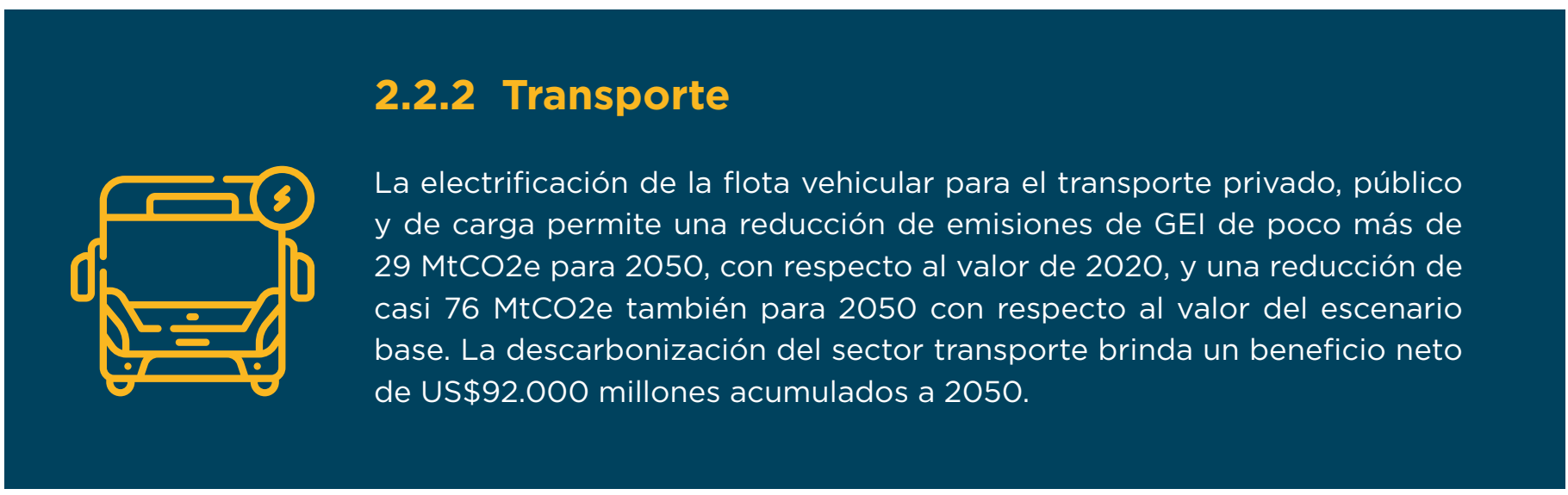

\section{Escenario base}

Se asume un crecimiento tendencial en el cual predomina el uso de hidrocarburos.

$>$ La demanda de pasajeros y de carga crece en razón de la población y la economía, respectivamente. Se asume que no se realizan cambios tecnológicos hacia el transporte eléctrico, por lo que la demanda de pasajeros y de carga se suple con tecnologías que usan los derivados del petróleo.

$>$ Se considera que el transporte continúa consumiendo la mayor cantidad de combustibles fósiles y que los principales productos energéticos que se utilizan son la gasolina, el diésel y el gas licuado de petróleo (GLP), con una ligera tendencia al uso de los biocombustibles debido a las regulaciones ambientales que se han implementado desde la creación de la Ley 28.054 (Ley de Promoción del Mercado de Biocombustibles).

$>$ La demanda se satisface entre los diferentes medios de transporte de forma constante para 2050. Esto quiere decir que el $52 \%$ de los viajes de las personas se hacen en buses, el $28 \%$ en transporte privado, el $13 \%$ en taxis o taxis con aplicaciones, y el $7 \%$ en motocicleta (BID, 2019). De igual forma, se considera que aproximadamente el $50 \%$ de la carga en Perú se transporta con camiones pesados durante todo el periodo. El $40 \%$ se satisface con camiones de carga mediana y el restante 10\% con camiones de carga liviana. Cabe resaltar que estos detalles no son exactos debido a la insuficiencia de información o la escasa precisión de la misma.

\section{Escenario de carbono-neutralidad}

Se contempla una transformación en la movilidad de pasajeros y de carga (gráfico 2.16), en cuyo caso se destacan los siguientes puntos:

$>$ Se considera una reducción de la demanda de pasajeros (en pasajeros-kilómetro) de aproximadamente un $15 \%$ para 2050 , producto de mejoras en la infraestructura vial que densifican las ciudades y acortan las distancias de los viajes. La disminución se asume lineal entre 2021 y 2050. 
$>$ Se asume un cambio modal hacia la movilidad no motorizada (peatonal y en bicicleta) que baja la demanda de pasajeros en alrededor de un $15 \%$ para 2050 . La reducción se asume lineal entre 2021 y 2050.

$>$ Se considera un despliegue del teletrabajo y un aumento de la digitalización de los trámites que contribuyen con una reducción de la demanda de aproximadamente otro $15 \%$ en 2050. La disminución se asume lineal entre 2021 y 2050.

$>$ Con respecto al transporte de carga, se considera una reducción de la demanda del $20 \%$ en 2050 , como resultado de mejoras en la logística e inversión pública en infraestructura que reduce las distancias para transportar la carga. Se estima que la demanda de carga se suple de forma proporcional con respecto a 2020: un $50 \%$ de carga pesada, un $40 \%$ de carga mediana y un $10 \%$ de carga liviana.

Se considera una electrificación paulatina de la flota de transporte privado, público y de carga que alcanza su totalidad a mitad de siglo (gráfico 2.17), del siguiente modo:

$>$ En el corto plazo el sistema de transporte sigue operando bajo combustibles fósiles. Es una condición natural que surge de la capacidad residual existente. En el caso del transporte de pasajeros, se inicia el proceso de electrificación, para lo cual se toma en cuenta la existencia de tecnologías. En cambio, por falta de opciones tecnológicas en el corto plazo, no se prevén cambios tecnológicos en el transporte de carga. Para 2025 se espera que al menos: el $10 \%$ de los automóviles sean eléctricos, $15 \%$ de las motocicletas sean cero emisiones, $10 \%$ de los buses operen libre de emisiones, y 10\% de los taxis estén electrificados.

$>$ En el mediano plazo, existe una penetración más acelerada hacia la electrificación del transporte de pasajeros. También es un punto intermedio en cuanto a la necesidad de sustitución de la flota vehicular y los precios competitivos de las tecnologías de cero emisiones. En el transporte de carga, el proceso de transformación se inicia en 2030, considerando que en este periodo ya existe una oferta tecnológica madura. El 50\% de la demanda de movilidad de pasajeros se satisface con transporte eléctrico al cierre del periodo; es decir, uno de cada dos vehículos en su segmento respectivo (automóvil, motocicleta, bus y taxi) es eléctrico. A partir de 2030 la carga del país se moviliza con camiones eléctricos, y se considera que aproximadamente el $20 \%$ de la demanda de carga se suple con camiones cero emisiones (a base de baterías o hidrógeno) para 2035.

$>$ En el largo plazo, se definió de la mano de los expertos locales que el $100 \%$ de la demanda de pasajeros y de carga se suple con tecnologías de cero emisiones; es decir, con baterías o con hidrógeno. $^{3}$ 


\section{Gráfico 2.16}

Tecnologías para satisfacer (a) la demanda de pasajeros y (b) la demanda de carga en el escenario base versus el escenario de carbono-neutralidad bajo supuestos estándar

a

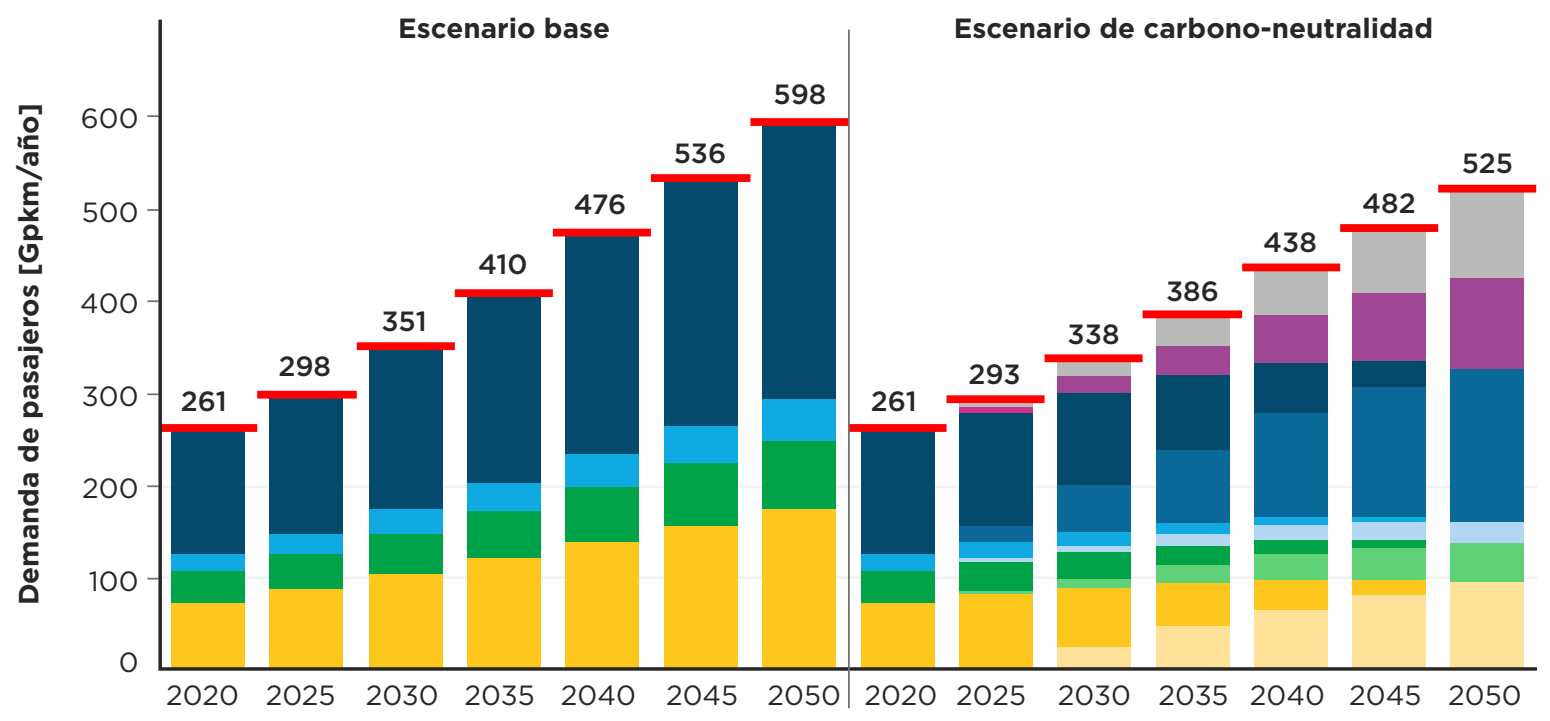

b

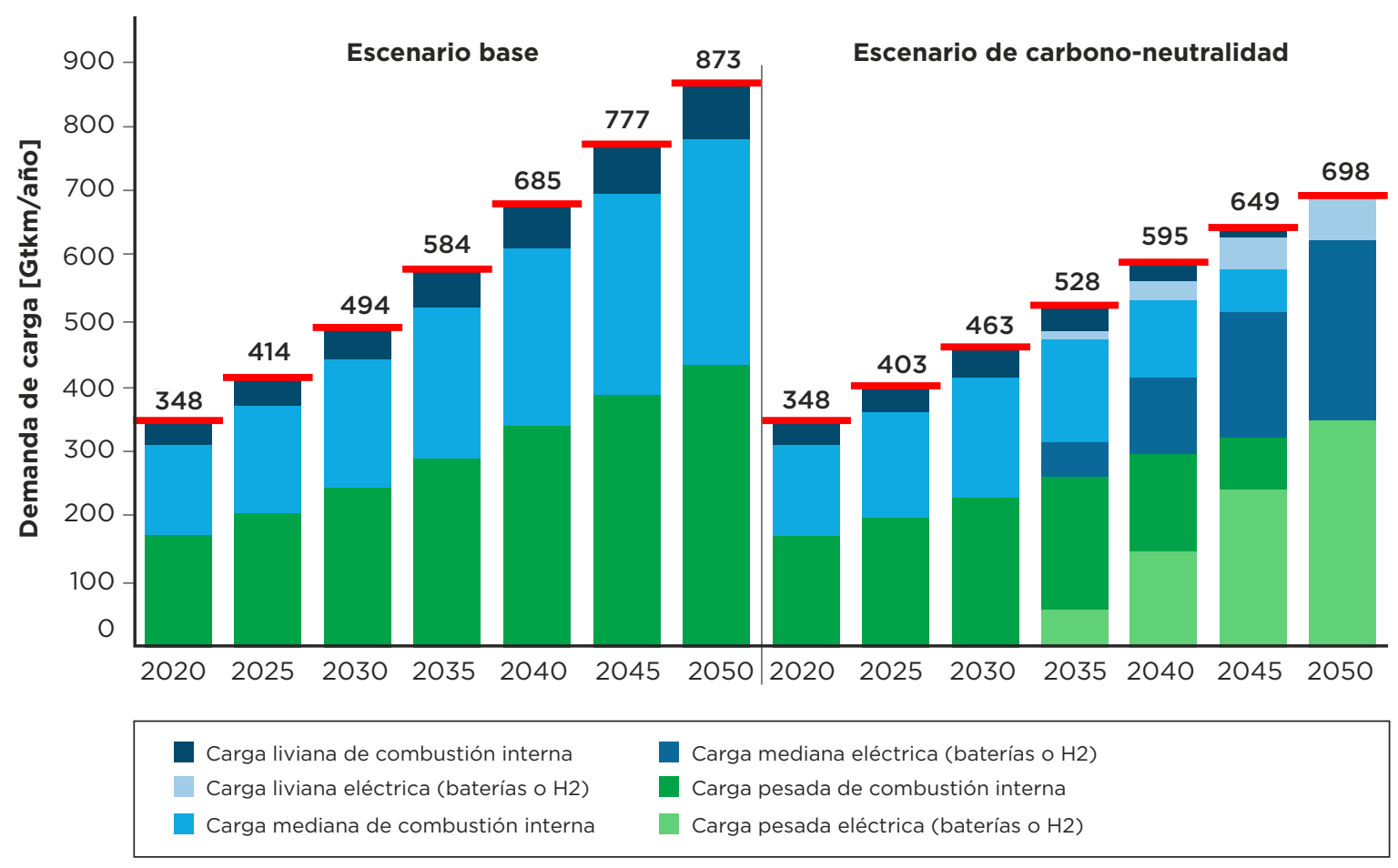

Fuente: Elaboración propia. 


\section{Gráfico 2.17}

Composición de la flotilla de (a) pasajeros y de (b) carga en el escenario base versus el escenario de carbono-neutralidad bajo supuestos estándar

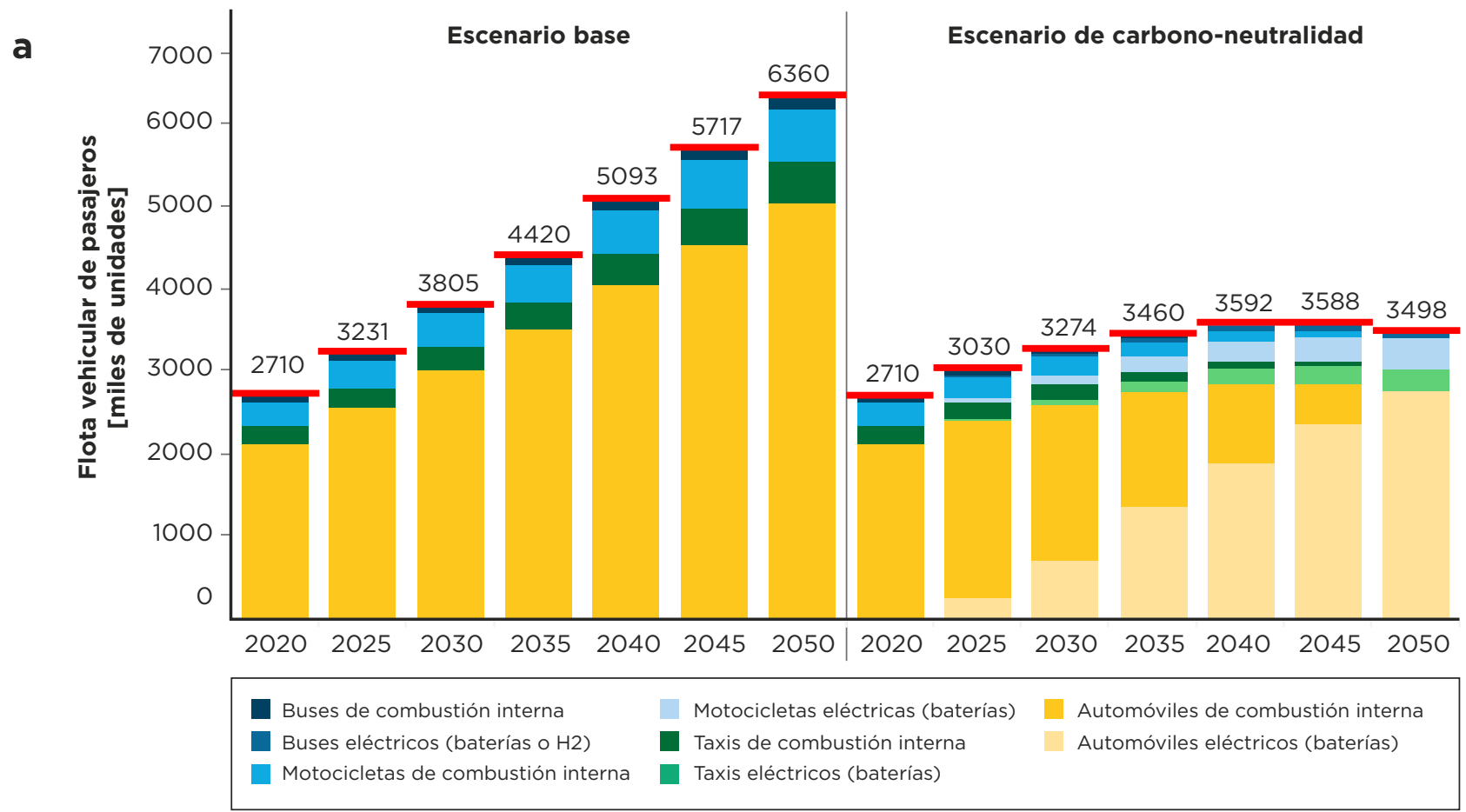

b

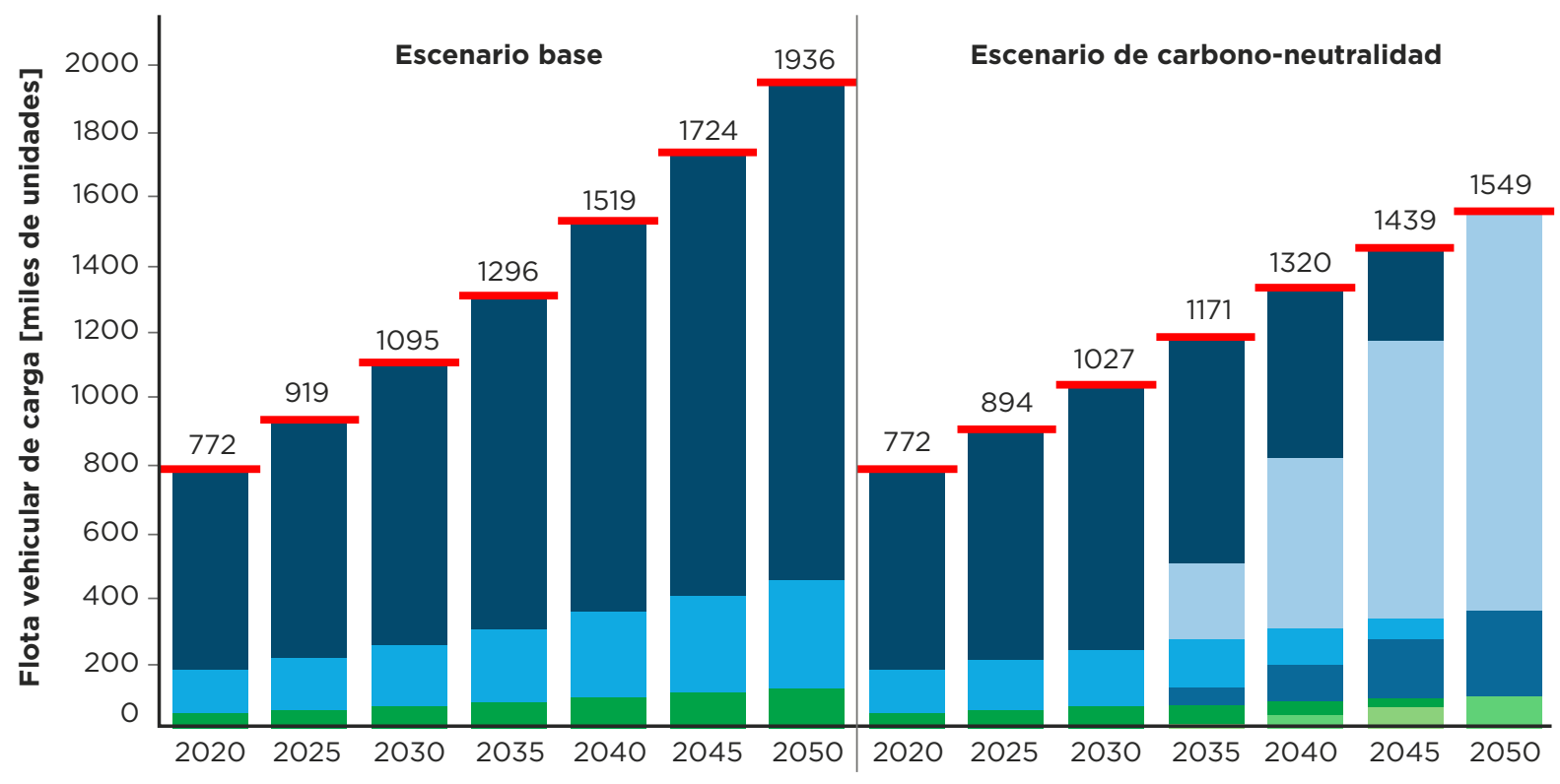

\footnotetext{
- Carga liviana de combustión interna

Carga liviana eléctrica (baterías o H2)

- Carga mediana eléctrica (baterías o H2)

Carga mediana de combustión interna

- Carga pesada de combustión interna

Carga pesada eléctrica (baterías o H2)
} 


\section{Emisiones}

Las acciones consideradas permiten reducir las emisiones de GEl del sector transporte (gráfico 2.18). Así, comparadas con las emisiones de GEI en 2020 (poco más de $29 \mathrm{MtCO}_{2 \mathrm{e}}$ ), el escenario de carbono-neutralidad logra una reducción total y alcanza cero emisiones anuales de GEI para 2050. El escenario base continúa aumentando sus emisiones y llega a unas $76 \mathrm{MtCO}_{2 e}$ en 2050. La transformación de la flotilla de pasajeros permite una disminución paulatina de las emisiones de este subsector. Sin embargo, el subsector del transporte de carga incrementa sus emisiones hasta 2030, momento en que empieza la electrificación. Luego de este evento, sus emisiones se reducen paulatinamente hasta 2050 y en conjunto habilitan la descarbonización del sector transporte.

\section{Gráfico 2.18}

Emisiones anuales del sector transporte en el escenario base versus el escenario de carbono-neutralidad bajo supuestos estándar

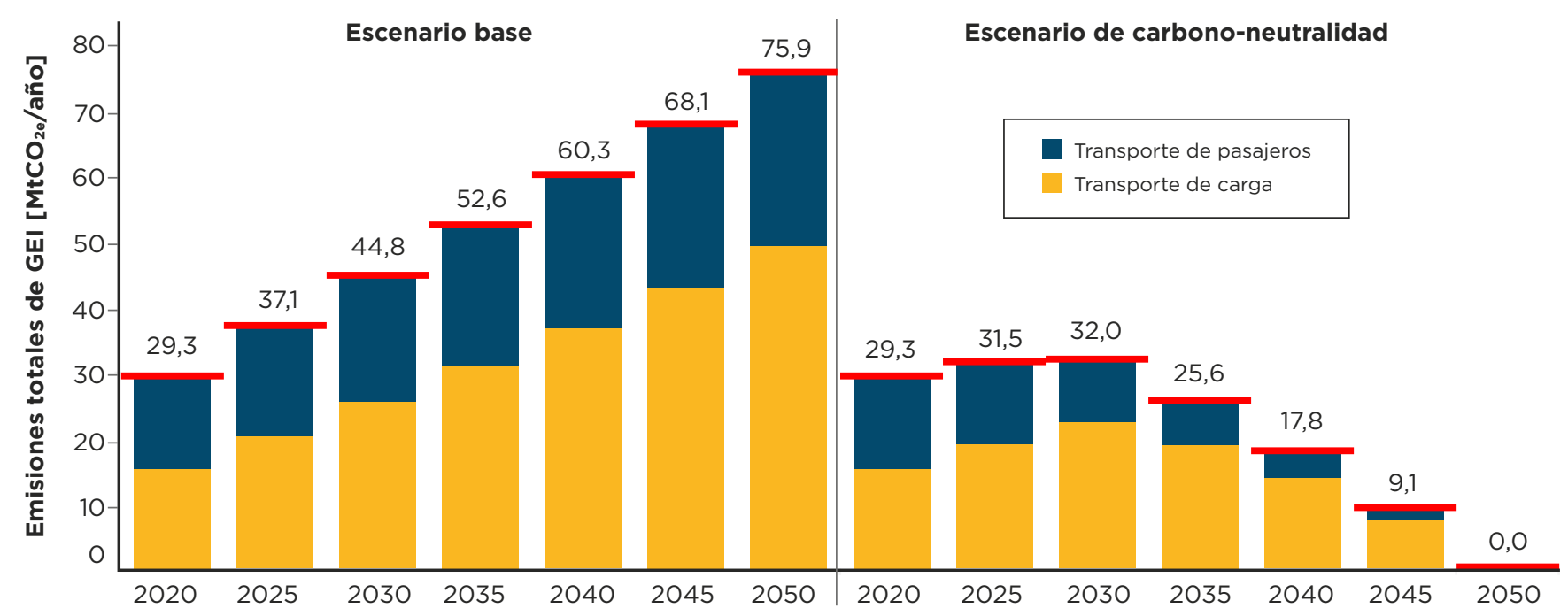

Fuente: Elaboración propia.

\section{Beneficios y costos}

Bajo los supuestos estándar, la descarbonización del sector transporte brinda beneficios totales (cercanos a US $\$ 139.000$ millones) que sobrepasan con creces las inversiones adicionales (de unos
US $\$ 47.000$ millones) y proporcionan un beneficio neto de US\$92.000 millones (gráfico 2.19). A continuación, se desglosan los detalles: 
$>$ El mayor beneficio proviene del ahorro de costos operativos y de mantenimiento de una flotilla renovada y electrificada, por un monto total de unos US $\$ 118.000$ millones acumulado a 2050. En el corto plazo, este beneficio es limitado (2,5\%), pero en el mediano plazo aumenta a un $21,4 \%$ y en el largo plazo cierra con un $76,1 \%$. Independientemente del periodo, la reducción de los costos operativos compensa las inversiones adicionales del mismo periodo y siempre resulta en un beneficio financiero. El beneficio financiero total acumulado asciende a US\$65.000 millones.
$>$ Los beneficios en términos de salud por la reducida combustión de fósiles (poco más de US\$14.000 millones), el aumento de la productividad como resultado de un menor congestionamiento (unos US\$4.000 millones) y la disminución del número de accidentes (US\$2.500 millones) producto de un menor uso del transporte privado multiplican los beneficios en el sector. Cada uno de estos beneficios aumenta paulatinamente en cada periodo producto del proceso transformador.

\section{Gráfico 2.19}

Beneficio neto del escenario de carbono-neutralidad versus el escenario base en el sector transporte bajo supuestos estándar

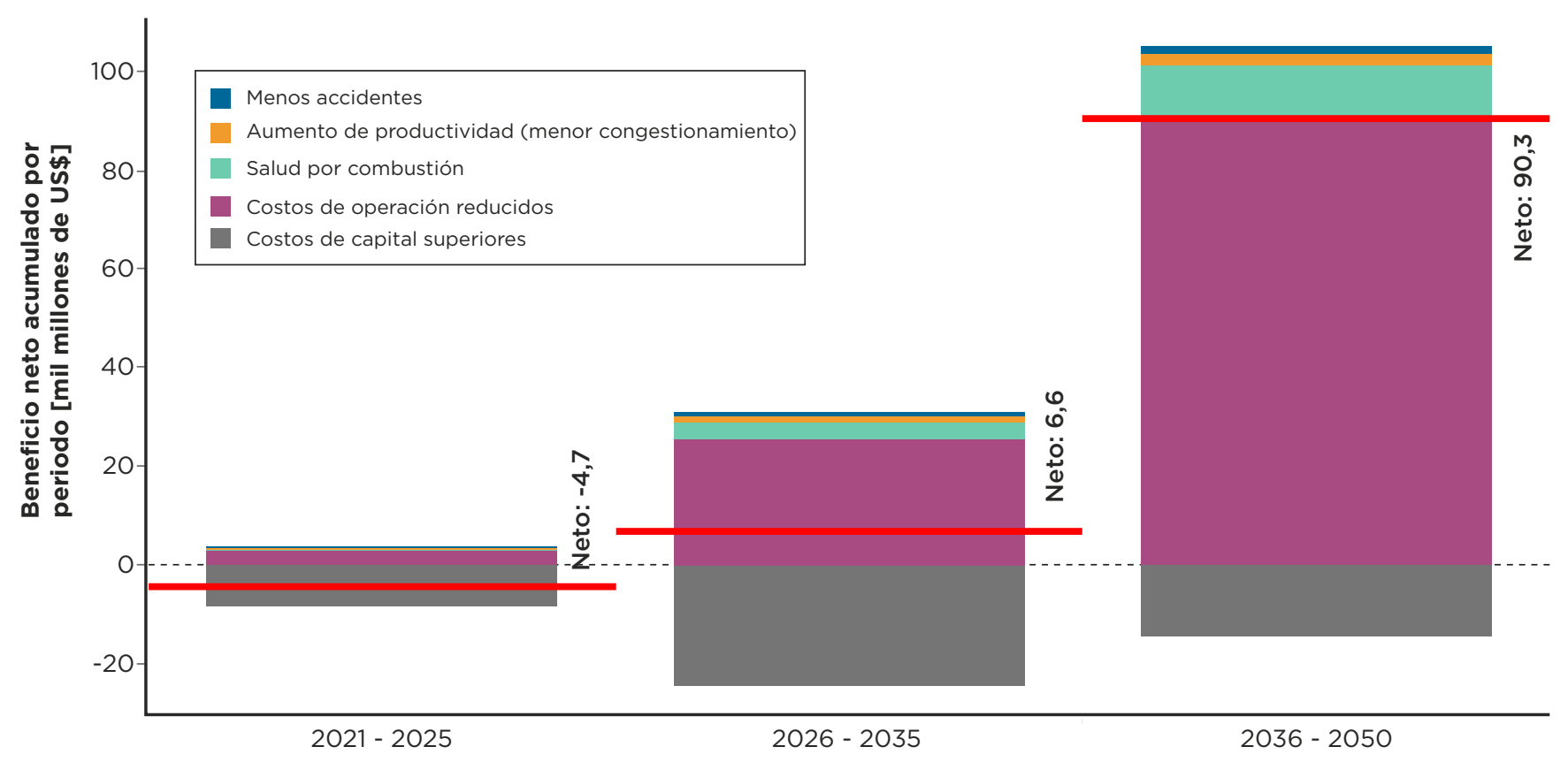

Fuente: Elaboración propia. 
El mayor beneficio bajo los supuestos estándar se asocia a la reducción de los costos operativos. Un sistema de transporte más eficiente y electrificado brinda ahorros en operación y mantenimiento que se estiman en poco más de US\$118.000 millones (gráfico 2.20). En detalle:

$>$ En el corto plazo, aumentar la eficiencia en el transporte de pasajeros y de carga, que reduce el consumo de combustibles fósiles, y sustituir la flota vehicular de pasajeros conllevan un ahorro de casi US $\$ 3.000$ millones: US $\$ 1.500$ millones provenientes del transporte de pasajeros y US\$1.400 millones del transporte de carga.
$>$ En el mediano plazo, se logran ahorros que superan los US $\$ 25.000$ millones. Estos se obtienen principalmente gracias a la reducción del consumo de combustibles fósiles: US $\$ 10.500$ millones del transporte de pasajeros y US $\$ 14.900$ millones del transporte de carga.

$>$ La sustitución total para 2050 conduce a mayores ahorros en el largo plazo, los cuales se estiman en US\$90.000 millones durante este periodo: US $\$ 26.700$ millones del transporte de pasajeros y US\$63.300 millones del transporte de carga.

\section{Gráfico 2.20}

Costos operativos y de mantenimiento del sector transporte en el escenario base versus el escenario de carbono-neutralidad bajo supuestos estándar

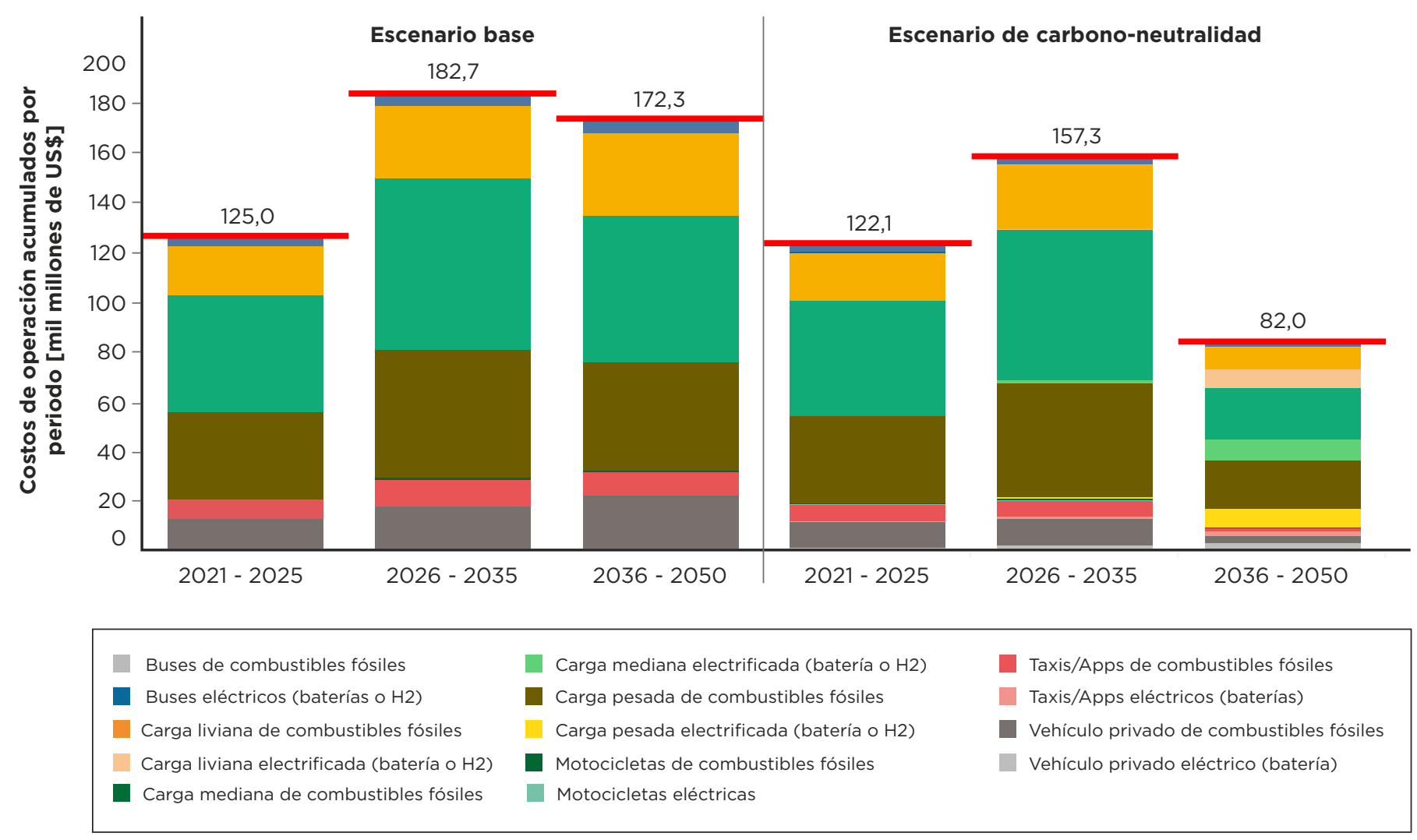

Fuente: Elaboración propia. 


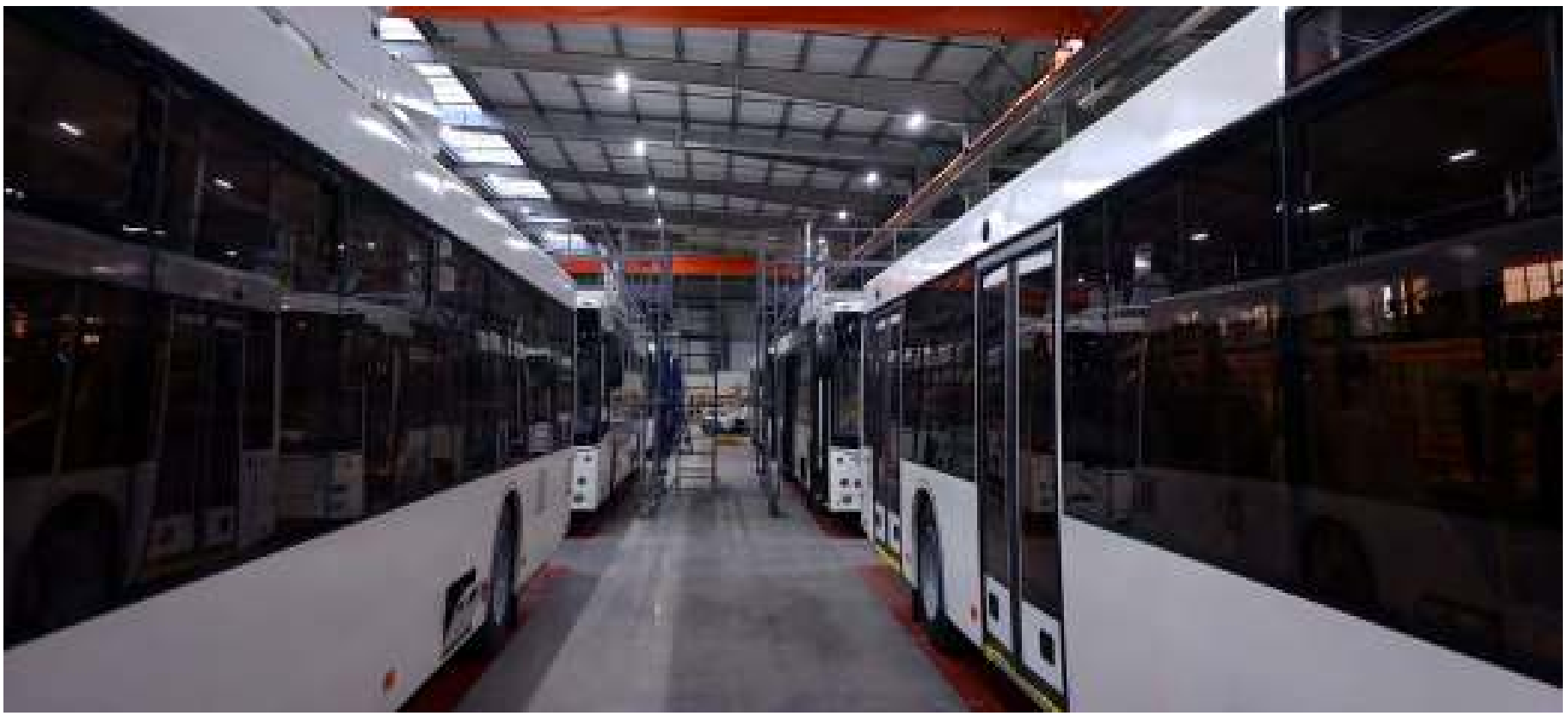

Alcanzar la carbono-neutralidad requiere inversiones adicionales estimadas en cerca de US\$47.000 millones bajo los supuestos estándar (gráfico 2.21):

$>$ En el corto plazo, se reducen las inversiones en vehículos, buses y camiones que usan combustibles fósiles, como resultado de un cambio modal a la movilidad activa y de la mejora en la logística de la carga. Esta transformación logra ahorros de cerca de US\$19.000 millones. En el mismo periodo, la modernización del transporte aumenta y requiere inversiones cercanas a los de US\$13.000 millones. Para habilitar cambios en el sector, se realizan inversiones en infraestructura (carreteras nacionales para la conexión entre ciudades, aceras, ciclovías) para el transporte de pasajeros y de carga, que se estiman en unos US\$7.000 millones y US\$8.000 millones, respectivamente. En el corto plazo, las inversiones en tecnologías eléctricas son mayores que las inversiones evitadas en vehículos de combustión interna. Esto, sumado a las inversiones en infraestructura, le imprime al sector un costo adicional de poco más de US\$8.000 millones durante este lapso.

$>$ En el mediano plazo, las inversiones en tecnologías que usan combustibles fósiles presentan una reducción de US\$59.000 millones con respecto al escenario base. Las inversiones en transporte eléctrico aumentan en poco más de US\$57.000 millones y las inversiones en infraestructura suman casi US\$26.000 millones. En total, el periodo requiere una inversión de unos US\$24.000 millones.

$>$ En el largo plazo, los casi US\$103.000 millones evitados en tecnologías de combustión interna se canalizan en los US\$103.000 millones invertidos en el periodo para electrificar el transporte. Si esto se suma a los casi US\$14.000 millones de inversión en infraestructura, este último periodo requiere una inversión adicional de unos US\$14.000 millones. 


\section{Gráfico 2.21}

Inversiones en el sector transporte en el escenario base versus el escenario de carbono-neutralidad bajo supuestos estándar

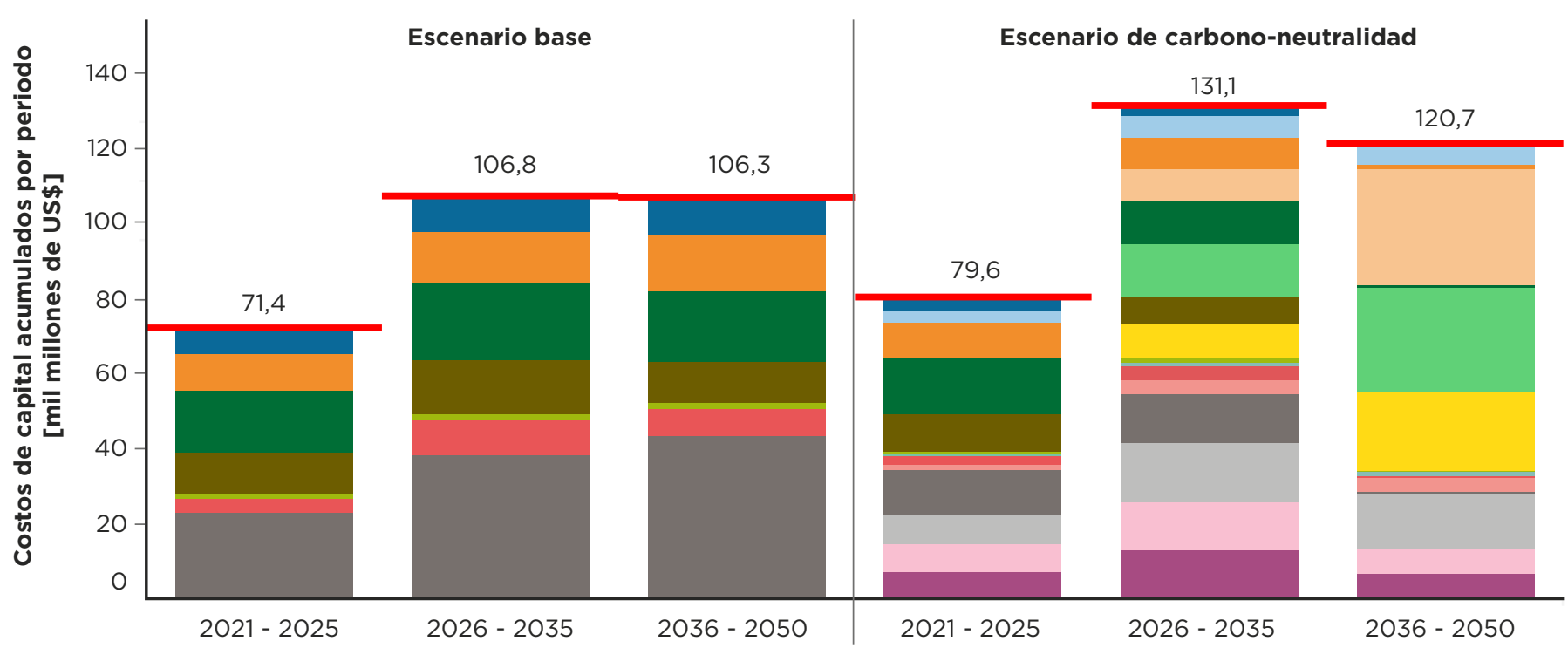

Buses de combustibles fósiles

Buses eléctricos (baterías o $\mathrm{H} 2$ )

Carga liviana de combustibles fósiles

- Carga liviana electrificada (batería o H2)

Carga mediana de combustibles fósiles

Carga mediana electrificada (batería o H2)
Carga pesada de combustibles fósiles Carga pesada electrificada (batería o H2)

Motocicletas de combustibles fósiles

Motocicletas eléctricas

Taxis/Apps de combustibles fósiles

Taxis/Apps eléctricos (baterías)
Vehículo privado de combustibles fósiles

Vehículo privado eléctrico (batería)

- Infraestructura para transporte de pasajeros

- Infraestructura para transporte de carga 


\subsubsection{Agricultura, silvicultura y otros usos de la tierra (AFOLU)}

Para 2050 las intervenciones en el sector AFOLU de Perú posibilitan una reducción de casi $183 \mathrm{MtCO}_{2 e}$ de emisiones de GEl con respecto al valor estimado de 2020. En contraste con las emisiones anuales de GEI del escenario base en 2050, la reducción se estima en unos 282 MtCO2e. La descarbonización del sector AFOLU brinda un beneficio neto de US $\$ 29.000$ millones acumulados a 2050 .

\section{Escenario base}

Este escenario refleja la evolución tendencial del sector para 2050, tomando en cuenta variables macroeconómicas exógenas, como el crecimiento poblacional y la tasa de crecimiento del PIB, y variables sectoriales específicas del subsector agrícola, ganadero y UTCUTS, que se detallan a continuación. Los siguientes son los supuestos más importantes que están incorporados en este escenario para cada uno de los tres subsectores:

\section{Agricola:}

$>$ La frontera agrícola en cada una de las regiones se considera constante en los niveles descritos por el Sistema de Estadísticas de Producción Agrícola del Ministerio de Desarrollo Agrario y Riego (MIDAGRI) (MIDAGRI, s/f). Solamente la región amazónica presenta una expansión de la frontera agrícola producto de la creciente deforestación. No se han incorporado las inversiones en infraestructura de irrigación ni proyectos de expansión de la frontera agrícola en la costa.
$>$ Los rendimientos por hectárea para cada una de las categorías de cultivos y regiones están dados por la información reportada en el Sistema de Estadísticas de Producción Agrícola del MIDAGRI.

$>$ Los costos de producción por hectárea fueron tomados de la Encuesta Nacional Agropecuaria de 2016 y se mantienen constantes durante el periodo.

$>$ Los precios internacionales de los productos transables se obtuvieron del modelo global COFFEE (Rochedo et al., 2016). Los precios de los productos no transables son estimados de manera endógena en el modelo POLYSYSPerú.

$>$ El consumo per cápita refleja los niveles existentes en 2016, y se proyectan en base al crecimiento del ingreso per cápita y a la variación de precios con elasticidades precio e ingreso constantes. 


\section{Ganadería:}

$>$ El número de cabezas de ganado muestra un crecimiento tendencial y su distribución regional es fija y refleja la distribución obtenida de la Encuesta Nacional Agropecuaria (INEI, 2020a), la cual se complementa con información proveniente del Sistema Integrado de Estadística Agraria del MIDAGRI.

$>$ El número de cabezas de ganado ovino, caprino y auquénido se ha mantenido constante a niveles de 2016.

$>$ La productividad del ganado se ha mantenido constante en los niveles de 2016.

$>$ El consumo per cápita de carnes hacia 2050 se consigna en función del cambio en el PIB per cápita.

> Para la evolución del precio de la carne avícola y porcina se ha considerado la tasa de crecimiento del precio del maíz amarillo duro, y para la evolución del precio de la carne vacuna se ha tomado en cuenta una tasa de crecimiento anual del $2 \%$.

> Para el caso del ganado vacuno solo se está considerando la producción cárnica.

\section{Uso de la tierra, cambio de uso de la tierra y silvicultura (UTCUTS):}

$>$ La deforestación se incrementa de acuerdo con su evolución tendencial por las principales causas: agrícola, en función de la tendencia histórica y del crecimiento del sector; minera, en función de las proyecciones del precio internacional del oro; de infraestructura, en función del crecimiento de la expansión de la red vial, y de urbanización, en función del crecimiento de la población rural en la región.

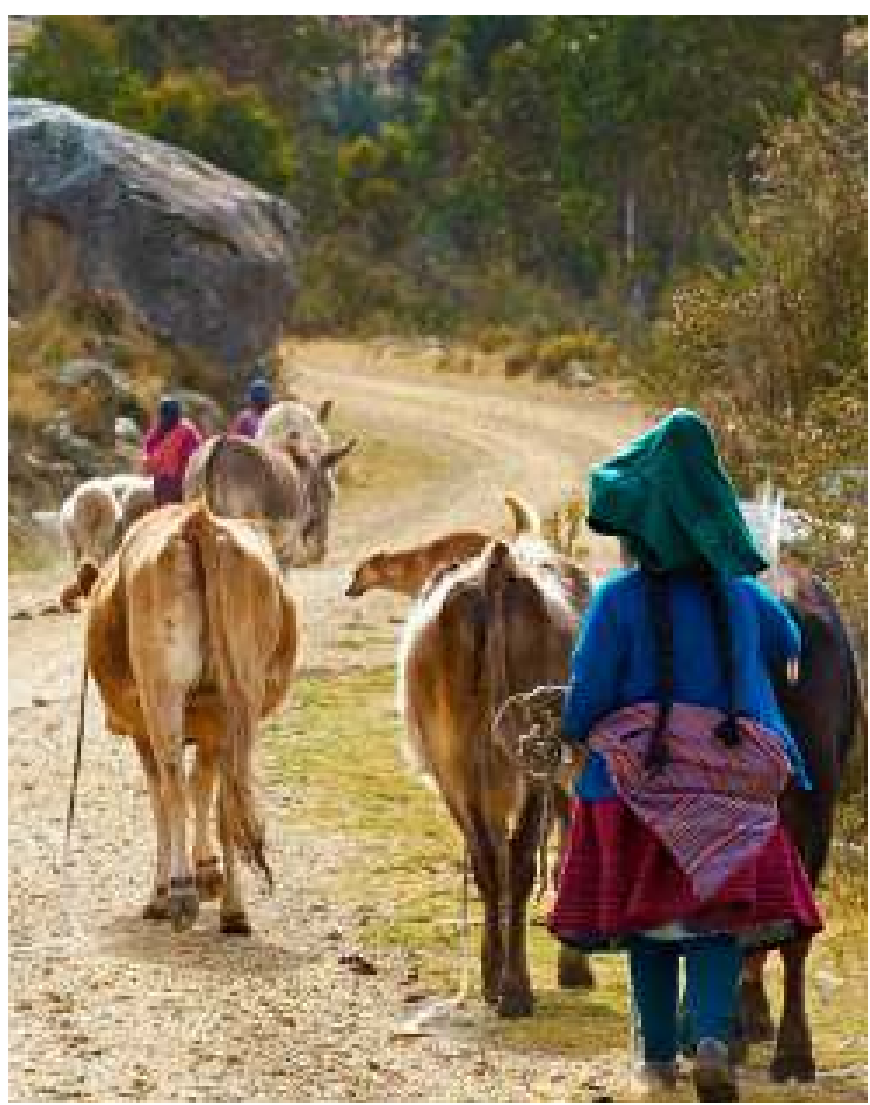

$>$ Las tasas de deforestación según categorías territoriales de bosque se mantienen constantes a lo largo del periodo 2020-50.

$>$ Para la valoración de los servicios ecosistémicos se ha utilizado el factor de US\$1.108 por hectárea de bosque primario, US\$554 para bosque secundario, y US\$831 por hectárea para plantaciones de restauración. El valor económico de los servicios ecosistémicos se basa en Carrasco et al. (2014), y en ellos se incluye la regulación del clima, la regulación de las precipitaciones, el suministro de materias primas y la provisión de recreo en los bosques tropicales; estudios recientes han encontrado que este valor podría multiplicarse por siete (Hernández-Blanco, 2020). 


\section{Escenario de carbono-neutralidad}

Este escenario representa un cambio transformacional del sector. Los siguientes son los supuestos más importantes que están incorporados para cada uno de los tres subsectores:

\section{Agricultura (subsector agrícola y ganadería):}

$>$ Sistema de riego por secas intermitentes. El reemplazo del riego por inundación característico de la Costa por un sistema de secas intermedias es una medida esencial para la transformación de la producción de arroz. Este sistema de producción alternativo al tradicional consiste en dar secas periódicas a la plantación de arroz en reemplazo de las inundaciones que se realizan en el sistema tradicional de cultivo. Este cambio permite mayores rendimientos, disminuye el uso del agua y reduce las emisiones de metano que resultan de la inundación de los suelos (Caldas Cueva y Lizárraga Travaglini, 2020). El gráfico 2.22 muestra la transición hacia la nueva tecnología hasta alcanzar casi un 50\% de participación en la superficie cosechada de arroz a nivel nacional en 2050.

\section{Gráfico 2.22}

Hectáreas de arroz bajo sistemas de riego por secas intermitentes en el escenario de carbono-neutralidad bajo supuestos estándar

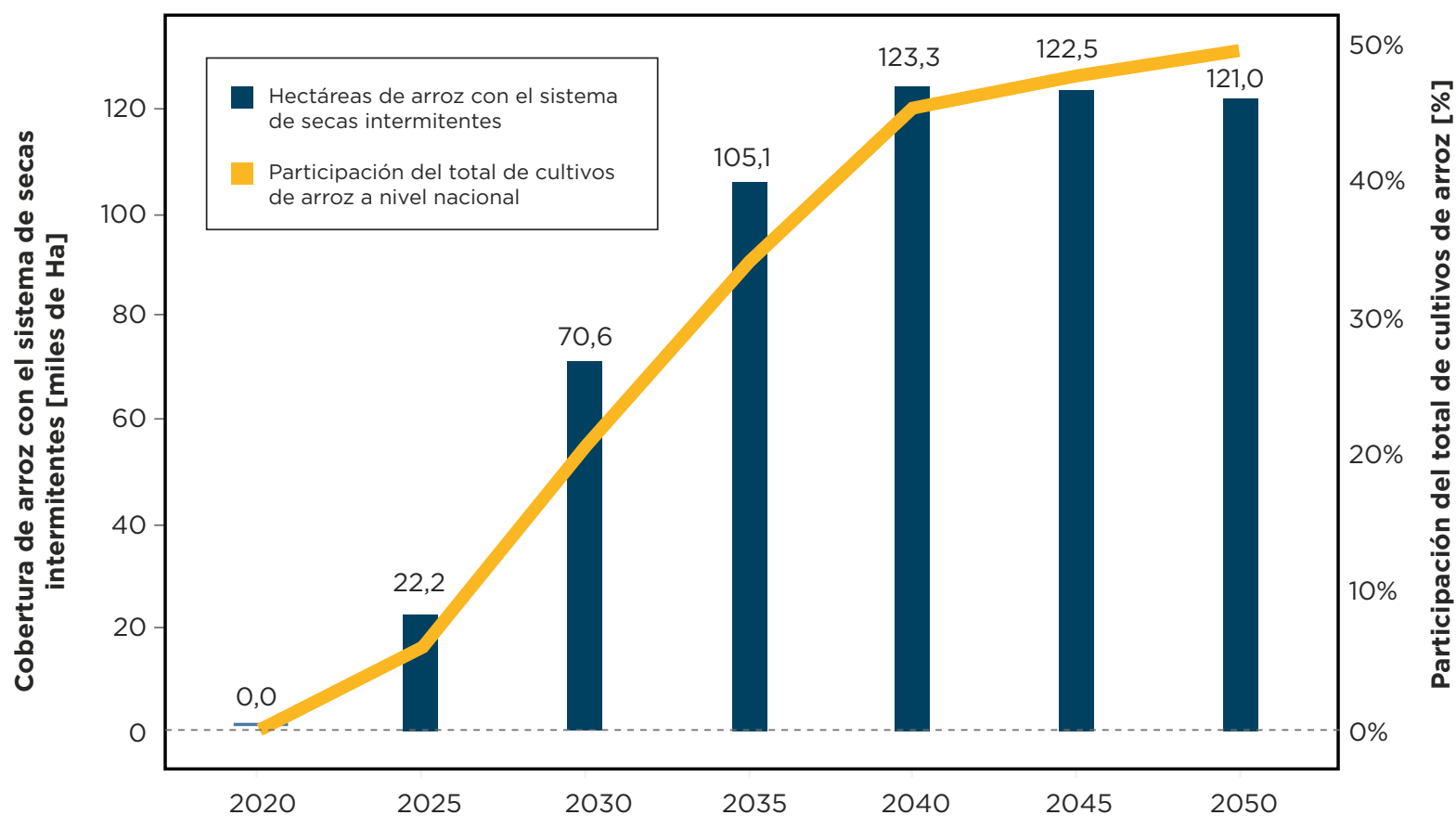


$>$ Sustitución de fertilizantes inorgánicos por fertilizantes orgánicos. El propósito de esta medida es reducir las emisiones producto de la quema y del desecho inapropiado de los residuos que se generan en la poda o la cosecha, principalmente en cultivos como frutas, granos, y cereales y arroz. Esto se logra con el aprovechamiento de los residuos orgánicos para la producción de fertilizantes orgánicos, los cuales son aplicados en los cultivos en sustitución de los fertilizantes inorgánicos. La meta es que en estos cultivos se pueda reemplazar hasta un 50\% del total de fertilizantes inorgánicos por fertilizantes orgánicos.

$>$ Sistemas silvopastoriles. La implementación de este tipo de sistemas en la Amazonía permite incrementar el secuestro de carbono; de la misma manera, la mejor calidad y disposición de pastos ayuda a mejorar el rendimiento del ganado y aumenta el peso del ganado vacuno en la Amazonía en hasta un $20 \%$, ayudando a reducir las emisiones por kilogramo de carne vacuna producida (MINAM, 2018).

$>$ Manejo de pastos naturales altoandinos. El mantenimiento y la segmentación de las áreas de pastos naturales altoandinos en la región Sierra, así como la alimentación rotativa del ganado vacuno con dichos pastos, permiten mejorar la calidad de los mismos, lo cual a su vez incrementa el peso del ganado vacuno en la Sierra en hasta un $20 \%$, ayudando a reducir las emisiones por kilogramo de carne vacuna producida (MINAM, 2018).

$>$ Cambio en el patrón de consumo de carbohidratos de la población. Se promueve un cambio en la composición del consumo de carbohidratos mediante la sustitución del consumo de arroz por una mayor ingesta de tubérculos, cereales y granos, así como leguminosas. Adicionalmente, esto ayuda a reducir la expansión de los cultivos de arroz y su transición hacia cultivos con menores emisiones. Esta medida promueve el consumo de alimentos con menores emisiones. El gráfico 2.23 indica el nivel de sustitución hacia 2050 tanto en la composición del consumo de carbohidratos como en la del consumo de carnes, el cual se detallará a continuación.

$>$ Cambio en el patrón de consumo de carnes de la población. Se considera que el crecimiento tendencial del consumo de carnes se mantiene, pero con una sustitución relativa de la ingesta de carnes rojas por carne de cerdo. Es decir, el cambio radica en que una parte cada vez mayor del crecimiento del consumo de carnes se traslade a la carne de cerdo. Adicionalmente, esto ayuda a reducir la presión de la expansión ganadera sobre el bosque. Tal como se puede observar en el gráfico 2.24, al final del periodo (2050) ambas carnes, rojas y de cerdo, experimentan un mayor nivel de consumo en comparación con 2020; sin embargo, el consumo per cápita se reduce en un $4 \%$ versus el escenario base para 2050.

Bajo supuestos estándar, las mejoras en las prácticas ganaderas (tanto en la Amazonía como en la Sierra) y el cambio de los patrones de consumo se traducen en una disminución del número de cabezas de ganado vacuno necesarias para mantener la producción de carne (gráfico 2.25), y reducen la presión de la expansión de la agricultura sobre el bosque. Esto influye de manera positiva y se traduce en menores emisiones de GEI. 


\section{Gráfico 2.23}

Cambio en el consumo per cápita de ciertos productos en el escenario de carbono-neutralidad versus el escenario base bajo supuestos estándar

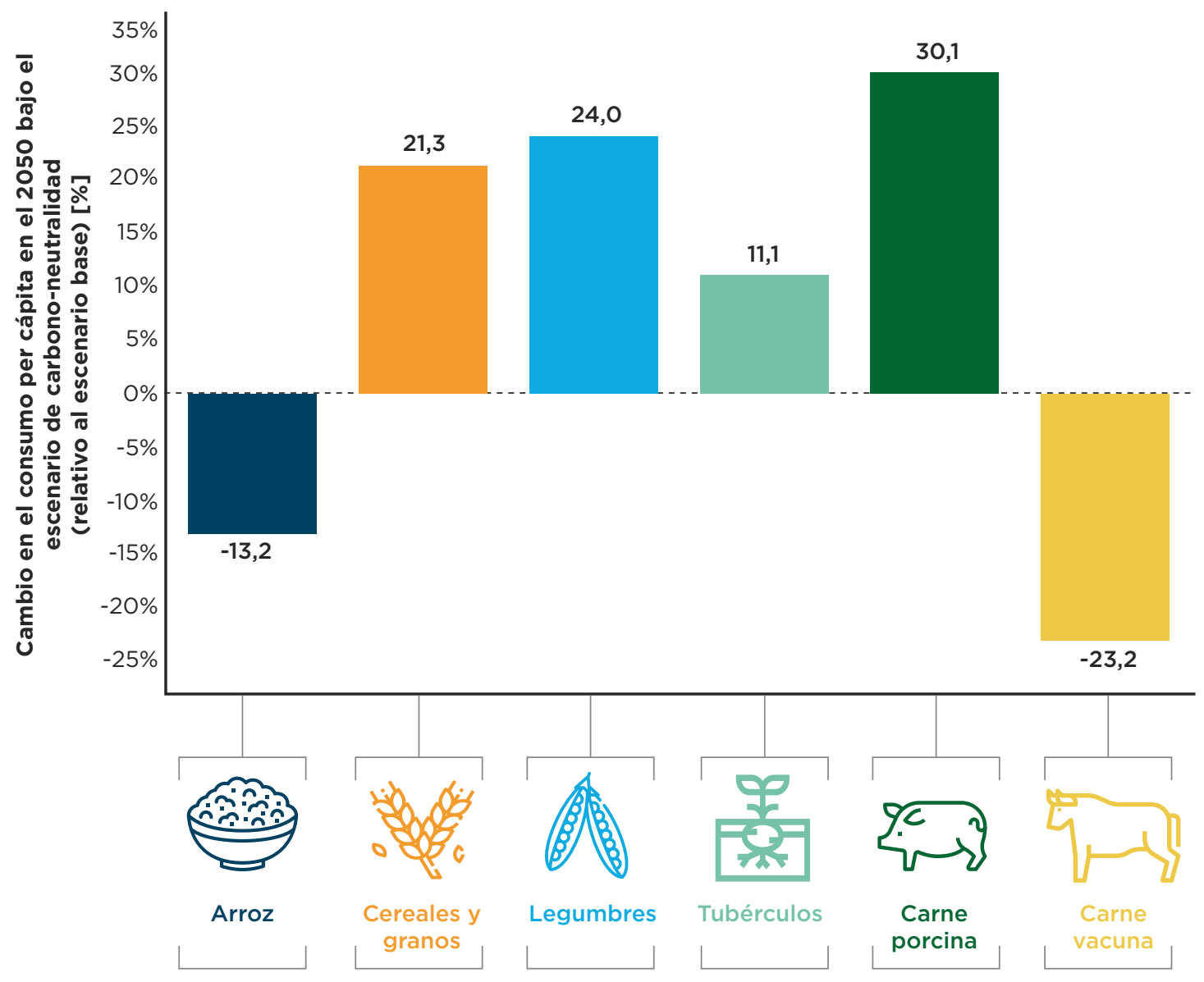

Fuente: Elaboración propia. 


\section{Gráfico 2.24}

Evolución del consumo de carne vacuna y de carne de cerdo en el escenario base versus el escenario de carbono-neutralidad bajo supuestos estándar

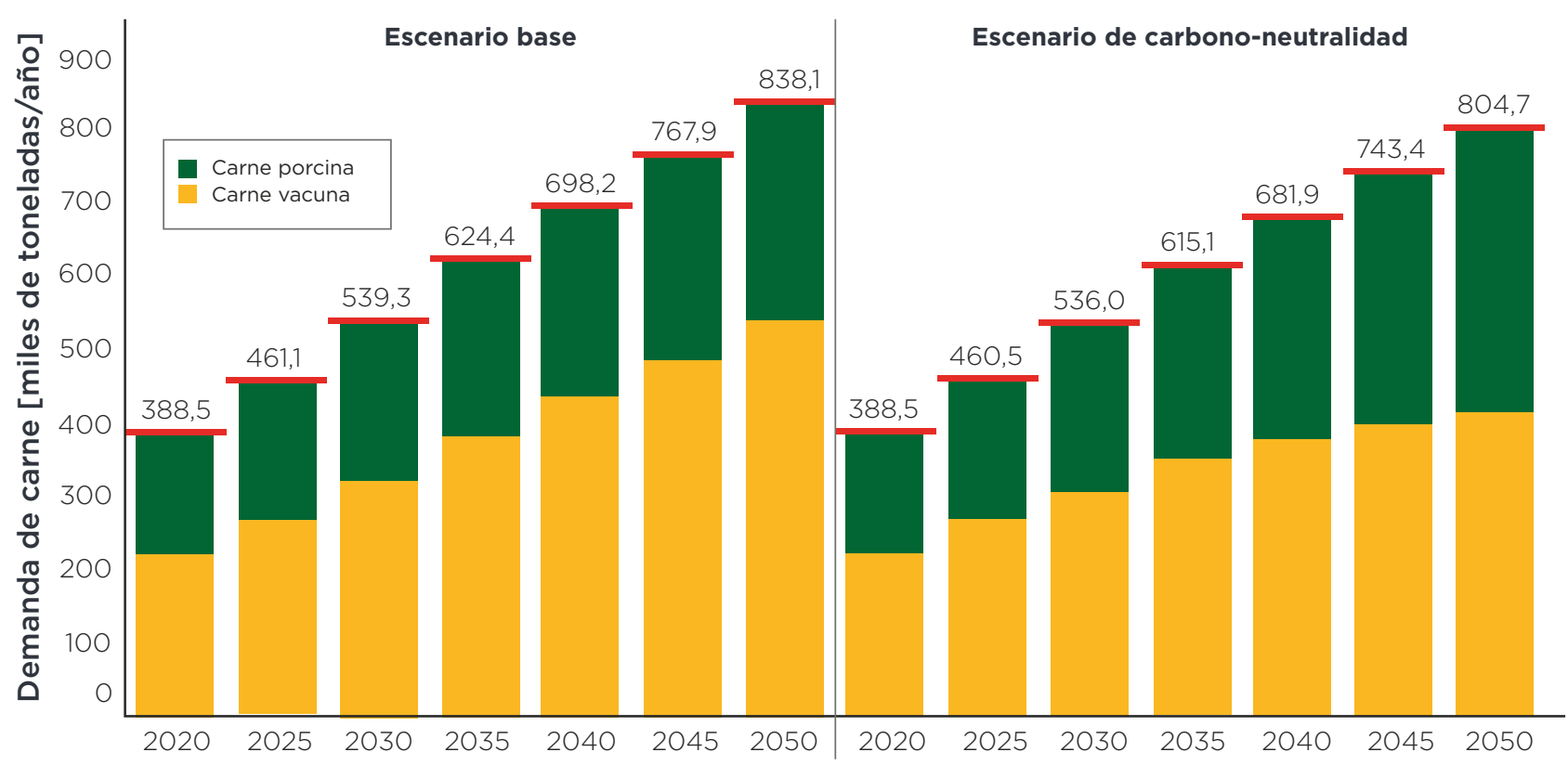

Fuente: Elaboración propia.

\section{Gráfico 2.25}

Número de cabezas de ganado vacuno en el escenario base versus el escenario de carbononeutralidad bajo supuestos estándar

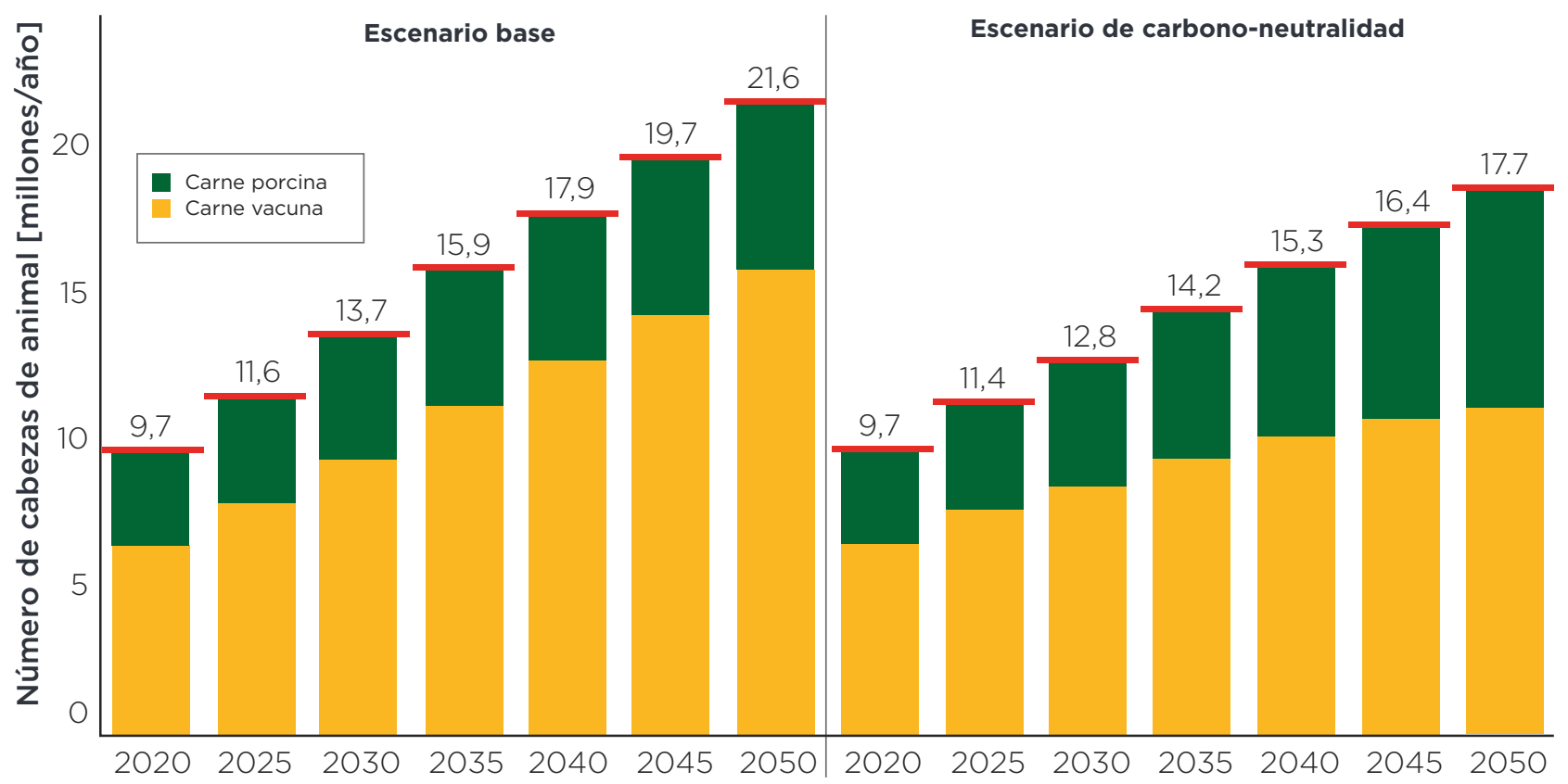




\section{Uso de la tierra, cambio de uso de la tierra y silvicultura (UTCUTS):}

$>$ Asignación de derechos en tierras no categorizadas de la Amazonía. El refuerzo de la institucionalidad en la gestión del paisaje del bosque amazónico se ve representado por la asignación de derechos a más de 12 millones Ha que carecen de derecho de uso asignado. En ningún caso se considera la asignación de concesiones en el bosque primario para el desarrollo de las plantaciones forestales. Esta asignación de derechos otorga protección a los bosques y contribuye a reducir la deforestación, porque se trata de la categoría de bosque que tiene la más alta tasa de deforestación; superior al 35\% anual. La implementación de esta medida en el tiempo se ve reflejada en el gráfico 2.26.

\section{Gráfico 2.26}

Número de hectáreas de bosque primario no categorizado a las que se les asigna derechos de uso bajo supuestos estándar

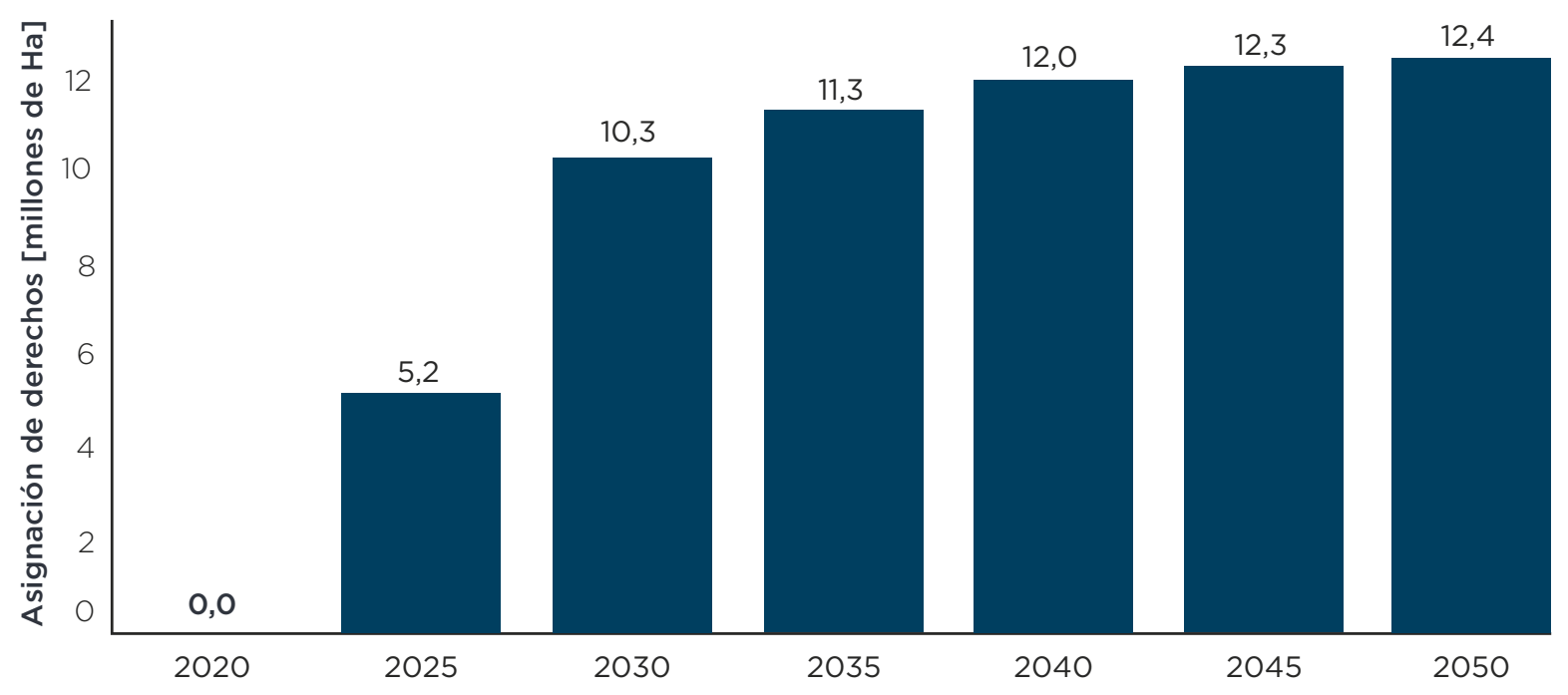

Fuente: Elaboración propia.

$>$ Sistemas agroforestales y plataforma de apoyo logístico para la producción agrícola. Si bien dichos sistemas están ligados directamente a la actividad agrícola, esta acción tiene un impacto considerable sobre la reducción de la deforestación y por ende se considera parte del subsector UTCUTS. Se estima que el $80 \%$ de la deforestación por agricultura se asocia al reemplazo de suelos que han perdido productividad, lo cual se explica por la falta de 
acceso de los pequeños productores a semillas, insumos, tecnología, financiamiento y mercados, como consecuencia de su poca capacidad de inversión y de los altos costos de transacción (Bedoya Garland, Aramburú y Burneo, 2017; Ravikumar et al., 2017). En este sentido, los sistemas agroforestales buscan, por un lado, generar condiciones de protección frente a la pérdida de productividad del suelo y para el incremento de su productividad, mediante inversiones para el desarrollo de plataformas de apoyo logístico cuyo objetivo es reducir los costos de transacción de los productores y, por otro, reemplazar la pérdida de productividad del suelo con capital físico que permita el acceso a semillas de calidad, insumos, tecnología, infraestructura, financiamiento y mercados a un costo razonable. Todo esto también se aplicará a tierras en áreas que no impliquen el reemplazo de la vegetación o de los hábitats naturales. Adicionalmente, los sistemas agroforestales permiten incrementar los ingresos por la venta de la madera y contribuyen en la captura de carbono. El gráfico 2.27 detalla el número de hectáreas, principalmente dedicadas al cultivo del café y del cacao, así como en pastos, en las que se introducen sistemas silvopastoriles y agroforestales. Se espera que para 2040 ya sean casi 1 millón Ha las que utilicen estos sistemas y que alrededor de $700.000 \mathrm{Ha}$ de cultivo reciban los beneficios de las plataformas logísticas. Cabe comentar que las plataformas de apoyo logístico consideradas en este estudio (para café y cacao en la Amazonía) se podrían extender a otros cultivos y a otras regiones, así como a la actividad ganadera.

\section{Gráfico 2.27}

Número de hectáreas que implementan sistemas silvopastoriles y agroforestales en la Amazonía bajo supuestos estándar

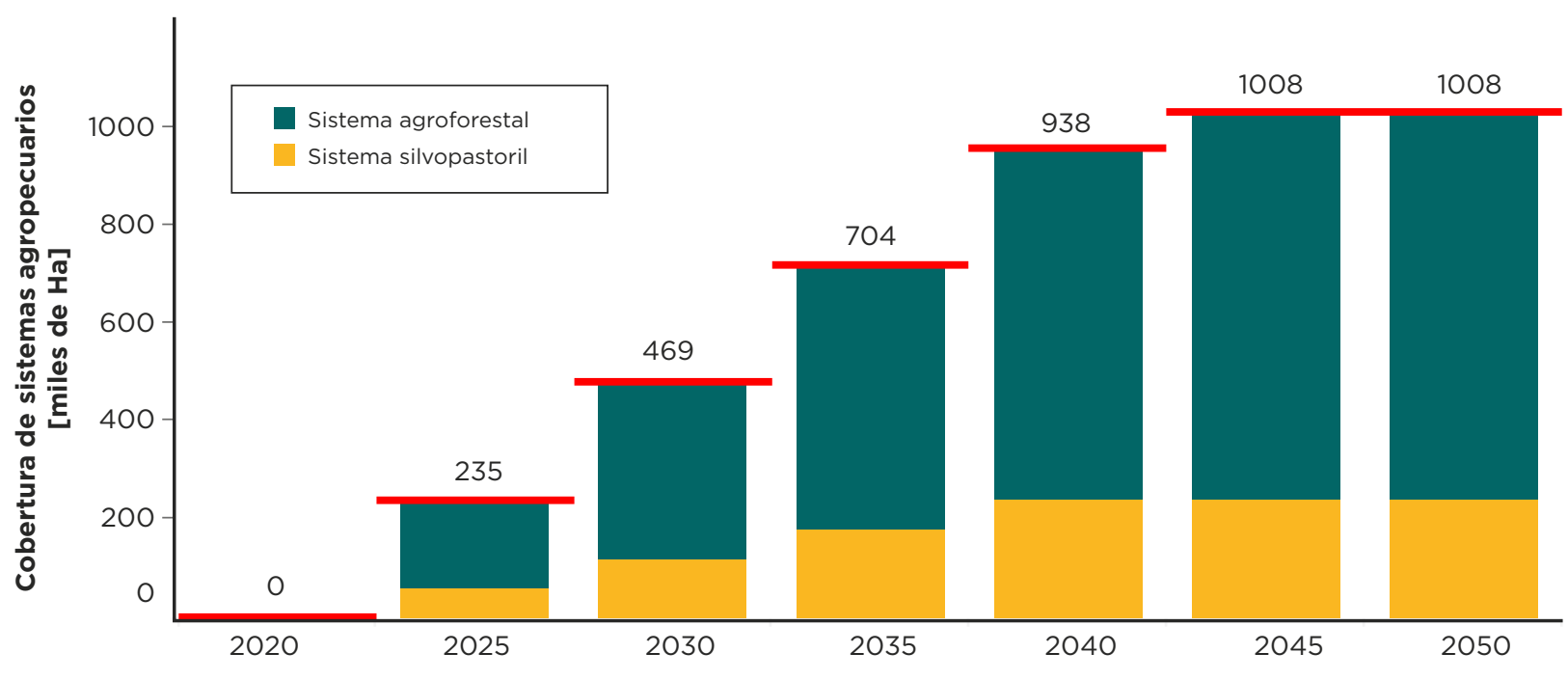


$>$ Manejo forestal sostenible en concesiones forestales. Para 2040 se considera un total de 14 millones Ha bajo explotación sostenible, lo cual contribuye no solo a una mayor captura de carbono sino también a la generación de actividad económica en la Amazonía. El gráfico 2.28 exhibe la evolución de dichas concesiones. Se asignan derechos de concesión maderera bajo manejo forestal sostenible a 7,5 millones de nuevas hectáreas de bosque no categorizado, mientras que, por otro lado, se promoverá la transición de las actuales concesiones forestales con un sistema tradicional de producción, de 7,7 millones $\mathrm{Ha}$, hacia concesiones forestales bajo manejo forestal sostenible. Esta medida ayuda tanto a dinamizar la economía y a generar nuevos ingresos a la Amazonía como a reducir la deforestación gracias al efecto del fortalecimiento de la institucionalidad requerida para ello.

\section{Gráfico 2.28}

Hectáreas en concesiones forestales sostenibles bajo supuestos estándar

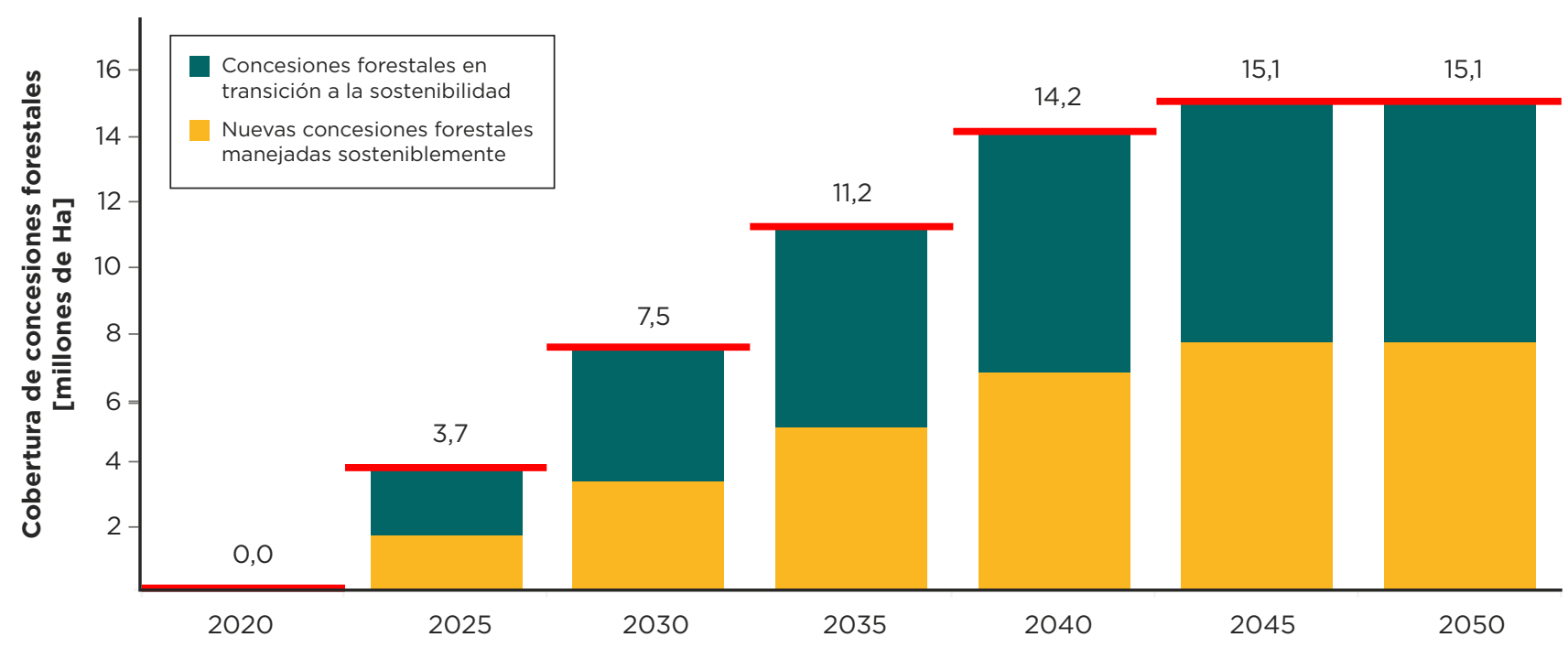

Fuente: Elaboración propia. 
$>$ Plantaciones forestales con fines de restauración y de comercialización. Se realizan en áreas que no impliquen el reemplazo de la vegetación o de los hábitats naturales. El gráfico 2.29 indica que para 2050 la meta es tener alrededor de 2 millones Ha reforestadas. De esta cantidad, unos 1,7 millones $\mathrm{Ha}$ se tratará con fines de restauración y otras 300.000 Ha se utilizará para plantaciones con fines comerciales. Estas últimas no solamente contribuyen a la captura de carbono, sino también a dinamizar la producción maderera. Se considera que se plantarán especies idóneas que permitan mantener el equilibrio del medio ambiente y la biodiversidad. Además, en ningún caso se considera el desarrollo de plantaciones forestales en el bosque primario. Se ha considerado una mayor promoción de las plantaciones con fines de restauración para alcanzar importantes niveles de secuestro de carbono, así como la reposición de servicios ecosistémicos perdidos por la deforestación. También se considerará que las plantaciones con fines comerciales requieren amplias extensiones para una adecuada operación logística, las cuales podrían ser difíciles de encontrar dada la atomización de la deforestación en la Amazonía.

\section{Gráfico 2.29}

Hectáreas en plantaciones de restauración y plantaciones comerciales bajo supuestos estándar

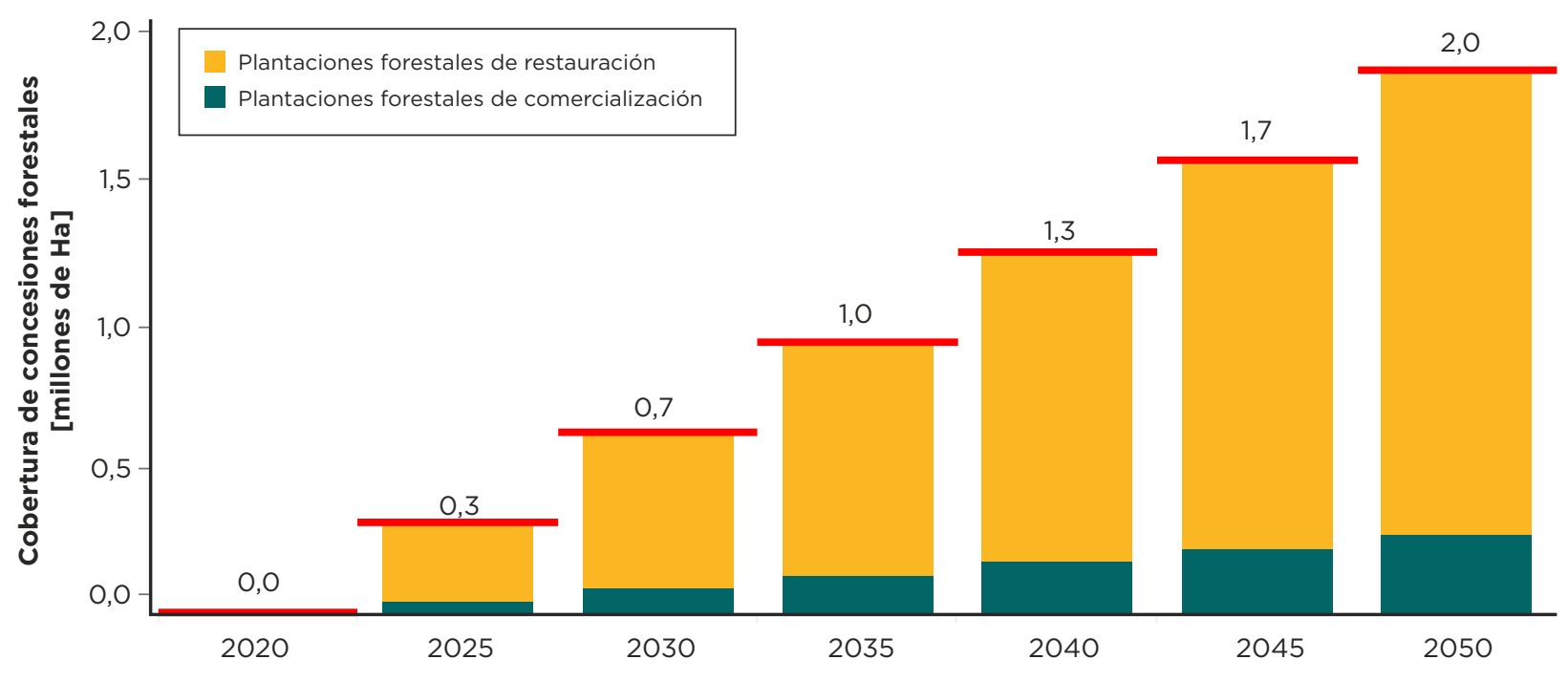


En lo que se refiere al componente más importante en términos de emisiones y captura de GEl (el subsector UTCUTS), las metas principales que se logran al implementar las transformaciones del sector son reducir la deforestación y recuperar tierras degradadas mediante la reforestación para restauración y las plantaciones comerciales (gráfico 2.30). Cabe destacar lo siguiente:

> La deforestación anual se reduce de manera consistente. Así, para 2050 se alcanza una disminución cercana al 90\%. La menor tasa de deforestación obedece principalmente a dos intervenciones: la asignación de derechos en tierras no categorizadas de la Amazonía y el desarrollo de sistemas agroforestales. En este estudio, no se ha considerado el efecto de las políticas implementadas sobre causales de deforestación, como la minería, la urbanización y los incendios forestales.

$>$ De manera complementaria, la profundización de las concesiones forestales con manejo sostenible permite darle valor al bosque y refuerza la reducción de la deforestación, con lo cual se brindan nuevas fuentes de ingresos a la población de la Amazonía.

\section{Gráfico 2.30}

Deforestación anual en el escenario base versus el escenario de carbono-neutralidad bajo supuestos estándar

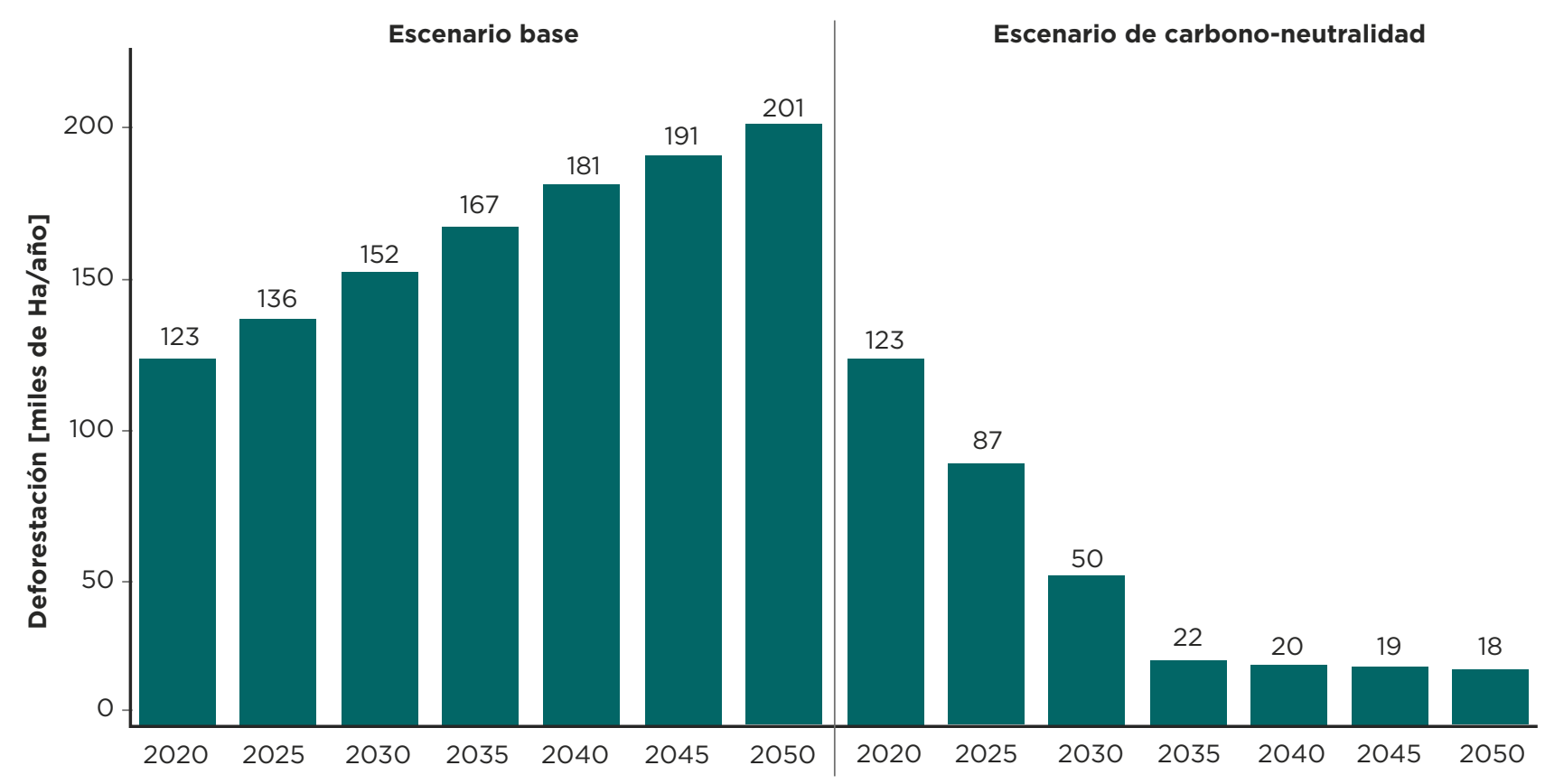




\section{Emisiones}

La implementación de las intervenciones resulta en la transformación del sector AFOLU, que pasa de ser el mayor emisor de GEI a convertirse en aquel que mayor secuestro de GEI realiza para 2050 (gráfico 2.31):

$>$ En el corto plazo, las emisiones se reducen cerca de $46 \mathrm{MtCO}_{2 \mathrm{e}}$ con respecto al escenario base y $29 \mathrm{MtCO}_{2 \mathrm{e}}$ con respecto a 2020.

$>$ En el mediano plazo, las emisiones disminuyen cerca de $169 \mathrm{MtCO}_{2 \mathrm{e}}$ con respecto al escenario base y $117 \mathrm{MtCO}_{2 \mathrm{e}}$ con respecto a 2020.

$>$ En el largo plazo, las emisiones netas descienden de $145 \mathrm{MtCO}_{2 \mathrm{e}}$ en 2020 a poco menos de - $38 \mathrm{MtCO}_{2 e}$; este cambio es aún mayor cuando se comparan las emisiones netas en el escenario base (alrededor de 244 $\mathrm{MtCO}_{2 \mathrm{e}}$ ) con las del escenario de carbononeutralidad (unas $-38 \mathrm{MtCO}_{2 \mathrm{e}}$ ).

La mayor transformación tiene lugar en el subsector UTCUTS, en cuyo caso se pasa de emitir unas $115 \mathrm{MtCO}_{2 \mathrm{e}}$ en 2020 a capturar casi 74 $\mathrm{MtCO}_{2 \mathrm{e}}$. Esto se consigue en gran medida gracias a la reducción de la deforestación, la cual se logra a partir del escalamiento en las actividades agroforestales y silvopastoriles, así como en la inversión para la asignación de derechos, y en actividades de monitoreo y vigilancia. La captura de carbono ocurre por el efecto de las plantaciones de restauración y las comerciales. Estas intervenciones permiten la transformación radical en la gestión del paisaje amazónico y conducen a alcanzar la meta de carbono-neutralidad de la economía peruana para 2050.

Si bien las actividades agrícolas y ganaderas no se pueden llevar a cabo con cero emisiones de
GEl, las medidas implementadas en esos sectores reducen las emisiones y contribuyen al objetivo de la carbono-neutralidad. De este modo, para 2050 las emisiones del subsector agrícola pasan de $5 \mathrm{MtCO}_{2 e}$ a poco menos de la mitad cuando se comparan el escenario base con el de carbononeutralidad. Cabe precisar que las emisiones del sector ganadero en el escenario de carbononeutralidad se incrementan en el tiempo, debido al crecimiento del consumo de carne inducido por el mayor ingreso de la población; sin embargo, este crecimiento es bastante menor que el que ocurre en el escenario base. Los resultados indican que para 2050 las emisiones en el sector ganadería para el escenario base ascienden a poco más de 43 $\mathrm{MtCO}_{2}$ y en el escenario de carbono-neutralidad se reducen a casi $34 \mathrm{MtCO}_{2 \mathrm{e}}$.

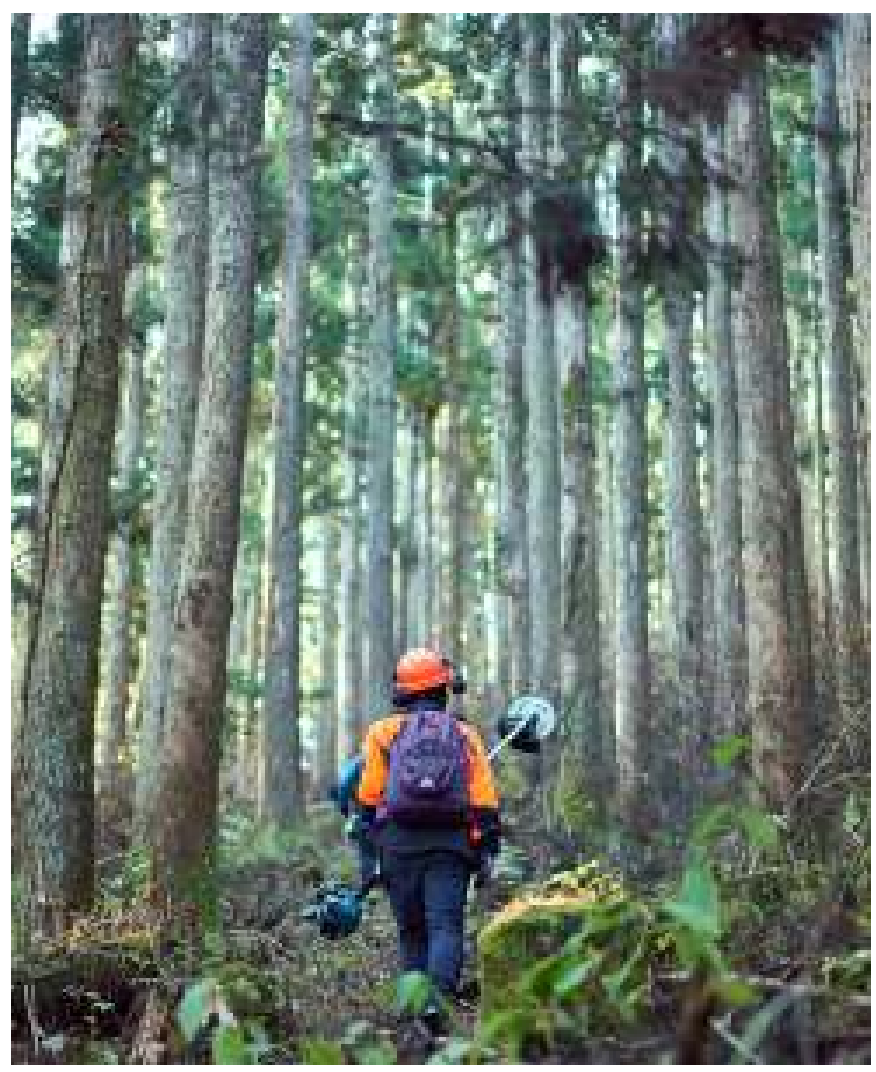




\section{Gráfico 2.31}

Emisiones anuales del sector AFOLU en el escenario base versus el escenario de carbono-neutralidad bajo supuestos estándar

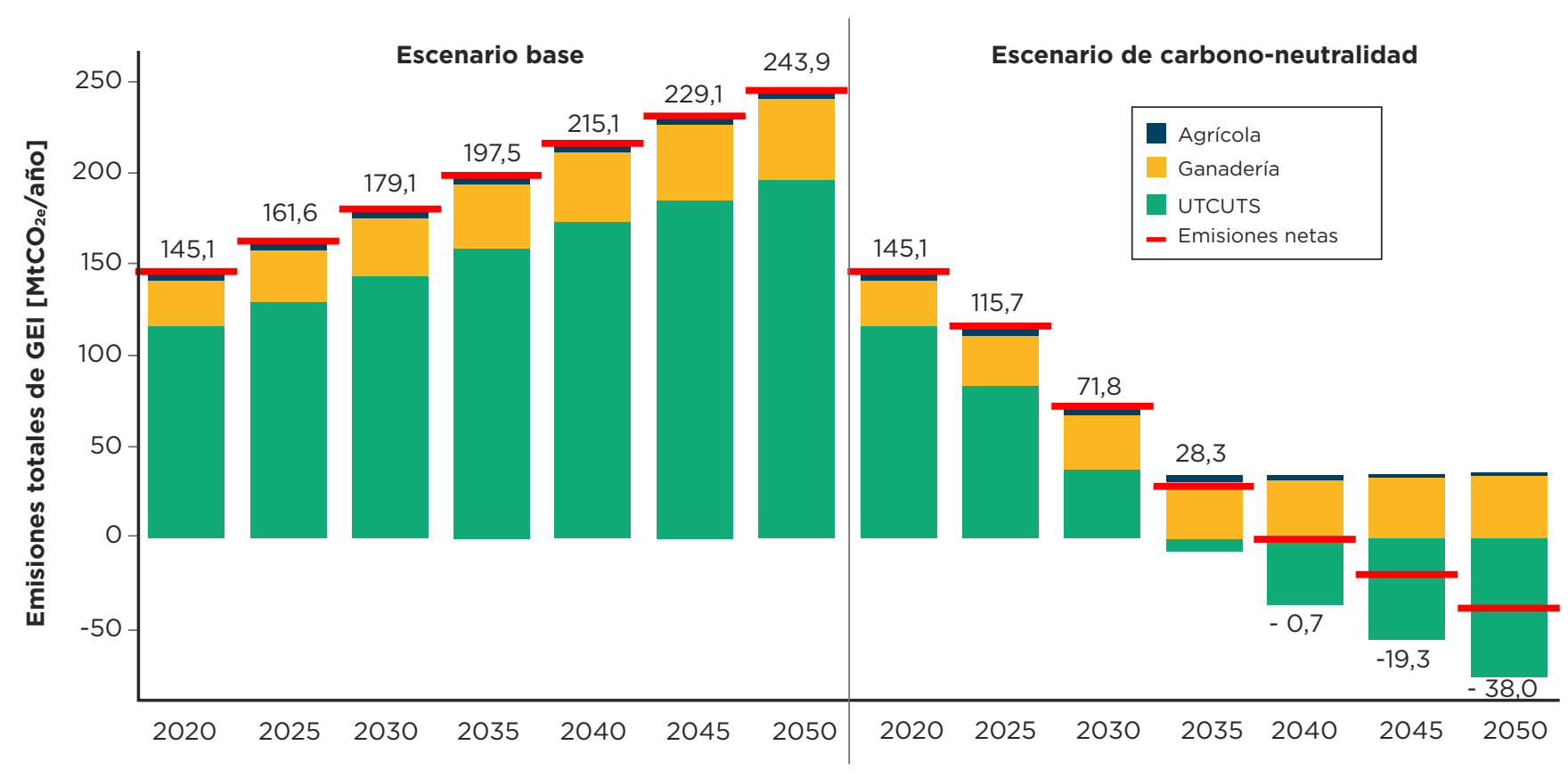

Fuente: Elaboración propia.

Nota: Los números sobre las barras corresponden al valor de las emisiones netas.

\section{Beneficios y costos}

La transformación del sector AFOLU resulta en beneficios acumulados netos para la economía peruana del orden de los US $\$ 29.000$ millones (gráfico 2.32). De manera detallada:

$>$ Los beneficios provienen principalmente de los ingresos adicionales generados por las actividades agroforestales, las plantaciones forestales con fines comerciales y el incremento de los precios agrícolas resultantes del cambio de preferencias en cuanto al consumo de arroz y la inclinación hacia los tubérculos y las leguminosas.
> La segunda fuente más importante de beneficios se deriva de la recuperación de los servicios ecosistémicos de una menor deforestación y de la reforestación con fines de restauración.

$>$ Estos beneficios superan al incremento en costos de capital y de operación, provenientes en su mayoría de las inversiones en plantaciones, del desarrollo de actividades agroforestales y de las mejoras institucionales relacionadas con la asignación de derechos en 12 millones $\mathrm{Ha}$ de bosque primario. 
Tal como se puede apreciar en el gráfico 2.32, los aumentos en los costos de capital se producen en el corto y el mediano plazo, mientras que los beneficios se generan principalmente en el mediano y el largo plazo. Esta temporalidad coincide con el tipo de inversiones requeridas tanto en plantaciones forestales (comerciales y de restauración) y en sistemas agroforestales, como en la institucionalidad para respaldar la asignación de derechos.

Si se observa la generación de beneficios por periodos (gráfico 2.32), se concluye lo siguiente:

$>$ En el corto plazo, se obtiene un beneficio neto negativo de alrededor de US\$1.200 millones, principalmente por el incremento de los costos de capital de poco más de US $\$ 2.000$ millones y de los costos de operación de alrededor de US\$1.000, pese a que hay un aumento de los ingresos de casi US\$2.000 millones y beneficios por servicios ecosistémicos de alrededor de US\$200 millones.

$>$ En el mediano plazo, se obtiene un beneficio neto de unos US\$10.000 millones, básicamente impulsado por un incremento de unos US $\$ 14.000$ millones en términos de ingresos, acompañado por un aumento de US $\$ 2.400$ millones en los servicios ecosistémicos. En contraposición, hay un incremento de casi US\$3.000 millones del costo de capital y de casi US $\$ 4.000$ millones de los costos de operación.

$>$ En el largo plazo, se obtiene un beneficio neto de aproximadamente US\$21.000 millones, los cuales resultan de un incremento de los ingresos (casi US $\$ 20.000$ millones) y servicios ecosistémicos (unos US\$6.600 millones), que compensan los costos de capital de poco más de US $\$ 1.000$ millones y operativos de alrededor de US\$4.000 millones.

\section{Gráfico 2.32}

Beneficio neto del escenario de carbono-neutralidad versus el escenario base en el sector AFOLU bajo supuestos estándar

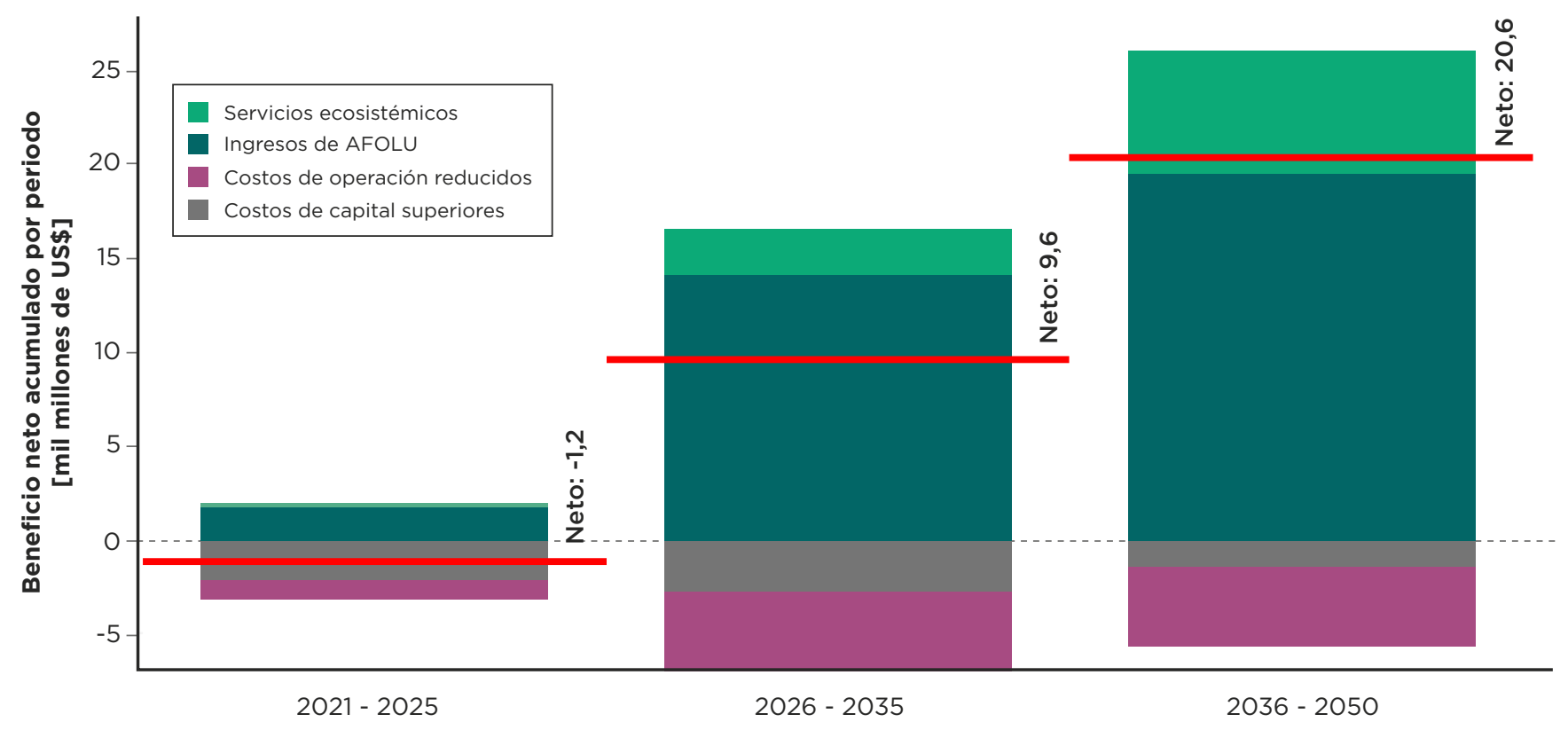


Los beneficios derivados del incremento de los ingresos se presentan en agricultura y sobre todo en UTCUTS. Este aumento ocurre por la dinamización de UTCUTS gracias a la profundización de las concesiones forestales, ahora bajo manejo forestal sostenible, así como por el incremento de las plantaciones comerciales, para las cuales se buscará realizar una implementación en armonía con el medio ambiente y la biodiversidad. El incremento de los ingresos de UTCUTS asciende a más de US\$28.000 millones y los de agricultura, a US\$7.000 millones entre 2021 y 2050 (gráfico 2.33). Si se analiza la evolución del ingreso por periodos, se obtiene lo siguiente:
$>$ En el corto plazo, el aumento del ingreso en UTCUTS es de casi US $\$ 2.000$ millones, mientras que en agricultura es nulo.

$>$ En el mediano plazo, el incremento del ingreso en UTCUTS es de casi US\$12.000 millones, mientras que el ingreso en agricultura es de poco más de US\$2.600 millones.

$>$ En el largo plazo, el aumento del ingreso en UTCUTS supera los US\$15.000 millones, mientras que en agricultura es de US $\$ 4.500$ millones.

\section{Gráfico 2.33}

Beneficio por ingresos en el sector AFOLU en el escenario de carbono-neutralidad versus el escenario base bajo supuestos estándar

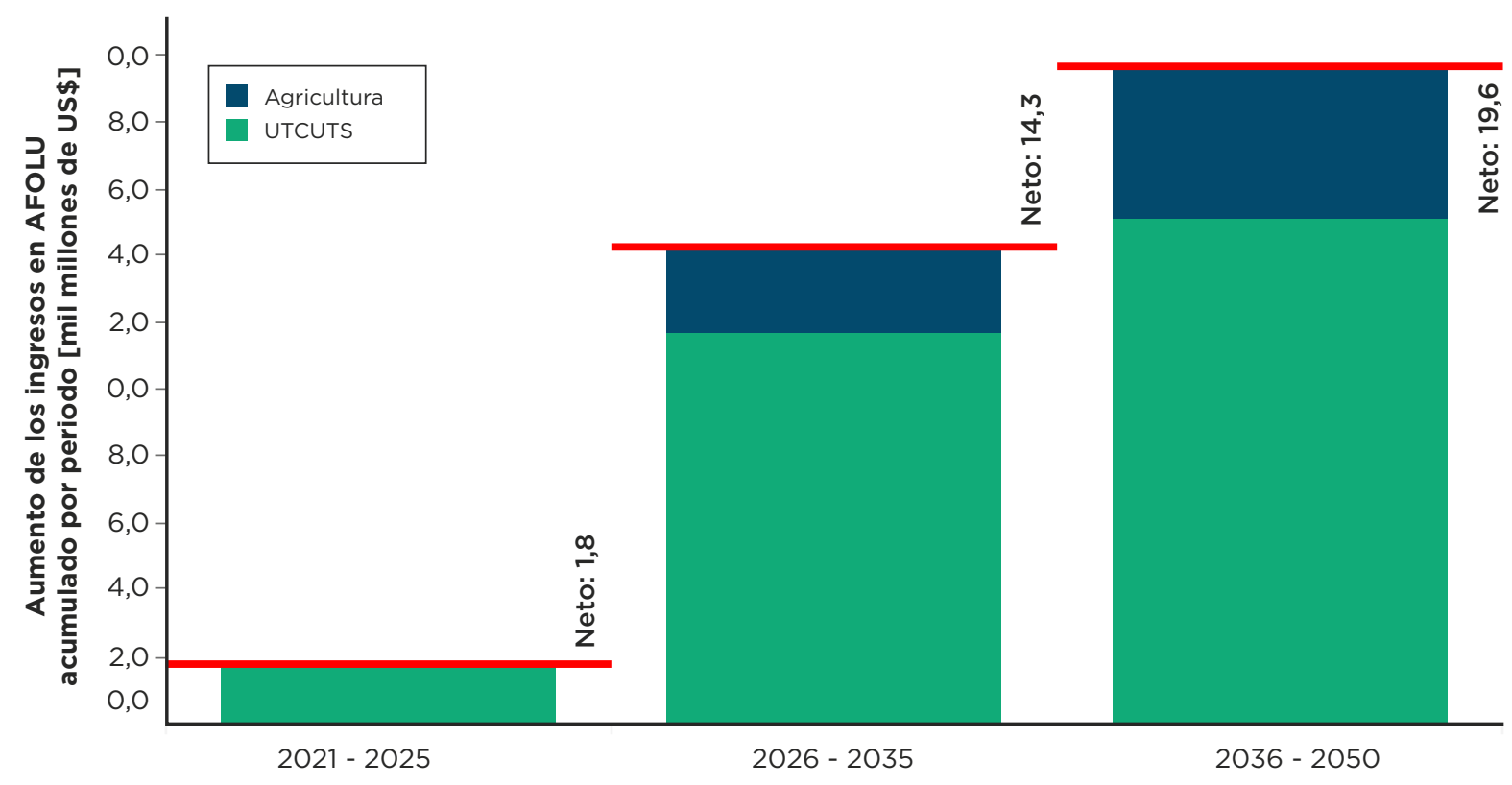




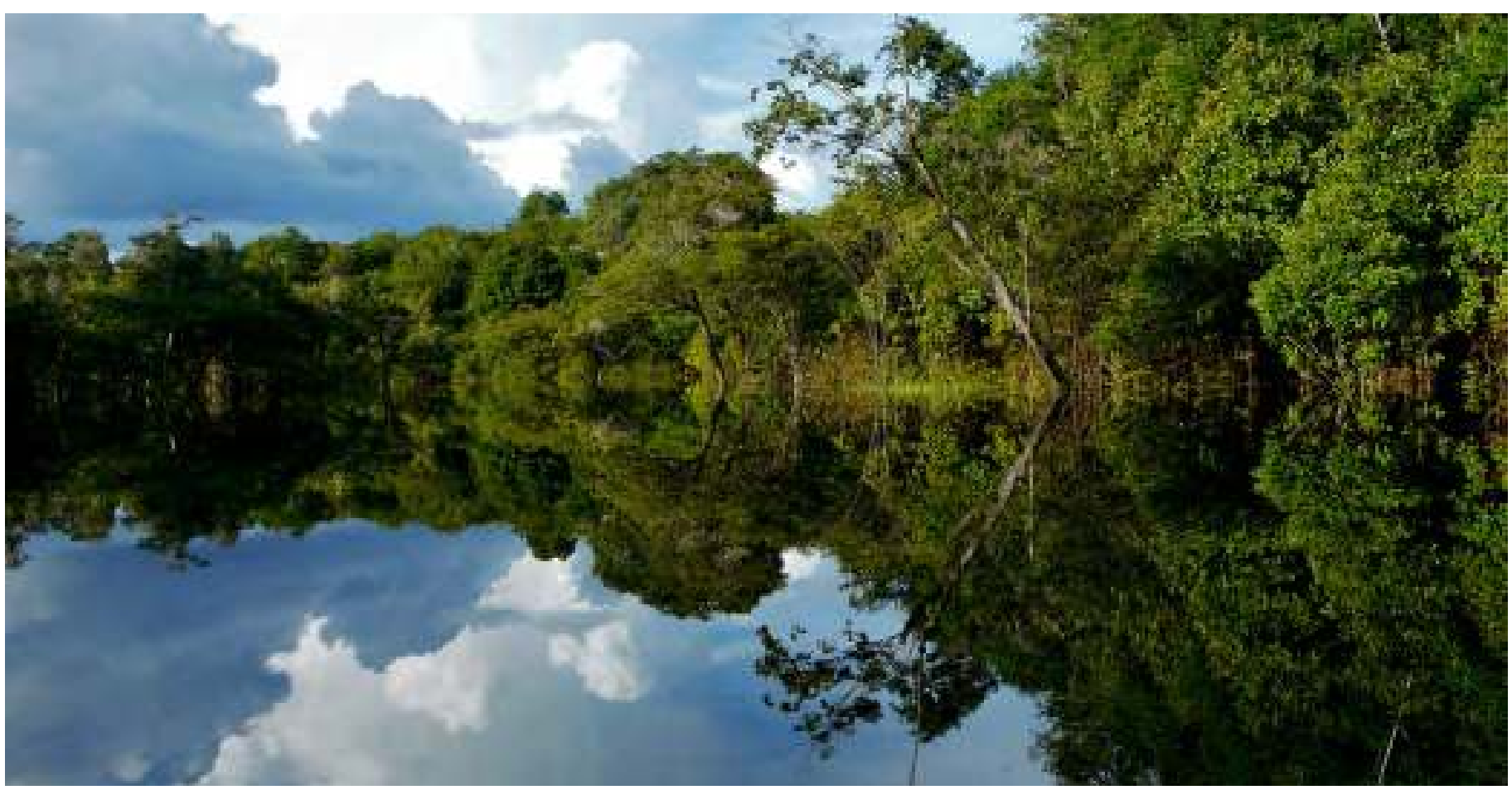

Otro de los beneficios del escenario de carbononeutralidad es la recuperación de los servicios ecosistémicos (gráfico 2.34). Los servicios mencionados se recuperan principalmente debido al incremento, con respecto al escenario base, de los bosques primarios, que generan alrededor de US\$10.000 millones; esto es resultado de la reducción de la deforestación. Las plantaciones con fines de restauración también contribuyen a aumentar los servicios ecosistémicos, generando poco más de US $\$ 2.000$ millones, mientras que hay una reducción de US $\$ 2.500$ millones de estos servicios proveniente de los bosques secundarios. Esto último se explica porque al disminuir la deforestación también se induce a una reducción en las hectáreas de bosques secundarios, ya que estos son el resultado de la transición de áreas deforestadas generalmente para uso agrícola y que han sido abandonadas, y que se transforman naturalmente en áreas boscosas. Si se analiza la evolución por periodo, se halla lo siguiente:

$>$ En el corto plazo, la evolución de los servicios ecosistémicos adicionales generados en el bosque primario es de US $\$ 200$ millones, mientras que no se observan cambios significativos en los servicios ecosistémicos generados en las plantaciones de restauración ni por el bosque secundario.

$>$ En el mediano plazo, la evolución de los servicios ecosistémicos adicionales generados en el bosque primario es de US $\$ 2.700$ millones, las plantaciones de restauración producen servicios ecosistémicos por US\$300 millones y hay una reducción de US\$600 millones de los servicios ecosistémicos generados por el bosque secundario. En conjunto se obtiene un beneficio de US $\$ 2.400$ millones.

$>$ En el largo plazo, la evolución de los servicios ecosistémicos adicionales generados en el bosque primario es de casi US $\$ 7.000$ millones. Las plantaciones de restauración producen servicios ecosistémicos cercanos a US $\$ 1.600$ millones, y se estima una reducción de los servicios ecosistémicos generados por el bosque secundario de unos US $\$ 2.000$ millones. 


\section{Gráfico 2.34}

Beneficio de los servicios ecosistémicos en el sector AFOLU en el escenario de carbono-neutralidad versus el escenario base bajo supuestos estándar

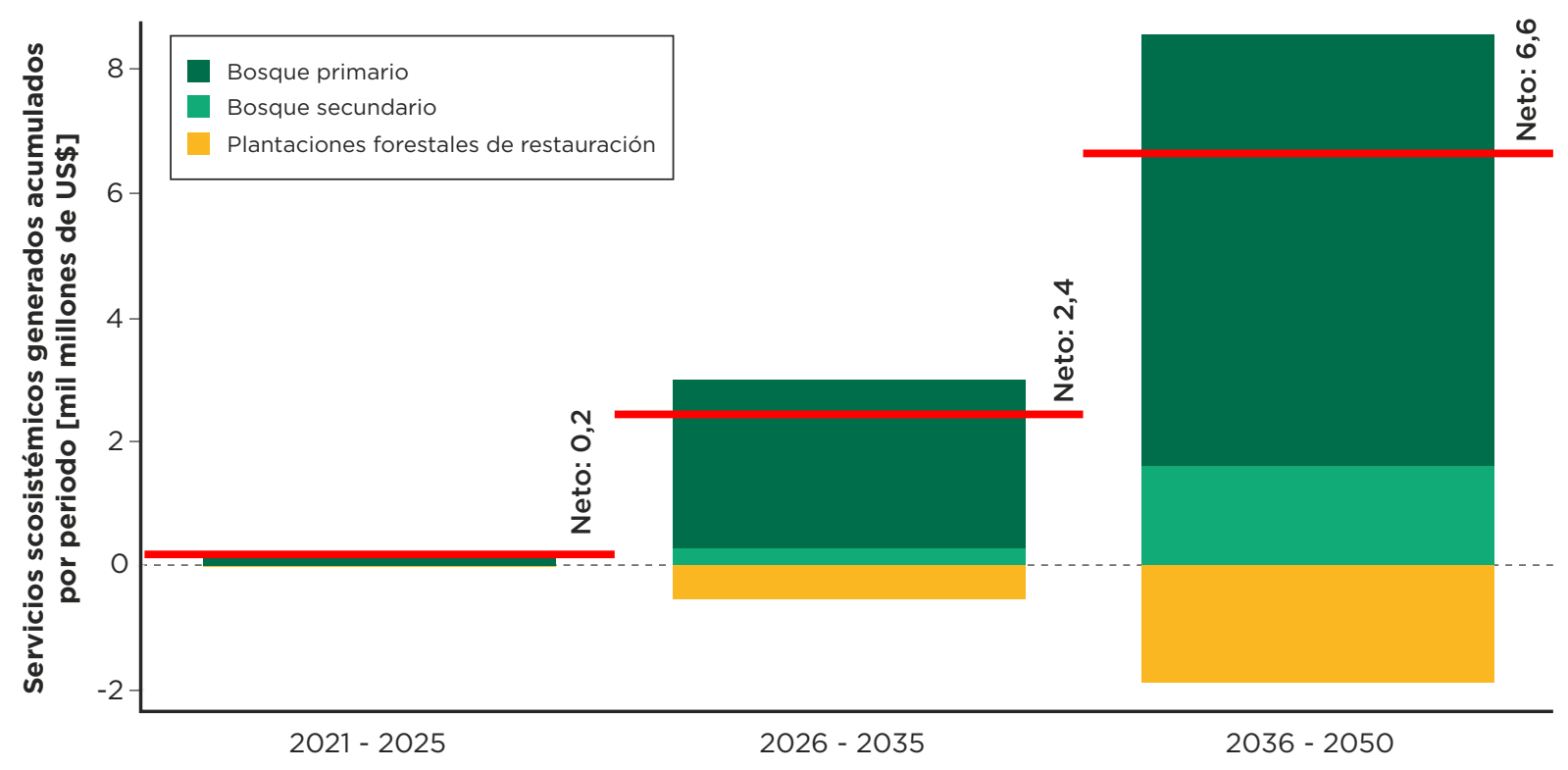

Fuente: Elaboración propia.

Las intervenciones en el sector AFOLU requieren inversiones de poco más de US\$9.000 millones. El gráfico 2.35 presenta las inversiones según los tres subsectores, tanto para el escenario base como para el escenario de carbono-neutralidad, y para distintos periodos de implementación. Los costos de capital varían con respecto al escenario base por la puesta en marcha de las intervenciones, y también como resultado de la reconfiguración de la estructura productiva agraria y ganadera derivada del cambio en las preferencias y del cambio tecnológico en el cultivo de arroz.

$>$ En el corto plazo, los costos de capital de UTCUTS se incrementan en poco más de US\$2.000 millones y lo correspondiente a ganadería y sector agrícola no tiene una variación significativa.

$>$ En el mediano plazo, los costos de capital de UTCUTS se incrementan en poco más de US\$3.000 millones, mientras que los de ganadería se reducen en US\$300 millones y el subsector agrícola no presenta ninguna variación.

$>$ En el largo plazo, los costos de capital de UTCUTS se incrementan en casi US $\$ 2.000$ millones, los de ganadería se reducen en US $\$ 600$ millones y el subsector agrícola presenta una reducción de US\$200 millones. 


\section{Gráfico 2.35}

Inversiones por subsector en AFOLU en el escenario base versus el escenario de carbono-neutralidad bajo supuestos estándar

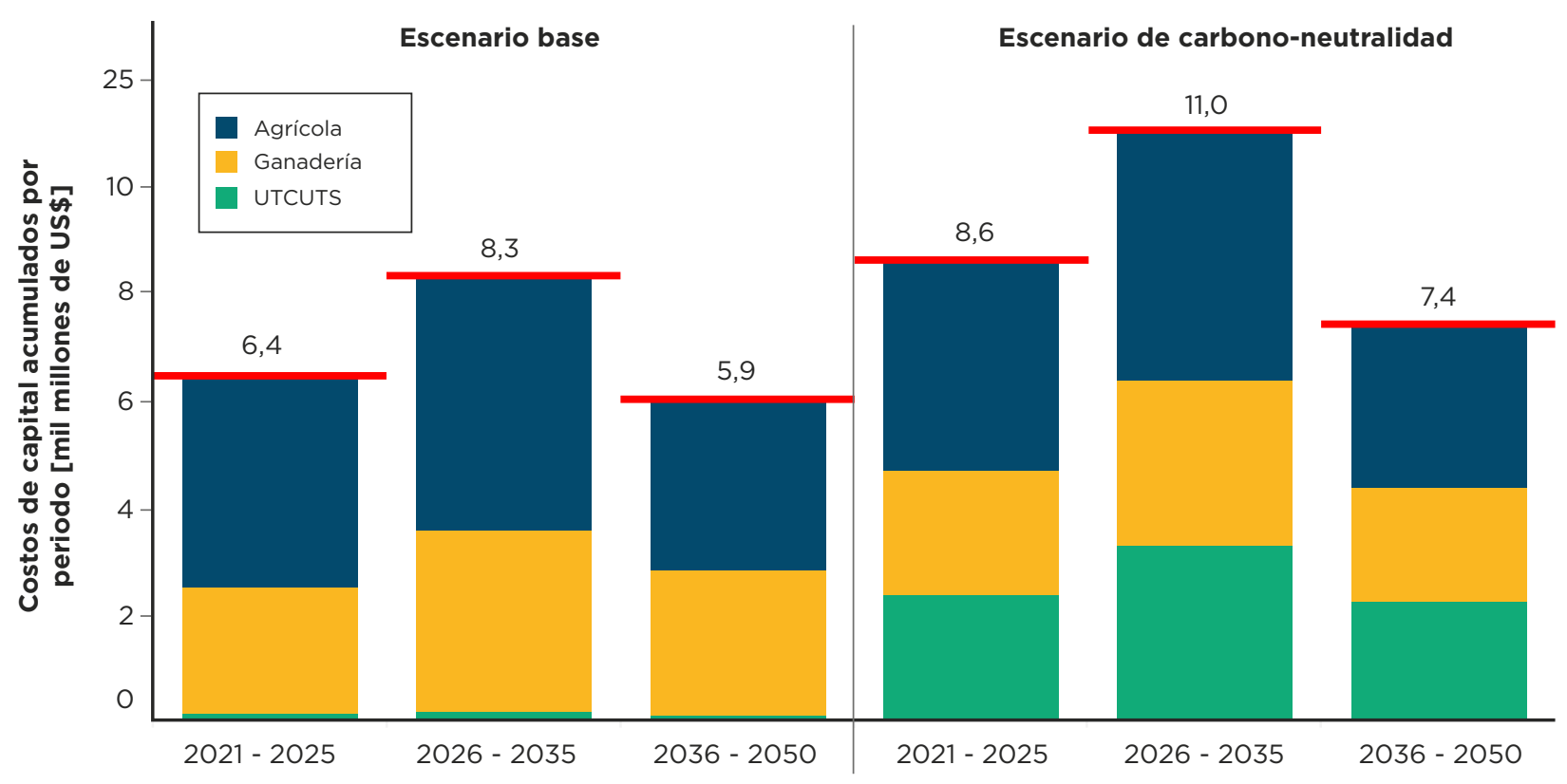

Fuente: Elaboración propia.

El grueso de las nuevas inversiones en UTCUTS, tal como se muestra en el gráfico 2.36, está directamente vinculado a las plantaciones con fines de restauración y con fines comerciales. Estas implican alrededor del $40 \%$ de las inversiones en AFOLU, mientras que las inversiones en agroforestería y la correspondiente plataforma agraria para su apoyo abarcan alrededor del $25 \%$. Los costos de capital requeridos para implementar sistemas agroforestales y silvopastoriles han sido considerados dentro de UTCUTS.

En cuanto al periodo de implementación, las mayores inversiones se deben hacer en el corto y el mediano plazo. Esto es de singular importancia, pues exige que el plazo para identificar las áreas y especies para las plantaciones, tanto con fines de restauración como comerciales, debe ser prioridad. Esto aseguraría que las inversiones de hoy contribuyan de manera eficaz al logro del objetivo de carbono-neutralidad. Por las mismas razones, es necesario crear el entorno habilitante para el desarrollo de esas actividades, tanto por parte del sector público, como del sector privado y de las comunidades nativas. Si se analiza el requerimiento de inversión por periodo, se observa lo siguiente:

$>$ En el corto plazo, la inversión total para implementar las políticas supera los US $\$ 2.000$ millones, que corresponden principalmente al costo de capital de las plantaciones de restauración (US $\$ 1.000$ millones) y al desarrollo de sistemas agroforestales (US $\$ 800$ millones). En menor medida, para la asignación de derechos sobre tierras no categorizadas en 
la Amazonía, se requieren US $\$ 200$ millones y para el desarrollo de plantaciones comerciales, US\$100 millones.

$>$ En el mediano plazo, la inversión total para ejecutar las políticas trasciende los US\$3.000 millones, que corresponden básicamente al costo de capital de las plantaciones de restauración (US $\$ 1.100$ millones), al desarrollo de sistemas agroforestales (US $\$ 1.000$ millones) y a concesiones forestales bajo manejo sostenible (US\$700 millones). En menor medida para la asignación de derechos sobre tierras no categorizadas en la Amazonía, se requieren US $\$ 100$ millones y para el desarrollo de plantaciones comerciales, US\$100 millones.

$>$ En el largo plazo, la inversión total para hacer efectivas las políticas asciende a casi US $\$ 2.000$ millones, que corresponden mayormente al costo de capital de las plantaciones de restauración (US\$600 millones), a concesiones forestales bajo manejo sostenible (US $\$ 800$ millones) y al desarrollo de sistemas agroforestales (US $\$ 600$ millones). En menor medida, para el desarrollo de plantaciones comerciales se requieren US\$100 millones.

\section{Gráfico 2.36}

Inversiones en el subsector UTCUTS en el escenario de carbono-neutralidad

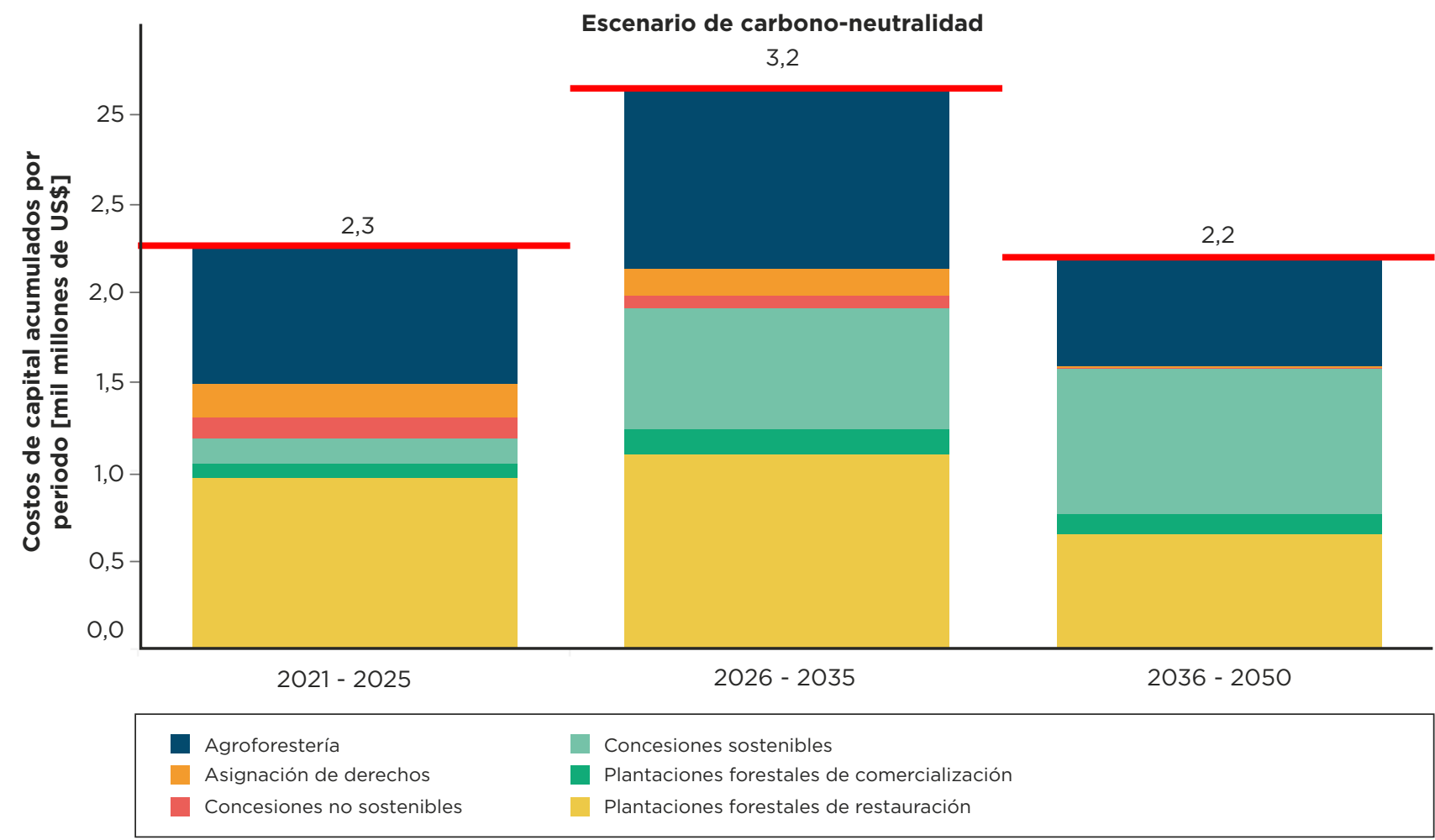

Fuente: Elaboración propia. 
Junto con las inversiones de capital, las intervenciones contenidas en el escenario de carbono-neutralidad requieren cambios en los costos de operación para las actividades del sector AFOLU (gráfico 2.37). Según las intervenciones incluidas, el mayor incremento de los costos de operación tiene lugar en UTCUTS, principalmente como resultado de las actividades de reforestación (restauración y comercial) y por la ampliación de las concesiones forestales maderables. Los costos operativos en las actividades agroforestales y silvopastoriles están considerados dentro de UTCUTS. Se presenta una disminución de los costos operativos en ganadería que corresponden al menor tamaño del inventario vacuno en el escenario de carbono-neutralidad. Por otro lado, no se observa una reducción significativa en los costos de operación agrícola. Los costos operativos aumentan en el tiempo, producto de la implementación paulatina de las intervenciones.

\section{Gráfico 2.37}

Costos operativos y de mantenimiento por subsector en el sector AFOLU en el escenario base versus el escenario de carbono-neutralidad bajo supuestos estándar

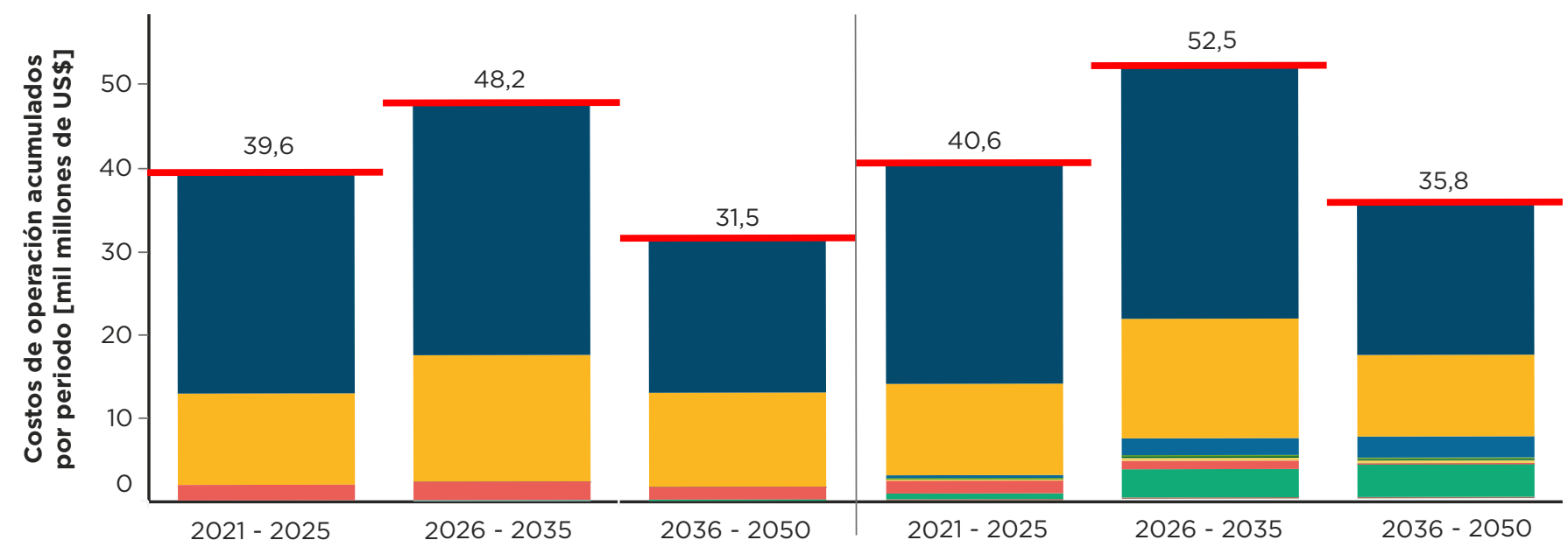

Agrícola

Ganadería

Agroforestería
Comunidades nativas

Plantaciones forestales de comercialización

Plantaciones forestales de restauración
Concesiones no sostenibles

Concesiones sostenibles

Sistemas silvopastoriles

Fuente: Elaboración propia. 


\section{Otros efectos de la carbono-neutralidad}

Un impacto de la implementación de las intervenciones de mitigación es el saldo entre exportaciones e importaciones agrícolas. El gráfico 2.38 indica que la balanza comercial sigue siendo positiva en el tiempo, aunque se ve reducida en US\$2.900 millones. Esta disminución se debe sobre todo al incremento de las importaciones de maíz amarillo duro, resultado de una mayor producción porcina; y aunque se observa un leve incremento en las exportaciones de café, este no contrarresta el crecimiento de las importaciones mencionadas. Cabe tener en cuenta dos aspectos. Las exportaciones están siendo valoradas a precios de producto agrícola y no de producto transformado; y el cambio en materia de comercio exterior es solamente resultado de la introducción de medidas de mitigación de emisiones de GEl. No se han considerado cambios en la apertura comercial peruana ni tampoco la firma de nuevos tratados de libre comercio.
La reducción de la deforestación permite frenar la expansión de la frontera agrícola en la Amazonía $y$, por otro lado, el cambio de preferencias, que implican el pasar del arroz a los tubérculos y leguminosas, tiene un impacto de impulso a la demanda. Ambas intervenciones, una por la reducción de la oferta y la otra por el incremento del consumo, inducen un aumento de los precios de los tubérculos y leguminosas, y en menor medida del maíz amiláceo. Por otra parte, el crecimiento en la participación relativa de la carne de cerdo en la composición del consumo de carnes tiene el efecto contrario en el costo de la dieta alimentaria, ya que el precio de la carne de cerdo es menor que el de la carne vacuna. El efecto agregado de estos impactos, en el escenario de carbono-neutralidad, es un aumento del $20 \%$ en el costo del consumo per cápita de alimentos para 2050 con respecto al escenario base, tal como ilustra el gráfico 2.39 . Cabe resaltar que el consumo per cápita diario se está valorando a precio de producto agrícola y no de producto transformado.

\section{Gráfico 2.38}

Evolución de la balanza comercial de productos agrícolas bajo supuestos estándar

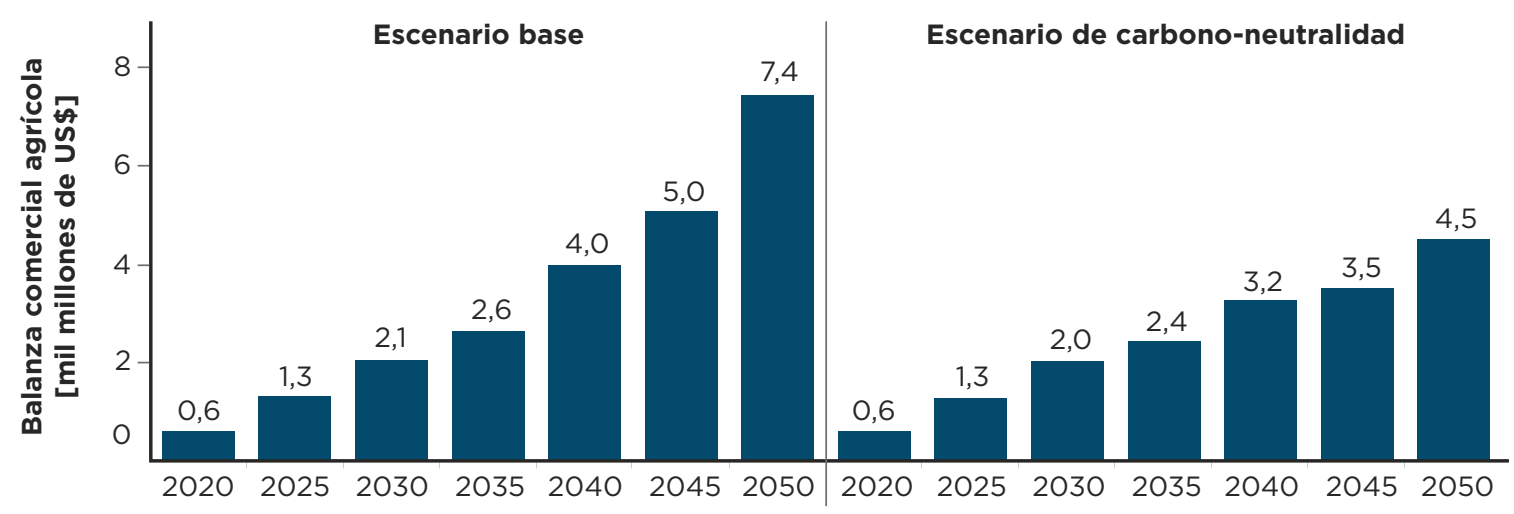




\section{Gráfico 2.39}

Evolución del costo del consumo per cápita diario de productos agropecuarios bajo supuestos estándar

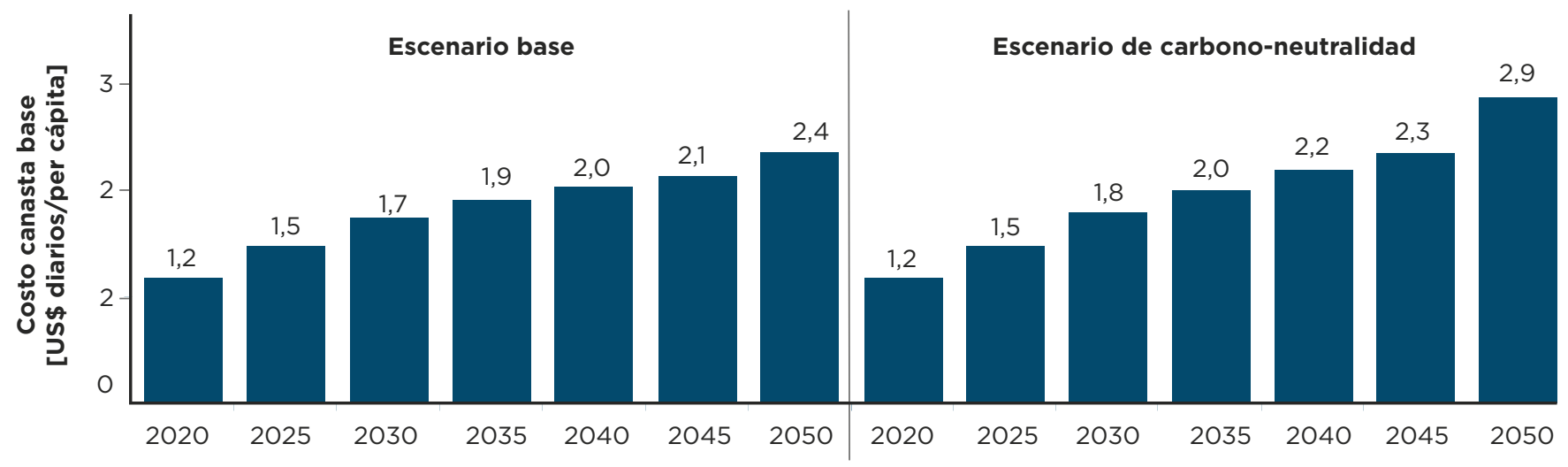

Fuente: Elaboración propia.

El aumento del precio de los productos agrícolas tiene un impacto positivo en el ingreso de los productores agrícolas. En el gráfico 2.40 se puede apreciar que este efecto es más notable en la Sierra Sur, una de las regiones con mayores índices de pobreza del país. En el escenario de carbono- neutralidad esta región recibe US\$17.000 millones de ingreso adicional durante el periodo 2021-50, o un aumento promedio del $7 \%$ anual. Así mismo, el ingreso agrícola también muestra incrementos en las otras regiones del país.

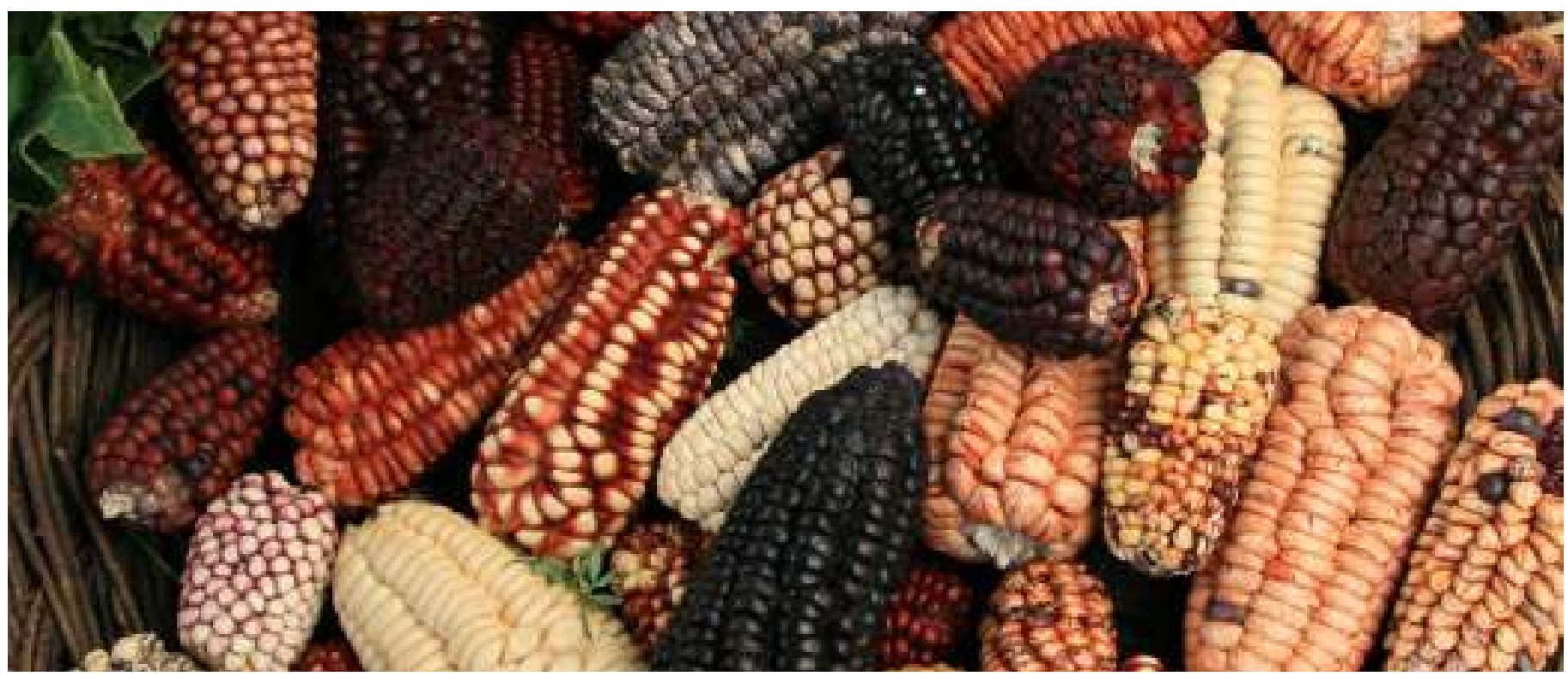




\section{Gráfico 2.40}

Impactos en el ingreso corriente agrícola por región

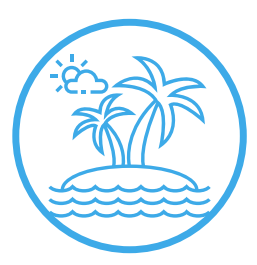

\section{Costa norte} 3,0 MM $1,0 \%$

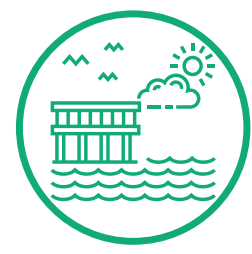

Costa centro $1,8 \mathrm{MM}$

$0,9 \%$

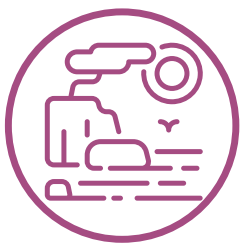

Costa sur

2,8 MM

$4,9 \%$

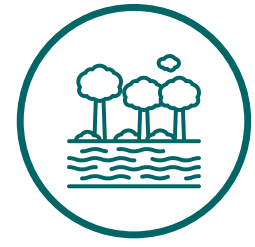

Amazonía

10,5 MM

$3,1 \%$

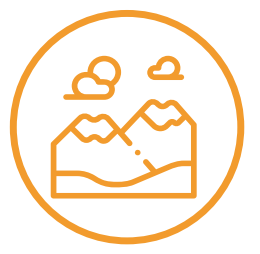

Sierra norte

2,5 MM

$3,6 \%$

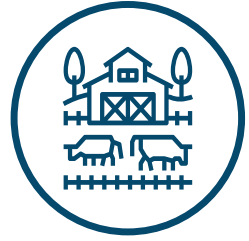

Sierra centro

1,1 MM

$0,9 \%$

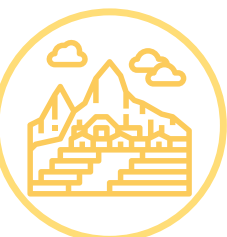

Sierra sur

17,3 MM

$6,9 \%$ 


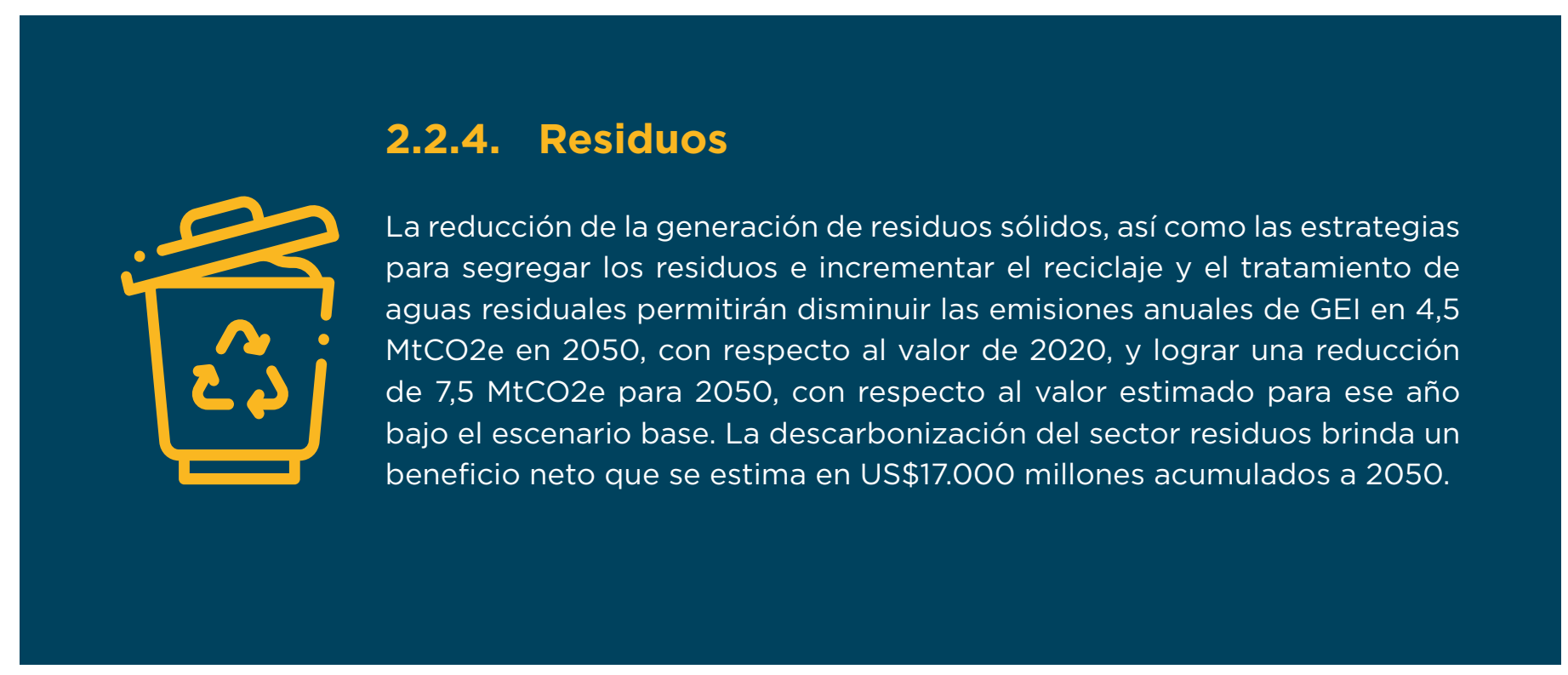

\section{Escenario base}

El escenario base presenta un comportamiento tendencial en cuanto a las emisiones y al nivel de actividad en el sector. Bajo un enfoque pragmático se proyecta el volumen de residuos sólidos y vertidos tomando como referencia los valores publicados en los inventarios nacionales de GEI y usando como variables explicativas el crecimiento poblacional y el PIB. Si bien el enfoque podrá mejorar en siguientes etapas, este análisis constituye un buen punto de partida, brinda una idea del potencial de reducción de emisiones de GEI y cuantifica los beneficios que se pueden percibir de la descarbonización del sector, así como los costos del proceso transformador.

Para la estimación de emisiones por residuos sólidos, se utilizan como referencia las toneladas y los coeficientes de emisión reportados en los inventarios. Como punto de partida se considera que esta cantidad de residuos es dispuesta en rellenos sanitarios y no cuenta con un proceso que permita reducir el nivel de emisiones. En cuanto a las aguas residuales domésticas y municipales, así como aquellas generadas en procesos productivos, se considera una dinámica similar, en la cual existe un punto de referencia basado en la demanda bioquímica de oxígeno (DBO) reportada en los inventarios, que crecerá en el largo plazo en función de la población y el PIB. Las aguas residuales domésticas y municipales son descargadas a los cuerpos de agua superficial o en ríos. De esta manera, la estimación de emisiones se realiza mediante el uso de coeficientes promedio basados en las toneladas de residuos y la DBO, sin considerar la regionalización, los procesos migratorios ni la composición de los residuos. 


\section{Escenario de carbono-neutralidad}

El escenario de carbono-neutralidad considera una reducción del volumen de residuos, asumiendo un cambio cultural y en términos de responsabilidad de la sociedad, en cuyo caso se considera que las buenas prácticas para el manejo de residuos permitirán una disminución de aquellos sólidos. Esto forma parte de un proceso educativo que siempre es transversal a la descarbonización y que se desarrolla desde las primeras etapas de formación. En este contexto, se considera como punto de partida que la generación de residuos sólidos se reducirá en un $25 \%$ para 2050 en relación con los valores proyectados en el escenario base. Se estima que el 50\% de las toneladas generadas restantes se reciclará, lo que implica que solo el $37 \%$ de los residuos proyectados en un escenario base a 2050 será depositados en un relleno sanitario (gráfico 2.41).

\section{Gráfico 2.41}

Evolución de la cantidad de residuos sólidos y de la distribución entre material reciclado y depositado en rellenos en el escenario base versus el de carbono-neutralidad bajo supuestos estándar

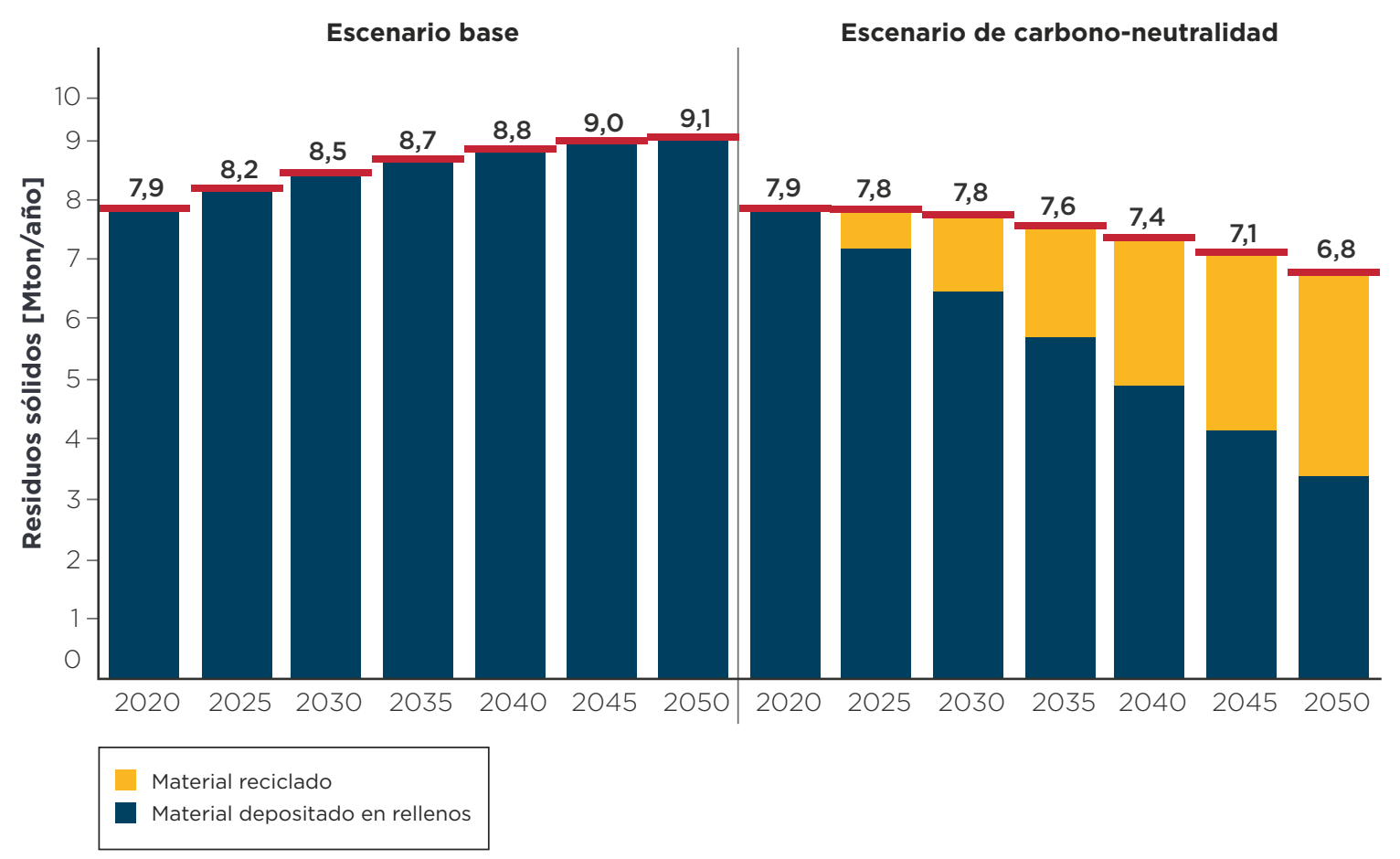

Fuente: Elaboración propia. 
El escenario de carbono-neutralidad contempla un aumento de las aguas residuales tratadas (gráfico 2.42). Aunque estas se incrementan en la misma proporción en ambos escenarios, producto del crecimiento poblacional, se asume que las políticas públicas de saneamiento lograrán que para 2050 un $50 \%$ de las aguas residuales sea tratado mediante plantas de tratamiento. Sin embargo, aún no se contemplan la gama tecnológica, los costos de operación asociados al proceso, ni una diferenciación entre aguas residuales urbanas y rurales. Se asumen una escala nacional y coeficientes de emisión y costos por nivel de actividad, basados en los inventarios. Se reconoce que las áreas rurales o urbanas que no cuentan con redes de captación de aguas residuales o se encuentran en zonas alejadas presentan un desafío adicional para reducir sus aguas residuales.

\section{Gráfico 2.42}

Evolución de la demanda bioquímica de oxígeno en aguas residuales y distribución entre aguas tratadas y sin tratar en el escenario base versus el de carbono-neutralidad bajo supuestos estándar

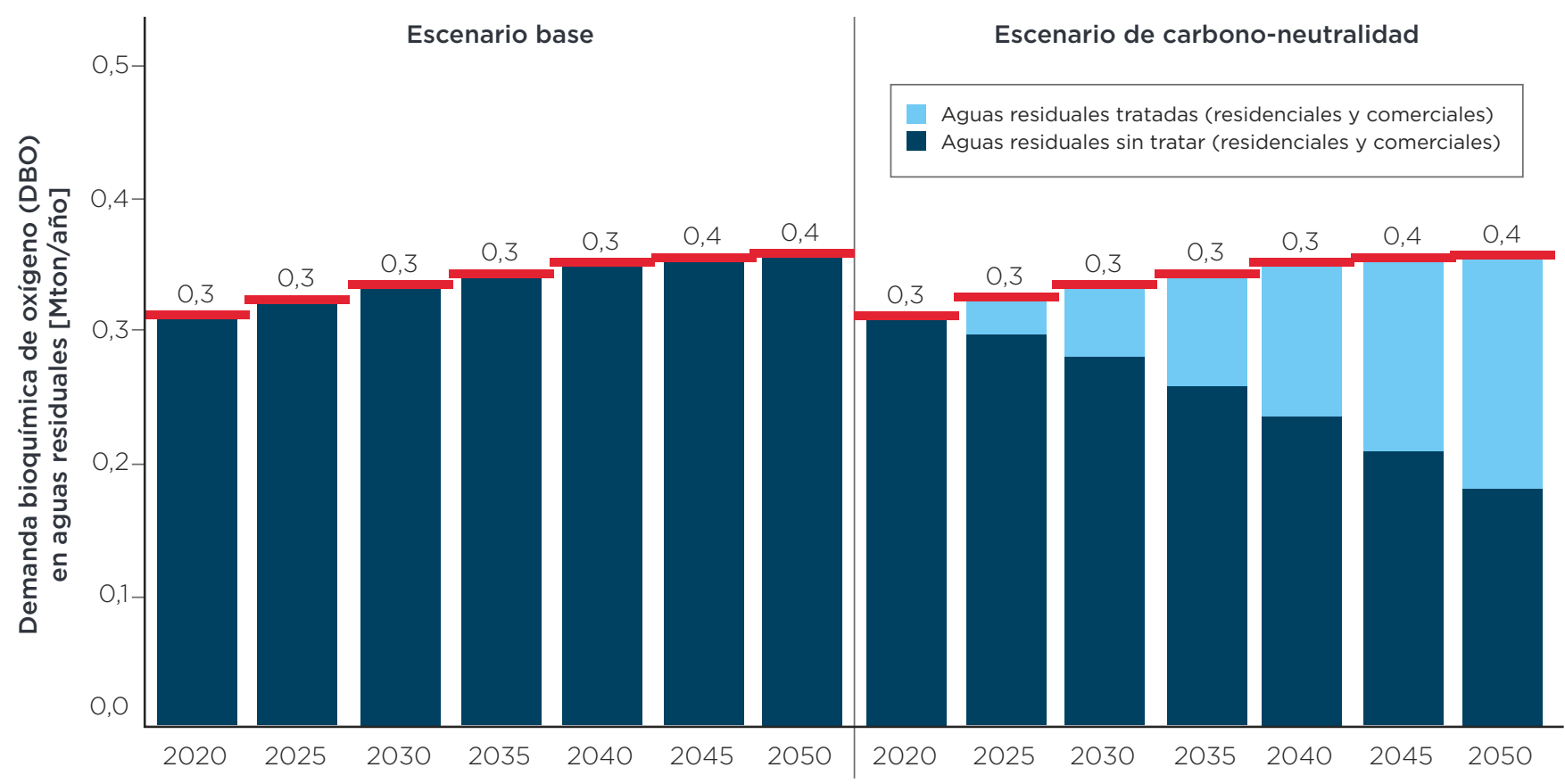


El escenario de carbono-neutralidad considera un aumento de la cantidad de efluentes industriales tratados (gráfico 2.43). En este caso, también se sigue aquí la lógica planteada en el caso anterior, en la cual se asume un incremento lineal para el tratamiento de efluentes: un $15 \%$ en el corto plazo, un $25 \%$ en el mediano plazo y un $50 \%$ al largo plazo. De esta manera, para 2050 un despliegue importante de sistemas de tratamiento permitirá reducir a la mitad la cantidad de efluentes sin tratamiento. Estas metas también serán objeto de experimentación en las siguientes etapas del proyecto.

\section{Gráfico 2.43}

Evolución de la demanda bioquímica de oxígeno en efluentes industriales y distribución entre efluentes tratados y sin tratar en el escenario base versus el de carbono-neutralidad bajo supuestos estándar

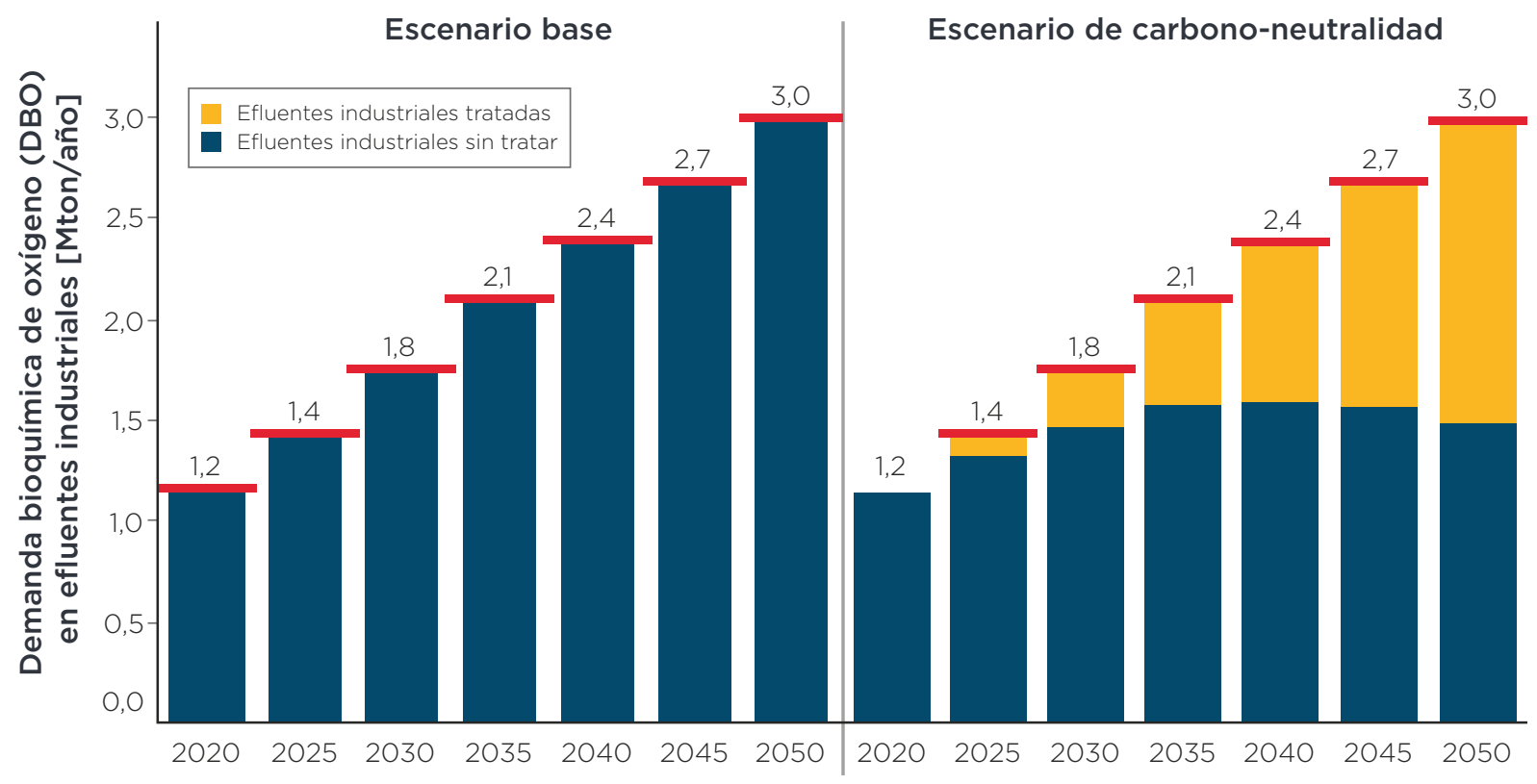




\section{Emisiones}

La segregación de residuos, el aumento del reciclaje, y el tratamiento de aguas residuales y efluentes industriales permitirá reducir las emisiones de GEl del sector residuos (gráfico 2.44). Así, para 2050 el escenario de carbononeutralidad proyecta emisiones anuales de GEI de menos de $6 \mathrm{MtCO}_{2 e}$, comparadas con poco más de $13 \mathrm{MtCO} 2 \mathrm{e}$ en el escenario base para ese mismo año. Esto implica una reducción de 7,5 MtCO2e a mitad de siglo y de 4,5 MtCO2e con respecto a los valores estimados para 2020.

\section{Gráfico 2.44}

Emisiones anuales del sector residuos en el escenario base versus el escenario de carbono-neutralidad bajo supuestos estándar

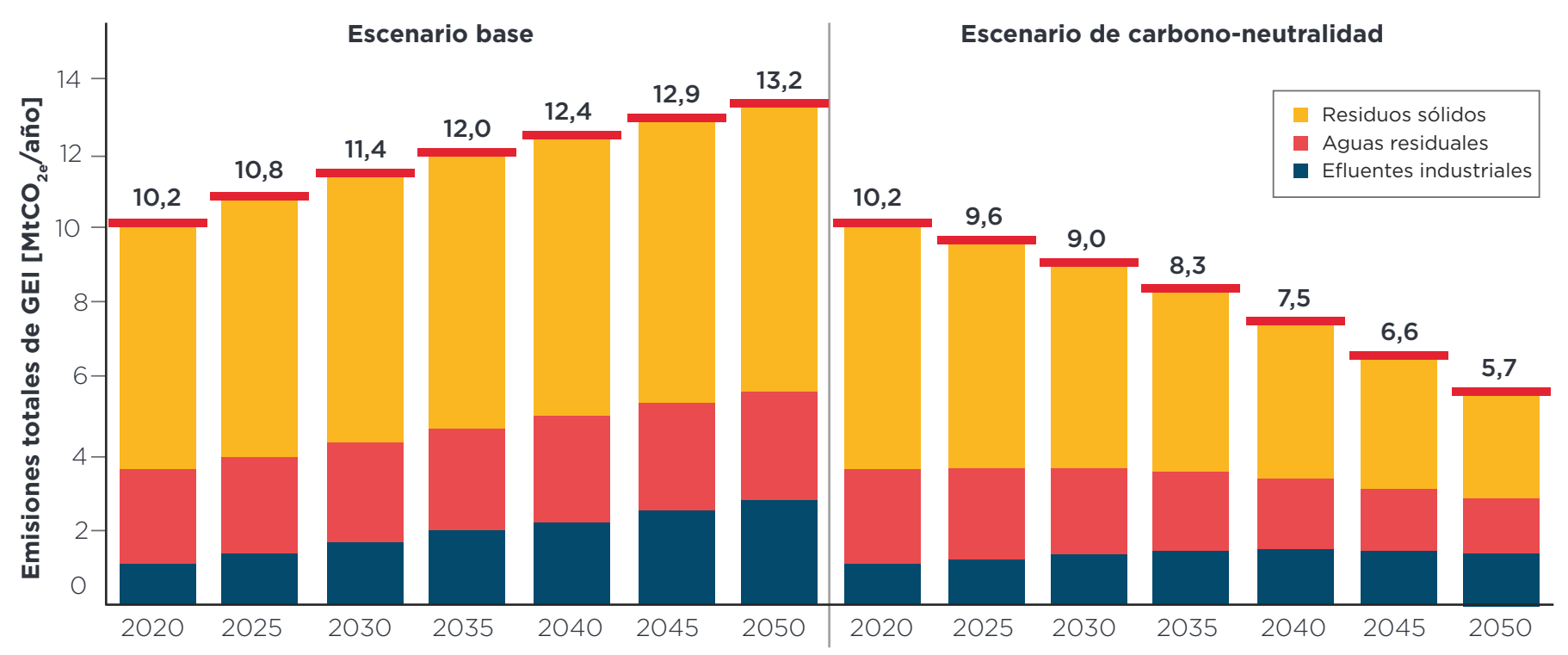

Fuente: Elaboración propia.

\section{Beneficios y costos}

La descarbonización del sector residuos brinda beneficios netos de US $\$ 17.000$ millones, los cuales resultan de casi US $\$ 30.000$ millones de beneficios totales y aproximadamente US\$13.000 millones en inversiones (gráfico 2.45). En detalle: 
$>$ En el corto plazo, se incurre en inversiones de capital de casi US\$1.000 millones que se ven compensadas por los beneficios por reciclaje (de unos US $\$ 1.000$ millones), agua recuperada (más de US\$1.000 millones) y las ganancias en salud derivadas del tratamiento de residuos (US $\$ 500$ millones), con todo lo cual en este periodo se obtiene un beneficio neto de alrededor de US $\$ 2.000$ millones.

$>$ El beneficio neto en el mediano plazo se estima en US $\$ 7.000$ millones. Las inversiones para reciclar y tratar aguas residuales aumentan a unos US $\$ 5.000$ millones, y se compensan con los casi US $\$ 12.000$ millones de beneficios percibidos, entre los que se incluyen: beneficios provenientes del reciclaje (de casi US $\$ 4.000$ millones), beneficios del agua recuperada (casi US\$6.000 millones) y ganancias en salud por el tratamiento de residuos (alrededor de US\$2.000 millones).

$>$ La tendencia se mantiene en el largo plazo y el beneficio neto se estima en poco más de US\$8.000 millones, como resultado de una inversión adicional de alrededor de US\$8.000 millones, y con beneficios estimados en casi US $\$ 16.000$ millones.

\section{Gráfico 2.45}

Beneficio neto del escenario de carbono-neutralidad versus el escenario base en el sector residuos bajo supuestos estándar

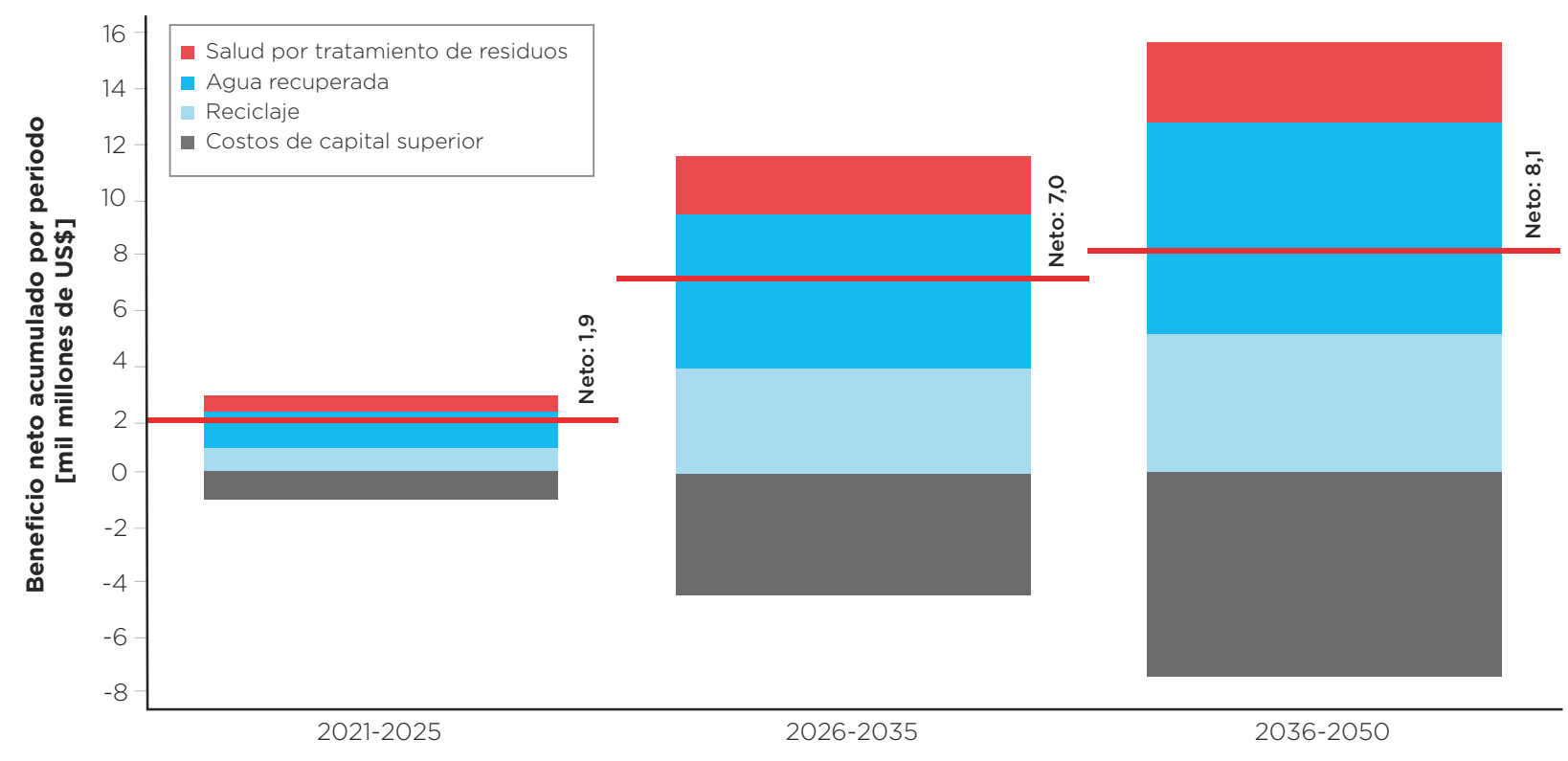

Fuente: Elaboración propia.

Nota: Por falta de información, el análisis de beneficios y costos del sector residuos no considera los costos de operación. 
Por falta de información, el análisis de beneficios y costos del sector residuos no considera los costos de operación. Sin embargo, sí se han estimado las inversiones.

Lograr la carbono-neutralidad requiere una inversióntotalacumuladaa2050 decasiUS $\$ 20.000$ millones (gráfico 2.46). Las inversiones en capital en el escenario base se estiman en poco más de US\$7.000 millones; o sea, la descarbonización del sector residuos requiere una inversión adicional de alrededor de US\$13.000 millones acumulados para 2050.

$>$ En el corto plazo, las inversiones adicionales (casi US\$1.000 millones) ocurren por la construcción de plantas de tratamiento de aguas residuales y efluentes industriales y el aumento del reciclaje. Producto de la reducción de los residuos, en este periodo las inversiones en recolección bajan US\$100 millones.

$>$ En el mediano plazo, estas inversiones suben a casi US $\$ 5.000$ millones con respecto al escenario base en el mismo periodo, producto del aumento de la cantidad de plantas de tratamiento y de un mayor reciclaje. Las inversiones en recolección se reducen en US\$200 millones.

$>$ En el largo plazo, las inversiones adicionales suben a poco más de US\$7.000 millones como resultado de un mayor despliegue de plantas de tratamiento de efluentes industriales y de costos para reciclar. Las inversiones en recolección se reducen en este periodo en US\$400 millones.

\section{Gráfico 2.46}

Inversiones en el sector residuos en el escenario base versus el escenario de carbono-neutralidad

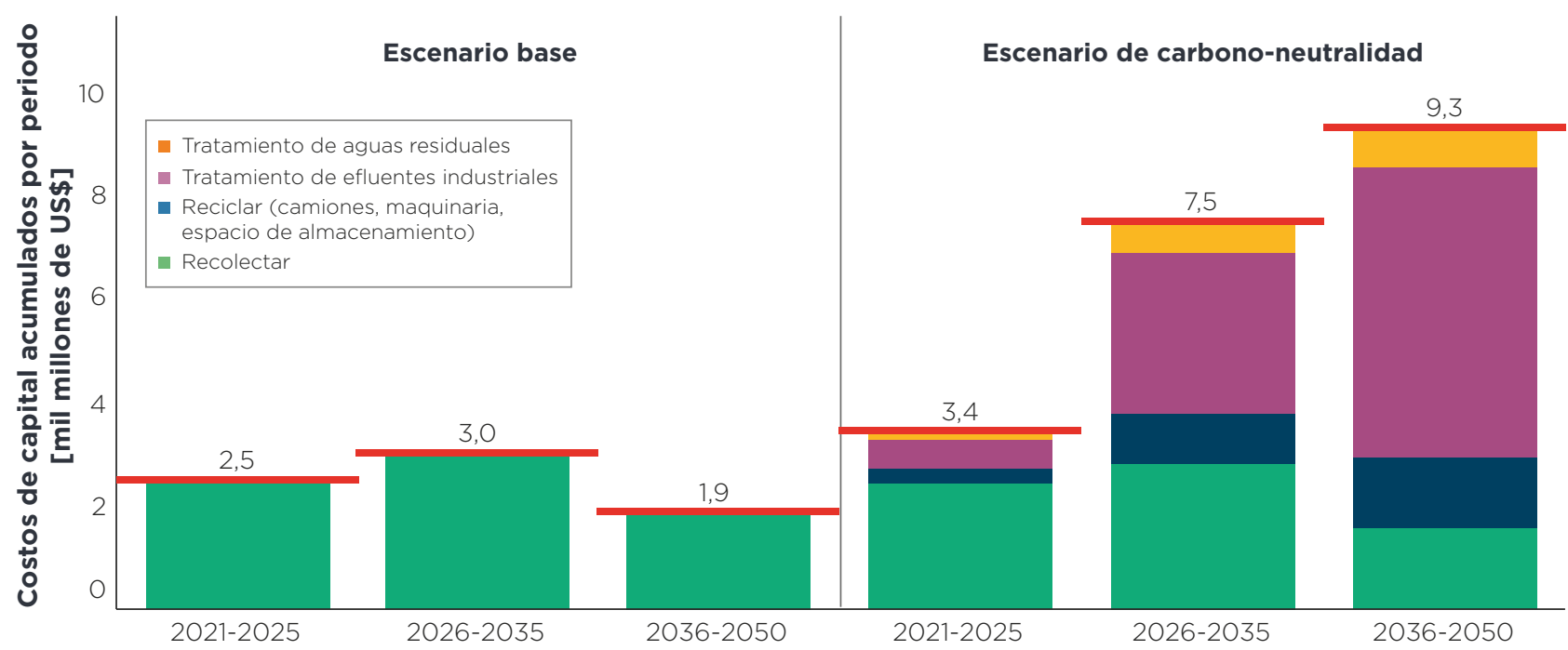

Fuente: Elaboración propia. 


\subsubsection{Procesos industriales y uso de productos (PIUP)}

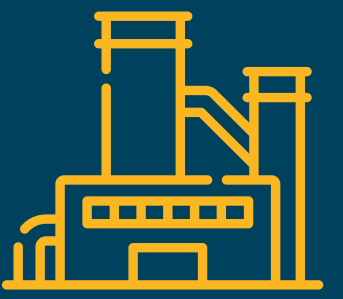

Este sector ha sido modelado de forma muy simple con el fin de tener un punto de partida. Su estudio se basa en el análisis de trayectorias de emisiones mediante proyecciones de datos históricos y acciones de políticas más específicas para la producción de cemento, usando la metodología del Grupo Intergubernamental de Expertos sobre el Cambio Climático (IPCC, por sus siglas en inglés), con Nivel 2. Se reconoce que el enfoque actual presentado en este informe es limitado y deberá ser actualizado con información de la hoja de ruta. No obstante, sobre la base de esta primera aproximación, se determinó que las acciones en la producción de clínker brindarán una reducción de poco más de $1 \mathrm{MtCO} 2 \mathrm{e}$ con respecto al valor del escenario base para 2050. Aunque existen múltiples beneficios del proceso de transformación del sector (por ejemplo, la calidad de las carreteras y la mejora de la capacidad de frenado de los vehículos), este estudio no ha contemplado este potencial y busca en su lugar comprender, además de la reducción de emisiones posibles, las inversiones necesarias para reducir el uso de clínker en la producción de cemento. Este estudio ha encontrado que esta transformación requiere de un costo modesto de US\$750 millones acumulados para 2050.

\section{Escenario base}

El análisis de este sector se ha enfocado principalmente en la producción de cemento, proceso de la industria de minerales que predomina notablemente en la generación de emisiones del sector, ya que aporta un $75 \%$ de las emisiones de GEI. Se estableció una proyección de producción de cemento basada en datos internacionales y en los últimos registros de Perú (FICEM, 2016; AIE, 2018). Debido al crecimiento poblacional y económico, que aumenta la cantidad de cemento en las edificaciones, la demanda de clínker pasaría de 9,6 Mton en 2020 a 10,9 Mton en 2050 (gráfico 2.47).

\section{Escenario de carbono-neutralidad}

En el escenario de carbono-neutralidad se toman como base consideraciones vinculadas a la hoja de ruta en que la Asociación de Productores de Cemento (ASOCEM) y la Federación Internacional de Cemento (FICEM) están trabajando desde 2017 y se observa una reducción del factor clínker. Dicho factor es la razón entre la cantidad total de clínker consumido al año para producir cemento y la cantidad total de cemento producido al año. Bajo estas premisas, se estima que el factor clínker se reduce en el tiempo y pasa de 0,77 en 2020 a 0,6 en 2050; esto a partir de valores latinoamericanos 
y de las metas que se establecen en la hoja de ruta tecnológica de la transición hacia la industria cementera baja en emisiones (AIE, 2018). El sector reconoce que lograr esa reducción depende de la aceptación de cemento adicionado por parte de los consumidores. Esta acción conlleva a que el consumo de clínker para 2050 disminuya a 8,7 Mton, lo que implica 2,2 Mton menos con respecto al valor proyectado para 2050 en el escenario base. Además, se notó que el valor considerado a 2050 podría estar cerca del límite de sustitución, el cual no puede ser superado, ya que se podría comprometer la calidad del cemento.
Como resultado de los talleres consultivos, se concluyó que la industria cementera de Perú contempla una estructura administrativa altamente activa en cuanto a la descarbonización (FICEM, 2016) y que está estructurando una hoja de ruta hacia tal finalidad a partir de las mejores prácticas basadas en las recomendaciones de la Agencia Internacional de Energía (AIE) (AIE, 2018). Esto incluye: i) eficiencia energética y térmica; ii) uso de combustibles alternativos; iii) sustitución del clínker; iv) captura y uso de $\mathrm{CO} 2$, y v) materiales aglomerantes alternativos. Sobre la base de la información disponible para realizar el estudio, se han considerado las acciones vinculadas a la reducción del clínker. Este enfoque podrá ser retomado en las siguientes etapas del proyecto.

\section{Gráfico 2.47}

Demanda de clínker para la producción de cemento en el escenario base versus el escenario de carbono-neutralidad bajo supuestos estándar

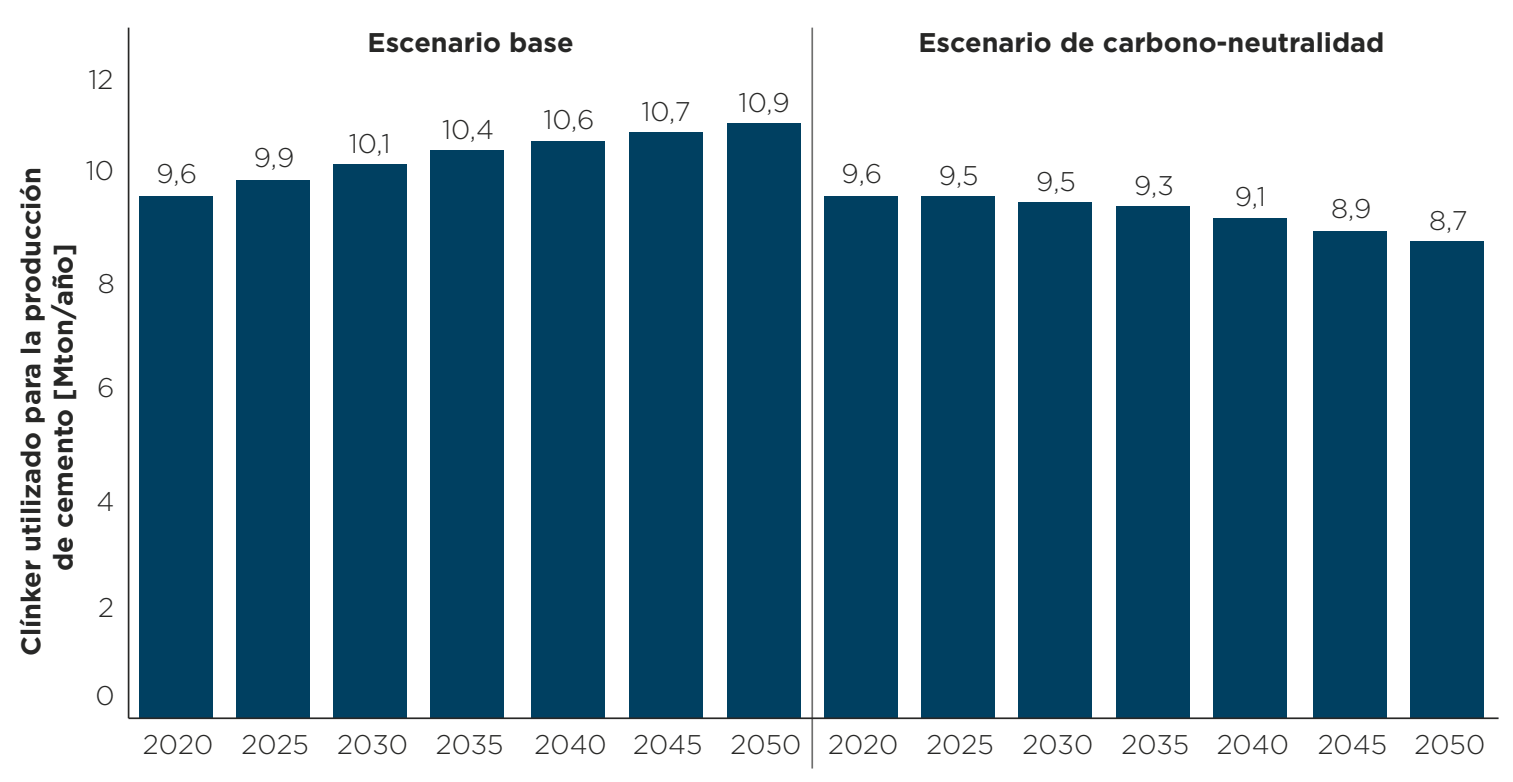

Fuente: Elaboración propia. 


\section{Emisiones}

La reducción del factor clínker logra una disminución de las emisiones anuales de GEI (gráfico 2.48). En el escenario base, y bajo supuestos estándar, las emisiones anuales de GEI del sector pasan de 6,3 MtCO2e en 2020 a 8,8 $\mathrm{MtCO} 2 \mathrm{e}$. Aunque no se consideran acciones en otros subsectores (metales y químicos), la acción en la producción del cemento logra una reducción de poco más de 1 MtCO2e en 2050 con respecto al valor del escenario base en ese mismo año.

\section{Beneficios y costos}

Por la falta de información del sector, este estudio no ha incluido beneficios de la descarbonización. Por la misma razón, no ha incluido costos operativos. En cuanto a los costos de capital, se ha incluido el de disminuir el factor clínker. Las estimaciones muestran que los costos de reducir el clínker aumentan en el tiempo (gráfico 2.49). En total, se ha estimado que el sector PIUP tendría un costo modesto de aproximadamente US\$750 millones acumulado a 2050 desglosados en el tiempo de la siguiente manera:

$>$ En el corto plazo, se requieren inversiones adicionales estimadas en US\$70 millones.

$>$ En el mediano plazo, las inversiones aumentan US\$290 millones.

$>$ En el largo plazo, las inversiones suben a US\$392 millones.

No obstante, se debe reconocer que este estudio ha dejado por fuera varios beneficios adicionales que este sector podría percibir; por ejemplo, el aumento de la capacidad de adhesión del cemento en las carreteras.

\section{Gráfico 2.48}

Emisiones anuales del sector PIUP en el escenario base versus el escenario de carbono-neutralidad bajo supuestos estándar

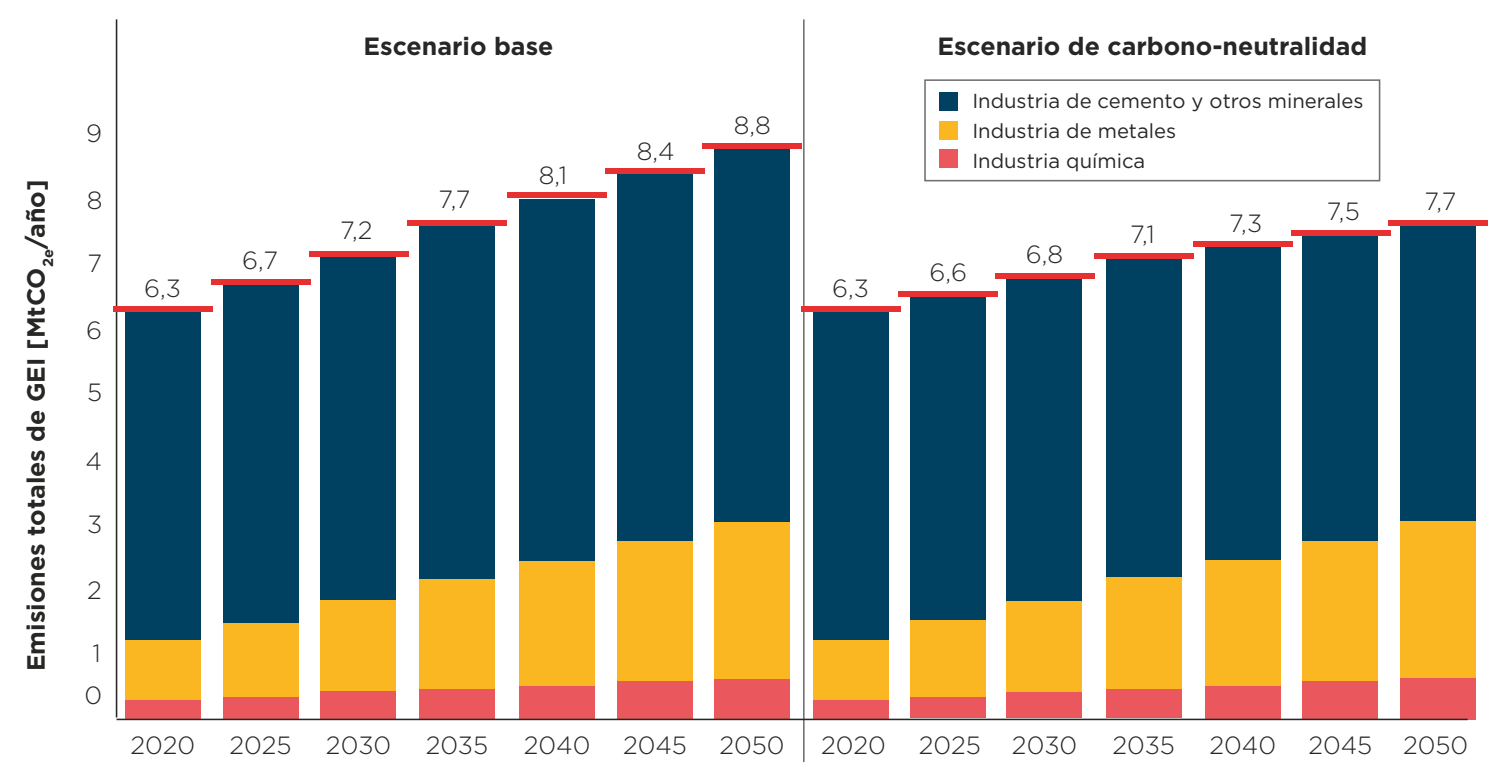




\section{Gráfico 2.49}

Beneficio neto del escenario de carbono-neutralidad versus el escenario base en el sector PIUP bajo supuestos estándar

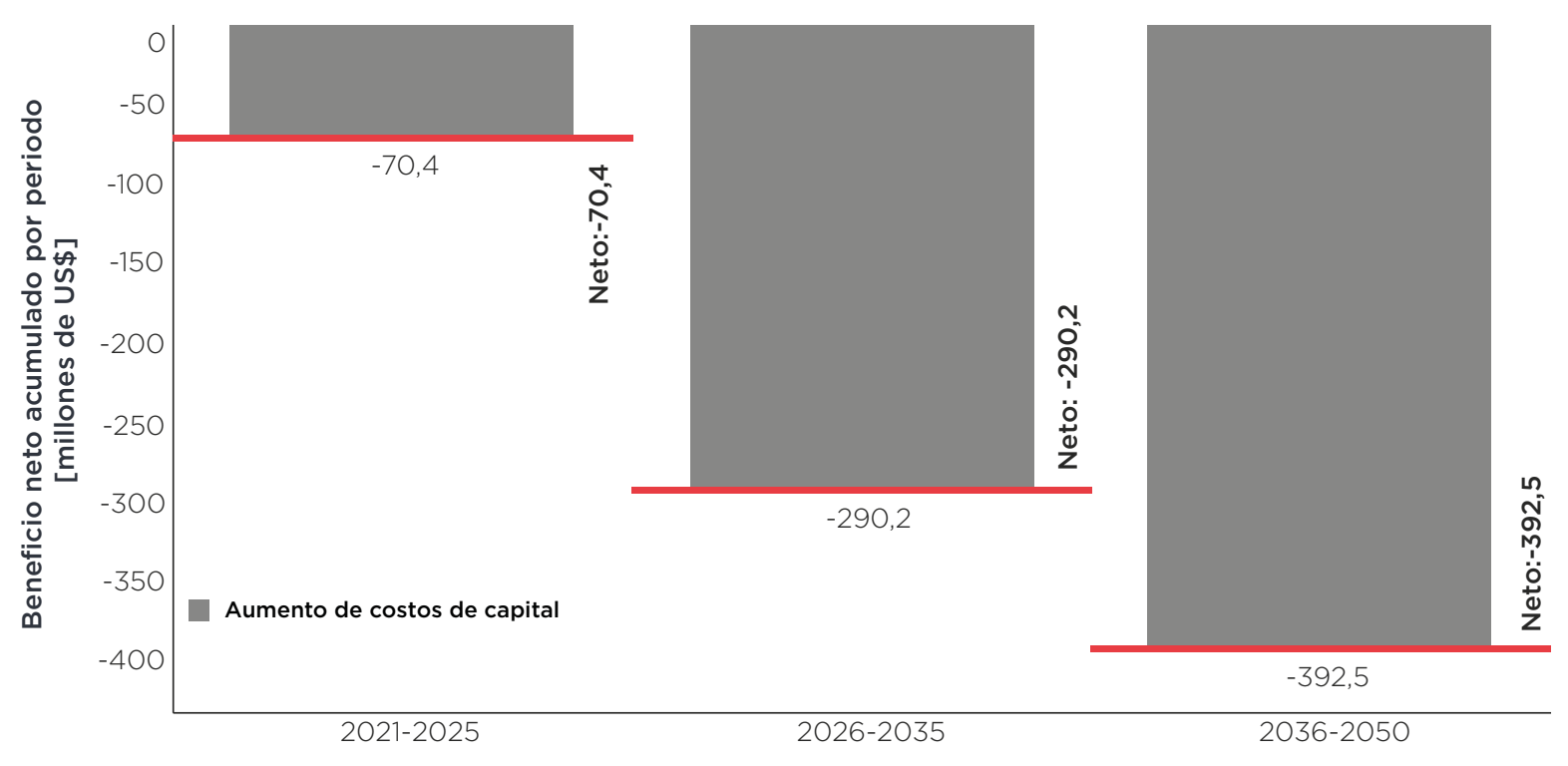

Fuente: Elaboración propia.

Nota: Por falta de información, el análisis de beneficios y costos del sector PIUP no considera los costos de operación ni beneficios potenciales de la descarbonización del sector. 
6.2.

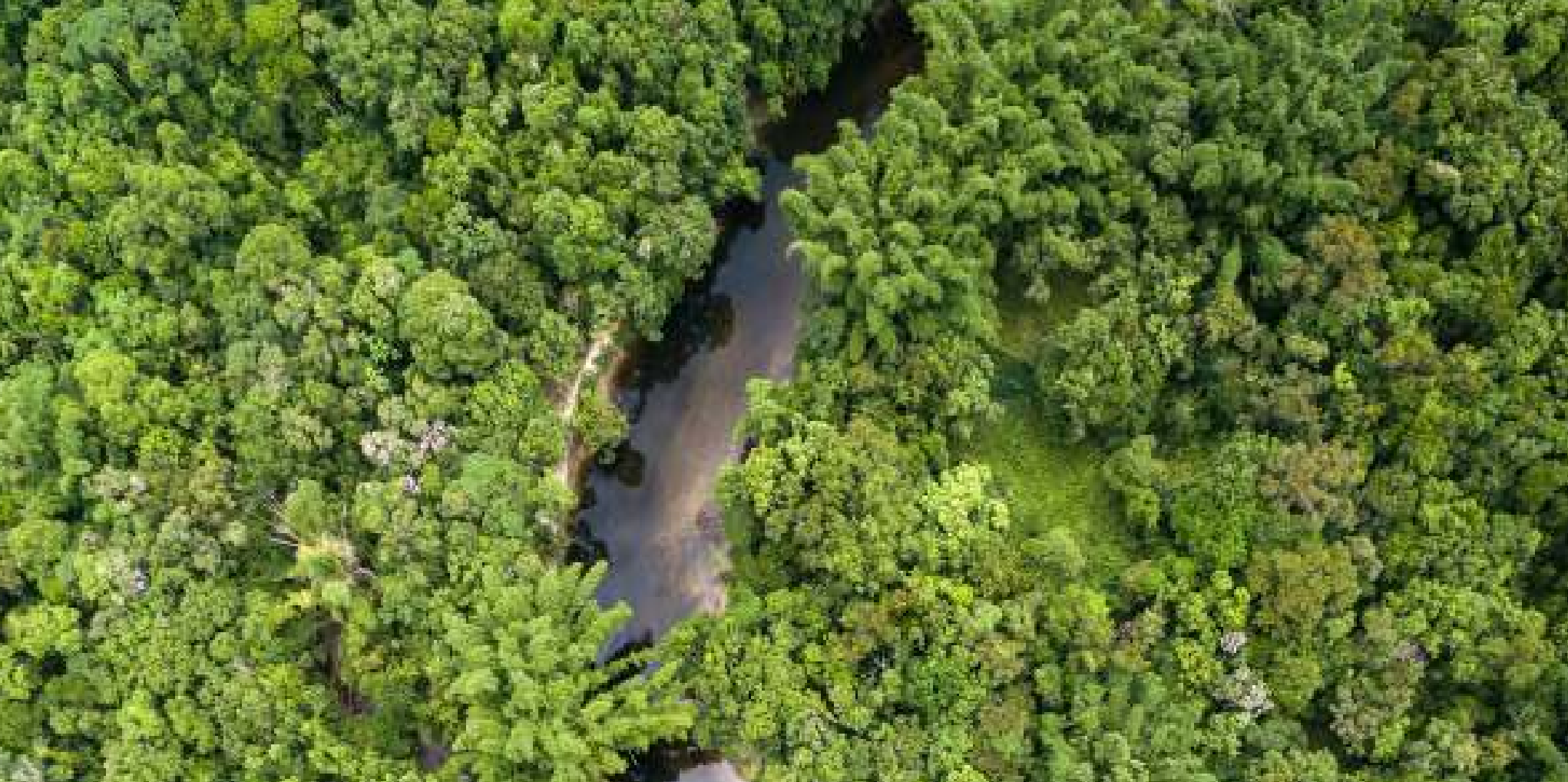

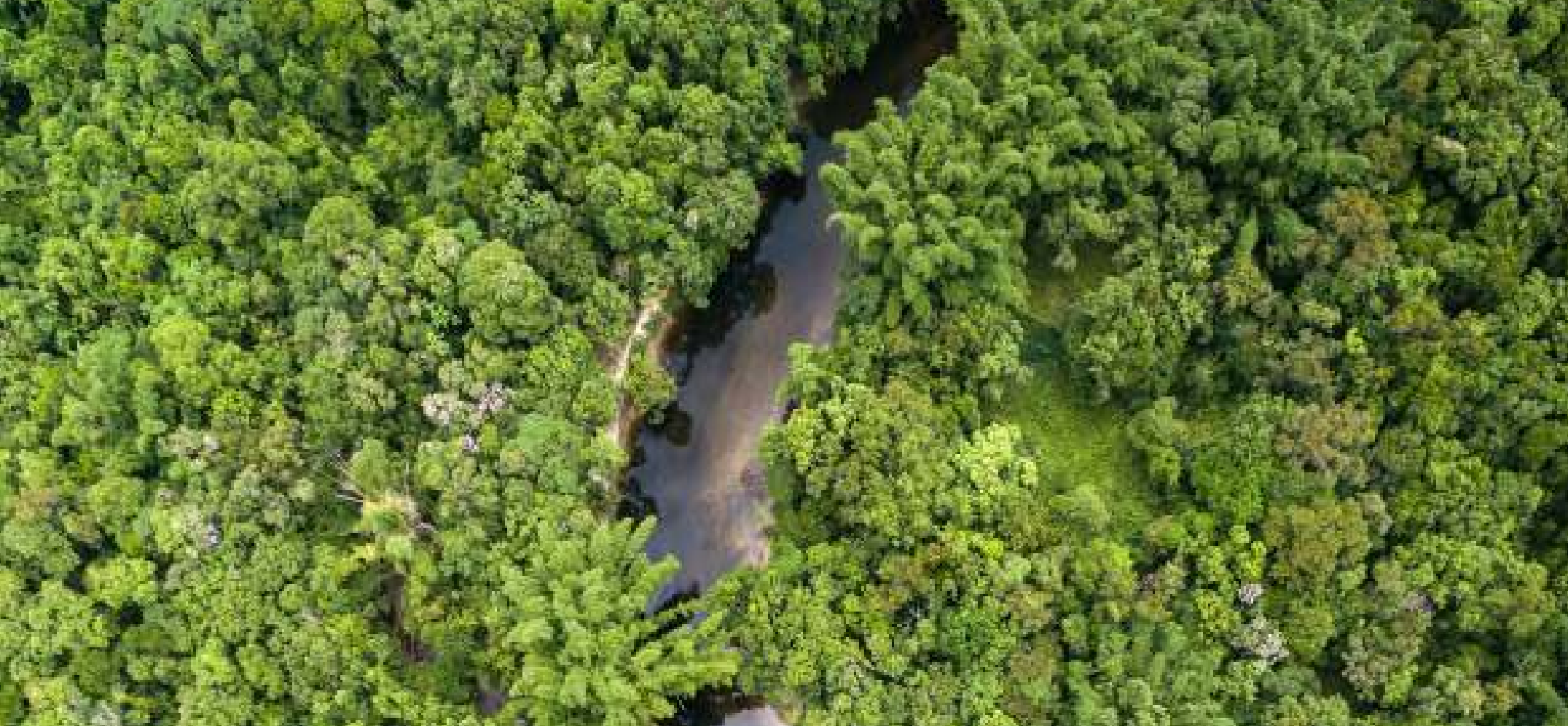

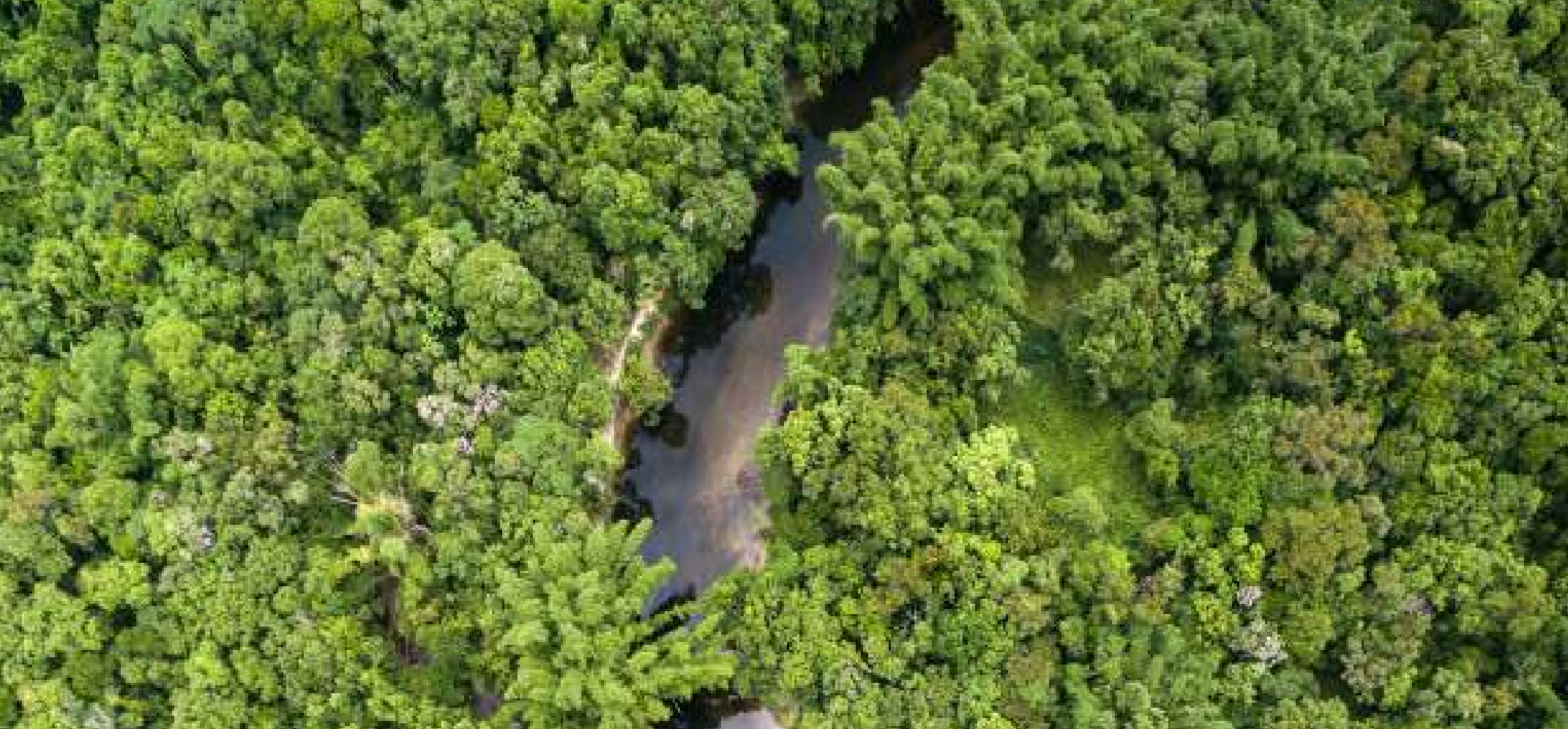

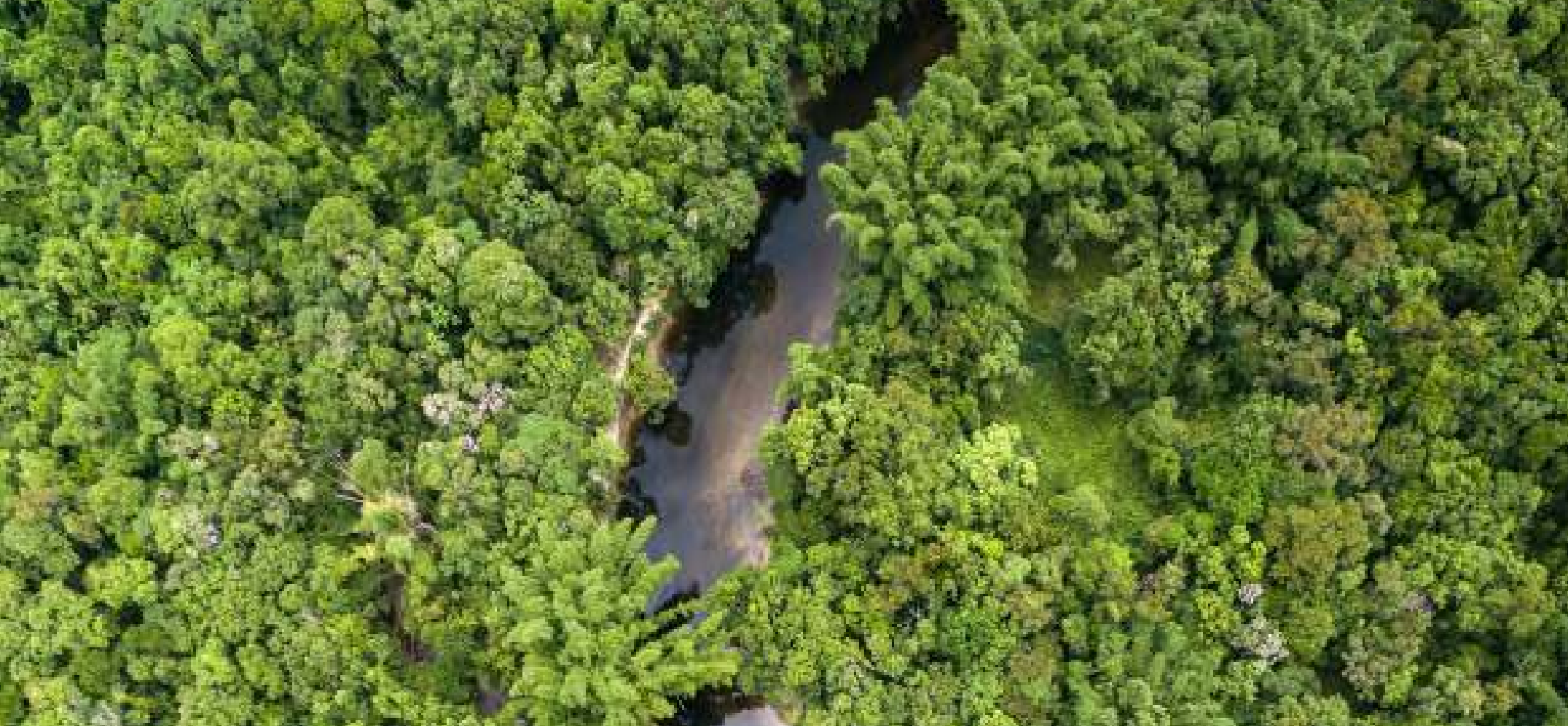

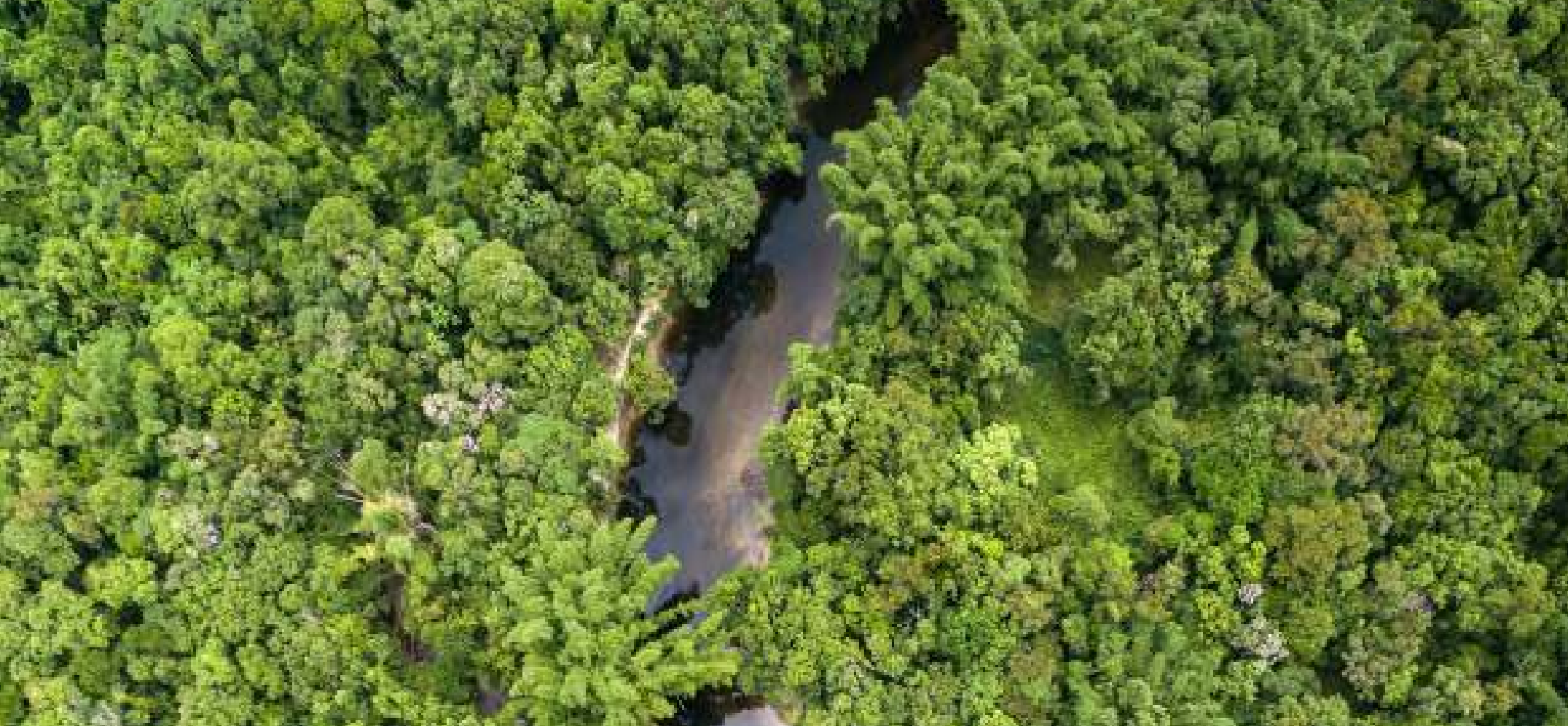

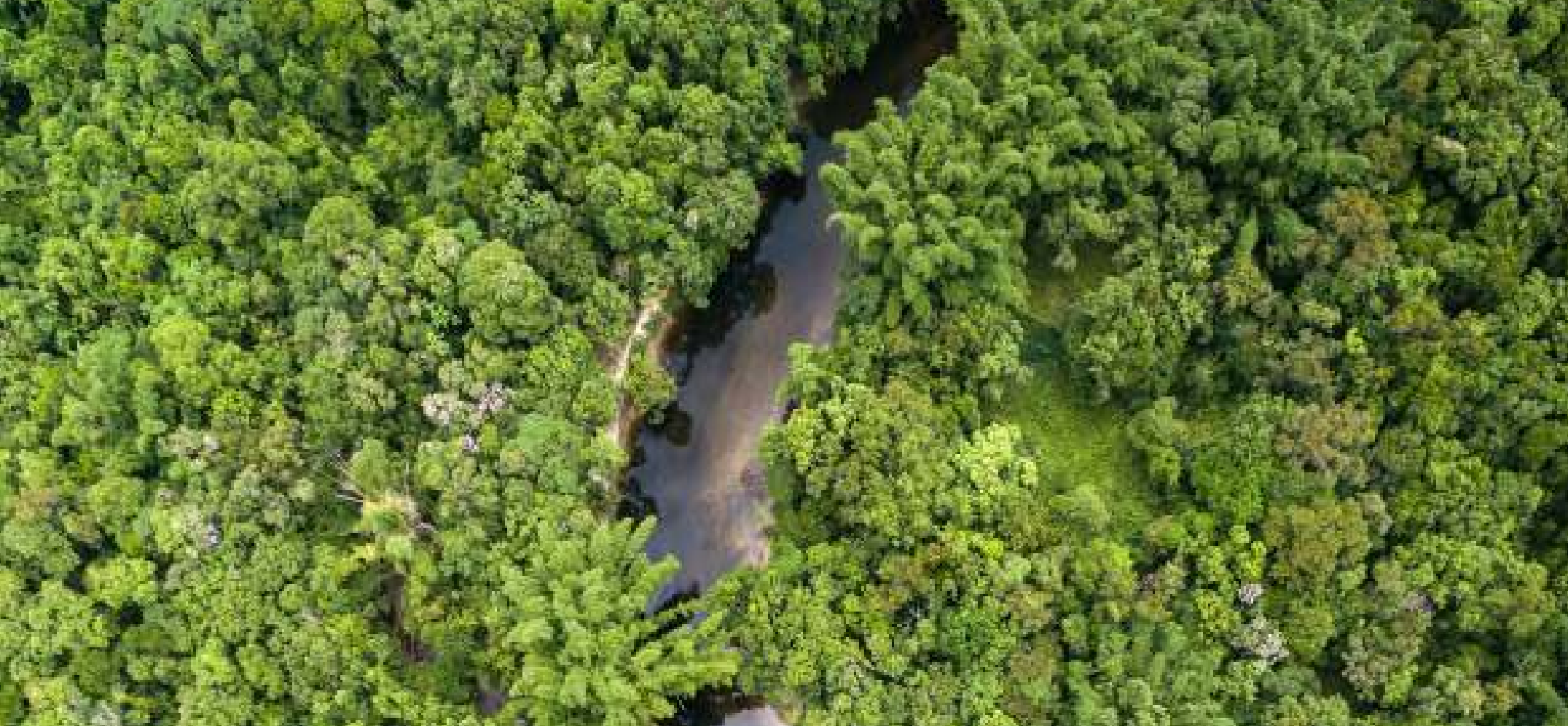

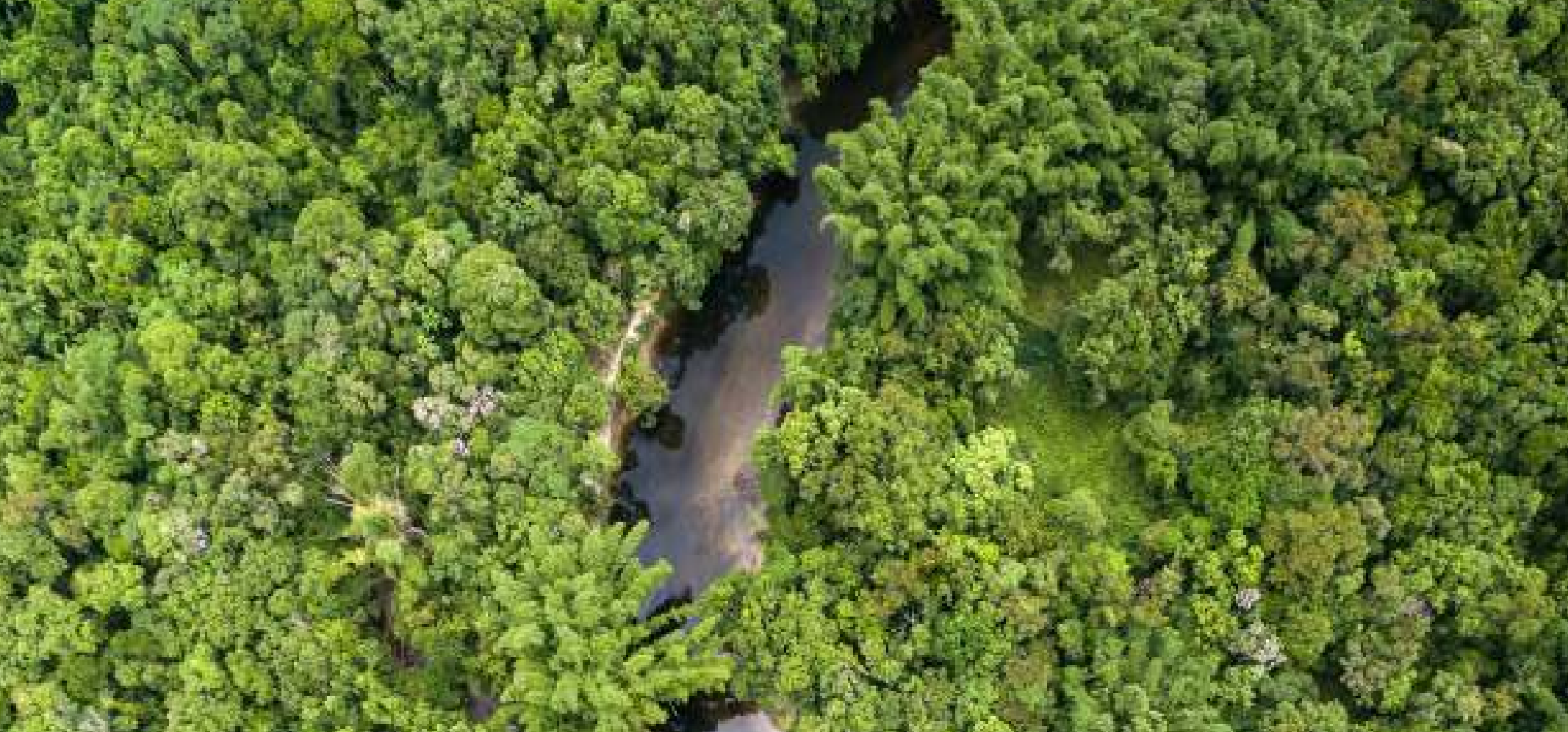

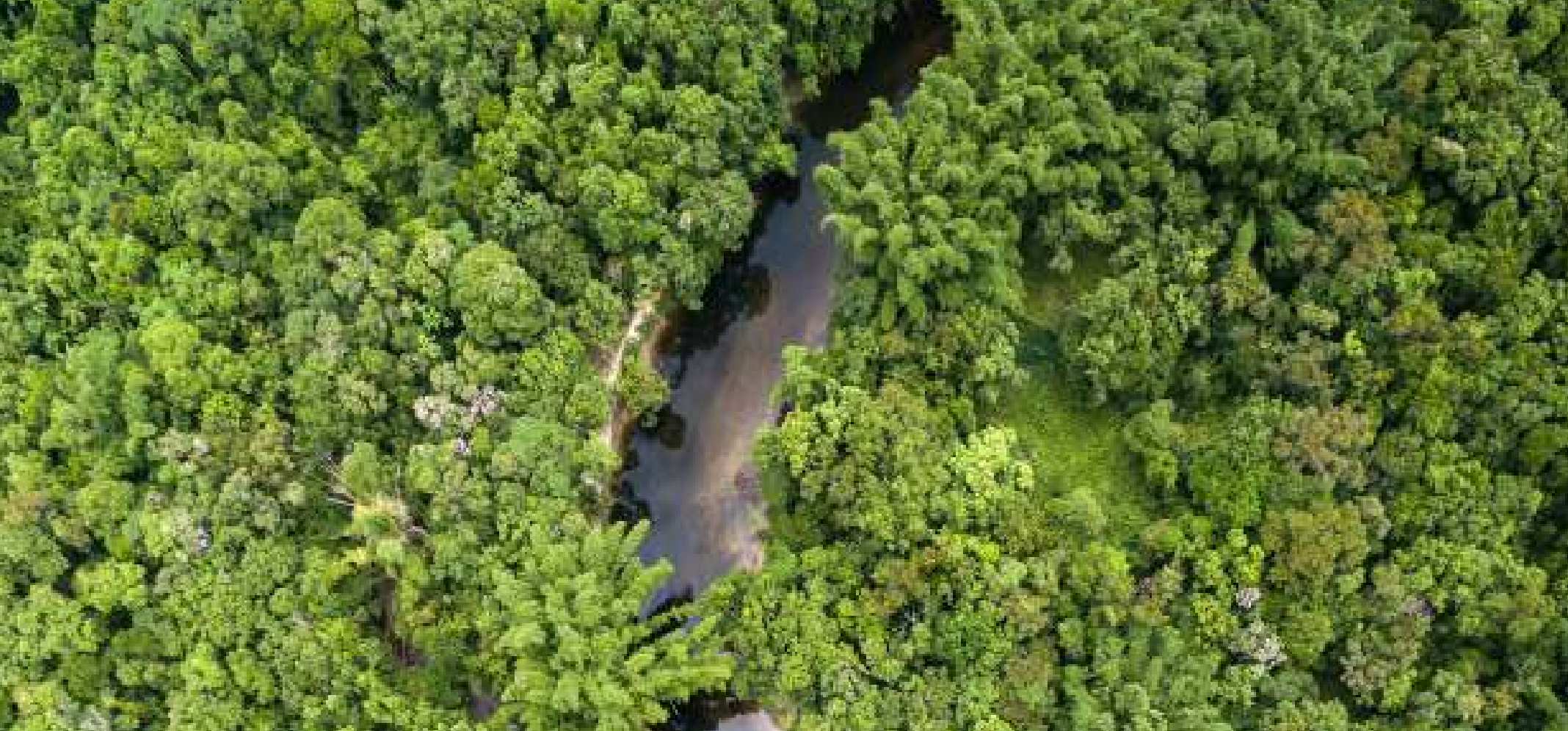

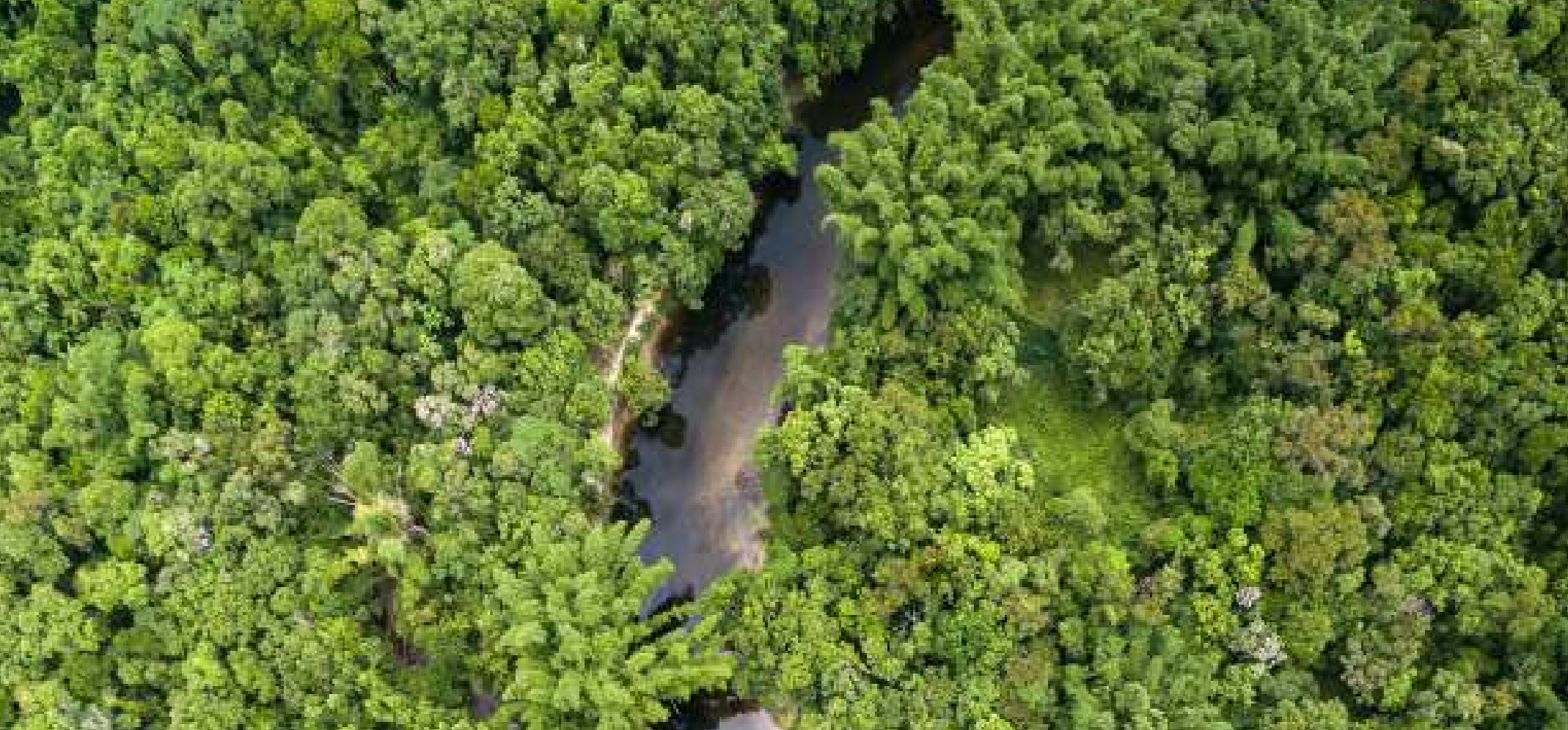

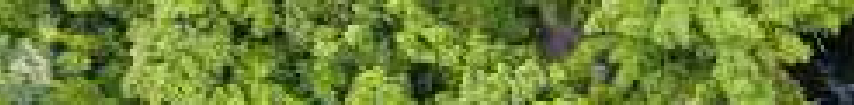

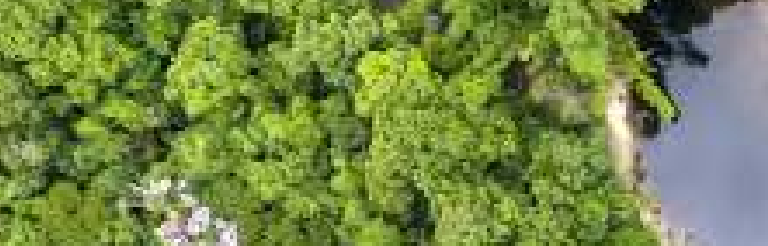

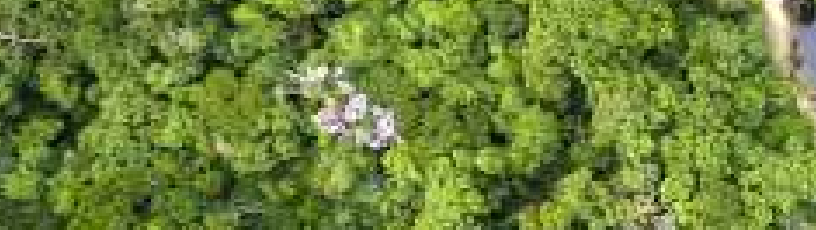

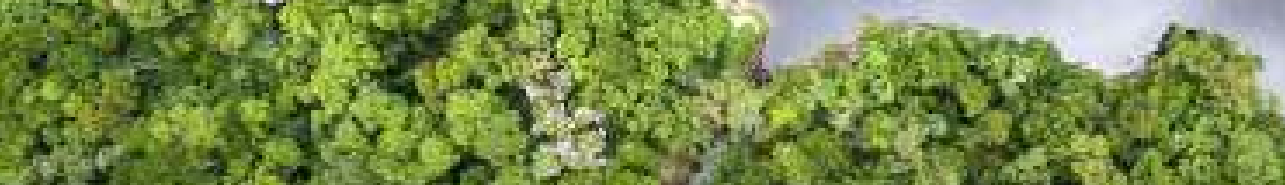

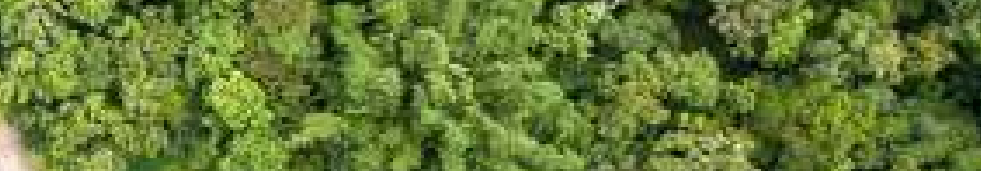

\section{Capítulo 03.}

Efecto de la

incertidumbre en la carbono-neutralidad en Perú 


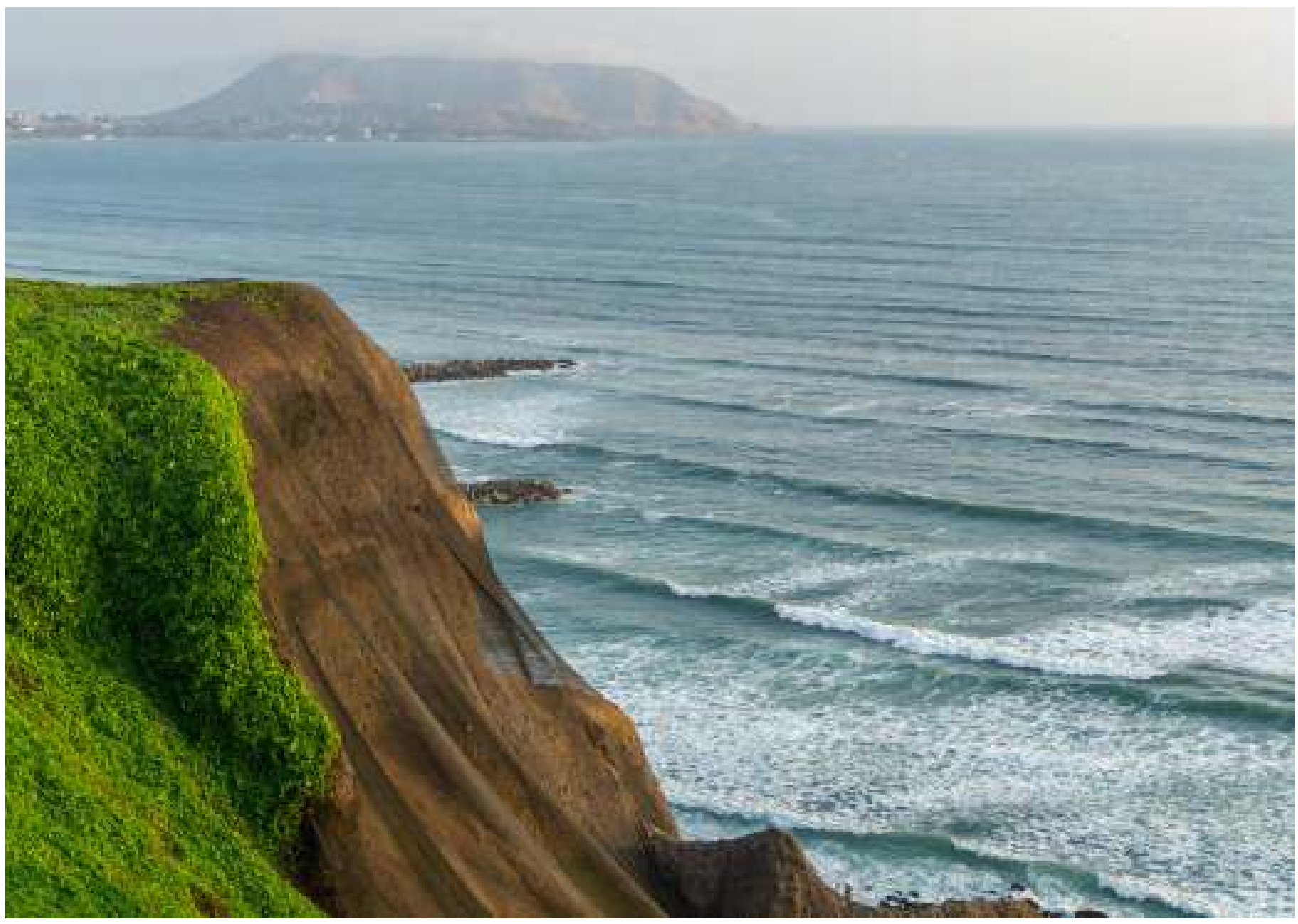

Las trayectorias de emisiones y beneficios netos presentadas en el capítulo 2 se basan en una serie de supuestos estándar que utilizan fuentes de información nacional e internacional actual. Sin embargo, existen múltiples variables inciertas que podrían causar diferentes trayectorias de emisiones, costos y beneficios. Por ejemplo, el costo de las nuevas tecnologías podría ser inferior a las tendencias actuales o bien podría aumentar. En este proyecto se ha evaluado el efecto de 201 posibles factores de incertidumbre. El anexo B presenta más detalles de los parámetros explorados y los rangos correspondientes.
Este capítulo expone el efecto de las variables inciertas sobre las trayectorias de emisiones, beneficios y costos. Los resultados se muestran para 1.000 implementaciones adicionales de cada escenario. Es decir, cada resultado se obtiene 1.001 veces, ya que revelan también la trayectoria tratada en el capítulo 2, que considera supuestos estándar.

Estudiar el rango de los resultados no sugiere la probabilidad de otras implementaciones, sino más bien tiene como finalidad señalar que existen múltiples rutas para lograr cero emisiones netas de gases de efecto invernadero (GEI) para 2050 y que cada ruta brinda un beneficio neto diferente. 


\subsection{Rango de emisiones}

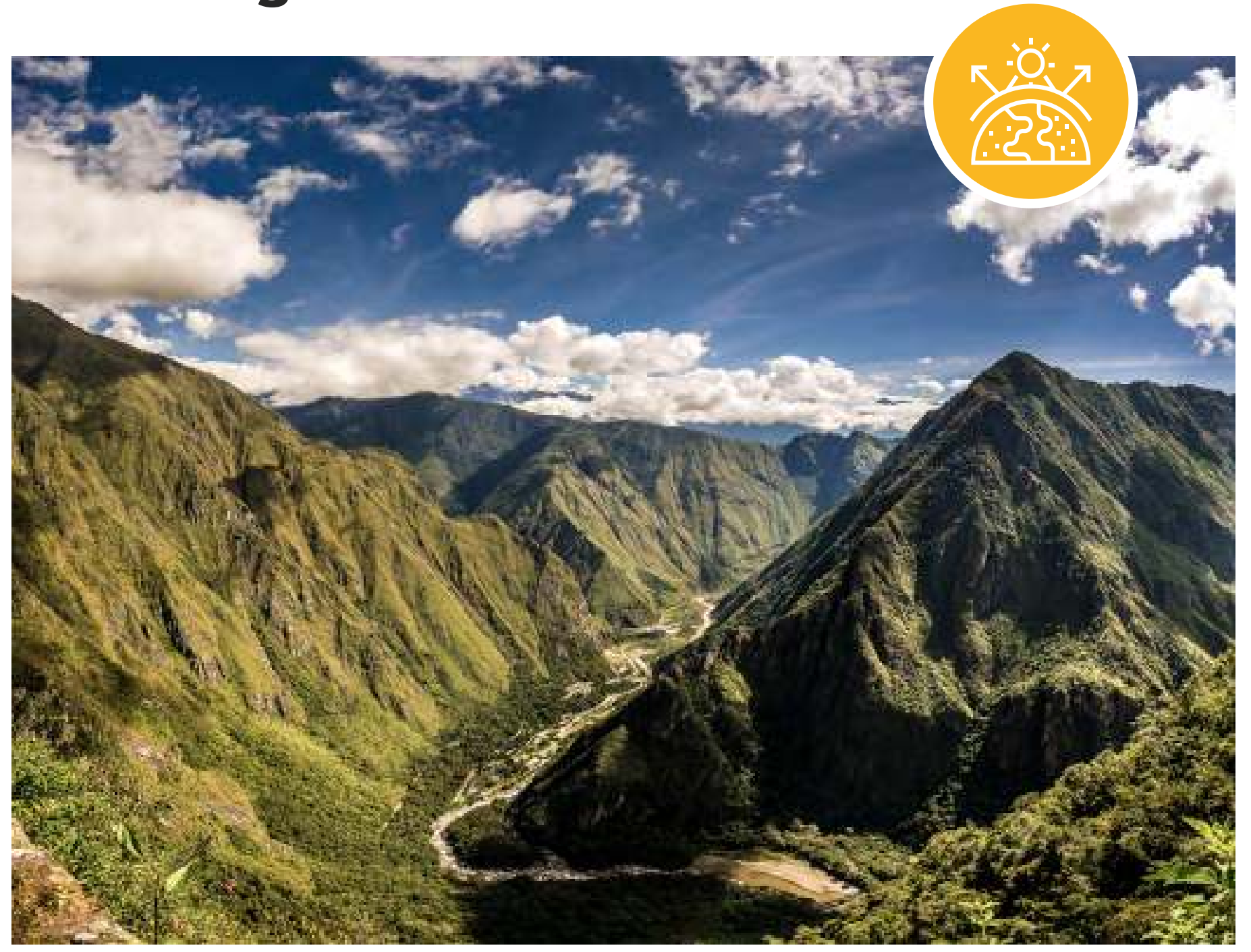

Con respecto a las emisiones de GEl estimadas en 2020 ( $220 \mathrm{MtCO}_{2 \mathrm{e}}$ ), estas aumentan en el escenario base para 2050 en todas las rutas plausibles exploradas. De hecho, diversos supuestos del escenario base podrían causar que las emisiones de GEI se duplicasen a mitad de siglo (gráfico 3.1). El $35 \%$ de las rutas del escenario base tendrían emisiones de GEl mayores que las estimaciones realizadas para la ruta con supuestos estándar.
Poner en marcha el escenario de carbononeutralidad reduce las emisiones de GEI en todas las rutas plausibles de implementación. El rango de reducción de emisiones del escenario de carbononeutralidad con respecto al escenario base en 2050 oscila entre $260 \mathrm{MtCO}_{2 \mathrm{e}}$ y $520 \mathrm{MtCO}_{2 \mathrm{e}}$, dependiendo del conjunto de supuestos de la ruta. El $67 \%$ de las rutas plausibles exploradas tienen una reducción sustancial de emisiones de GEI a 
2050; es decir, reducen al menos el 95\% de las emisiones estimadas a 2020. El 70\% de esas rutas tienen absorciones que superan las emisiones no evitadas; o sea, poseen emisiones netas inferiores a $\mathrm{O} \mathrm{MtCO}_{2 \mathrm{e}}$. El restante $33 \%$ de las rutas plausibles exploradas no reduce las emisiones de GEI por debajo de $10 \mathrm{MtCO}_{2 \mathrm{e}}$ ( $5 \%$ del valor de 2020); sin embargo, se reconoce una reducción sustancial en todas esas rutas. A futuro se explorarán las causas de estas altas emisiones y se podrán brindar insumos sobre acciones que contrarresten las mismas.
La magnitud de la reducción de emisiones de GEI varía por sector en cada ruta plausible (gráfico 3.2). Todos los sectores en el total de las rutas exploradas del escenario de carbono-neutralidad contribuyen con una disminución de las emisiones en 2050 con respecto al escenario base. El sector de agricultura, silvicultura y otros usos de la tierra (AFOLU) continúa siendo el que logra la mayor reducción, seguido por el sector transporte y complementado por energía, residuos y procesos industriales y uso de productos (PIUP).

\section{Gráfico 3.1}

Proyección de emisiones de GEI en 1.001 rutas plausibles del escenario base versus el escenario de carbono-neutralidad, 2050

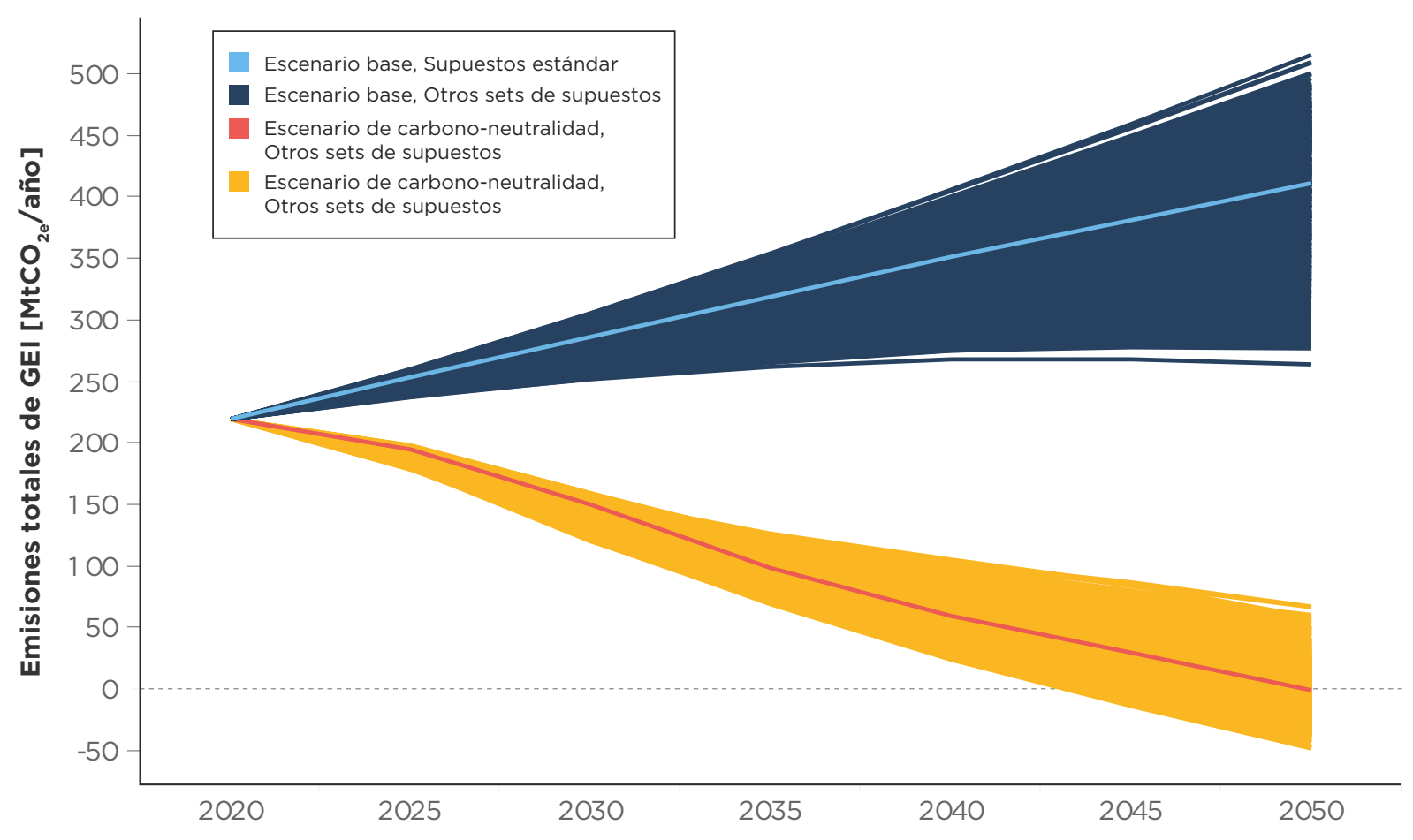

Fuente: Elaboración propia.

Nota: El escenario base es de color celeste y el escenario de carbono-neutralidad, rojo. Cada línea representa una trayectoria de emisiones de GEI a 2050. 


\section{Gráfico 3.2}

Reducción de emisiones de GEI en 1.001 rutas plausibles del escenario base versus el escenario de carbono-neutralidad por sector

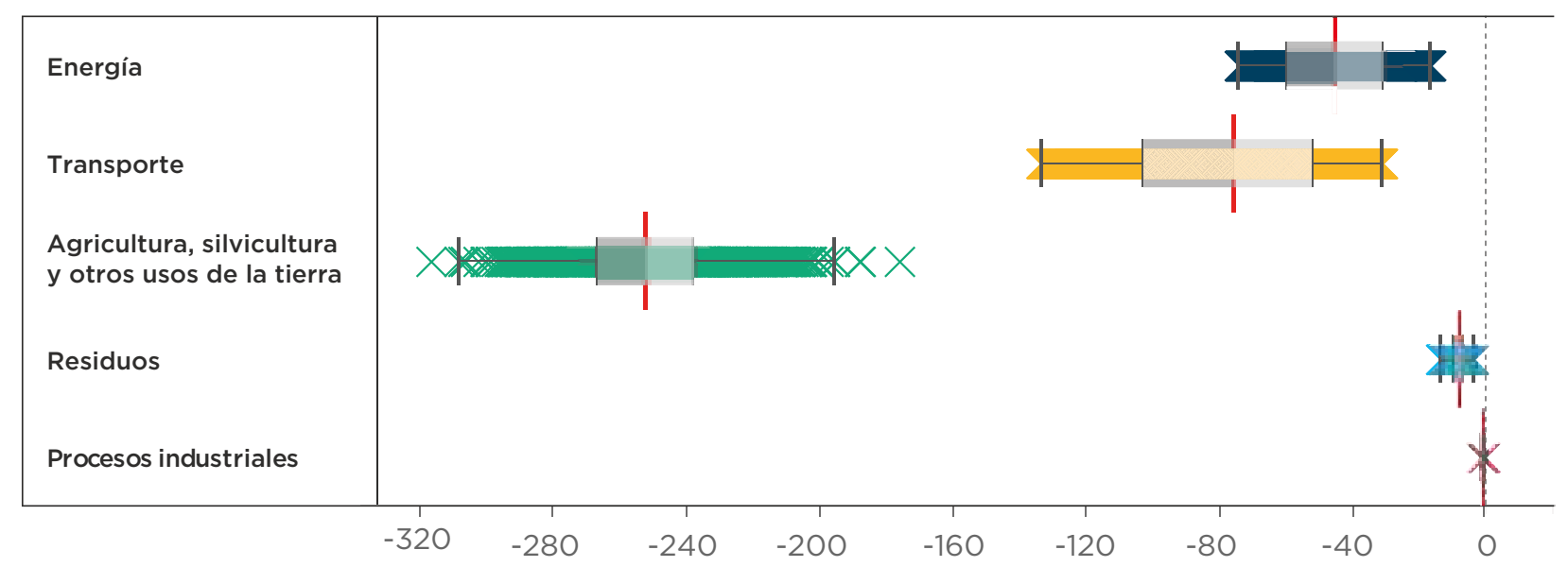

Fuente: Elaboración propia.

- Notas: Cada cruz representa la reducción de emisiones de GEI en cada ruta plausible. Los extremos del diagrama de caja se extienden hasta 1,5 veces el rango intercuartil. La caja se extiende desde el cuartil 1 hasta el cuartil 3 y la línea roja representa la mediana. En la parte interior de la caja se concentra el $50 \%$ de las rutas exploradas. El rango de emisiones en procesos industriales y uso de productos (PIUP) es nulo, ya que la única incertidumbre explorada es el costo de reducir el clínker en la producción de cemento. 


\subsection{Rango de beneficios netos}

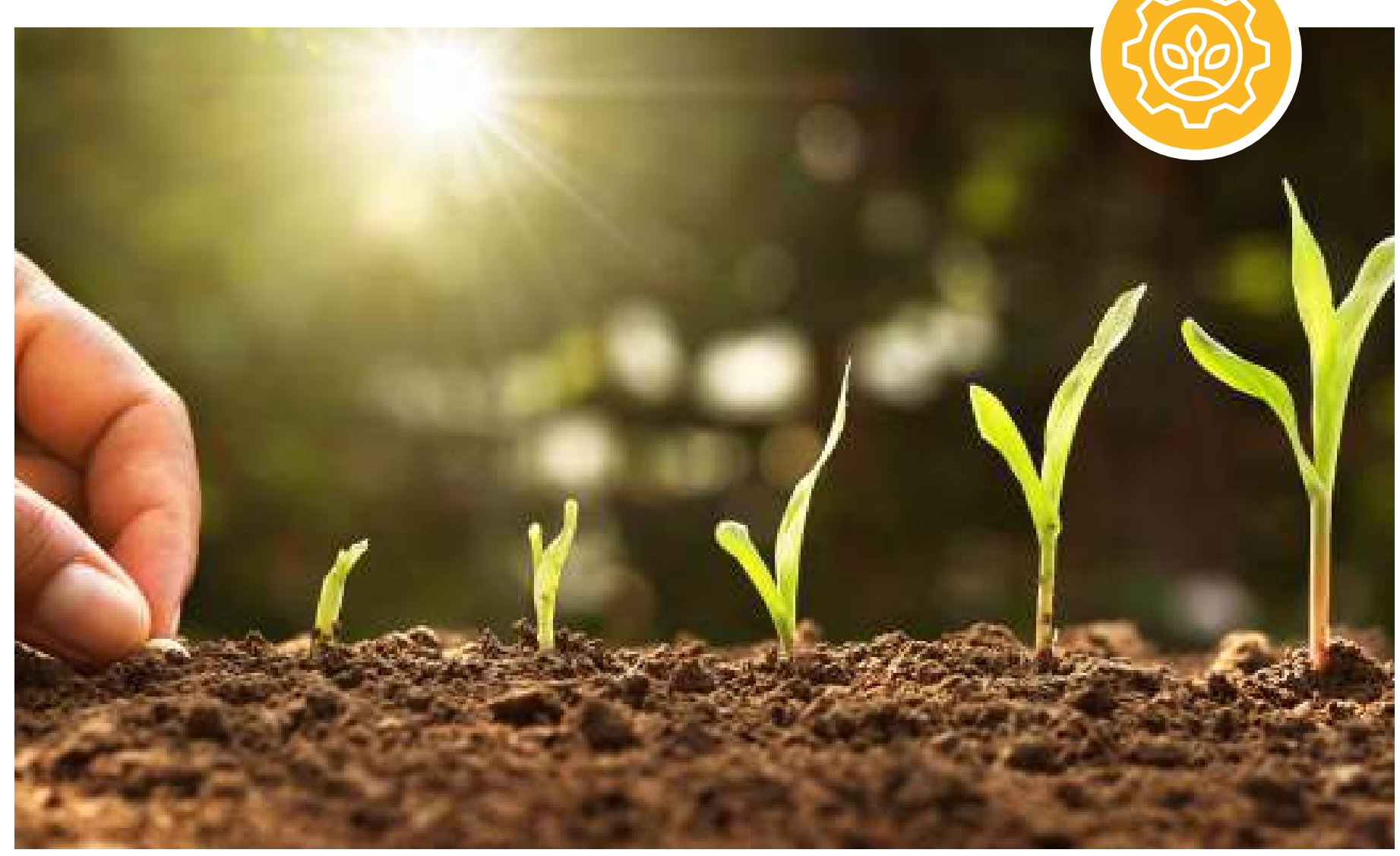

Los beneficios netos del escenario de carbononeutralidad son amplios y varían según los supuestos de cada ruta de implementación. El gráfico 3.3 muestra el rango de beneficios netos en las 1.001 rutas. El desuso de las plantas térmicas y de las refinerías permite grandes ahorros operativos.

La eficiencia energética también reduce estos consumos en las actividades que no se pudieron descarbonizar por completo; por ejemplo, en el consumo de fósiles en la industria. Dicha disminución brinda ahorros operativos de todas maneras. Además, la electrificación reduce el consumo de combustibles fósiles, con lo cual proporciona ahorros operativos para los usuarios y las empresas del sector transporte. Esto posibilita que en el $100 \%$ de las rutas de implementación del escenario de carbono-neutralidad se obtengan beneficios gracias a menores costos operativos. En algunas rutas de implementación estos beneficios son modestos y se estiman en US\$11.000 millones; sin embargo, hay rutas en las cuales el beneficio podría alcanzar los US\$273.000 millones. El rango del beneficio neto de la carbono-neutralidad acumulado a 2050 es amplio y se encuentra entre US\$20.000 millones y US\$391.000 millones. 


\section{Gráfico 3.3}

Beneficios netos en 1.001 rutas plausibles del escenario de carbono-neutralidad

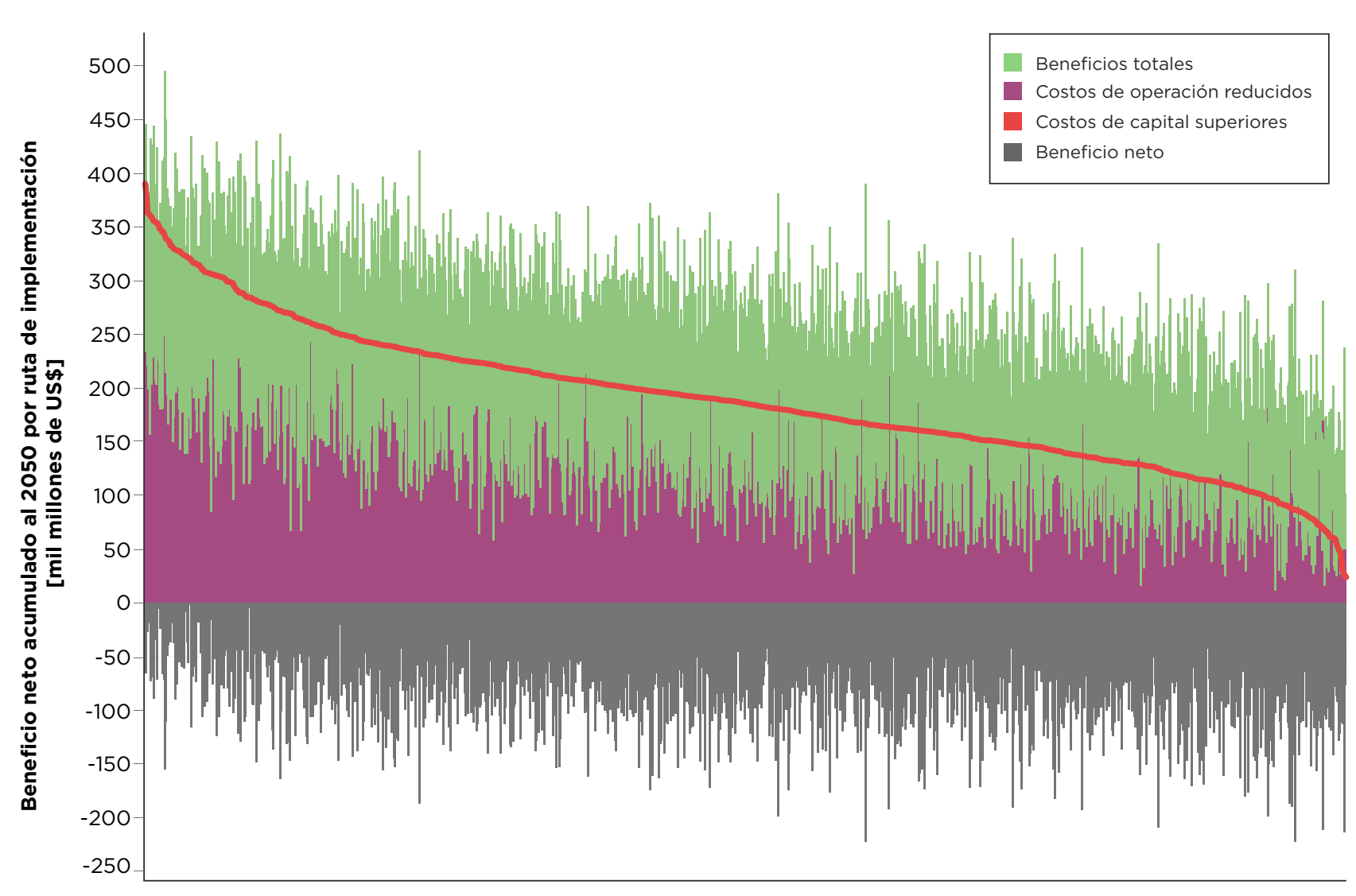

Ruta de implementación

Los beneficios se reparten entre los sectores. El gráfico 3.4 muestra los rangos de beneficios netos por sector. AFOLU, transporte, residuos y energía percibirán los mayores beneficios:

$>$ En el sector AFOLU el $50 \%$ de las rutas plausibles brinda un beneficio neto que ronda entre US\$59.000 millones y US\$103.000 millones con una mediana de US\$82.000 millones.
$>$ En el sector transporte el $50 \%$ de las rutas proporciona un beneficio de entre US $\$ 54.000$ millones y US\$124.000 millones con una mediana de US $\$ 85.000$ millones.

$>$ En el sector energía el 50\% de las rutas plausibles tienen un beneficio neto que ronda entre -US\$11.000 millones y US $\$ 9.000$ millones, con una mediana que se estima en -US\$2.000 millones. 
$>$ En el sector residuos el $50 \%$ de las rutas plausibles tienen un beneficio neto que ronda entre US $\$ 14.000$ millones y US $\$ 21.000$ millones, con una mediana que se estima en US\$18.000 millones.

$>$ Por su parte, los límites físicos de reducción de clínker para la producción de cemento brindan un rango de costos relativamente bajo en el sector PIUP. En todas las rutas exploradas para el sector se incurre en más costos, aunque estos son modestos, con valores que van desde los US $\$ 600$ millones hasta los US $\$ 900$ millones, con una mediana de US\$800 millones.

Independientemente del sector, los beneficios percibidos por la carbono-neutralidad aumentan en el tiempo (gráfico 3.5). Estos son modestos en el corto plazo, pero se multiplican en el mediano y el largo plazo.

\section{Gráfico 3.4}

Proyección de emisiones de GEI en 1.001 rutas plausibles del escenario base versus el escenario de carbono-neutralidad, 2050

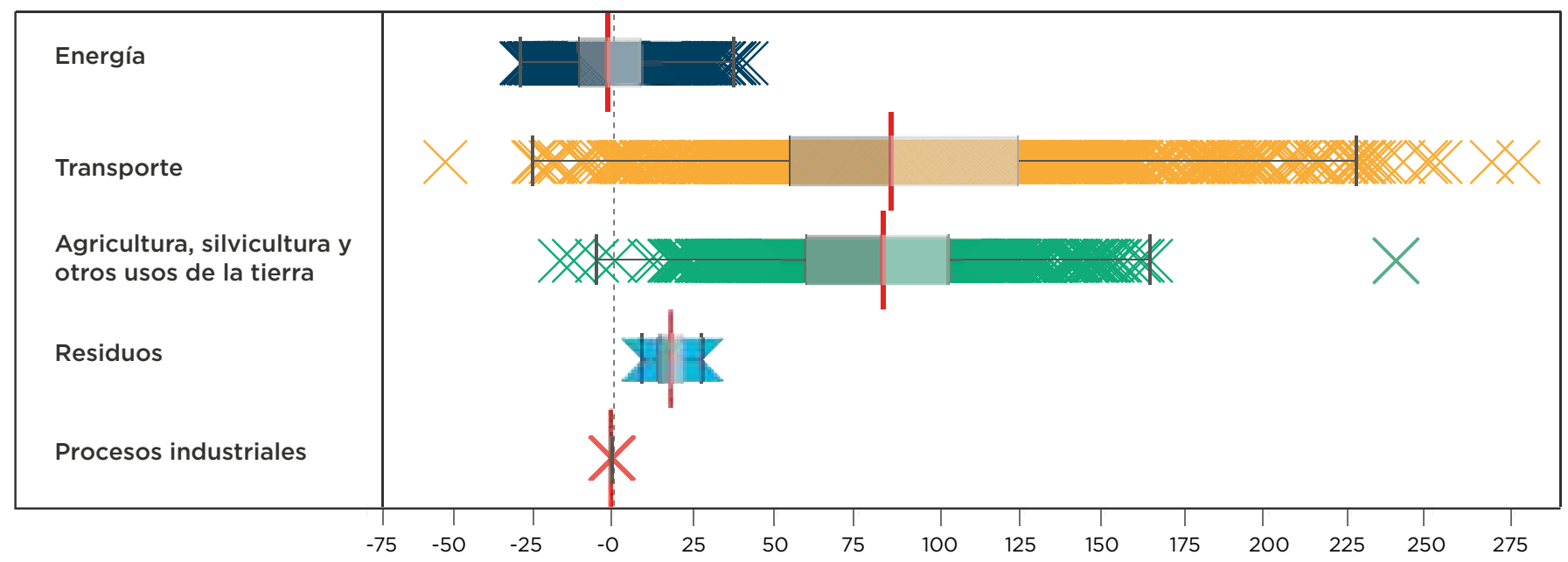

Beneficios netos acumulados al 2050 por sector [mil millones de US\$]

Fuente: Elaboración propia.

Notas: Cada cruz representa un beneficio neto por ruta plausible. Los extremos del diagrama de caja se extienden hasta 1,5 veces el rango intercuartil. La caja se extiende desde el cuartil 1 hasta el cuartil 3 y la línea roja representa la mediana. En la parte interior de la caja se concentra el $50 \%$ de las rutas exploradas. 


\section{Gráfico 3.5}

Beneficios netos por sector en el corto, mediano y largo plazo en las 1.001 rutas plausibles exploradas del escenario de carbono-neutralidad versus el escenario base

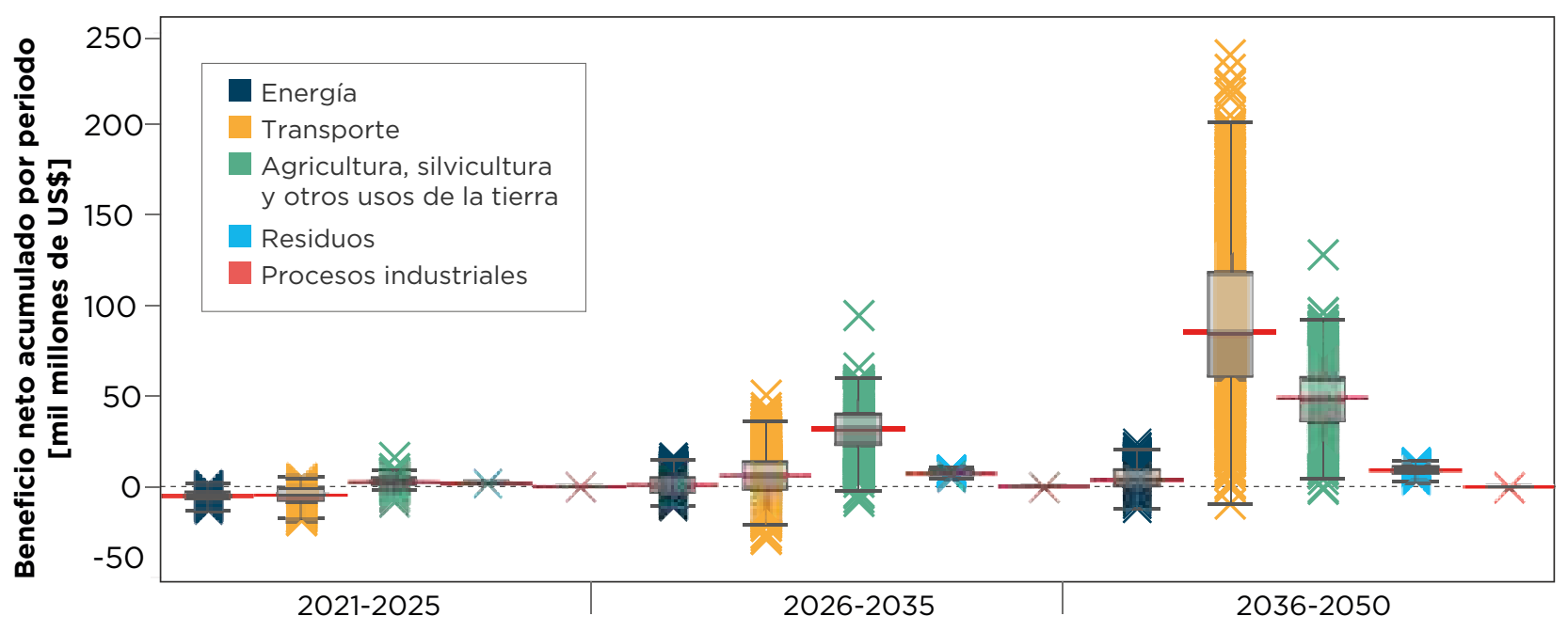

Fuente: Elaboración propia.

\ Notas: Cada cruz representa un beneficio neto por ruta plausible. Los extremos del diagrama de caja se extienden hasta 1.5 veces el rango intercuartil. La caja se extiende desde el cuartil 1 hasta el cuartil 3 y la línea roja representa la mediana. En la parte interior de la caja se concentra el $\mathbf{5 0 \%}$ de las rutas exploradas. 


\subsection{Beneficios netos acumulados versus emisiones netas en 2050}

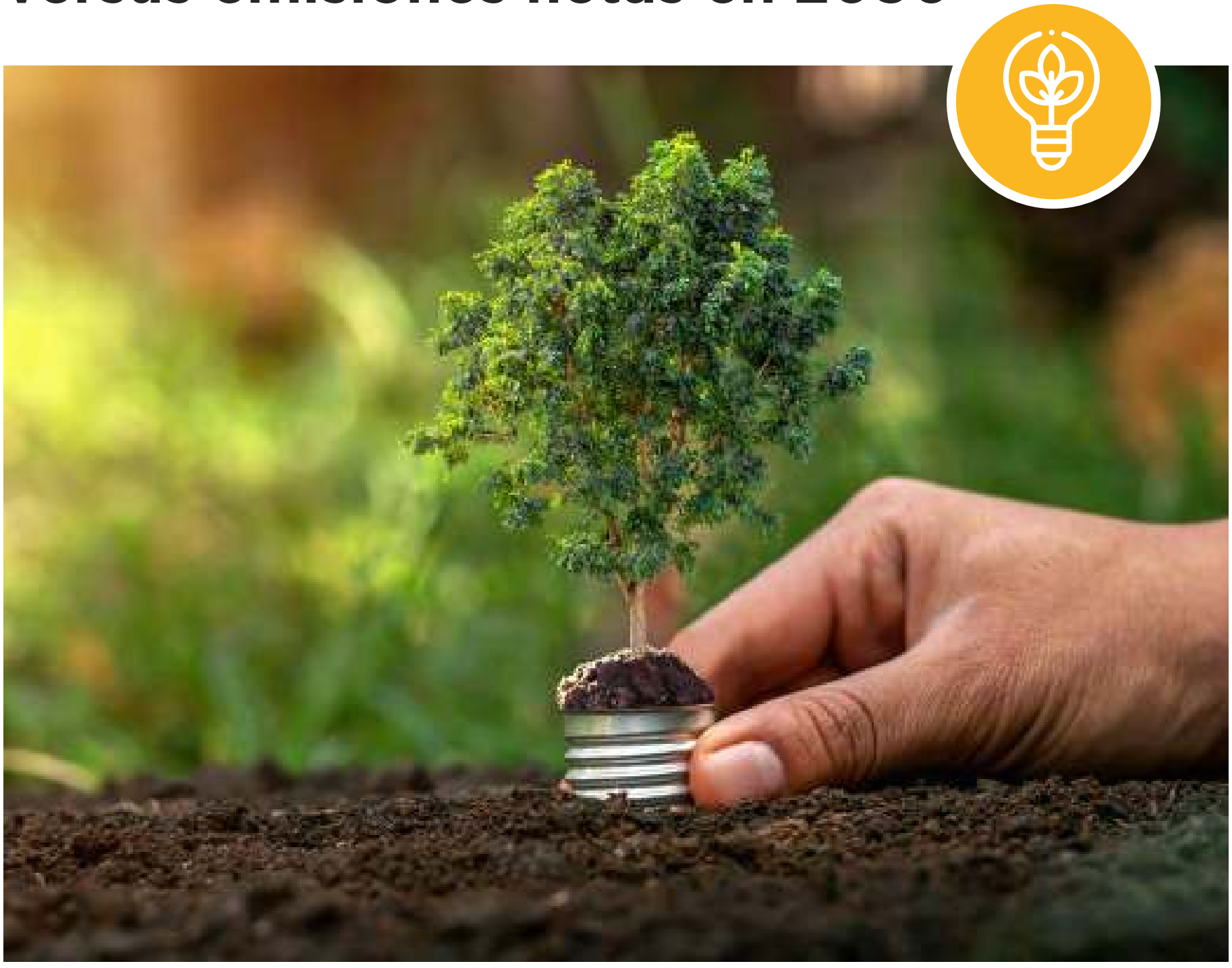

En el eje vertical del gráfico 3.6 se pueden apreciar los beneficios netos acumulados a 2050 del escenario de carbono-neutralidad (con respecto al escenario base), mientras que el eje horizontal detalla las emisiones netas del escenario de carbono-neutralidad en 2050 para las 1.001 rutas plausibles de implementación. Para efectos de este estudio, se consideran altos beneficios todos aquellos valores que son superiores al beneficio neto obtenido en la ruta de implementación con supuestos estándar (US\$140.000 millones). De igual forma, se asume que altas emisiones corresponden a las rutas plausibles que tienen emisiones netas superiores al $5 \%$ de aquellas estimadas en 2020 (10 $\mathrm{MtCO}_{2 \mathrm{e}}$ ). 
El 50\% de las rutas de implementación plausibles tiene altos beneficios y bajas emisiones (triángulos verdes). El $17 \%$ de las rutas de implementación arroja bajos beneficios y bajas emisiones (cruces naranjas). El 26\% de las rutas de implementación plausibles provee altos beneficios, pero incurre en emisiones superiores a $10 \mathrm{MtCO}_{2 \mathrm{e}}$ (cuadrados azules). El restante $7 \%$ de los futuros plausibles trae aparejados bajos beneficios y altas emisiones (rombos rojos).

Para comprender cuáles son los factores que podrían llevar a escenarios indeseados (beneficios bajos y emisiones altas), así como estrategias para anticiparlos, será necesario realizar en el futuro un análisis de vulnerabilidad.

\section{Gráfico 3.6}

Reducción de emisiones de GEI en 2050 y beneficios netos acumulados a 2050 en 1.001 rutas plausibles del escenario de carbono-neutralidad versus el escenario base

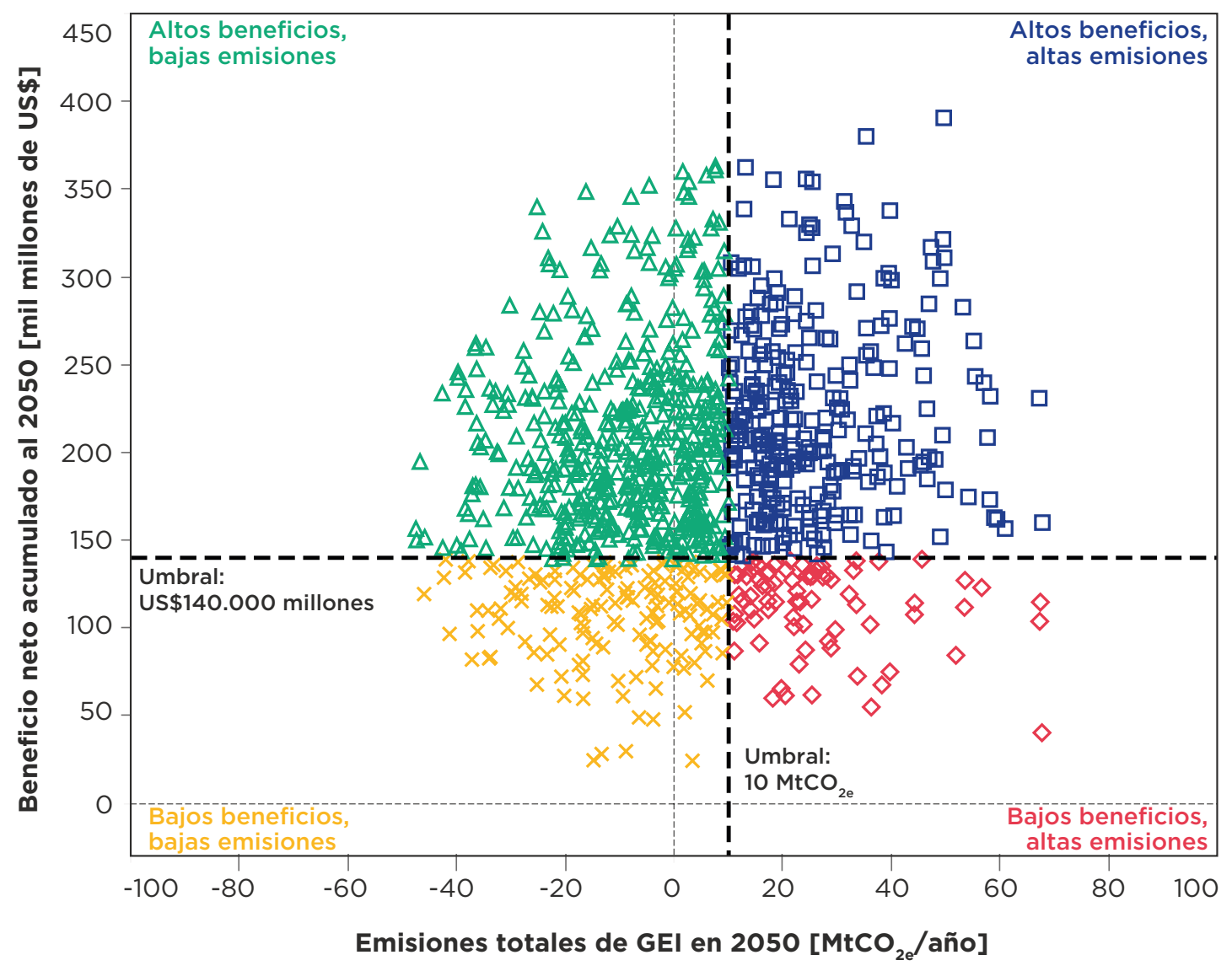

Fuente: Elaboración propia. 


\subsection{Rango de costos}

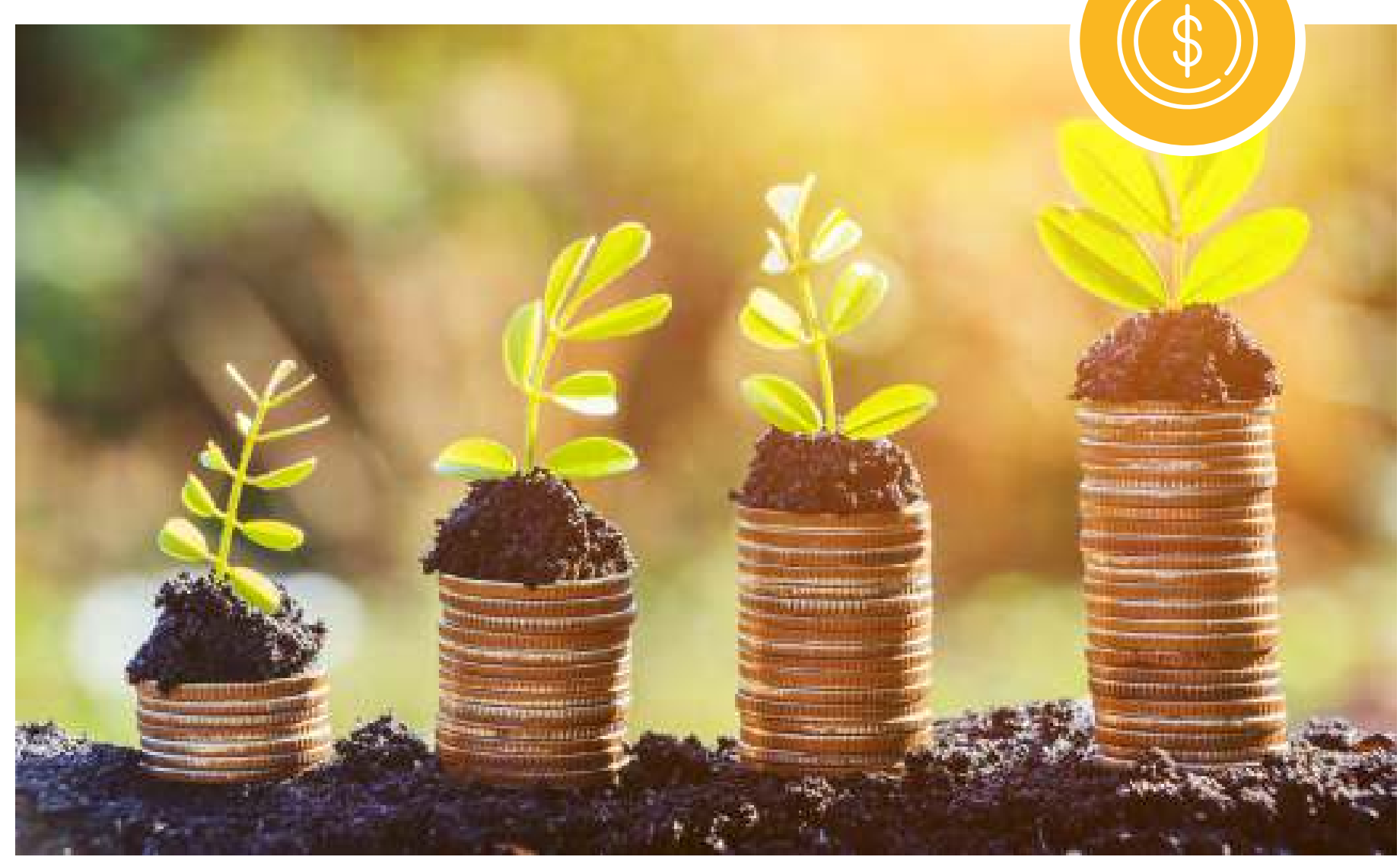

El gráfico 3.7 muestra la dispersión entre los beneficios netos acumulados a 2050 y los aumentos de costos de capital acumulados al mismo año. El $100 \%$ de las rutas plausibles exploradas del escenario de carbono-neutralidad requiere inversiones para habilitar los beneficios. El 43\% de las rutas plausibles (cruces rojas) demandará inversiones superiores al valor estimado para la ruta de implementación con supuestos estándar (US\$93.000 millones). Sin embargo, el gráfico resalta nuevamente que todas las rutas exploradas conllevan beneficios netos, los cuales ya capturan estas inversiones.
El gráfico 3.8 exhibe estas inversiones por sector y por periodo. En general, las inversiones en energía y transporte son más altas. Las inversiones en energía, residuos y PIUP crecen en el tiempo. En transporte y AFOLU aumentan del corto al mediano plazo, pero caen en el largo plazo, debido al cumplimiento de las metas de políticas o bien por el costo reducido de las tecnologías en el futuro. 


\section{Gráfico 3.7}

Aumento de costos de capital acumulados y beneficios netos acumulados en 1.001 rutas plausibles del escenario de carbono-neutralidad versus el escenario base

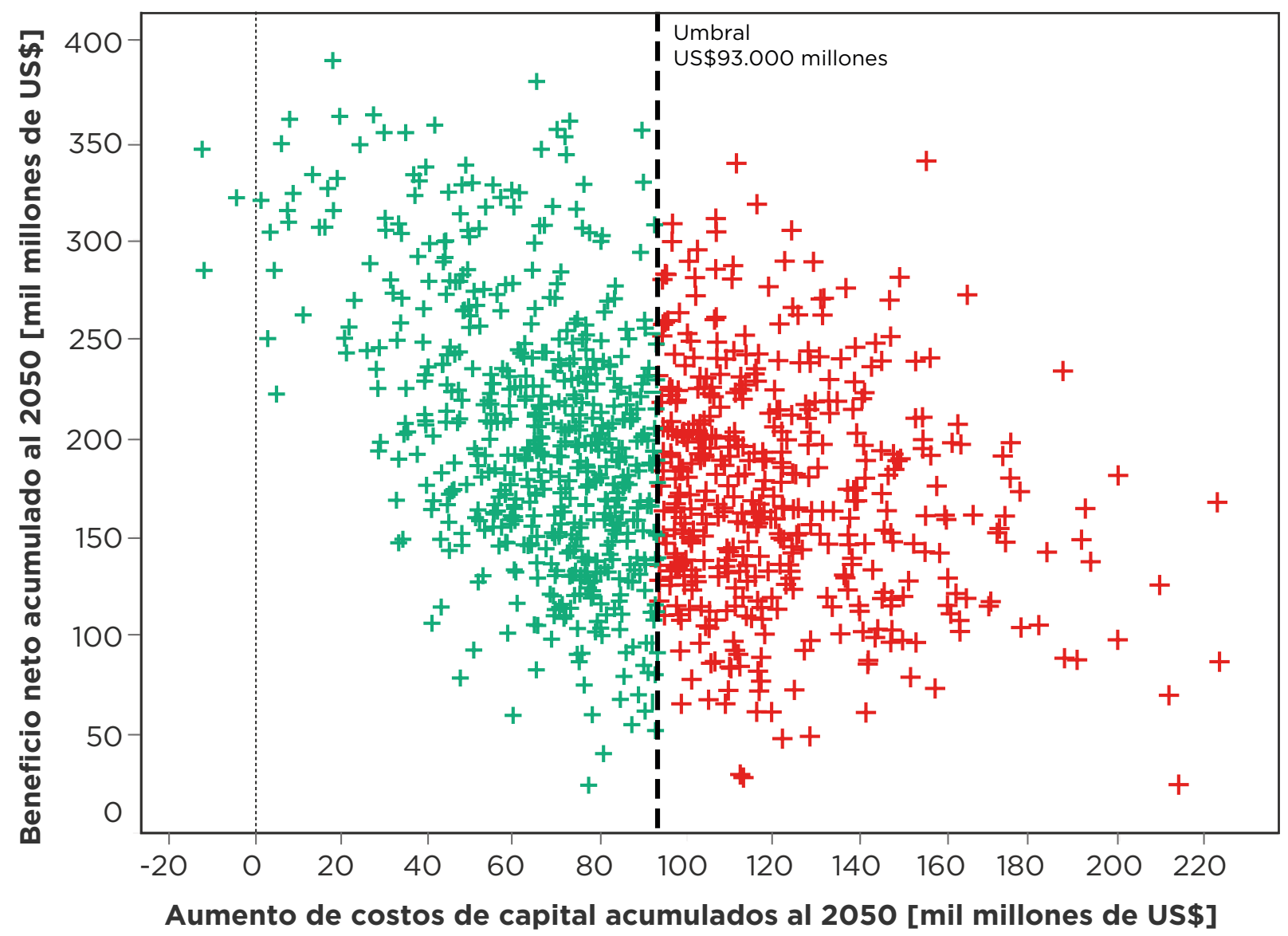

Fuente: Elaboración propia.

Nota: Las cruces verdes representan rutas que conllevan ahorros en términos de inversiones y las rojas, aquellas con un aumento de las inversiones. 


\section{Gráfico 3.8}

Aumento de costos de capital por sector y por periodo en 1.001 rutas plausibles del escenario de carbono-neutralidad

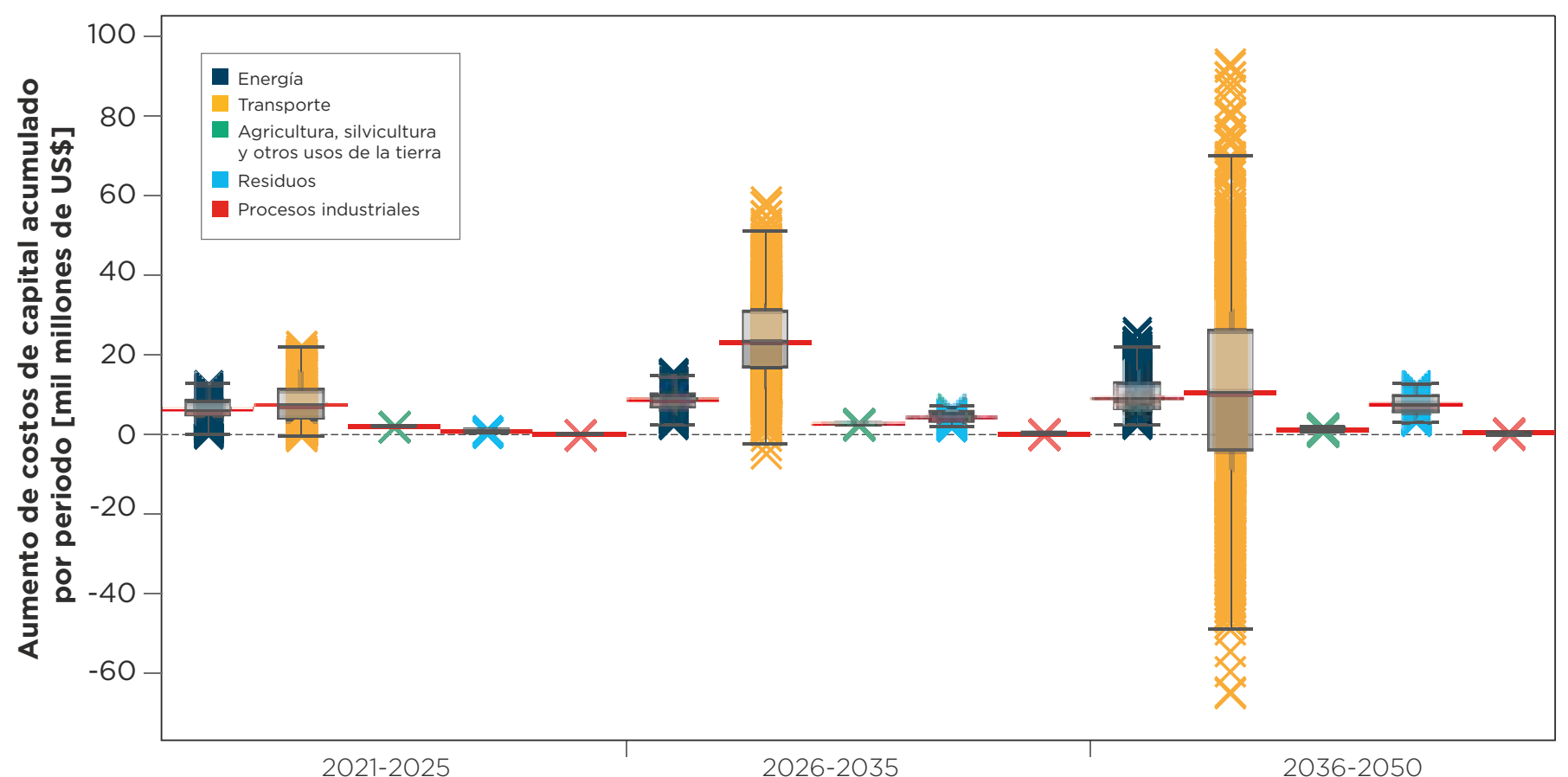

Fuente: Elaboración propia.

Notas: Cada cruz representa un beneficio neto por ruta plausible. Los extremos del diagrama de caja se extienden hasta 1,5 veces el rango intercuartil. La caja se extiende desde el cuartil 1 hasta el cuartil 3 y la línea roja representa la mediana. En la parte interior de la caja se concentra el $50 \%$ de las rutas exploradas. 


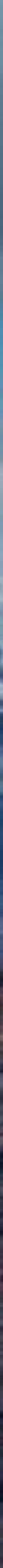




\section{Epílogo}

\section{Apoyo a la estrategia para 2050 y la recuperación sostenible}

Este estudio ha evaluado los costos y beneficios de lograr la carbononeutralidad en Perú a 2050. Se ha creado un escenario de carbononeutralidad con una descripción detallada del proceso transformacional en cada sector de la economía: energía; transporte; agricultura, silvicultura y otros usos de la tierra; residuos; y procesos industriales y uso de productos (PIUP). El marco analítico desarrollado en este estudio se inspira en un método novedoso de toma de decisiones robusta bajo incertidumbre profunda que ha incorporado las diferentes ideas de las partes interesadas que representan a más de 90 agencias gubernamentales, industrias y organizaciones no gubernamentales de Perú, para comprender mejor la forma en que la descarbonización interactúa con objetivos de desarrollo sectoriales. El marco analítico aplicado estima trayectorias de emisiones por sector y a nivel nacional, y permite entender los costos y beneficios de lograr la carbononeutralidad del país. Estas estimaciones se han realizado para 1.001 rutas de implementación plausibles del escenario, considerando incertidumbre en 201 parámetros inciertos desde la actualidad hasta 2050. Además, el marco analítico es flexible y facilita efectuar mejoras en el tiempo cuando nueva información esté disponible.

Este estudio sirvió de soporte técnico al Estudio Técnico para la CarbonoNeutralidad elaborado por el Ministerio del Ambiente (MINAM), de cara a la actualización de la Estrategia Nacional ante el Cambio Climático. El mismo brindó insumos técnicos relevantes en la actualización de las existentes Contribuciones Determinadas a Nivel Nacional, que representan el compromiso inicial de Perú según el Acuerdo de París, realizada durante 2020. Igualmente, los resultados obtenidos pueden ser relevantes para informar inversiones que generen beneficios económicos que puedan servir al proceso de recuperación económica tras los impactos de la pandemia de COVID-19. 
Bajo supuestos estándar, el estudio ha demostrado que es técnicamente posible lograr cero emisiones netas de gases de efecto invernadero (GEI) con intervenciones que incluyen: i) la transformación de la matriz energética; ii) el aumento del transporte público y el cambio modal al transporte no motorizado; iii) la electrificación de las actividades, entre ellas, el transporte; iv) la detención de la deforestación y el incremento de la reforestación; y v) el aumento de prácticas más sostenibles, que implican reducir los residuos, hacer cambios en las dietas y utilizar nuevos materiales en la construcción. Este proceso transformador trae consigo beneficios socioeconómicos para Perú que han sido estimados al valor presente neto de 2021 en US $\$ 140.000$ millones, con una tasa de descuento del $8 \%$.

Al incorporar incertidumbre se logró determinar que el 100\% de las rutas plausibles del escenario de carbono-neutralidad trae consigo beneficios socioeconómicos netos para Perú que podrían llegar a ser de hasta US $\$ 391.000$ millones acumulados a 2050 , y que el $67 \%$ de las rutas plausibles exploradas tienen una reducción sustancial de emisiones de GEI a 2050; es decir, reducen al menos el 95\% de las emisiones estimadas a 2020.

Los resultados de este estudio sirven de base técnica sólida para un posterior desarrollo de hojas de ruta de política pública para su implementación, así como de estudios de aspectos regulatorios, tarifarios y de empleabilidad asociados a la descarbonización de la economía de Perú.

Próximas iteraciones del presente estudio podrían fortalecer las evaluaciones de los sectores residuos y PIUP, así como complementar los modelos usados y desarrollados por el equipo técnico con resolución temporal y espacial, de modo que se puedan mejorar las estimaciones efectuadas. La incorporación de los efectos intersectoriales mediante la creación de un modelo integrado que permita capturar sinergias entre sectores, así como el completo desarrollo de un análisis de vulnerabilidad para robustecer el análisis, también podrían mejorar el estudio. 


\section{Referencias}

Aguilar Jaber, A., Anderson, B., Nachtigall, D. y Ngom, F. 2020. Long-term low emissions development strategies: Cross-country experience. OECD Environment Working Papers No. 160. París: OCDE. Disponible en https:// doi.org/10.1787/1c1d8005-en.

AIE (Agencia Internacional de Energía). 2018. Technology Roadmap-Low-Carbon Transition in the Cement Industry. Documento 66. París: AIE.

Banco Mundial. 2012. Inside Costa Rica. Costa Rica's Waste Generation Expected to Double by 2025 Washington, D.C.: Banco Mundial.

Bataille, C., H. Waisman, Y. Briand, J. Svensson, A. Vogt-Schilb, M. Jaramillo, R. Delgado, R. Argüello, L. Clarke, T. Wild, F. Lallana, G. Bravo, G. Nadal, G. Le Treut, G. Godinez, J. Quirós-Tortos, E. Pereira, M. Howells, D., Buira, M. Imperio et al. 2020. Net-zero deep decarbonization pathways in Latin America: Challenges and opportunities. Energy Strategy Reviews, 30, 100510. Disponible en https://doi.org/10.1016/j.esr.2020.100510.

Bedoya Garland, E., C. E. Aramburú y Z. Burneo. 2017. Una agricultura insostenible y la crisis del barbecho: El caso de los agricultores del valle de los ríos Apurímac y Ene, VRAE. Anthropologica, 35(38): 211-240. Disponible en https://doi. org/10.18800/anthropologica.201701.008.

BID (Banco Interamericano de Desarrollo). 2019. Sistema de planificación energética, diseño del sistema de información energético nacional y desarrollo del plan energético (Programa para la Gestión Eficiente y Sostenible de los Recursos Energéticos del Perú [PROSE-MER]). Washington, D.C.: BID.

BID y DDPLAC (Rutas de Descarbonización Profunda en Latinoamérica y el Caribe). 2019. Cómo llegar a cero emisiones netas: Lecciones de América Latina y el Caribe. Washington, D.C.: BID y DDPLAC. Disponible en http://dx.doi. org/10.18235/0002024.

Broin E. Ó. y C. Guivarch. 2016. Transport infrastructure costs in low-carbon pathways. Transportation Research Part D: Transport and Environment, Elsevier, 55: 389-403. Disponible en 10.1016/j.trd.2016.11.02.

Caldas Cueva, J. F. y A. Lizárraga Travaglini. 2020. Guía técnica: Manejo del cultivo de arroz bajo el sistema de riego con secas intermitentes en las regiones de Tumbes, Piura, Lambayeque y la Libertad. Lima: Instituto Nacional de Innovación Agraria. Disponible en http://repositorio.inia.gob.pe/handle/inia/1053.

Carrasco, L. R., T. P. L. Nghiem, T. Sunderland y L. P. Koh. 2014. Economic valuation of ecosystem services fails to capture biodiversity value of tropical forests. Biological Conservation, 178: 163-170. Disponible en https://doi. org/10.1016/j.biocon.2014.08.007.

Coady, D., I. Parry, N.P. Le y B. Shang. 2019. Global Fossil Fuel Subsidies Remain Large: An Update Based on Country-Level Estimates. Documento de trabajo_No. 19/89; p. 39. Washington, D.C.: Fondo Monetario Internacional. Disponible en https://www.imf.org/en/Publications/WP/Issues/2019/05/02/Global-Fossil-Fuel-Subsidies-Remain-Large-An-Update-Based-on-Country-Level-Estimates-46509.

COES (Comité de Operación Económica del Sistema Interconectado Nacional). 2020. Propuesta definitiva de actualización del plan de transmisión 2021-2030_(INFORMECOES/DP-01-2020). Lima: COES. Disponible en https:// www.coes.org.pe/Portal/Planificacion/PlanTransmision/ActualizacionPTG.

COVEC. 2017. Recycling: Cost Benefit Analysis. Auckland: COVEC, Ministry of Environment. 
De la Torre Ugarte, D. G. y D. E. Ray. 2000. Biomass and bioenergy applications of the POLYSYS modeling framework. Biomass and Bioenergy, 18(4): 291-308. Disponible en https://doi.org/10.1016/S0961-9534(99)00095-1.

Dixon. J. 2012. Enhanced Cost Benefit Analysis of IDB Waste Water Treatment Projects with Special Consideration to Environmental Impacts: Lessons Learned from a Review of Four Projects. Documento de discusión del BID No. IDB-DP-254. Washington, D.C.: BID.

Dourejeanni, M. 1987. Aprovechamiento del barbecho forestal en áreas de agricultura migratoria en la amazonia peruana. Revista Forestal Del Perú, 14(2): 1-33._Disponible en http://dx.doi.org/10.21704/rfp.v14i2.136.

Echevarría, M., D. Pizarro y Gómez, C. 2019. Alimentación de ganadería en sistemas silvopastoriles de la Amazonia peruana. Lima, Perú: Universidad Nacional Agraria La Molina.

EPERLab-UCR. s/f. Documentación de OSeMOSYS-CR. Disponible en https://osemosys-cr.readthedocs.io/en/latest/.

EPRI (Instituto de Investigación en Sistemas Eléctricos). 2011. Estimating the Costs and Benefits of the Smart Grid. A Preliminary Estimate of the Investment Requirements and the Resultant Benefits of a Fully Functioning Smart Grid. Washington, D.C.: EPRI.

Escobedo, L. 2010. Bosques tropicales y salud pública: Aportes desde la geografía al análisis de la incidencia de la Malaria en la selva de Loreto. Lima: Grupo de Análisis para el Desarrollo (GRADE).

ETSAP-IEA. 2020. Data Technology. Disponible en https://iea-etsap.org/index.php/energy-technology-data

Fay, M., S. Hallegatte, A. Vogt-Schilb, J. Rozenberg, U. Narloch y T. Kerr. 2015. Decarbonizing Development: Three Steps to a Zero-Carbon Future. Washington, D.C.: Banco Mundial.

FICEM (Federación Interamericana de Cemento). 2016. Reporte de la aplicación del sMRV-FICEM para la producción de cemento del Perú. Bogotá: FICEM.

García de Fonseca, L., M. Parikh y R. Manghani. 2019. Evolución futura de costos de las energías renovables y almacenamiento en América Latina. Washington, D.C.: BID. Disponible en http://dx.doi.org/10.18235/0002101.

Godínez, G., L. Víctor-Gallardo, J. Angulo-Paniagua, E. Ramos, M. Howells, W. Usher, F. De León, A. Meza y J. Quirós-Tortós. 2020. Decarbonising the transport and energy sectors: Technical feasibility and socioeconomic impacts in Costa Rica. Energy Strategy Reviews, 32. Disponible en https://doi.org/10.1016/j.esr.2020.100573.

Hernández-Blanco, M., R. Costanza, S. Anderson, I. Kubiszewski y P. Sutton. 2020. Future scenarios for the value of ecosystem services in Latin America and the Caribbean to 2050. Current Research in Environmental Sustainability, 2: 1-12. Disponible en https://doi.org/10.1016/j.crsust.2020.100008.

Hills, T., N. Florin y P. S. Fennell. 2016. Decarbonising the cement sector: A bottom-up model for optimizing carbon capture application in the UK. Journal of Cleaner Production, 139: 1351-61. Disponible en https://doi.org/10.1016/j. jclepro.2016.08.129

Howells, M., H. Rogner, N. Strachan, C. Heaps, H. Huntington, S. Kypreos, A. Hughes, S. Silveira, J. DeCarolis, M. Bazillian y A. Roehrl. 2011. OSeMOSYS: The Open Source Energy Modeling System. Energy Policy, 39(10): $5850-70$. Disponible en https://doi.org/10.1016/j.enpol.2011.06.033. 
INEI (Instituto Nacional de Estadísticas e Informática). 2020a. Encuesta Nacional Agropecuaria 2014-2018. Lima: INEI. 2020b. IV Censo Nacional Agropecuario 2012. Lima: INEI.

IPCC (Panel Intergubernamental de Expertos sobre el Cambio Climático). 2006. 2006 IPCC Guidelines for National Greenhouse Gas Inventories-Volume 5, Prepared by the National Greenhouse Gas Inventories Programme. Ginebra: IPCC. Disponible en https://www.ipcc-nggip.iges.or.jp/public/2006gl/.

2018. Global Warming of $1.5^{\circ} \mathrm{C}$. Ginebra: IPCC. Disponible en https://www.ipcc.ch/site/assets/uploads/sites/2/2019/06/SR15_Full_Report_High_Res.pdf.

Jaramillo, M. y V. Saavedra. 2021. NDC Invest: Supporting transformational climate policy and finance. Washington, D.C.: BID. (De pronta publicación.)

Lempert, R., S. W. Popper y S. C. Bankes. 2003. Shaping the next One Hundred Years: New Methods for Quantitative, Long-Term Policy Analysis. Santa Monica, CA: RAND.

Lempert, R. 2013. Scenarios that illuminate vulnerabilities and robust responses. In Climatic Change. Disponible en https://doi.org/10.1007/s10584-012-0574-6.

2019. Robust Decision Making (RDM). In Decision Making under Deep Uncertainty. Nueva York: Springer.

León G. 2020. Esquema de gestión de aguas residuales.

Lobo S. et al. 2016. Analysis of the challenges in the development of the recycling value chain in Central America. Monografía del BID No. 485. Washington, D.C.: BID.

Marchau, V. A. W. J., W. E. Walker, P. J. T. M. Bloemen y S. W. Popper. 2019. Chapter 1: Introduction. In Decision Making under Deep Uncertainty. Nueva York: Springer. Disponible en https://doi.org/10.1007/978-3-030-05252-2.

MIDAGRI (Ministerio de Desarrollo Agrario y Riego). s/f. Serie de Estadísticas de Producción Agrícola (SEPA) y Serie de Estadísticas de Producción Ganadera y Avícola (SEPGA). Lima: MIDAGRI. Disponible en http://frenteweb. minagri.gob.pe/sisca; http://sitiodea.com/siscipa/index.html.

MINAM (Ministerio del Ambiente). 2018. Informe final del Grupo de Trabajo Multisectorial de naturaleza temporal encargado de generar información técnica para orientar la implementación de las Contribuciones Nacionalmente Determinadas (GTM-NDC)._Lima: MINAM. Disponible en http://www.minam.gob.pe/cambioclimatico/ wp-content/uploads/sites/127/2018/12/Informe-final-GTM-NDC_v17dic18.pdf.

2021. Inventario Nacional de Gases de Efecto Invernadero 2016. Lima: MINAM. (De pronta publicación.)

MINEM (Ministerio de Energía y Minas). 2020a. Anuario ejecutivo de electricidad 2019_(pp. 1-65). Lima: MINEM. Disponible en http://www.minem.gob.pe/_publicacion.php?idSector=6\&idPublicacion=614.

2020b. Balance Nacional de Energía 2018. Lima: MINEM. Disponible en https://sinia.minam.gob.pe/documentos/balance-nacional-energia-2018.

MEF (Ministerio de Economía y Finanzas). 2020. Anexo 11. Parámetros de evaluación social. Lima: Ministerio de Economía y Finanzas. Disponible en https://www.mef.gob.pe/contenidos/inv_publica/anexos/anexo11_directivaO01_2019EF6301.pdf. 
Naciones Unidas. 2015. Acuerdo de París. Nueva York: Naciones Unidas. Disponible en https://unfccc.int/sites/default/ files/spanish_paris_agreement.pdf.

OCDE (Organización para la Cooperación y el Desarrollo Económicos). 2017. Investing in Climate, Investing in Growth. París: OCDE. Disponible en https://doi.org/10.1787/9789264273528-en.

OSINFOR (Organismo de Supervisión de los Recursos Forestales y de Fauna Silvestre). 2018. Directiva para la compensación del pago de multas mediante el mecanismo de recuperación de áreas degradadas. Lima: OSINFOR.

Plan CC. 2013. Actualización del inventario de GEI año 2009. Disponible en http://planccperu.org/.

ProNaturaleza. 2007. Manual para la implementación y manejo de un sistema silvopastoril en el valle de Palcazú-Oxapampa. Disponible en http://www.iiap.org.pe/Upload/Publicacion/PUBL387.pdf.

Quintanilla, C., A. Sancho y H. Buttgenbach. 2018. Informe final. Servicio de análisis financiero de la Contribución Nacional "Manejo Forestal Comunitario" en el marco del Proyecto de Apoyo a la Gestión del Cambio Climático.

Ravikumar, A., Sear, R. R., Cronkleton, P., Menton M. y Pérez冈Ojeda del Arco, M. 2017. Is small-scale agriculture really the main driver of deforestation in the Peruvian Amazon? Moving beyond the prevailing narrative. Conservation Letters, 10(2): 170-177. Disponible en https://doi.org/10.1111/conl.12264.

Rochedo, P. R. R., Costa, I. V. L., Império, M., Hoffmann, B. S., de C. Merschmann, P. R., Oliveira, C. C. N., Szklo A. y Schaeffer, R. 2016. Carbon capture potential and costs in Brazil. Journal of Cleaner Production, 131: $280-295$. Disponible en https://doi.org/10.1016/j.jclepro.2016.05.033.

Schroten, A., et al. 2019. Overview of transport infrastructure expenditures and costs. Bruselas: Comisión Europea.

SEDAPAL (Servicio de Agua y Alcantarillado de Lima). 2019. Estructura tarifaria por los servicios de agua potable y alcantarillado. Lima: SEPADAL.

SERFOR (Servicio Nacional Forestal y de Fauna Silvestre). 2020. Sistema Nacional de Información Forestal y de Fauna Silvestre (SNIFFS). Lima: SERFOR.

UN PAGE. 2017. Perú: Crecimiento Verde. Análisis cuantitativo de políticas verdes en sectores seleccionados de la economía. Nueva York, NY: Naciones Unidas.

Vittor, A. Y., R. H. Gilman, J. Tielsch, G. Glass, T. Shields, W. S. Lozano, V. Pinedo-Cancino y J. A. Patz. 2006. The effect of deforestation on the human-biting rate of Anopheles darlingi, the primary vector of Falciparum malaria in the Peruvian Amazon. The American Journal of Tropical Medicine and Hygiene, 74(1): 3-11. Disponible en https:// doi.org/10.4269/ajtmh.2006.74.3.

Vogt-Schilb, A. 2021. "Stronger Sustainable Growth.” En: E. Cavallo y A. Powell (eds.), Opportunities for Stronger and Sustainable Postpandemic Growth. Washington, D.C.: BID. Disponible en http://dx.doi.org/10.18235/0003107.

Waisman, H., C. Bataille, H. Winkler, F. Jotzo, P. Shukla, M. Colombier, D. Buira, P. Criqui, M. Fischedick, M. Kainuma, E. La Rovere, S. Pye, G. Safonov, U. Siagian, F. Teng, M-R. Virdis, J. Williams, S. Young, G. Anandarajah, H. Trollip et al. 2019. A pathway design framework for national low greenhouse gas emission development strategies. Nature Climate Change, 9(4): 261-268. Disponible en https://doi.org/10.1038/s41558-019-0442-8.

Zare, K. y S. Nojavan. 2018. Operation of Distributed Energy Resources in Smart Distribution Networks. Ámsterdam: Elsevier. Disponible en https://doi.org/10.1016/C2017-0-02272-3. 


\section{Anexos}

\section{Anexo A: Proceso participativo y matriz DAMI}

En este anexo se presentan la lista de participantes de los talleres realizados y los elementos de la matriz denominada métricas de Desempeño, Acciones de política, Modelos y datos, e Incertidumbres (DAMI), co-creada en los talleres.

\section{A.1. Lista de asistentes a los talleres participativos}

El proceso participativo se desarrolló mediante dos talleres virtuales realizados del 21 al 23 de abril de 2020 y del 25 al 27 de agosto de 2020. En ellos se intercambiaron ideas y se expusieron resultados preliminares que sirvieron para fomentar una discusión co-creativa. El objeto de los talleres ha sido crear y repasar las variables principales de la matriz DAMI. El cuadro A1 muestra la lista de participantes que formaron parte de dichos espacios.

\section{Cuadro A1: Participantes de los talleres e institución de pertenencia}

\begin{tabular}{l|l}
\hline \multicolumn{1}{c|}{ Nombre completo } & \multicolumn{1}{c}{ Institución } \\
\hline Adolfo Rojas & Sustainablearth Latam \\
\hline Adrián Lazo Díaz & Ministerio de Transportes y Comunicaciones (MTC) \\
\hline Adrián Montalvo & SWISSCONTACT(MTC) \\
\hline Alan Campos & Ministerio de Energía y Minas (MINEM) \\
\hline Alberto Mamani Cahuana & $\begin{array}{l}\text { Servicio Nacional Forestal y de Fauna } \\
\text { Silvestre (SERFOR) }\end{array}$ \\
\hline Aldo Rosas & \begin{tabular}{l} 
Q-Energy Perú \\
\hline Alex Ascón Jiménez
\end{tabular} \\
\hline Alexander Galiano Uscapi & $\begin{array}{l}\text { Enex } \\
\text { (MIDAGRI) }\end{array}$ \\
\hline Alexis Luján & \begin{tabular}{l} 
Aceros Arequipa \\
\hline Alexs Arana
\end{tabular} \\
\hline
\end{tabular}




\begin{tabular}{|c|c|}
\hline Nombre completo & Institución \\
\hline Alfonso Florez & Transitemos \\
\hline Almendra Cáceres & Libélula \\
\hline Álvaro Torres & $\begin{array}{l}\text { Servicio de Agua Potable y Alcantarillado } \\
\text { de Lima (SEDAPAL) }\end{array}$ \\
\hline Amalia Delgado & SERFOR \\
\hline Ana Belén Sánchez & Organización Internacional del Trabajo (OIT) \\
\hline Anastasio Martínez Gómez & $\begin{array}{l}\text { Ministerio de Vivienda, Construcción y } \\
\text { Saneamiento (MVCS) }\end{array}$ \\
\hline Aníbal Requena & ANEPSSA PERU \\
\hline Anny Sofía López Castro & Consultora independiente \\
\hline Anthony Tuñón & MINEM \\
\hline Antonio Arenas & MINEM \\
\hline Arturo Caballero & A2G / PIR \\
\hline Augusto Mostajo & Ministerio del Ambiente (MINAM) \\
\hline Beatriz Calixto & $\begin{array}{l}\text { Autoridad de Transporte Urbano para } \\
\text { Lima y Callao (ATU) }\end{array}$ \\
\hline Belmira Alicia Carrera La Torre & SERFOR \\
\hline Beltrán Duhart & Implementa Sur \\
\hline Boris Villa & $\begin{array}{l}\text { Organismo de Supervisión de los Recursos } \\
\text { Forestales y de Fauna Silvestre (OSINFOR) }\end{array}$ \\
\hline Brendan Oviedo Doyle & Sociedad Peruana de Energías Renovables \\
\hline Brett Cohen & The Green House \\
\hline Carlos Adrianzen & Celepsa \\
\hline Carlos Alfredo Gómez Bravo & Universidad Nacional Agraria La Molina \\
\hline Carlos Candia & OSINFOR \\
\hline Carlos Echeverría & Banco Interamericano de Desarrollo (BID) \\
\hline Carlos Egúsquiza & MINAM \\
\hline Carlos Enrique Gallardo Torres & Ministerio de Economía y Finanzas (MEF) \\
\hline Carlos Ferraro & Asociación de Productores de Cemento (ASOCEM) \\
\hline
\end{tabular}




\begin{tabular}{|c|c|}
\hline Nombre completo & Institución \\
\hline Carlos Gómez & Universidad Nacional Agraria La Molina \\
\hline Carlos Rueda & Practical Action \\
\hline Carlos Sánchez & MINAM \\
\hline Carmen Rosa Chávez Hurtado & MIDAGRI \\
\hline Catalina Marinkovic & Pontificia Universidad Católica de Chile \\
\hline Cecilia Torre & PRODUCE \\
\hline Celestina Cruz Flores & MIDAGRI \\
\hline Celia Bedoya Jiménez & MIDAGRI \\
\hline César Hugo Dávila & MINAM \\
\hline César Ricardo Ramos Torero & MTC \\
\hline Claudia Arndt & Universidad Nacional Agraria La Molina \\
\hline Belmira Alicia Carrera La Torre & SERFOR \\
\hline Claudia Ato & $\begin{array}{l}\text { Autoridad de Transporte Urbano para } \\
\text { Lima y Callao (ATU) }\end{array}$ \\
\hline Claudia Espinoza & MINEM \\
\hline Claudia Monsalve & AMBERO Consulting \\
\hline Claudia Ochoa & $\begin{array}{l}\text { Servicio Nacional de Áreas Naturales } \\
\text { Protegidas por el Estado (SERNANP) }\end{array}$ \\
\hline Claudia Pasquel García & SERNANP \\
\hline Claudia Vela & MIDAGRI \\
\hline Claudio Schneider & Conservación Internacional \\
\hline Cristian Serricchio & Deloitte \\
\hline Cristina Urrutia & OI \\
\hline Damián Grignaffini & Deloitte \\
\hline Daniel Castillo Castillo & PNCBMCC \\
\hline Daniel Coronel & Mecanismos de Desarrollo Alternos (MDA) \\
\hline Daniel Lacca & MTC \\
\hline Danny Oswaldo Peñaloza Macha & SERFOR \\
\hline
\end{tabular}




\begin{tabular}{|c|c|}
\hline Nombre completo & Institución \\
\hline Dante Mauricio Pizarro Paz & Universidad Nacional Agraria La Molina \\
\hline David Aldana & SERFOR \\
\hline David Enrique Cueto Sánchez & Unión Andina de Cementos (UNACEM) \\
\hline Deyvis Huamán & SERNANP \\
\hline Diana Josefina Porlles Hurtado & Municipalidad Metropolitana de Lima \\
\hline Diego Cebreros & MINAM \\
\hline Doris Huamán Loaiza & $\begin{array}{l}\text { Empresa Prestadora de Saneamiento } \\
\text { Tacna S.A. }\end{array}$ \\
\hline Edith Rojas Perea & MIDAGRI \\
\hline Elena Ogusuku & DIGESA-MINSA \\
\hline Elena Rubio & SERFOR \\
\hline Elizabeth Escobar & MINAM \\
\hline Elizabeth Merino & MINAM \\
\hline Ellioth Tarazona Álvarez & Asociación Automotriz del Perú (AAP) \\
\hline Elvira Gómez Rivero & SERFOR \\
\hline Emilio García Conde & QEV Technologies S.L. \\
\hline Enrique Sarco Valdivieso & Pamolsa \\
\hline Erick Gidelberth García Portugal & MINEM \\
\hline Ethel Huaman Fuertes & MIDAGRI \\
\hline Ezio Varese & SOLIDARIDAD \\
\hline Fabiola Carreño & SERFOR \\
\hline Félix Domingo Marmanillo Bustamante & MVCS \\
\hline Fernando Acosta & MINAM \\
\hline Fernando Chiok & MVCS \\
\hline Fernando Hugo Cerna Chorres & MTC \\
\hline Fernando Romero & AMBERO Consulting \\
\hline Florencia Aquerreta & Deloitte \\
\hline Francisco Barrera & YURA S.A. \\
\hline
\end{tabular}




\begin{tabular}{|c|c|}
\hline Nombre completo & Institución \\
\hline Francisco Retuerto & MIDAGRI \\
\hline Franco Canziani & WAIRA ENERGÍA SAC \\
\hline Freddy Cerna Cobian & Koplast \\
\hline Gabriel Lenin Bazan Alcántara & SERFOR \\
\hline Gaby Rivera & Embajada Británica \\
\hline Gari Pascual & MIDAGRI \\
\hline Georg Schmid & $\mathrm{GIZ}$ \\
\hline Gerson Vélez & $\begin{array}{l}\text { Ente nazionale per l'energia elettrica } \\
\text { (ENEL) Perú }\end{array}$ \\
\hline Giannina Ibarra & MINEM \\
\hline Greta Castañeda & MVCS \\
\hline Guadalupe Alegría & OIT \\
\hline Guillaume Meyssonnier & Agencia Francesa de Desarrollo (AFD) \\
\hline Guillermo Ernesto Paz Guillén & SERFOR \\
\hline Guillermo León & MINAM \\
\hline Gustavo Rondón & $\begin{array}{l}\text { Centro Nacional de Planeamiento } \\
\text { Estratégico (CEPLAN) }\end{array}$ \\
\hline Gustavo Suárez de Freitas & Earth Innovation Institute (EII) \\
\hline Hans Buttgenbach Verde & MINAM \\
\hline Heduen Estrella & AFD \\
\hline Helliot Levano & $\begin{array}{l}\text { Sociedad Alemana para la Cooperación } \\
\text { Internacional (GIZ) }\end{array}$ \\
\hline Hernán Rodríguez & MINAM \\
\hline Hilany Buchelli & Libélula \\
\hline Hilda Lisseth Diaz Vargas & MINAM \\
\hline Hugo Rojas Senisse & SERFOR \\
\hline Víctor Hernan Villanueva Velásquez & Cementos Pacasmayo \\
\hline Iris Olivera & Derecho, Ambiente y Recursos Naturales (DAR) \\
\hline Irma Romero & MIDAGRI \\
\hline
\end{tabular}




\begin{tabular}{|c|c|}
\hline Nombre completo & Institución \\
\hline Dante Mauricio Pizarro Paz & Universidad Nacional Agraria La Molina \\
\hline Isaac Cieza Ruiz & Instituto Nacional de Innovación Agraria \\
\hline Isabel Málaga Cueva & MVCS \\
\hline Iván Maita & MTC \\
\hline Jaime Mansilla Rivera & MIDAGRI \\
\hline Jan Amaru Palomino Tofflinger & $\begin{array}{l}\text { Pontificia Universidad Católica del Perú } \\
\text { (PUCP) }\end{array}$ \\
\hline Javier Ernesto Hernández Campanella & MVCS \\
\hline Javier Game & $\mathrm{BID}$ \\
\hline Javier Peón & AEDIVE PERU - ALAMOS \\
\hline Jenny Chimayco & MINAM \\
\hline Jesica Medina & UNACEM \\
\hline Jessica Marroquin & SERFOR \\
\hline Jesús Salazar Nichi & Koplast \\
\hline Jesús Walter Carrasco Chacón & MINEM \\
\hline Johan León Moreno & Ministerio de la Producción \\
\hline Johanna Ventocilla Pazo & Cemento Yura \\
\hline Jorge Castro & UNACEM \\
\hline Jorge Correa Saldaña & CALIZA CEMENTO INCA S.A. \\
\hline Jorge Elliot & MINAM \\
\hline Jorge Figueroa & MIDAGRI \\
\hline Jorge Urbina & ONUDI \\
\hline José Atuncar & ANEPSSA PERU \\
\hline José Dextre & SERFOR \\
\hline José Luis Caro Jara & MINEM \\
\hline José Luis Torres De La Piedra & BYD Motors Peru SAC \\
\hline José Miguel Oporto Vargas & MINEM \\
\hline José Salinas Medina & EPS TACNA S.A. \\
\hline
\end{tabular}




\begin{tabular}{|c|c|}
\hline Nombre completo & Institución \\
\hline José Sánchez-Choy & $\begin{array}{l}\text { Centro Internacional de Agricultura Tropical } \\
\text { (CIAT) }\end{array}$ \\
\hline Juan Carlos Mesías & UNACEM \\
\hline Juan Coronado Lara & Auster Energía \\
\hline Juan Daniel Lao Olivares & MINAM \\
\hline Juan José Arrué & Fundación Transitemos \\
\hline Juan José Javier Jara & ENEL Perú \\
\hline Juan José Quintanilla Tuppia & ANEPSSA PERÚ \\
\hline Juan Pavel Olazábal Loaiza & Universidad Nacional Mayor de San Marcos \\
\hline Juan Tapia & $\begin{array}{l}\text { Centro de Investigación y Asesoría del } \\
\text { Transporte Terrestre (CIDATT) }\end{array}$ \\
\hline Julie Rozenberg & Banco Mundial \\
\hline Karina Viton & MIDAGRI \\
\hline Kely Alfaro Montoya & Libélula \\
\hline Laura Avellaneda & MIDAGRI \\
\hline Laura Secada & MINAM \\
\hline Leonor Marilez Orbegoso & SEDAPAL \\
\hline Lisseth Margot Zavaleta Castañeda & ATU \\
\hline Liz Rosales & MEF \\
\hline Lizbeth Cortez & SEDAPAL \\
\hline Lorena Magaly Durand Vivanco & SERFOR \\
\hline Lourdes Fernandez & OIT \\
\hline Lubinda Velásquez & CFI-Banco Mundial \\
\hline Lucero Luciano & MINEM \\
\hline Lucía Ruiz & Consultora independiente \\
\hline Luis Alberto Carranza Barrena & MVCS \\
\hline Luis Flores Alvarado & ENEL Perú \\
\hline Luis Orezzoli & $\mathrm{GIZ}$ \\
\hline
\end{tabular}




\begin{tabular}{|c|c|}
\hline Nombre completo & Institución \\
\hline Luis Vilchez & MINEM \\
\hline Maick Gómez Camarena & Caliza Cemento Inca S.A. \\
\hline Majed Ulises Velásquez Veliz & SERFOR \\
\hline Manuel Heredia & MINEM \\
\hline Manuel Salirrosas & SERFOR \\
\hline Marcela Jaramillo & $\mathrm{BID}$ \\
\hline Marco Antonio Llanos Ramírez & SERFOR \\
\hline Marco Antonio Osorio Villegas & PRODUCE \\
\hline Marco Arenas Aspilcueta & $\begin{array}{l}\text { Servicio Nacional de Áreas Nacionales } \\
\text { Protegidas por el Estado (SERNANP) }\end{array}$ \\
\hline Marco Llanos & SERFOR \\
\hline Marco Morales Valencia & Cementos Pacasmayo \\
\hline Marco Tinoco & Consultor independiente \\
\hline Margoth Espinoza & MINAM \\
\hline María Angélica Rondón & MINAM \\
\hline María Elena Díaz & SERNANP \\
\hline Maria Laura Lopez & MEF \\
\hline María Luisa Ángeles Grandez & BACKUS \\
\hline María Tristán & $\mathrm{CIAT}$ \\
\hline Mariano Morazzo & ENEL \\
\hline Marissa Andrade & MVCS \\
\hline Maritza D’Arrigo & MINAM \\
\hline Maritza Mayo & MINAM \\
\hline Marta Suber & ICRAF \\
\hline Marta Torres Gunfaus & IDDRI \\
\hline Martín Orellana & MEF \\
\hline Martín Reyes & ICRAF \\
\hline
\end{tabular}




\begin{tabular}{|c|c|}
\hline Nombre completo & Institución \\
\hline Mauro Ríos Torres & SERFOR \\
\hline Max Horstink & SouthSouthNorth \\
\hline Melissa Marengo & MEF \\
\hline Miguel Morales Rodríguez & Yura S.A. \\
\hline Milagros Morales Lavado & MTC \\
\hline Miriam Cerdán & SERFOR \\
\hline Mishael Espinoza & MINEM \\
\hline Modesto Edilberto Galvez Ríos & SERFOR \\
\hline Nadia Farje & MINAM \\
\hline Nadir Pallqui & MINAM \\
\hline Nelly Cabrera & MINAM \\
\hline Norma Salinas Revilla & Universidad Pacífico \\
\hline Octavio Rueda & llumina \\
\hline Orlando Ardito & EPEI-Perú \\
\hline Orlando Dávila & MTC \\
\hline Paola Vela Brandon & Municipalidad Metropolitana de Lima \\
\hline Patricia Angélica Aymar Olivera & MTC \\
\hline Patricia Durán Montesinos & SERFOR \\
\hline Patricia Luna del Pozo & Ell \\
\hline Patricia Patrón & MINAM \\
\hline Patricia Valdez Castro & $\begin{array}{l}\text { Comité de Sostenibilidad de la Sociedad } \\
\text { Nacional de Industrias }\end{array}$ \\
\hline Patricio Zambrano & BID \\
\hline Paúl Werner Caiguaray Pérez & MTC \\
\hline Pedro Lerner Rizo Patrón & CELEPSA \\
\hline Pedro Olivares & MTC \\
\hline Peggy Sztuden Wolfenzon & ARCA CONTINENTAL LINDLEY \\
\hline
\end{tabular}




\begin{tabular}{|c|c|}
\hline Nombre completo & Institución \\
\hline Pía Zevallos & Libélula \\
\hline Próspero Aurelio Yance & SERFOR \\
\hline Raquel Soto & MTC \\
\hline Raúl Delgado & BID \\
\hline Raúl Javier Dancé Sifuentes & SERFOR \\
\hline Ricardo Pareja & Federación Interamericana de Cemento (FICEM) \\
\hline Ricardo Villavicencio Ferro & MINEM \\
\hline Richard Tito León & PUCP \\
\hline Riquel Mitma & OSINERGMIN \\
\hline Roberto Obradovich & BYD Motors Perú SAC \\
\hline Roberto Piselli & MINAM \\
\hline Roberto Prieto & MVCS \\
\hline Roberto Tamayo & $\begin{array}{l}\text { Universidad Nacional de Ingeniería (UNI) } \\
\text { de Perú }\end{array}$ \\
\hline Rocío Aldana & Libélula \\
\hline Rocío Robles & ATU \\
\hline Rogelio Humberto Campos García & MINAM \\
\hline Rolando Vivanco & $\begin{array}{l}\text { Programa Nacional de Conservación de } \\
\text { Bosques (PNCBMCC) }\end{array}$ \\
\hline Rosa María Román & CIFOR \\
\hline Rosalyn Gozar & MINAM \\
\hline Pía Zevallos & Libélula \\
\hline Próspero Aurelio Yance & SERFOR \\
\hline Raquel Soto & MTC \\
\hline Raúl Delgado & BID \\
\hline Raúl Javier Dancé Sifuentes & SERFOR \\
\hline Ricardo Pareja & Federación Interamericana de Cemento (FICEM) \\
\hline
\end{tabular}




\begin{tabular}{|c|c|}
\hline Nombre completo & Institución \\
\hline Ricardo Villavicencio Ferro & MINEM \\
\hline Richard Tito León & PUCP \\
\hline Riquel Mitma & OSINERGMIN \\
\hline Roberto Obradovich & BYD Motors Perú SAC \\
\hline Roberto Piselli & MINAM \\
\hline Roberto Prieto & MVCS \\
\hline Roberto Tamayo & $\begin{array}{l}\text { Universidad Nacional de Ingeniería (UNI) } \\
\text { de Perú }\end{array}$ \\
\hline Rocío Aldana & Libélula \\
\hline Rocío Robles & ATU \\
\hline Rogelio Humberto Campos García & MINAM \\
\hline Rolando Vivanco & $\begin{array}{l}\text { Programa Nacional de Conservación de } \\
\text { Bosques (PNCBMCC) }\end{array}$ \\
\hline Rosa María Román & CIFOR \\
\hline Rosalyn Gozar & MINAM \\
\hline Ruddy Mendoza Calla & $\mathrm{GIZ}$ \\
\hline Sandra Alencastre Vega & The Coca-Cola Company \\
\hline Sandra Roncal & MIDAGRI \\
\hline Santiago Dunne & UNEP \\
\hline Scarleth Núñez & BID \\
\hline Segundo Fausto Roncal Vergara & MTC \\
\hline Segundo Orlando Dávila Vizconde & PROMOVILIDAD \\
\hline Silvana Rebaza & $\begin{array}{l}\text { Ministerio de Relaciones Exteriores y de la } \\
\text { Mancomunidad de Naciones (FCDO) del } \\
\text { Reino Unido }\end{array}$ \\
\hline Sonia Beatriz Aranibar Tapia & MINAM \\
\hline Sonia León & ANEPSSA PERÚ \\
\hline Stephany Basurto & MBCC Group \\
\hline
\end{tabular}




\begin{tabular}{|c|c|}
\hline Nombre completo & Institución \\
\hline Susan Aragón & INTE-PUCP \\
\hline Susana Zárate & Textil Amazonas \\
\hline Susi Salazar Hinostroza & MIDAGRI \\
\hline Tania Ysabel Zamora & $\mathrm{GIZ}$ \\
\hline Tatiana Erika Boza Espinoza & PUCP \\
\hline Teófilo Beingolea & Rikolto \\
\hline Valentina Robiglio & $\begin{array}{l}\text { Consejo Internacional para la } \\
\text { Investigación en Agroforestería (ICRAF) }\end{array}$ \\
\hline Verónica Villena & MEF \\
\hline Veronika Magaly Mendoza Díaz & MINAM \\
\hline Victoire de Wever & AFD \\
\hline Víctor Galarreta & MDA \\
\hline Víctor Santillán & MINAM \\
\hline Victoria Ribera & MINAM \\
\hline Víctor Cisneros & Unión Andina de Cementos (UNACEM) \\
\hline Wiliam Segura & Flesan Energía SAC \\
\hline Will Dulanto & BYD Motors Perú SAC \\
\hline William Agustín Chata Yauri & MINAM \\
\hline Ximena Guardia Muguruza & $\begin{array}{l}\text { Universidad de Energía y Tecnología } \\
\text { (UTEC) de Perú }\end{array}$ \\
\hline Yovita Ivanova & $\mathrm{CIAT}$ \\
\hline
\end{tabular}




\section{A.2. Medidas de desempeño (Ds) de la matriz DAMI}

El cuadro A2 resume las principales medidas de desempeño identificadas con los participantes de los talleres. Se incluyen las emisiones de gases de efecto invernadero (GEI), las relaciones de costobeneficio por sector y en total, los beneficios por salud, los ingresos, la tasa de deforestación, etc. No es posible reportar la totalidad de las medidas en este estudio, pero las que se presentan sirven para informar futuros proyectos que puedan extender el análisis aquí expuesto.

\section{Cuadro A2: Medidas de desempeño utilizadas en el proyecto}

\begin{tabular}{|c|c|}
\hline Sector & Métrica \\
\hline Transversal & Relación costo-beneficio por sector y total \\
\hline Transversal & Emisiones sectoriales y totales de $\mathrm{GEI}\left(\mathrm{CO}_{2 \mathrm{e}}\right)$ \\
\hline Transversal & Importaciones y exportaciones por sector \\
\hline Transversal & Intensidad carbono por sector \\
\hline Energía & Intensidad energética \\
\hline Energía & Tarifa electricidad \\
\hline Energía & Acceso a la electricidad \\
\hline Energía & Empleo \\
\hline Transporte & $\begin{array}{l}\text { Beneficios en salud, congestión, } \\
\text { accidentes y daños en carreteras }\end{array}$ \\
\hline Transporte & Tiempo en tráfico \\
\hline AFOLU & Ingreso neto forestal \\
\hline AFOLU & $\begin{array}{l}\text { Dólares por tonelada de } \mathrm{CO}_{2 \mathrm{e}} \text { secuestrada } \\
\text { por el bosque }\end{array}$ \\
\hline AFOLU & Tasa de deforestación \\
\hline AFOLU & $\begin{array}{l}\text { Costo del consumo per cápita diario de } \\
\text { productos agropecuarios }\end{array}$ \\
\hline AFOLU & Consumo total de calorías \\
\hline AFOLU & Costo por tonelada de $\mathrm{CO}_{2 \mathrm{e}}$ emitida por la actividad \\
\hline Residuos & Emisiones por tonelada de residuos $\left(\mathrm{CO}_{2 \mathrm{e}} /\right.$ ton $)$ \\
\hline Procesos industriales & Emisiones por tonelada de producción $\left(\mathrm{CO}_{2 \mathrm{e}} / \mathrm{ton}\right)$ \\
\hline
\end{tabular}




\section{A.3. Acciones de políticas (As) de la matriz DAMI}

El cuadro A3 sintetiza las acciones de políticas que los participantes de los talleres consideraron relevantes y que pueden estudiarse junto con los modelos propuestos para el proceso de descarbonización de Perú. Resaltan como acciones comunes entre sectores los cambios estructurales (matriz eléctrica, composición de la flotilla y dietas). El cambio modal al transporte público y al transporte no motorizado (o movilidad activa) se mencionó para reducir el uso del transporte privado. Se exploran la preservación y reforestación de los bosques, así como mejoras en los rendimientos del sector agrícola, los residuos y los procesos industriales en la descarbonización

\section{Cuadro A3: Acciones de políticas exploradas en el proyecto}

\begin{tabular}{|c|c|}
\hline Sector & Acción de políticas \\
\hline Energía & Cambios en la matriz eléctrica y energética. \\
\hline Energía & Cambios en el consumo de energía por eficiencia energética. \\
\hline Transporte & Composición del parque vehicular (e.g., fracción de vehículos eléctricos). \\
\hline Transporte & $\begin{array}{l}\text { Cambio modal en transporte motorizado (implementación de los } \\
\text { Corredores Complementarios del Sistema Integrado de Transporte } \\
\text { de Lima, operación actual del Metropolitano y ampliaciones, e } \\
\text { implementación de las Líneas } 1 \text { y } 2 \text { del Metro de Lima y Callao). }\end{array}$ \\
\hline Transporte & $\begin{array}{l}\text { Cambio modal de transporte motorizado por transporte no motori-zado } \\
\text { y digitalización de las actividades. }\end{array}$ \\
\hline Transporte & $\begin{array}{l}\text { Mejoras y creación de infraestructura para aumentar la eficiencia del } \\
\text { sistema de transporte y reducir las distancias de viaje. }\end{array}$ \\
\hline AFOLU & $\begin{array}{l}\text { Área conservada y reforestada (puede responder a manejo fores-tal } \\
\text { sostenible en concesiones forestales, manejo forestal comuni-tario en } \\
\text { CCNN tituladas y mecanismos de conservación de bos-ques en CCNN } \\
\text { tituladas). }\end{array}$ \\
\hline AFOLU & Mejoras en el rendimiento de la producción agrícola y ganadera. \\
\hline AFOLU & $\begin{array}{l}\text { Reducción de emisiones (factor de emisión) de los procesos de } \\
\text { producción (e.g., debido al uso de fertilizantes orgánicos). }\end{array}$ \\
\hline AFOLU & $\begin{array}{l}\text { Cambios en las preferencias de los consumidores (promoción de cambios } \\
\text { de hábitos de las personas hacia una dieta saludable y sostenible). }\end{array}$ \\
\hline Residuos & Reciclaje y compostaje. \\
\hline Residuos & Construcción de plantas de tratamiento. \\
\hline Procesos industriales & $\begin{array}{l}\text { Reducción del factor clínker, eficiencia en la producción de cemento, } \\
\text { captura de carbono en concreto, cambio en el uso de combustibles } \\
\text { fósiles hacia alternativas renovables. }\end{array}$ \\
\hline
\end{tabular}




\section{A.4. Modelos y datos (Ms) de la matriz DAMI}

Los participantes de los talleres mencionaron múltiples fuentes de información para alimentar los modelos (cuadro A4). Gran parte de la información utilizada en este estudio proviene de instituciones públicas y es de acceso público. La información se ha empleado para ajustar los modelos existentes y explorar los modelos sugeridos en aras de estudiar las opciones de descarbonización y el desempeño del escenario de carbono-neutralidad.

\section{Cuadro A4: Modelos y datos utilizados en el proyecto}

\begin{tabular}{|c|c|}
\hline Sector & Fuente de datos \\
\hline Transversal & INGEI \\
\hline Energía & COES \\
\hline Energía & Geotermia INGEME \\
\hline Energía & OSINERGMIN (SCOP-Demanda Departamental) \\
\hline Energía & Encuesta OSINERGMIN (Departamento) \\
\hline Energía & Mapa de índice de radiación solar \\
\hline Energía & Mapa solar 2003 \\
\hline Energía & $\begin{array}{l}\text { Parque nacional de luminarias (MINEM- DGEE/ } \\
\text { CUANTO 2016) }\end{array}$ \\
\hline Energía & SUNAT \\
\hline Transporte & $\begin{array}{l}\text { Base de datos de transporte de carga (a nivel } \\
\text { regional) }\end{array}$ \\
\hline Transporte & $\begin{array}{l}\text { Base de datos transporte urbano (Lima, } \\
\text { Arequipa, Trujillo, Cusco) }\end{array}$ \\
\hline Transporte & $\begin{array}{l}\text { Data de desplazamiento logístico (Orlando } \\
\text { Dávila, MTC) }\end{array}$ \\
\hline Transporte & Plan Maestro 2012 - Cooperación Japonesa \\
\hline Transporte & $\begin{array}{l}\text { Flota de vehículos (MTC; municipalidades } \\
\text { transporte urbano en operación) }\end{array}$ \\
\hline Transporte & Lima cómo vamos - Portal Web \\
\hline Transporte & Infogas \\
\hline
\end{tabular}




\begin{tabular}{|c|c|}
\hline Sector & Fuente de datos \\
\hline Transporte & Movilidad eléctrica (GEF) \\
\hline Transporte & $\begin{array}{l}\text { MTC (Transporte Urbano Sostenible - Lima y } \\
\text { Callo 2018) }\end{array}$ \\
\hline Transporte & $\begin{array}{l}\text { OSINERGMIN (reportes de ventas de } \\
\text { combustible líquidos) }\end{array}$ \\
\hline Transporte & Fondo Monetario Internacional (FMI) \\
\hline Transporte & Geobosques \\
\hline AFOLU & Geoserfor \\
\hline AFOLU & Sistema de alerta temprana \\
\hline AFOLU & Perú en números \\
\hline AFOLU & SUNAT \\
\hline AFOLU & Infocarbono (emisiones de GEI anuales) \\
\hline AFOLU & $\begin{array}{l}\text { Mapa de bosques y no bosques (actualizado a } \\
\text { 2018) }\end{array}$ \\
\hline AFOLU & $\begin{array}{l}\text { Sistema Nacional de información Forestal y Fauna } \\
\text { Silvestre }\end{array}$ \\
\hline AFOLU & US Forest Service \\
\hline AFOLU & AGRIMONITOR \\
\hline AFOLU & Encuesta Nacional Agropecuaria \\
\hline AFOLU & Encuesta Nacional de Hogares \\
\hline AFOLU & $\begin{array}{l}\text { Organización de las Naciones Unidas para la } \\
\text { Alimentación y la Agricultura (FAO) }\end{array}$ \\
\hline
\end{tabular}




\section{A.5. Incertidumbres (Is) de la matriz DAMI}

Hay múltiples incertidumbres que podrían tener un efecto en la estrategia de descarbonización (cuadro A5). El producto interno bruto (PIB) y la población afectarán las demandas de energía, transporte, cultivos y carnes. Los costos tecnológicos, los de los combustibles fósiles, la eficiencia tecnológica y los rendimientos del sector agrícola incidirán en los costos, los beneficios y las emisiones de GEI. Los precios internacionales de los cultivos y los cambios en los patrones de consumo complementan la lista de incertidumbres exploradas.

\section{Cuadro A5: Incertidumbres exploradas en el proyecto}

\begin{tabular}{|c|c|}
\hline Sector & Incertidumbre \\
\hline Transversal & Producto interno bruto (PIB) \\
\hline Transversal & Población \\
\hline Energía & $\begin{array}{l}\text { Costos capitales y operativos de tecnologías } \\
\text { renovables }\end{array}$ \\
\hline Energía & Demanda de electricidad dependiente del PIB \\
\hline Energía & Precios de electricidad y combustibles \\
\hline Energía & Factores de eficiencia \\
\hline Energía & Potencial de energías renovables \\
\hline Transporte & Costos de las tecnologías \\
\hline Transporte & Costo de combustibles fósiles \\
\hline Transporte & Factores de eficiencia \\
\hline Transporte & Factores de uso \\
\hline AFOLU & Precio internacional del carbono forestal \\
\hline AFOLU & Precio de la madera de plantaciones forestales \\
\hline AFOLU & Valor económico de los servicios ecosistémicos \\
\hline AFOLU & $\begin{array}{l}\text { Rendimiento maderero de las concesiones } \\
\text { forestales }\end{array}$ \\
\hline AFOLU & $\begin{array}{l}\text { Rendimiento maderero de las } \\
\text { plantaciones forestales }\end{array}$ \\
\hline AFOLU & $\begin{array}{l}\text { Precios internacionales de los cultivos y } \\
\text { productos pecuarios }\end{array}$ \\
\hline
\end{tabular}




\begin{tabular}{l|l}
\hline Sector & \multicolumn{1}{c}{ Incertidumbre } \\
\hline AFOLU & $\begin{array}{l}\text { Rendimientos de los cultivos y productos } \\
\text { pecuarios }\end{array}$ \\
\hline AFOLU & Costos de inversión \\
\hline AFOLU & Costos de operación \\
\hline AFOLU & Factores de emisión \\
\hline AFOLU & Geoserfor \\
\hline Residuos & Factor de emisión de residuos \\
\hline Residuos & Cantidad de residuos producidos \\
\hline Procesos industriales & Factor de emisión de los procesos \\
\hline Procesos industriales & Demanda de cemento \\
\hline Procesos industriales & Relación importación/producción de cemento \\
\hline
\end{tabular}

\section{Anexo B: Método y modelos}

El proyecto utiliza el método de toma de decisiones robustas (RDM, por sus siglas en inglés). Se han combinado modelos sectoriales para estudiar integralmente la evolución de la economía y su relación con las emisiones de GEI, más los beneficios y los costos del proceso de descarbonización. El estudio analiza el efecto de la incertidumbre tecnológica, política y social mediante la exploración de rutas plausibles de implementación de los escenarios desarrollados. El gráfico B1 muestra un esquema general de la metodología aplicada, la cual contempla un diseño experimental y una etapa de exploración de las rutas plausibles. Ambas etapas se sirven de la información que surge de los procesos participativos y de la formulación de la matriz
DAMI, y han sido producidas con la finalidad de que a futuro se retroalimenten con nueva información. A continuación, se describen las dos etapas:

- Diseño experimental: Constituye la etapa inicial del proceso exploratorio. En ella se definen los objetivos de políticas y las incertidumbres que deberán ser exploradas, junto con sus correspondientes rangos de variación. Se define la cantidad de rutas de implementación que se examinarán (1.001 rutas en este estudio). Cada ruta utiliza el valor base de los parámetros, que son modificados según el resultado de un algoritmo de muestreo. Se utiliza el método estadístico "Latin hypercube sampling" (LHS) en código Python [B1]. 
- Modelado y simulación: Esta etapa representa la caracterización del sector de la economía mediante modelos computacionales que, bajo una serie de consideraciones, permite representar los cambios transformacionales por sector, así como la transformación nacional representada por la suma de los sectores.
El desarrollo de este proceso requiere la generación de bases de datos (típicamente es una compilación de datos). El proceso está compuesto por subrutinas computacionales para evaluar el efecto de las políticas de descarbonización e incluye una etapa de visualización para comunicar resultados.

Gráfico B1: Esquema general para evaluar beneficios y costos de la descarbonización

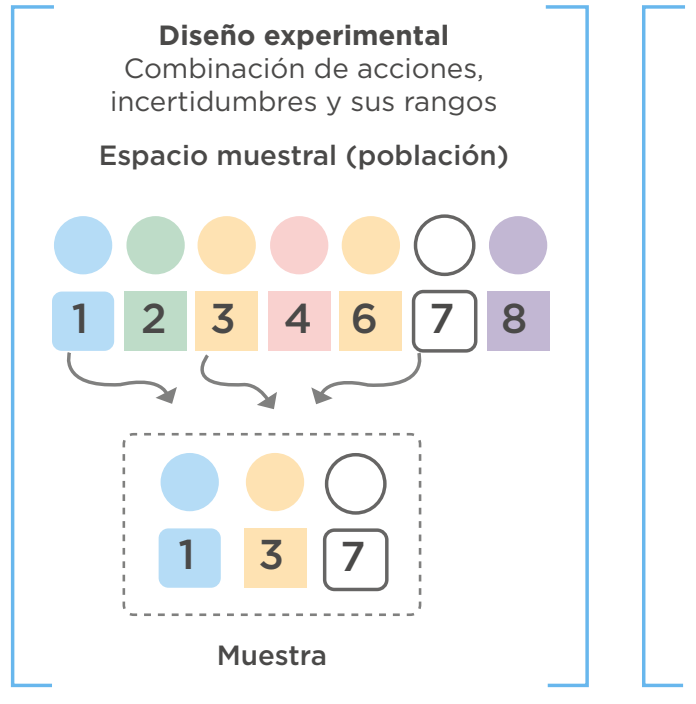

\section{B.1. Diseño experimental utilizado en el proyecto}

El diseño experimental se basa en el muestreo de parámetros con el fin de generar una distribución de datos multidimensionales que permitan explorar la relación de variables de manera óptima sin necesidad de muestrear el $100 \%$ del espacio muestral. En el contexto de la metodología de toma de decisiones robustas (RDM, por sus siglas en inglés), el muestreo de incertidumbres profundas se hace típicamente de forma uniforme con rangos que van desde el 50\% hasta el 150\%
Modelado y simulación

Ejecución de múltiples simulaciones para explorar futuros

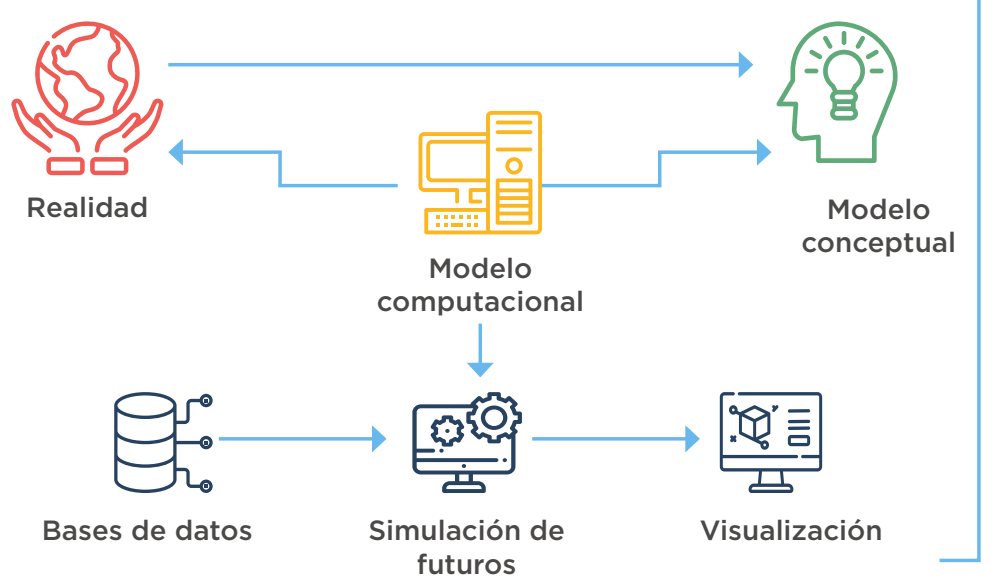

del valor base. Existen otras variables que no obedecen esta regla, por ejemplo el precio del carbono cuyo valor base es US\$O por tonelada de $\mathrm{CO}_{2 \mathrm{e}}$. El gráfico B2 presenta este concepto a partir de un sistema de variables independientes $X Y Z$ en un espacio normalizado de $O$ a 1 con 100 eventos. EI algoritmo LHS selecciona combinaciones de estas variables que facilitan una distribución uniforme en todo el espacio de datos (solo se permite una variable por dimensión). En este ejemplo 
simple, cada punto en el espacio representa una posibilidad que combina tres variables, las cuales a su vez serán modeladas.

El proyecto utilizó un diseño experimental considerando 63 variables independientes normalizadas, que a su vez permiten modificar 201 parámetros dentro de los modelos. Por ejemplo, los cambios en el PIB ajustan 23 variables en los modelos. Cada parámetro es representado mediante una serie de tiempo en el horizonte de estudio (2020-50) que toma como referencia la trayectoria base creada a partir de supuestos estándar sobre la evolución del sistema. Se han realizado 1.001 rutas plausibles de implementación de los escenarios que permiten generar evidencia de las incertidumbres y responder a preguntas como la siguiente:

"¿Qué pasa si en una ruta de descarbonización los costos de las plantas fotovoltaicas se reducen considerablemente, pero los vehículos eléctricos mantienen sus costos? ¿Y si en esta combinación la demanda de consumo de carne vacuna sube o aumenta el precio del carbono?"

En los cuadros B1 a B6 se muestran el conjunto de variables independientes, los rangos explorados y las incertidumbres asociadas para cada uno de los sectores.

\section{Gráfico B2: Concepto de muestreo con LHS}
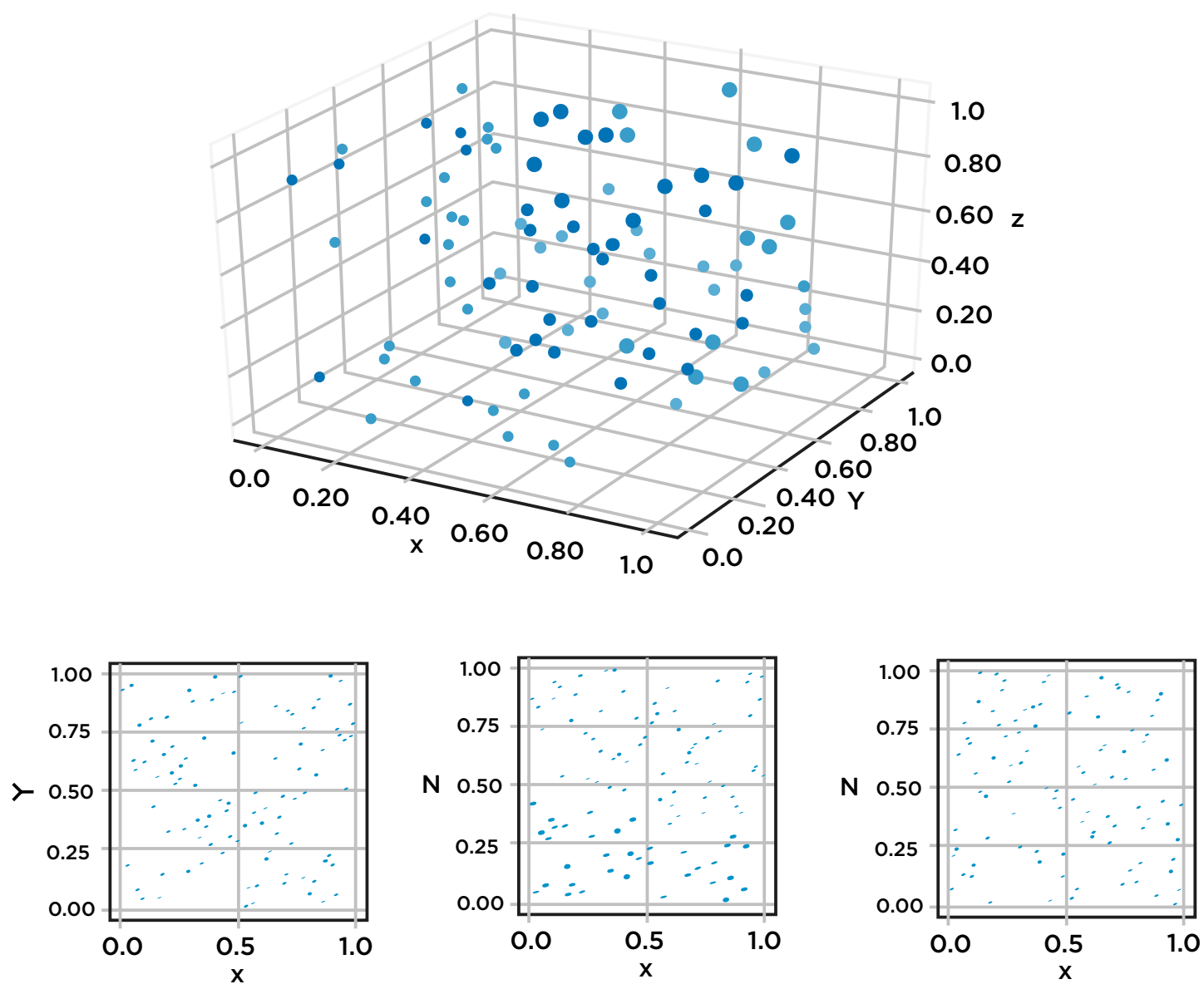
El cuadro B1 muestra las incertidumbres transversales; es decir, que afectan a múltiples variables en los modelos. Las demandas de los modelos se estiman sobre la base del crecimiento de la población y los cambios en el PIB. El impacto económico del cambio climático sobre Perú se calcula usando el costo social del carbono y se aplica a las emisiones de todos sectores; los costos de las emisiones en salud son exclusivos del sector energía y transporte, y se asocian a enfermedades ligadas al uso de hidrocarburos.

\section{Cuadro B1: Conjuntos de variables normalizadas, rango de variación e incertidumbres (transversales)}

\begin{tabular}{|c|c|c|}
\hline Variables independientes & Rangos* & Incertidumbres asociadas (variables dependientes) \\
\hline Producto interno bruto & 0,5 a 1,5 & \multirow{2}{*}{$\begin{array}{l}\text { Demanda: energía (1), electricidad (1), transporte de } \\
\text { pasajeros (1), transporte de carga (1), cultivos (12), } \\
\text { ganadería (3), residuos sólidos (1), vertidos (1), efluentes } \\
\text { industriales (1) y uso de clínker (1) }\end{array}$} \\
\hline Población & 0,9 a 1 & \\
\hline Efectos sociales & 0,5 a 1,5 & Costo de las emisiones en términos de salud (1) \\
\hline
\end{tabular}

* Para el rango de variación se considera que el valor de referencia es 1. El valor de referencia es el correspondiente a 2050 en la serie tiempo bajo los supuestos estándar.

Las incertidumbres en energía contemplan costos de capital, costos operativos, factores de planta, precios de combustibles, coeficiente de beneficios y coeficiente de emisión (cuadro B2).

\section{Cuadro B2: Conjuntos de variables normalizadas, rango de variación e incertidumbres (energía)}

\begin{tabular}{l|l|l} 
Variables independientes & Rangos* & Incertidumbres asociadas (variables dependientes) \\
$\begin{array}{l}\text { Costos capitales de } \\
\text { plantas renovables } \\
\text { convencionales }\end{array}$ & 0,5 a 1,5 & Hidro (1), biomasa (1) y geotermia (1) \\
\hline $\begin{array}{l}\text { Costos capitales de } \\
\text { plantas renovables } \\
\text { no convencionales }\end{array}$ & 0,5 a 1,5 & Solar (1) y eólica (1) \\
\hline $\begin{array}{l}\text { Costos capitales de } \\
\text { plantas térmicas }\end{array}$ & 0,5 a 1,5 & Gas natural (1) y diésel (1) \\
\hline $\begin{array}{l}\text { Costos capitales de } \\
\text { las redes eléctricas }\end{array}$ & 0,5 a 1,5 & Transmisión y distribución (1) \\
\hline $\begin{array}{l}\text { Costos capitales } \\
\text { de refinería }\end{array}$ & 0,5 a 1,5 & Refinería de petróleo (1) \\
\hline
\end{tabular}




\begin{tabular}{|c|c|c|}
\hline $\begin{array}{l}\text { Variables } \\
\text { independientes }\end{array}$ & Rangos* & Incertidumbres asociadas (variables dependientes) \\
\hline $\begin{array}{l}\text { Costos capitales } \\
\text { de plantas de } \\
\text { gas natural }\end{array}$ & 0,5 a 1,5 & Plantas procesadoras de gas natural (1) \\
\hline $\begin{array}{l}\text { Costos capitales } \\
\text { de carboneras }\end{array}$ & 0,5 a 1,5 & Carboneras (1) \\
\hline $\begin{array}{l}\text { Costos operativos } \\
\text { de plantas } \\
\text { renovables }\end{array}$ & 0,5 a 1,5 & $\begin{array}{l}\text { Hidro (1), solar (1), eólica (1), biomasa (1) y geotermia } \\
\text { (1) }\end{array}$ \\
\hline $\begin{array}{l}\text { Costos operativos de } \\
\text { plantas térmicas }\end{array}$ & 0,5 a 1,5 & Gas natural (1) y diésel (1) \\
\hline $\begin{array}{l}\text { Costos operativos } \\
\text { de redes eléctricas }\end{array}$ & 0,5 a 1,5 & Transmisión y distribución (1) \\
\hline $\begin{array}{l}\text { Costos operativos } \\
\text { de refinería }\end{array}$ & 0,5 a 1,5 & Refinería de petróleo (1) \\
\hline $\begin{array}{l}\text { Costos operativos } \\
\text { de plantas de gas } \\
\text { natural }\end{array}$ & 0,5 a 1,5 & Plantas procesadores gas natural (1) \\
\hline $\begin{array}{l}\text { Costos operativos } \\
\text { de carboneras }\end{array}$ & 0,5 a 1,5 & Carboneras (1) \\
\hline $\begin{array}{l}\text { Costos en el sistema } \\
\text { eléctrico moderno }\end{array}$ & 0,5 a 1,5 & $\begin{array}{l}\text { Costos de implementar redes inteligentes (1) y } \\
\text { cargadores eléctricos (1) }\end{array}$ \\
\hline $\begin{array}{l}\text { Precios de } \\
\text { combustibles }\end{array}$ & 0,5 a 1,5 & Importaciones (1) y exportaciones (1) \\
\hline $\begin{array}{l}\text { Coeficientes de } \\
\text { emisión }\end{array}$ & 0,8 a 1,2 & Electricidad (1) y energía (1) \\
\hline Factores de planta & 0,5 a 1,5 & $\begin{array}{l}\text { Hidro (1), solar (1), eólica (1), biomasa (1), } \\
\text { geotermia (1), gas natural (1) y diésel (1) }\end{array}$ \\
\hline
\end{tabular}

* Para el rango de variación se considera que el valor de referencia es 1. El valor de referencia es el correspondiente a 2050 en la serie tiempo bajo los supuestos estándar.

Las incertidumbres en transporte contemplan costos de capital, costos operativos, eficiencias, coeficiente de beneficios y coeficiente de emisión (cuadro B3). 


\section{Cuadro B3: Conjuntos de variables normalizadas, rango de variación e incertidumbres (transporte)}

\begin{tabular}{|c|c|c|}
\hline $\begin{array}{c}\text { Variables } \\
\text { independientes }\end{array}$ & Rangos* & Incertidumbres asociadas (variables dependientes) \\
\hline $\begin{array}{l}\text { Costos capitales } \\
\text { del transporte cero } \\
\text { emisiones (pasajeros) }\end{array}$ & 0,5 a 1,5 & Vehículos (1), buses (1), taxis (1), motos (1) \\
\hline $\begin{array}{l}\text { Costos capitales } \\
\text { del transporte cero } \\
\text { emisiones (carga) }\end{array}$ & 0,5 a 1,5 & Liviana (1), mediana (1), pesada (1) \\
\hline $\begin{array}{l}\text { Costos capitales del } \\
\text { transporte de gas } \\
\text { natural (pasajeros) }\end{array}$ & 0,5 a 1,5 & Vehículos (1), buses (1), taxis (1) \\
\hline $\begin{array}{l}\text { Costos capitales del } \\
\text { transporte de gas } \\
\text { natural (carga) }\end{array}$ & 0,5 a 1,5 & Liviana (1), mediana (1), pesada (1) \\
\hline $\begin{array}{l}\text { Costos capitales } \\
\text { del transporte } \\
\text { fósil (pasajeros) }\end{array}$ & 0,5 a 1,5 & Vehículos (1), buses (1), taxis (1), motos (1) \\
\hline $\begin{array}{l}\text { Costos capitales } \\
\text { del transporte } \\
\text { fósil (carga) }\end{array}$ & 0,5 a 1,5 & Liviana (1), mediana (1), pesada (1) \\
\hline $\begin{array}{l}\text { Costos operativos } \\
\text { del transporte cero } \\
\text { emisiones (pasajeros) }\end{array}$ & 0,5 a 1,5 & Vehículos (1), buses (1), taxis (1), motos (1) \\
\hline $\begin{array}{l}\text { Costos operativos } \\
\text { del transporte cero } \\
\text { emisiones (carga) }\end{array}$ & 0,5 a 1,5 & Liviana (1), mediana (1), pesada (1) \\
\hline $\begin{array}{l}\text { Costos operativos } \\
\text { del transporte de gas } \\
\text { natural (pasajeros) }\end{array}$ & 0,5 a 1,5 & Vehículos (1), buses (1), taxis (1) \\
\hline $\begin{array}{l}\text { Costos operativos } \\
\text { del transporte de } \\
\text { gas natural (carga) }\end{array}$ & 0,5 a 1,5 & Liviana (1), mediana (1), pesada (1) \\
\hline $\begin{array}{l}\text { Costos capitales } \\
\text { del transporte } \\
\text { fósil (pasajeros) }\end{array}$ & 0,5 a 1,5 & Vehículos (1), buses (1), taxis (1), motos (1) \\
\hline $\begin{array}{l}\text { Costos capitales } \\
\text { del transporte } \\
\text { fósil (carga) }\end{array}$ & 0,5 a 1,5 & Liviana (1), mediana (1), pesada (1) \\
\hline $\begin{array}{l}\text { Eficiencias en } \\
\text { tecnologías }\end{array}$ & 0,5 a 1,5 & Carga (9), pasajeros (12) \\
\hline
\end{tabular}




\begin{tabular}{l|l|l}
$\begin{array}{c}\text { Variables } \\
\text { independientes }\end{array}$ & Rangos* & Incertidumbres asociadas (variables dependientes) \\
$\begin{array}{l}\text { Costo de } \\
\text { infraestructura }\end{array}$ & 0,5 a 1,5 & Pasajeros (1) y carga (1) \\
\hline $\begin{array}{l}\text { Beneficios en } \\
\text { transporte }\end{array}$ & 0,5 a 1,5 & Congestión (1), accidentes (1) \\
\hline $\begin{array}{l}\text { Coeficientes de } \\
\text { emisión }\end{array}$ & 0,8 a 1,2 & Carga (1), pasajeros (1) \\
\hline
\end{tabular}

* Para el rango de variación se considera que el valor de referencia es 1. El valor de referencia es el correspondiente a 2050 en la serie tiempo bajo los supuestos estándar.

Las incertidumbres en agricultura, silvicultura y otros usos de la tierra (AFOLU) contemplan costos de capital, costos operativos, rendimientos, precios del carbono y de la madera, y valor de los servicios ecosistémicos (cuadro B4).

\section{Cuadro B4: Conjuntos de variables normalizadas, rango de variación e incertidumbres (AFOLU)}

\begin{tabular}{l|c|l}
$\begin{array}{c}\text { Variables } \\
\text { independientes }\end{array}$ & Rangos* & Incertidumbres asociadas (variables dependientes) \\
\hline Mercado del carbono & 0 a 200 & Precios del carbono \\
\hline Precios de los cultivos & 0,75 a 3 & Cultivos (10) \\
\hline $\begin{array}{l}\text { Tasa de incremento } \\
\text { de los rendimientos } \\
\text { en agricultura }\end{array}$ & 0,5 a 3 & Cultivos (14) \\
\hline $\begin{array}{l}\text { Costos capitales de } \\
\text { agricultura }\end{array}$ & 0,8 a 2 & Cultivos (14) \\
\hline $\begin{array}{l}\text { Costos capitales } \\
\text { de ganadería }\end{array}$ & 0,75 a 1,25 & Ganado (3) \\
\hline $\begin{array}{l}\text { Costos capitales } \\
\text { de UTCUTS }\end{array}$ & 0,8 a 2 & Inversiones en el sector UTCUTS (1) \\
\hline $\begin{array}{l}\text { Costos operativos } \\
\text { en agricultura }\end{array}$ & 0,75 a 1,35 & Cultivos (14) \\
\hline
\end{tabular}




\begin{tabular}{|c|c|c|}
\hline $\begin{array}{l}\text { Variables } \\
\text { independientes }\end{array}$ & Rangos* & Incertidumbres asociadas (variables dependientes) \\
\hline $\begin{array}{l}\text { Costos operativos de } \\
\text { ganadería }\end{array}$ & 0,75 a 1,35 & Ganado (3) \\
\hline $\begin{array}{l}\text { Costos operativos de } \\
\text { UTCUTS }\end{array}$ & 0,85 a 1,25 & Operaciones en el sector UTCUTS (1) \\
\hline $\begin{array}{l}\text { Coeficientes de emisión } \\
\text { de cultivos }\end{array}$ & 0,5 a 1,5 & Cultivos (14) \\
\hline $\begin{array}{l}\text { Coeficientes } \\
\text { de emisión de } \\
\text { ganadería }\end{array}$ & 0,5 a 1,5 & Cultivos (14) \\
\hline $\begin{array}{l}\text { Coeficientes de emisión } \\
\text { de UTCUTS }\end{array}$ & 0,85 a 1,15 & Coeficientes de emisión de UTCUTS (1) \\
\hline $\begin{array}{l}\text { Parámetro de secuestro de } \\
\text { carbono de plantaciones }\end{array}$ & 0,85 a 1,15 & Plantaciones forestales (1) \\
\hline $\begin{array}{l}\text { Rendimiento de } \\
\text { concesiones forestales y } \\
\text { concesiones bajo manejo } \\
\text { forestal sostenible }\end{array}$ & 0,3 a 1,7 & Concesiones forestales (1) \\
\hline $\begin{array}{l}\text { Rendimiento de planta- } \\
\text { ciones comerciales }\end{array}$ & 0,85 a 1,15 & Plantaciones forestales (1) \\
\hline $\begin{array}{l}\text { Valor económico de los } \\
\text { servicios ecosistémicos }\end{array}$ & 0,7 a 2,2 & Ingresos por los servicios ecosistémicos (1) \\
\hline $\begin{array}{l}\text { Precio de la madera/ } \\
\text { concesiones forestales y } \\
\text { concesiones bajo manejo } \\
\text { forestal sostenible }\end{array}$ & 0,8 a 2,5 & $\begin{array}{l}\text { Ingresos por venta de madera por } \\
\text { concesión (1) }\end{array}$ \\
\hline $\begin{array}{l}\text { Precio de la madera/ } \\
\text { plantaciones forestales } \\
\text { comerciales }\end{array}$ & 0,75 a 1,5 & $\begin{array}{l}\text { Ingresos por venta de madera/ } \\
\text { plantaciones ( } 1 \text { ) }\end{array}$ \\
\hline
\end{tabular}

* Para el rango de variación se considera que el valor de referencia es 1. El valor de referencia es el correspondiente a 2050 en la serie de tiempo bajo los supuestos estándar. Excepto para el precio del carbono, cuya base es 0 US\$/tCOze y puede aumentar hasta 200 US\$/tCO2e.

Las incertidumbres en residuos contemplan costos de capital, costos operativos, coeficiente de beneficios y coeficiente de emisión (cuadro B5). 


\section{Cuadro B5: Conjuntos de variables normalizadas, rango de variación e incertidumbres (residuos)}

\begin{tabular}{l|l|l}
\multicolumn{1}{c|}{$\begin{array}{c}\text { Variables } \\
\text { independientes }\end{array}$} & Rangos* & Incertidumbres asociadas (variables dependientes) \\
$\begin{array}{l}\text { Costos en residuos } \\
\text { O,5 a } 1,5\end{array}$ & Costos de recolectar residuos (1) \\
\hline $\begin{array}{l}\text { Inversiones en } \\
\text { residuos }\end{array}$ & 0,5 a 1,5 & Costo de reciclar y tratar aguas residuales \\
\hline $\begin{array}{l}\text { Beneficios en } \\
\text { residuos }\end{array}$ & 0,8 a 1,2 & Ingresos por reciclaje (1), ingresos por tratar aguas (1) \\
\hline $\begin{array}{l}\text { Emisiones en } \\
\text { residuos sólidos }\end{array}$ & 0,5 a 1,5 & Coeficientes de emisión en residuos sólidos (1) \\
\hline $\begin{array}{l}\text { Emisiones en } \\
\text { aguas residuales }\end{array}$ & 0,5 a 1,5 & Coeficientes de emisión en aguas residuales (1) \\
\hline
\end{tabular}

* Para el rango de variación se considera que el valor de referencia es 1. El valor de referencia es el correspondiente a 2050 en la serie de tiempo bajo los supuestos estándar.

Las incertidumbres en procesos industriales y uso de productos (PIUP) contemplan costos de capital para reducir el uso de clínker y coeficiente de emisión (cuadro B6).

\section{Cuadro B6: Conjuntos de variables normalizadas, rango de variación e incertidumbres (PIUP)}

\begin{tabular}{l|l|l}
$\begin{array}{c}\text { Variables } \\
\text { independientes }\end{array}$ & Rangos* & Incertidumbres asociadas (variables dependientes) \\
$\begin{array}{l}\text { Inversiones en el } \\
\text { sector cemento }\end{array}$ & 0,5 a 1,5 & Costos de reducir el uso de clínker (1) \\
\hline $\begin{array}{l}\text { Emisiones de } \\
\text { cemento }\end{array}$ & 0,5 a 1,5 & Coeficientes de emisión para el sector cemento (1) \\
\hline
\end{tabular}

* Para el rango de variación se considera que el valor de referencia es 1. El valor de referencia es el correspondiente a 2050 en la serie de tiempo bajo los supuestos estándar. 


\section{B.2. Estimación de emisiones, beneficios y costos}

Las emisiones de GEl se estiman en función de los niveles de actividad que tiene cada uno de los sectores, procesos o tecnologías, a saber: vehículos, toneladas de cultivos, cantidad de residuos, usos de la tierra y procesos industriales, entre otros. Para tal efecto, se consideran coeficientes de emisiones por actividad y se calibra con el año base de los modelos. En este estudio, se usa el Inventario Nacional de Gases de Efecto Invernadero de 2014 [B2]. Mediante la construcción de múltiples proyecciones de los niveles de actividad (demandas o uso particular de algunas tecnologías) se genera una gran cantidad de trayectorias de emisiones.

Los beneficios del escenario de descarbonización se estiman con las diferencias entre los niveles de actividad. Por ejemplo, los beneficios en la salud producto de una reducida combustión de hidrocarburos en los sectores energía y transporte se calculan multiplicando los cambios en los consumos de combustibles fósiles por coeficientes disponibles en la literatura del Fondo Monetario Internacional (FMI) que reflejan los costos asociados al tratamiento de enfermedades cardiorrespiratorias debido a la contaminación para Perú. De igual forma, el beneficio por servicios ecosistémicos se estima multiplicando las diferencias de cobertura de cada tipo de bosque por un coeficiente que representa el valor ecosistémico.

Los costos de capital y de operación de las transiciones tecnológicas o los cambios en procesos se calculan de manera similar. Se multiplica el nivel de actividad o la cantidad de una tecnología por el valor unitario de la tecnología. Por ejemplo, el costo de invertir en plantas solares fotovoltaicas equivale a la capacidad instalada por el costo por unidad de potencia instalada. De igual forma, los costos operativos de los vehículos eléctricos se estiman multiplicando la cantidad de electricidad consumida (en petajulios [PJ]) por el costo de la electricidad.

\section{B.2.1. Parámetros transversales en los modelos}

Existen cuatro variables transversales a los modelos sectoriales; es decir, se trata de parámetros que afectan las estimaciones en más de un modelo. Estas variables a su vez fueron sometidas a incertidumbre. El cuadro B7 presenta el valor base y su correspondiente rango de variación.

Los rangos de variación de los parámetros en cada uno de los modelos se presentaron en los cuadros B2 a B6. Cabe destacar que, en muchas ocasiones, el valor del parámetro es fijo a 2050. Por ejemplo, el costo social del carbono (US\$7,7 por cada tonelada de $\mathrm{CO}_{2}$; véase el cuadro $\mathrm{B} 7$ ) es el mismo en el horizonte de tiempo (el valor descontado si reduce su magnitud). En el experimento para producir las rutas plausibles, las variables inciertas que poseen un valor fijo cambian su magnitud con un factor multiplicador definido por el LHS. Sin embargo, el valor del parámetro mantiene la tendencia constante en el horizonte. Cuando se posee una serie de tiempo de un parámetro, como el crecimiento de la población y la tasa de cambio del PIB, el factor multiplicador afecta la magnitud de la curva base. Por ejemplo, el gráfico B3 muestra las distintas trayectorias del crecimiento poblacional y la tasa de cambio del PIB. Como se observa, las distintas parametrizaciones de estas variables poseen una curva similar a la base (que aparece en azul oscuro con los números base), pero con diferente magnitud. 
Cuadro B7: Incertidumbres transversales en los modelos

\begin{tabular}{l|c|c}
$\begin{array}{c}\text { Nombre del } \\
\text { parámetro }\end{array}$ & \multicolumn{1}{|c}{ Valor } & Fuente \\
\hline Población & $\begin{array}{l}\text { A 2050, el valor base varía entre un }+/-10 \% \\
\text { (gráfico B3) }\end{array}$ & [B3] \\
\hline $\begin{array}{l}\text { Tasa de } \\
\text { cambio del } \\
\text { PIB }\end{array}$ & $\begin{array}{l}\text { A 2050, la tasa de cambio varía entre un } \\
+/-50 \% \text { (gráfico B3) }\end{array}$ & [B3] \\
\hline $\begin{array}{l}\text { Costo en } \\
\text { salud por } \\
\text { combustión }\end{array}$ & $\begin{array}{l}\text { Valores base: } \$ 0,0263 / \text { I (gasolina) } \$ 0,3141 / / \\
\text { (diésel); se experimenta entre un }+/-50 \%\end{array}$ \\
\hline
\end{tabular}

Gráfico B3: Trayectorias de largo plazo para el PIB y la población
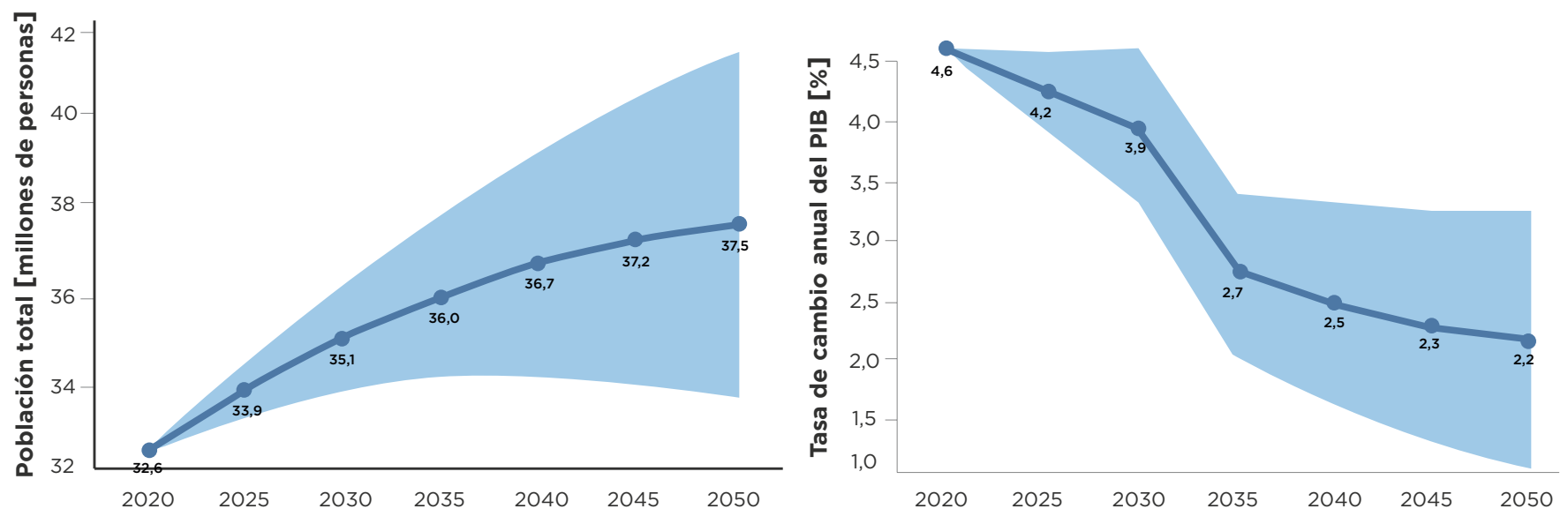


\section{B.2.2. Energía}

A continuación, se presentan los principales supuestos de modelación del sector energía, los coeficientes base de los costos y beneficios, y las trayectorias de los parámetros.

\section{Supuestos de modelación}

- El modelo representa el comportamiento de todo el país; es decir, no hay regionalización. La división temporal es anual y las series de tiempo van a 2050.

- Las acciones de descarbonización se consideran a partir de 2021.

- Costos de las energías renovables: Se asume que los costos de capital de las energías renovables (energía eólica, energía solar y almacenamiento) tienen un pronóstico decreciente.

- Demanda de la energía eléctrica: Se supone un crecimiento de la demanda de energía eléctrica a 2040 según el informe del Comité de Operación Económica del Sistema Interconectado Nacional (COES). Esta se proyecta de manera jerárquica y se distribuye por subsector de acuerdo con los porcentajes del año base.

- Costos de los combustibles fósiles: Se proyecta que los valores de costos de los combustibles fósiles aumentan según el informe 9 del Programa para la Gestión Eficiente y Sostenible de los Recursos Energéticos del Perú (Prosemer).

- Se considera que, para el escenario de descarbonización, no existirán fuertes inversiones en refinerías ni plantas de procesamiento de gas natural.

- Las acciones de descarbonización toman como referencia las políticas del catálogo de medidas de mitigación del Ministerio del Ambiente (MINAM) publicado en 2018.

- Se incluye una mayor cantidad de equipos con eficiencias (un 35\% a 2050).

\section{Factores de beneficios y costos}

El cuadro B8 muestra los factores base de costos y beneficios utilizados en el sector energía. Aunque en un sistema renovable existen otros beneficios, como la empleabilidad y las tarifas reducidas, en el momento de este estudio no se obtuvo información para su estimación.

\section{Trayectorias de los parámetros}

Los gráficos B4 a B6 muestran las trayectorias de los distintos parámetros que poseen una serie de tiempo en el sector energía. 
Cuadro B8: Factores de costos y beneficios para el sector energía

\begin{tabular}{|c|c|c|}
\hline Parámetro & Valor & Fuente \\
\hline $\begin{array}{l}\text { Plantas de } \\
\text { generación } \\
\text { eléctrica; } \\
\text { costos: capital } \\
\text { y operación }\end{array}$ & $\begin{array}{l}\text { Plantas térmicas fósiles: US } \$ 1.250 / \mathrm{kW} \& \text { US } \$ 44 / \mathrm{kW} \\
\text { Plantas térmicas a gas: US } \$ 1.100 / \mathrm{kW} \& \text { US } \$ 47,9 / \mathrm{kW} \\
\text { Plantas biomasa: US } \$ 1.270 / \mathrm{kW} \& \text { US } \$ 44 / \mathrm{kW} \\
\text { Plantas hidroeléctricas: US } \$ 1.111,55 / \mathrm{kW} \& \text { \& } \$ 44 / \mathrm{kW} \\
\text { Plantas geotérmicas: US } \$ 3.495 / \mathrm{kW} \& \text { US } \$ 44,5 / \mathrm{kW} \\
\text { Plantas fotovoltaicas US } \$ 1.009,34 / \mathrm{kW} \& \text { US } \$ 13 / \mathrm{kW} \\
\text { Plantas eólicas: US\$1.099,34/kW \& US\$44/kW }\end{array}$ & [B9]-[B13] \\
\hline $\begin{array}{l}\text { Red eléctrica } \\
\text { de transmisión } \\
\text { y distribución }\end{array}$ & $\begin{array}{l}\text { Se asume un costo por nivel de actividad de } 61,98 \\
\text { MUSD/PJ de manera anual. }\end{array}$ & [B11] \\
\hline $\begin{array}{l}\text { Red de } \\
\text { cargadores } \\
\text { eléctricos }\end{array}$ & $\begin{array}{l}\text { Se asume un costo por nivel de actividad de } \\
\text { 70,6 MUSD/PJ de manera anual, vinculada a la } \\
\text { demanda del transporte. }\end{array}$ & [B11] \\
\hline $\begin{array}{l}\text { Implementación } \\
\text { de redes } \\
\text { inteligentes }\end{array}$ & $\begin{array}{l}\text { Se considera un costo de inversión de US } \$ 2.500 / \\
\text { kW (se utiliza como referencia la capacidad de } \\
\text { renovables no convencionales). }\end{array}$ & [B14] \\
\hline $\begin{array}{l}\text { Plantas de } \\
\text { procesamiento } \\
\text { de gas natural, } \\
\text { refinerías y } \\
\text { carboneras }\end{array}$ & $\begin{array}{l}\text { Plantas de gas: 3,7 MUSD/PJ \& 8,67 MUSD/PJ } \\
\text { Refinería: 8,06 MUSD/PJ \& 5,6 MUSD/PJ } \\
\text { Carbonera. 2,5 MUSD/PJ \& 2,5 MUSD/PJ }\end{array}$ & [B9]-[B10] \\
\hline
\end{tabular}


Gráfico B4: Variaciones para la demanda de electricidad y energía eléctrica
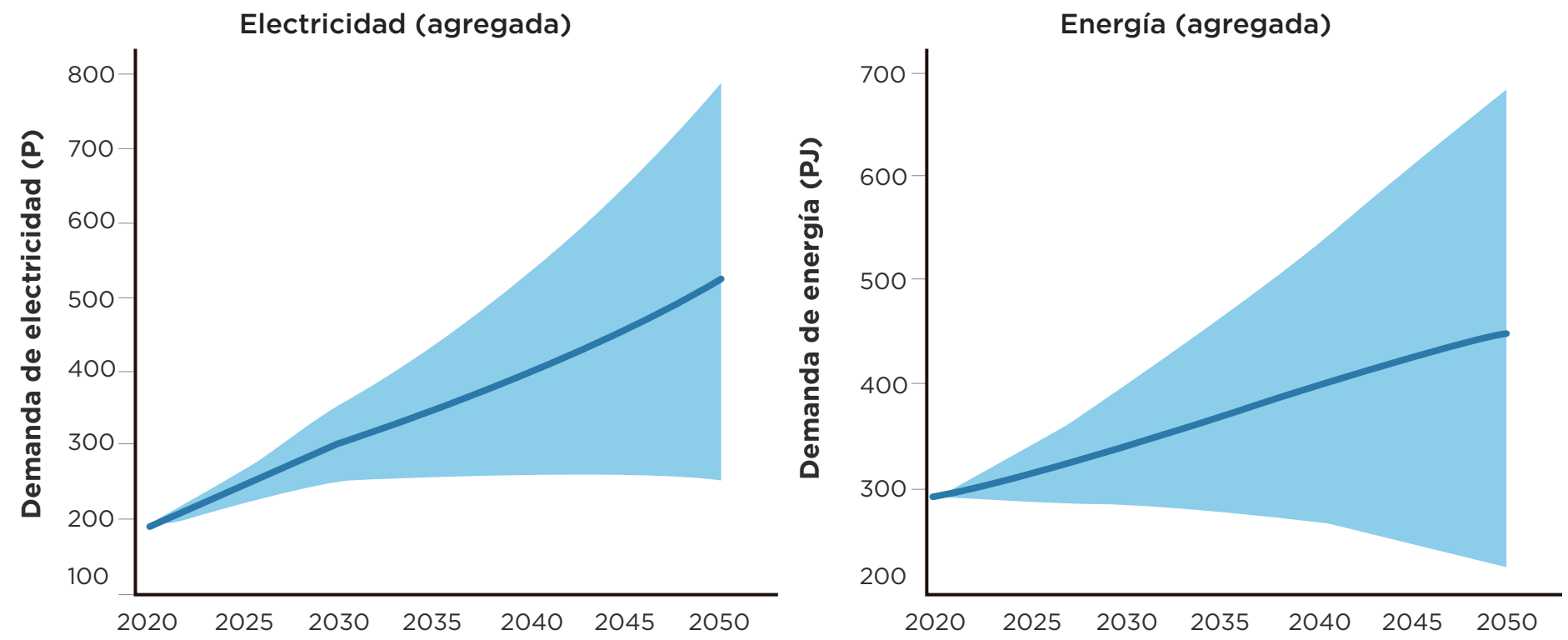

Gráfico B5: Costos de capital de plantas eléctricas
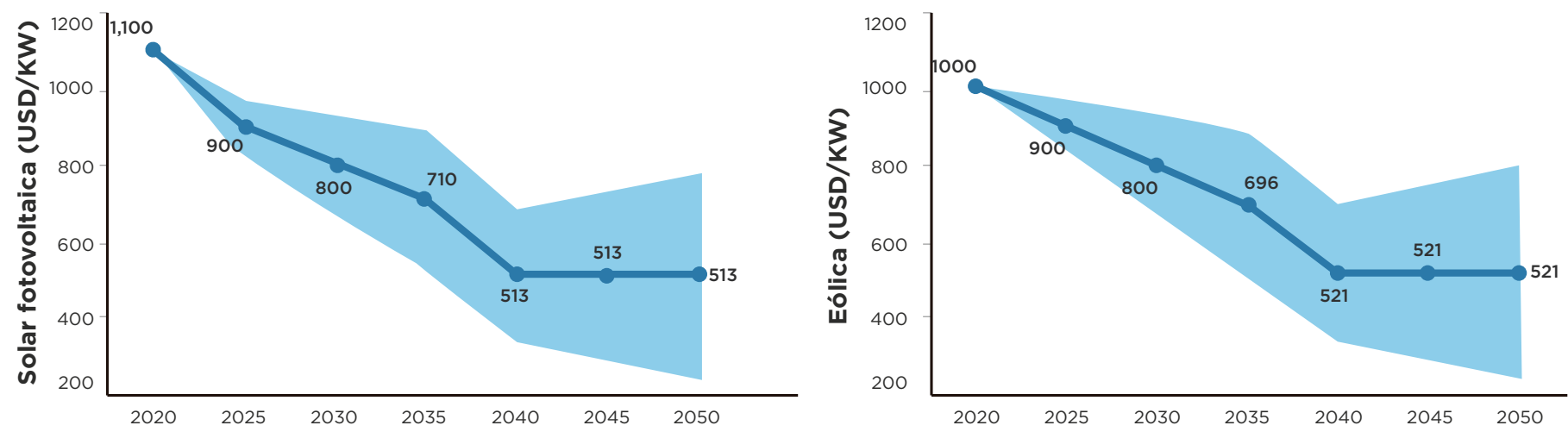


\section{Gráfico B6: Factores de plantas para la generación de electricidad}
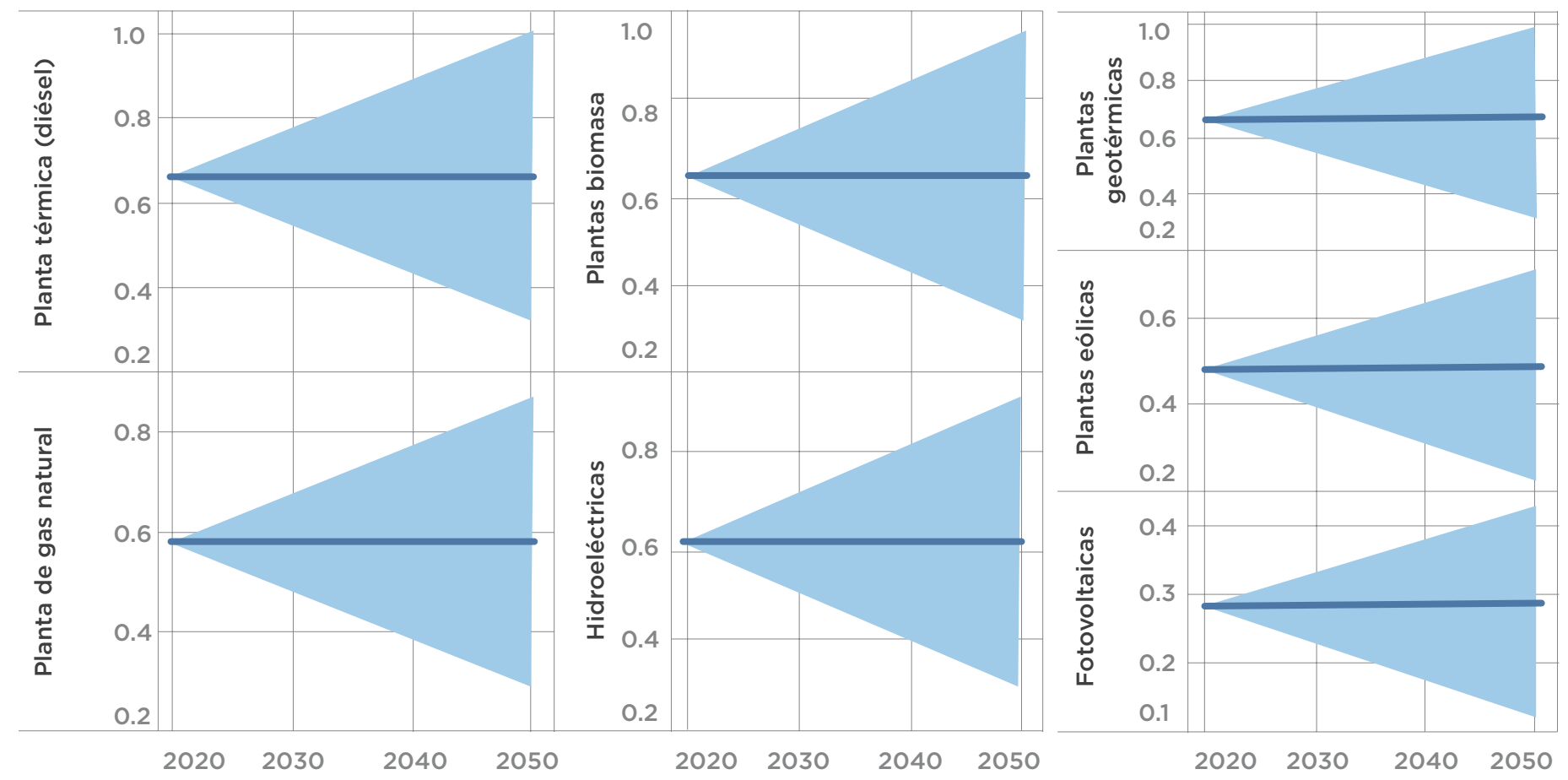

\section{B.2.3. Transporte}

A continuación, se presentan los principales supuestos de modelación del sector transporte, los coeficientes base de los costos y beneficios, y las trayectorias de los parámetros.

\section{Supuestos de modelación}

- El modelo representa el comportamiento de todo el país; es decir, no hay regionalización. La división temporal es anual y las series de tiempo van a 2050.
- Las acciones de descarbonización se consideran a partir de 2021.

- Costos de los vehículos eléctricos: Se supone que los precios de los vehículos eléctricos disminuyen en el tiempo según el Informe 9 del Prosemer y las tendencias internacionales.

- Se considera que el sistema de transporte será electrificado en su totalidad para 2050 y que existirán las condiciones habilitadoras para esta transición. 
- Infraestructura del sector transporte: Se asume que los proyectos del sector transporte aumentan según el Plan Nacional de Infraestructura para la Competitividad del Ministerio de Economía y Finanzas emitido en 2018. En este contexto, se considera que las inversiones en infraestructura permitirán una disminución de la demanda tanto de transporte de pasajeros como de carga.

- Demanda de energía para transporte de los diferentes sectores de consumo de energía: Los pronósticos de la demanda de energía en el sector transporte se basan en el Informe 9 del Prosemer. En este apartado, se considera un incremento predominante en el transporte de carga.

- Se estima que el transporte público de pasajeros seguirá predominando y que el servicio mejorará sus estándares para evitar el cambio modal hacia vehículos privados.
- Se calcula que existirá un cambio modal hacia el transporte no motorizado. Esta condición se basa en la tendencia global de impulsar un desarrollo urbano sostenible. Se considera que esta condición permitirá reducir la demanda de transporte de pasajeros.

- Se asume que las condiciones de teletrabajo experimentadas en 2020 se mantendrán parcialmente y promoverán una disminución adicional de la demanda de pasajeros. Se considera que esto irá acompañado por un proceso de digitalización de los servicios públicos.

\section{Factores de beneficios y costos}

El cuadro B9 muestra los factores base de costos y beneficios utilizados en el sector transporte. Aunque en un sistema renovable existen otros beneficios, como la empleabilidad y las tarifas del transporte, en el momento de este estudio no se obtuvo información para su análisis. 


\section{Cuadro B9: Factores de costos y beneficios para el sector transporte}

\begin{tabular}{|c|c|c|}
\hline Parámetro & Valor & Fuente \\
\hline $\begin{array}{l}\text { Costo de la } \\
\text { congestión }\end{array}$ & $\begin{array}{l}\text { US } \$ 0,162 / \text { I (gasolina); US } \$ 0,135 / \text { I (diésel) } \\
\text { También aplica para vehículos eléctricos } \\
\text { En livianos se usa el coeficiente de gasolina y en buses y } \\
\text { camiones el de diésel }\end{array}$ & [B6] \\
\hline $\begin{array}{l}\text { Costo de } \\
\text { accidentes }\end{array}$ & $\begin{array}{l}\text { US } \$ 0,12 / \text { I (gasolina); US } \$ 0,056 / \text { l (diésel) } \\
\text { También aplica para vehículos eléctricos } \\
\text { En livianos se usa el coeficiente de gasolina y en buses y } \\
\text { camiones el de diésel }\end{array}$ & [B6] \\
\hline $\begin{array}{l}\text { Costos de } \\
\text { vehículos; } \\
\text { capital y } \\
\text { operación }\end{array}$ & $\begin{array}{l}\text { Vehículos livianos: } \\
\text { Combustión interna: 901,6 MUSD/Gpkm \& 32,8 MUSD/Gpkm } \\
\text { Gas natural: 1.127,02 MUSD/Gpkm \& 32,8 MUSD/Gpkm } \\
\text { Eléctricos: 1.870,06 MUSD/Gpkm \& 10,8 MUSD/Gpkm } \\
\text { Autobuses: } \\
\text { Combustión interna: 132,77 MUSD/Gpkm \& 6,7 MUSD/Gpkm } \\
\text { Gas natural: 146,68 MUSD/Gpkm \& 3,9 MUSD/Gpkm } \\
\text { Eléctricos: 5.936 MUSD/Gpkm \& 2,2 MUSD/Gpkm } \\
\text { Motocicletas: } \\
\text { Combustión interna: 122,33 MUSD/Gpkm \& 5,4 MUSD/Gpkm } \\
\text { Eléctricos: } 202 \text { MUSD/Gpkm \& 1,79 MUSD/Gpkm } \\
\text { Taxis: } \\
\text { Combustión interna: 410,1 MUSD/Gpkm \& 49,3 MUSD/Gpkm } \\
\text { Gas natural: 526,1 MUSD/Gpkm \& 49,3 MUSD/Gpkm } \\
\text { Eléctricos: 719 MUSD/Gpkm \& 16,28 MUSD/Gpkm } \\
\text { Camionetas (carga liviana): } \\
\text { Combustión interna: 680,5 MUSD/Gpkm \& 118,2 MUSD/Gtkm } \\
\text { Gas Natural: 794,1 MUSD/Gpkm \& 118,2 MUSD/Gtkm } \\
\text { Eléctricos: 4.190 MUSD/Gpkm \& 35,2 MUSD/Gtkm } \\
\text { Camiones (carga media): } \\
\text { Combustión interna: 335,9 MUSD/Gpkm \& 70,2 MUSD/Gtkm } \\
\text { Gas natural: 470,4 MUSD/Gpkm \& 62,5 MUSD/Gtkm } \\
\text { Eléctricos: 4.320 MUSD/Gpkm \& 20,8 MUSD/Gtkm } \\
\text { Trailer (carga pesada): } \\
\text { Combustión interna: 202,33 MUSD/Gpkm \& 42,2 MUSD/Gtkm } \\
\text { Gas natural: 283,3 MUSD/Gpkm \& 35,2 MUSD/Gtkm } \\
\text { Eléctricos: 4.450 MUSD/Gpkm \& 13,94 MUSD/Gtkm }\end{array}$ & [B9]-[B11] \\
\hline $\begin{array}{l}\text { Inversiones en } \\
\text { infraestructura }\end{array}$ & $\begin{array}{l}\text { Costo de reducir unidades de demanda } 150 \text { MUSD/ } \\
\text { Gpkm (pasajeros) y } 150 \text { MUSD/Gtkm (carga) }\end{array}$ & [B15]-[B16] \\
\hline
\end{tabular}

\section{Trayectorias de los parámetros}

Los gráficos B7 a B9 muestran las trayectorias de los distintos parámetros que poseen una serie de tiempo en el sector transporte. 
Gráfico B7: Proyecciones de demanda en el sector transporte y rangos de variación

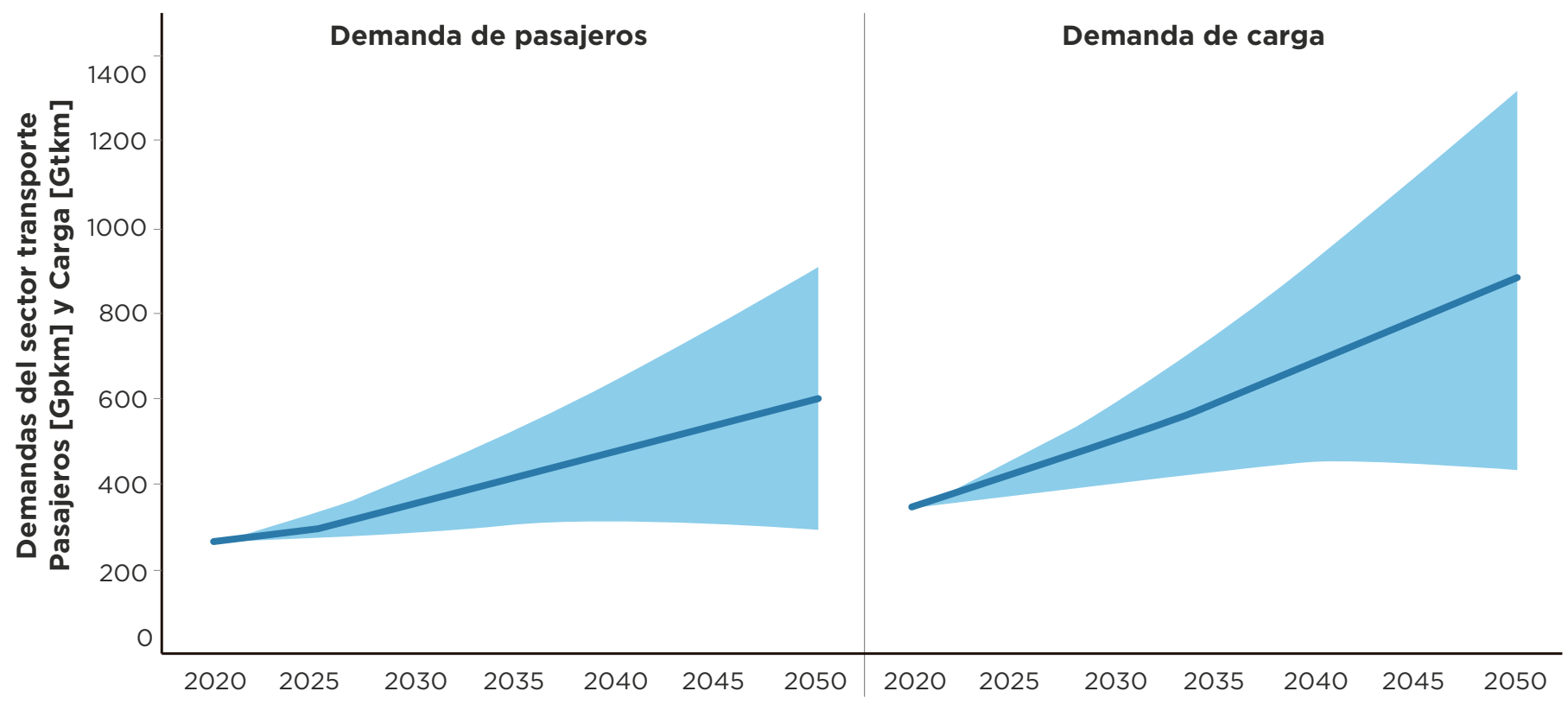

Gráfico B8: Costos capitales para el transporte de pasajeros

\section{Costos capitales (MUSD/Gpkm)}

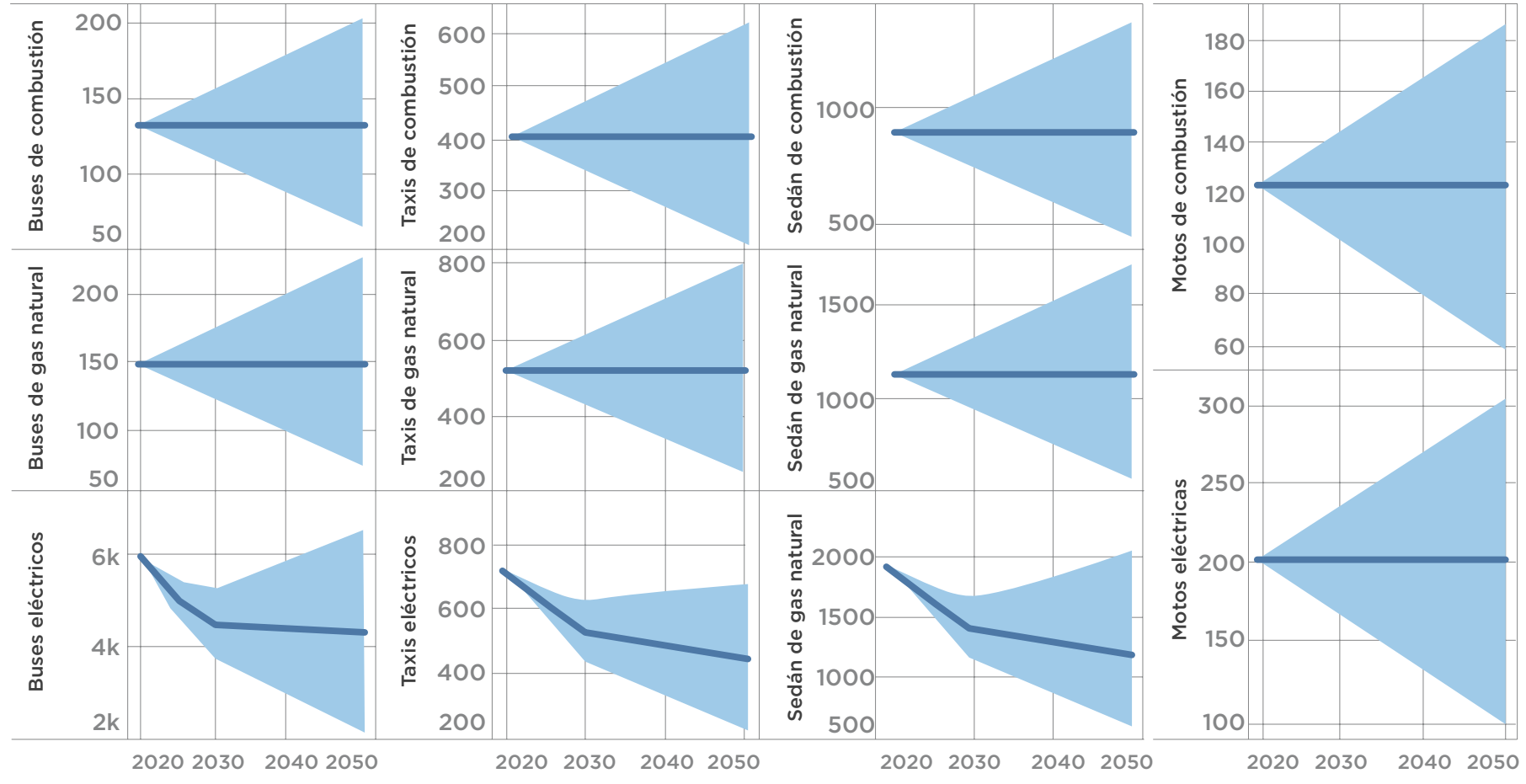


Gráfico B9: Costos capitales para el transporte de carga

\section{Costos capitales} (MUSD/Gpkm)

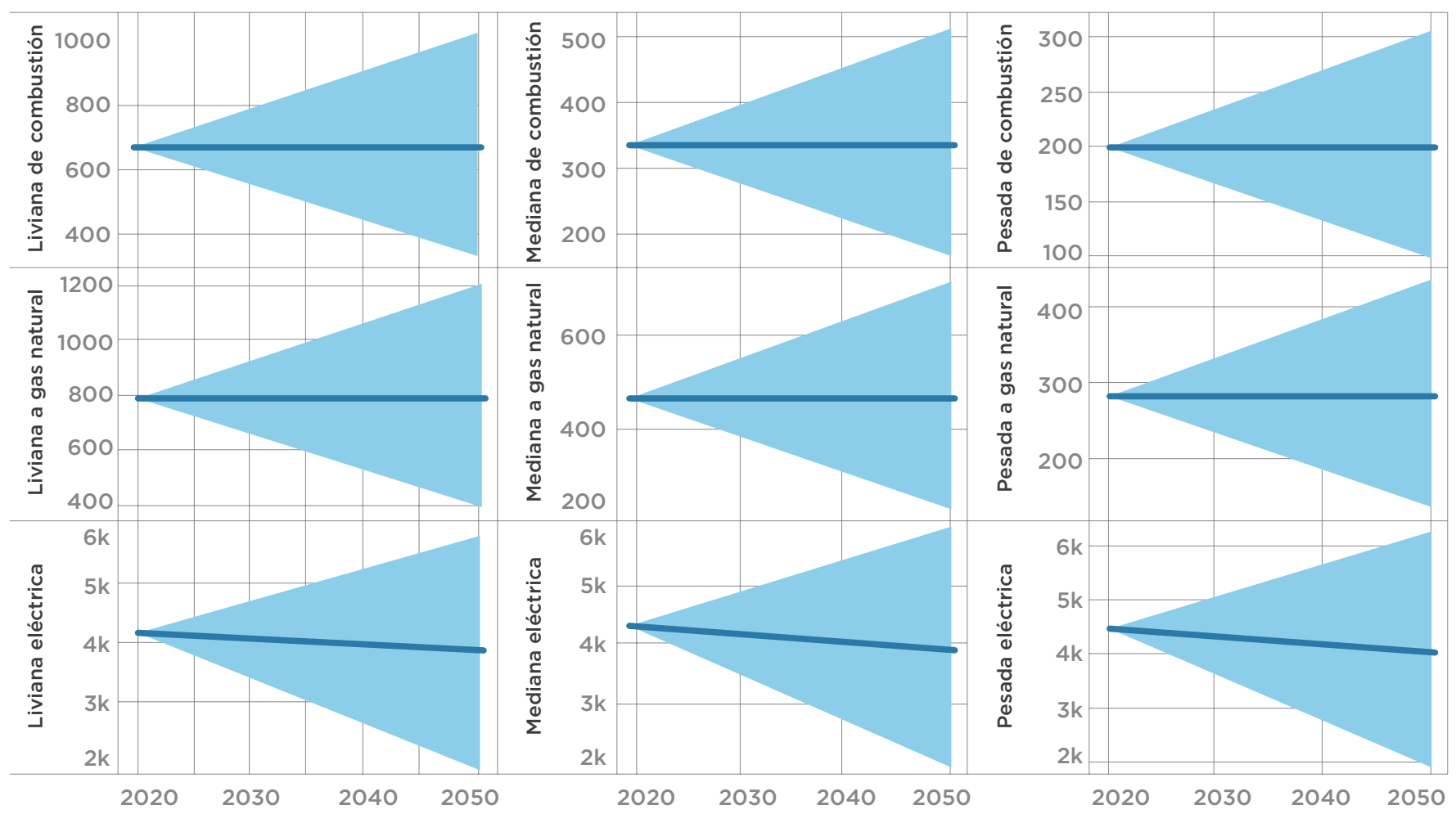




\section{B.2.4. Agricultura, silvicultura y otros usos de la tierra (AFOLU)}

\section{B.2.4.1. Agricultura (subsector agrícola y ganadería)}

A continuación, se presentan los principales supuestos de modelación del sector AFOLU, los coeficientes base de los costos y beneficios, y las trayectorias de los parámetros.

\section{Supuestos de modelación}

- Las emisiones generadas por las sabanas no están asociadas a la producción de ningún cultivo en particular. Esta fuente de emisión está asociada directamente a las características del ecosistema y se la excluye de este modelo, ya que solo representa el $4 \%$ de las emisiones agrícolas.

- Se ha definido una restricción de variación de tierras cultivadas para cada categoría de cultivo con el objetivo de suavizar los cambios de un periodo a otro y evitar que se decida cultivar únicamente la categoría más rentable del periodo anterior, lo cual sería poco realista. Además, las restricciones de cambios de cada cultivo de un periodo a otro se consideran iguales para todo el país.

- Los cultivos permanentes no generan beneficios durante los dos primeros años.

- Se ha considerado un rendimiento constante en la producción ganadera y se usa el promedio nacional del rendimiento para cada una de las regiones. Así también se considera que la distribución regional de los grupos de ganado se mantiene en el tiempo.

\section{Factores de beneficios y costos}

El cuadro B10 muestra los factores base de costos y beneficios utilizados en agricultura. Aunque existen otros beneficios, como la reducción de la incidencia de la malaria gracias a la reversión de la deforestación y a la disminución de la producción de arroz por medio del riego por inundación, en el momento de este estudio no se obtuvo información para su estimación. 


\section{Cuadro B10: Factores de costos y beneficios para el subsector agricultura}

\begin{tabular}{|c|c|c|}
\hline Parámetro & Valor & Fuente \\
\hline $\begin{array}{l}\text { Costos de } \\
\text { inversión } \\
\text { (escala } \\
\text { nacional, } \\
\text { valores por } \\
\text { hectárea) }\end{array}$ & $\begin{array}{l}\text { Alfalfa = US } \$ 1.050 ; \text { maíz = US } \$ 875 \text {; legumbres }=\text { US } \$ 525 ; \\
\text { tubérculos = US } \$ 123 ; \text { frutas de consumo doméstico }= \\
\text { US } \$ 2.975 ; \text { vegetales de consumo doméstico = US } \$ 2.975 ; \\
\text { frutas de exportación = US } \$ 2.975 ; \text { vegetales de exportación } \\
=\text { US } \$ 2.975 ; \text { café y cacao = US } \$ 1.575 ; \text { maíz amarillo duro } \\
=\text { US } \$ 385 ; \text { caña de azúcar = US } \$ 472,5 ; \text { arroz }=\text { US } \$ 525 ; \\
\text { algodón = US } \$ 525 ; \text { cereales y granos = US } \$ 525 \text {. }\end{array}$ & [B17]-[B19] \\
\hline $\begin{array}{l}\text { Costos de } \\
\text { operación } \\
\text { (Costa Norte, } \\
\text { valores por } \\
\text { hectárea) }\end{array}$ & $\begin{array}{l}\text { Alfalfa = US } \$ 1.374,17 ; \text { maíz }=\text { US } \$ 1.628,15 \text {; legumbres }= \\
\text { US } \$ 1.233,77 ; \text { tubérculos }=\text { US } \$ 4.188,4 \text {; frutas de consu-mo } \\
\text { doméstico = US } \$ 1.876,24 \text {, vegetales de consumo doméstico = } \\
\text { US } \$ 1.699,71 ; \text { frutas de exportación }=\text { US } \$ 1.722,09 ; \text { vegetales de } \\
\text { exportación = US } \$ 5.064,87 ; \text { café y cacao = US } \$ 1.410,87 ; \text { maíz } \\
\text { amarillo duro = US } \$ 2.181,04 ; \text { caña de azúcar }=\text { US } \$ 1.028,42 ; \\
\text { arroz = US } \$ 3.703,67 ; \text { algodón = US } \$ 1.974,47 \text {; cereales y granos } \\
=\text { US } \$ 1.125,7 \text {. }\end{array}$ & [B17]-[B19] \\
\hline $\begin{array}{l}\text { Costos de } \\
\text { operación } \\
\text { (Costa Centro, } \\
\text { valores por } \\
\text { hectárea) }\end{array}$ & 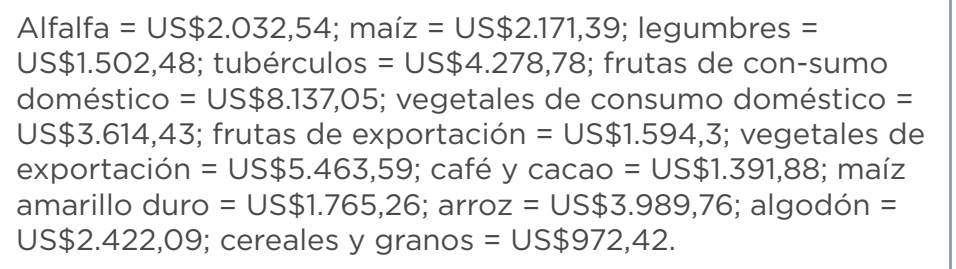 & [B17]-[B19] \\
\hline $\begin{array}{l}\text { Costos de } \\
\text { operación } \\
\text { (Costa Sur, } \\
\text { valores por } \\
\text { hectárea) }\end{array}$ & $\begin{array}{l}\text { Alfalfa = US } \$ 2.475,75 ; \text { maíz }=\text { US } \$ 2.367,48 \text {; legumbres }= \\
\text { US } \$ 2.881,2 ; \text { vegetales de consumo doméstico = US } \$ 2.182,33 \text {; } \\
\text { frutas de exportación = US } \$ 1.594,3 \text {; café y cacao = US } \$ 1.391,26 \text {; } \\
\text { maíz amarillo duro = US } \$ 2.215,66 \text {; arroz = US } \$ 3.153,62 ; \text { algodón } \\
=\text { US } \$ 0,00 ; \text { cereales y granos = US } \$ 5.803,99 \text {. }\end{array}$ & [B17]-[B19] \\
\hline $\begin{array}{l}\text { Costos de } \\
\text { operación } \\
\text { (Sierra Norte, } \\
\text { valores por } \\
\text { hectárea) }\end{array}$ & 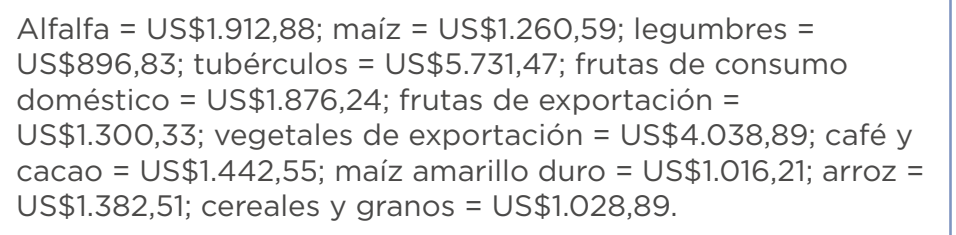 & [B17]-[B19] \\
\hline $\begin{array}{l}\text { Costos de } \\
\text { operación } \\
\text { (Sierra } \\
\text { Centro, } \\
\text { valores por } \\
\text { hectárea) }\end{array}$ & 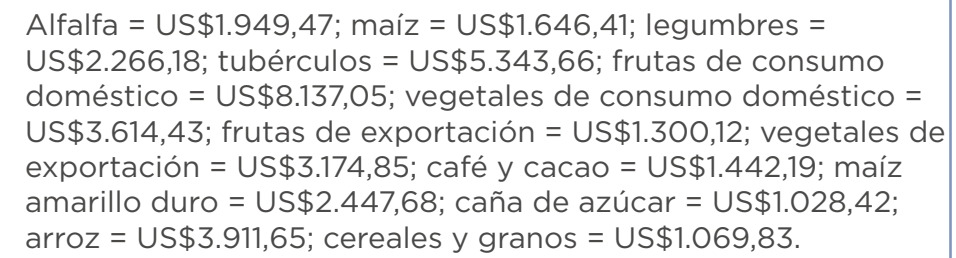 & [B17]-[B19] \\
\hline
\end{tabular}




\begin{tabular}{|c|c|c|}
\hline Parámetro & Valor & Fuente \\
\hline $\begin{array}{l}\text { Costos de } \\
\text { operación } \\
\text { (Sierra Sur, } \\
\text { valores por } \\
\text { hectárea) }\end{array}$ & $\begin{array}{l}\text { Alfalfa = US } \$ 1.915,15 ; \text { maíz = US } \$ 2.142,92 \text {; legumbres } \\
=\text { US } \$ 2.569,5 ; \text { tubérculos = US } \$ 4.881,87 \text {; frutas } \\
\text { de consumo doméstico = US } \$ 1.876,24 \text {; vegetales } \\
\text { de consumo doméstico = US } \$ 2.182,33 \text {; frutas de } \\
\text { exportación = US } \$ 1.325,12 ; \text { vegetales de exportación = } \\
\text { US } \$ 3.052,13 ; \text { café y cacao = US } \$ 1.398,39 ; \text { maíz amarillo } \\
\text { duro = US } \$ 1.016,21 ; \text { arroz = US } \$ 4.004,99 ; \text { cereales y } \\
\text { granos = US } \$ 1.024,75 \text {. }\end{array}$ & [B17]-[B19] \\
\hline $\begin{array}{l}\text { Costos de } \\
\text { operación } \\
\text { (Amazonía, } \\
\text { valores por } \\
\text { hectárea) }\end{array}$ & $\begin{array}{l}\text { Maíz = US } \$ 1.617,69 ; \text { legumbres = US } \$ 2.225,89 ; \\
\text { tubérculos = US } \$ 3.959,12 ; \text { frutas de consumo } \\
\text { doméstico = US } \$ 1.876,24 \text {; frutas de exportación = } \\
\text { US } \$ 1.300,54 ; \text { café y cacao = US } \$ 1.470,45 ; \text { maíz amarillo } \\
\text { duro = US } \$ 1.016,21 ; \text { caña de azúcar = US } \$ 1.028,42 ; \\
\text { arroz = US } \$ 2.946,81 \text {; cereales y granos = US } \$ 1.177,36 \text {. }\end{array}$ & [B17]-[B19] \\
\hline $\begin{array}{l}\text { Costos de } \\
\text { operación } \\
\text { (Pastos) }\end{array}$ & $\begin{array}{l}\text { Costo del mantenimiento de una hectárea } \\
\text { de pastos naturales altoandinos. OPEX por } \\
\text { hectárea: US } \$ 1.500 \text { por hectárea. }\end{array}$ & [B2O]-[B22] \\
\hline $\begin{array}{l}\text { Costos de } \\
\text { inversión y } \\
\text { operación } \\
\text { de la } \\
\text { plataforma } \\
\text { de servicios, } \\
\text { sistemas } \\
\text { agrofo- } \\
\text { restales y } \\
\text { sistemas } \\
\text { silvo- } \\
\text { pastoriles }\end{array}$ & $\begin{array}{l}\text { Costo de la implementación de una plataforma de } \\
\text { servi-cios agrícolas CAPEX por hectárea: US } \$ 300 \\
\text { por hectárea. Costo de la implementación de } \\
\text { sistemas agroforestales: US } \$ 5.400 \text { por hectárea } \\
\text { para CAPEX; US } \$ 1.300 \text { por hectá-rea para OPEX. } \\
\text { Costo de la implementación de sistemas } \\
\text { silvopastoriles en la Amazonía: US } \$ 400 \text { para } \\
\text { CAPEX y US } \$ 240 \text { para OPEX. }\end{array}$ & [B2O]-[B22] \\
\hline
\end{tabular}

\section{Trayectorias de los parámetros}

Los gráficos B10 a B13 muestran las trayectorias de los distintos parámetros que poseen una serie de tiempo en el sector agricultura y ganadería. 
Gráfico B10: Proyecciones y variaciones de las demandas de cultivos

\section{Demandas de cultivos (Mtons)}
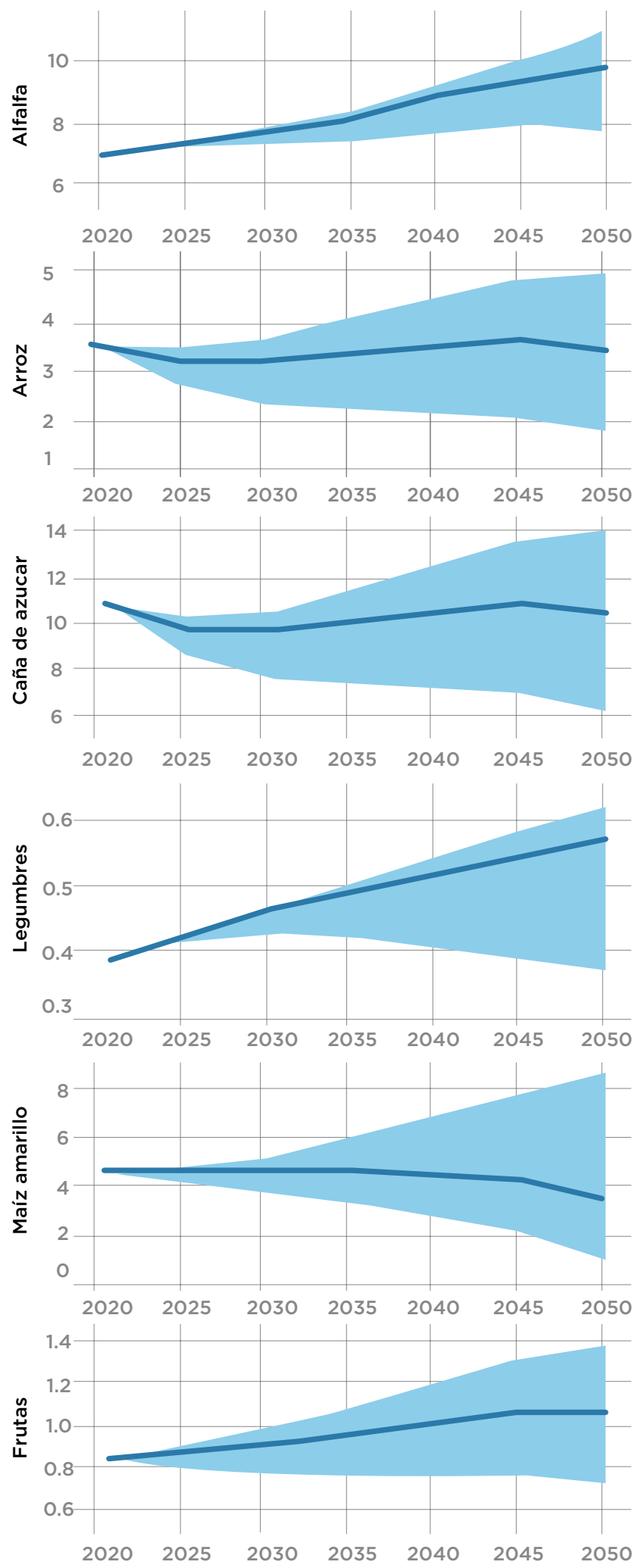
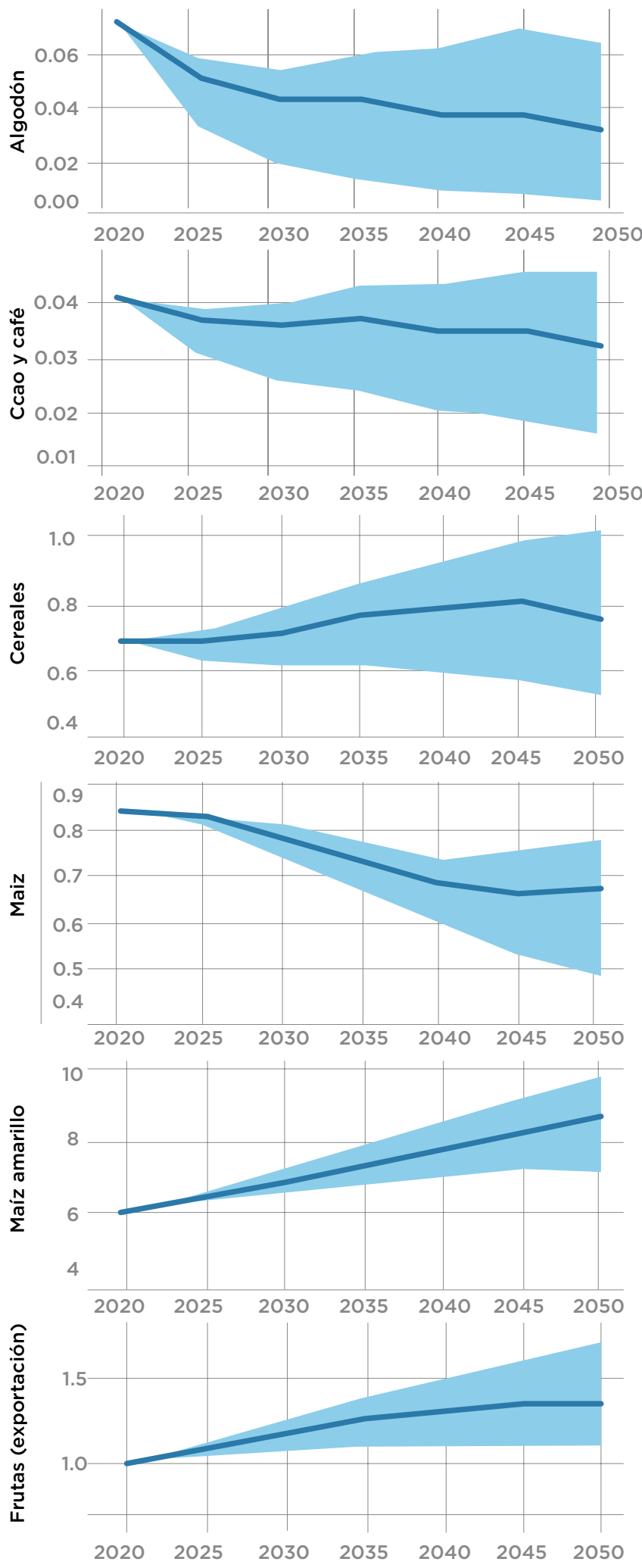


\section{Gráfico B11: Proyecciones y variaciones de las demandas de carne}
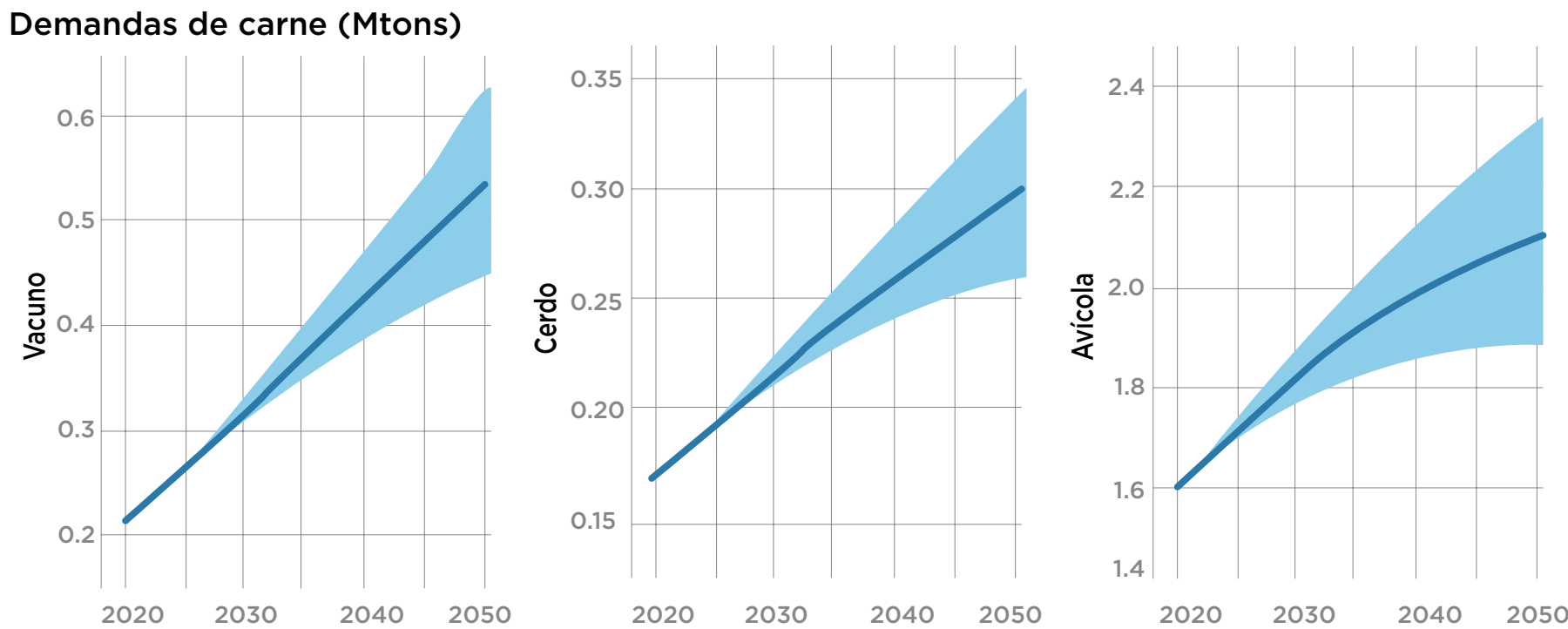

Gráfico B12: Trayectorias de precios para los cultivos

\section{Precios de los cultivos (USD/kg)}
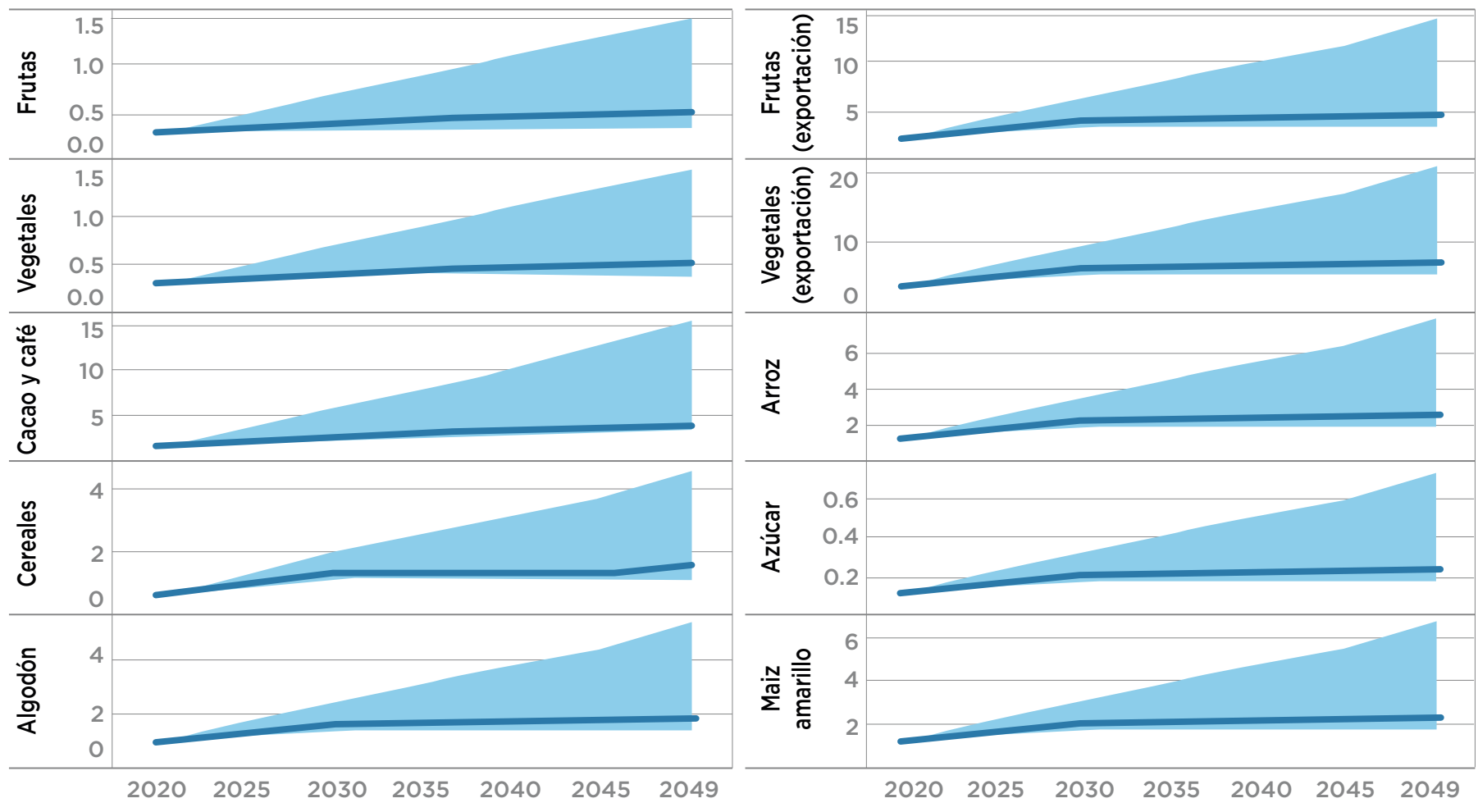
Gráfico B13: Trayectorias de la variación en el rendimiento de los cultivos

Tasa de variación de los rendimientos por cultivo cultivos ( $\mathrm{kg} / \mathrm{ha}$ )

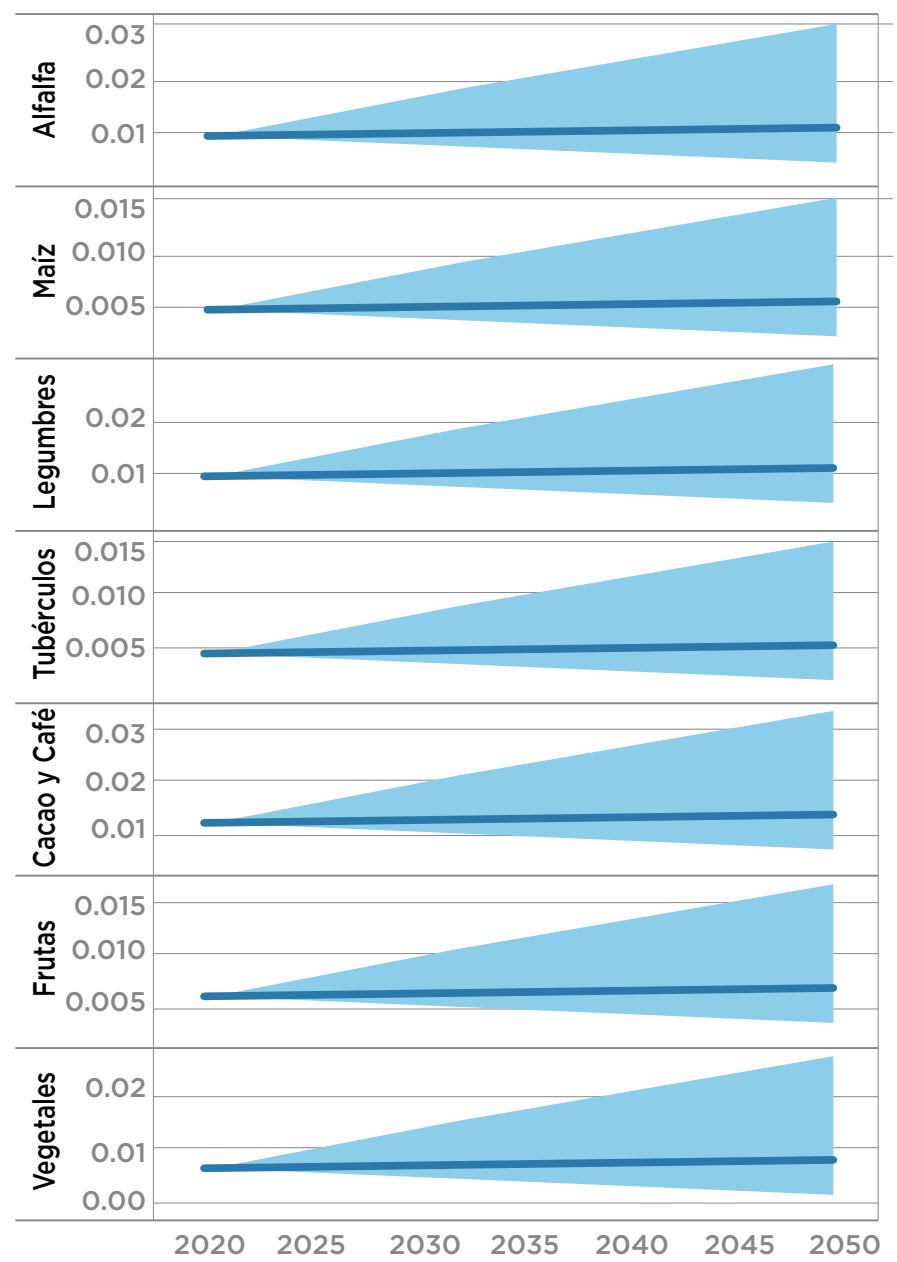

\section{B.2.4.2. Uso de la tierra, cambio de uso de la tierra y silvicultura (UTCUTS)}

A continuación, se presentan los principales supuestos de modelación del subsector de uso de la tierra, cambio de uso de la tierra y silvicultura (UTCUTS) y los coeficientes base de los costos y beneficios.

\section{Supuestos de modelación}

El modelo consiste en un manejo de inventarios de stock de suelos de bosque primario, bosque secundario, tierra agrícola, pasturas, tierra para

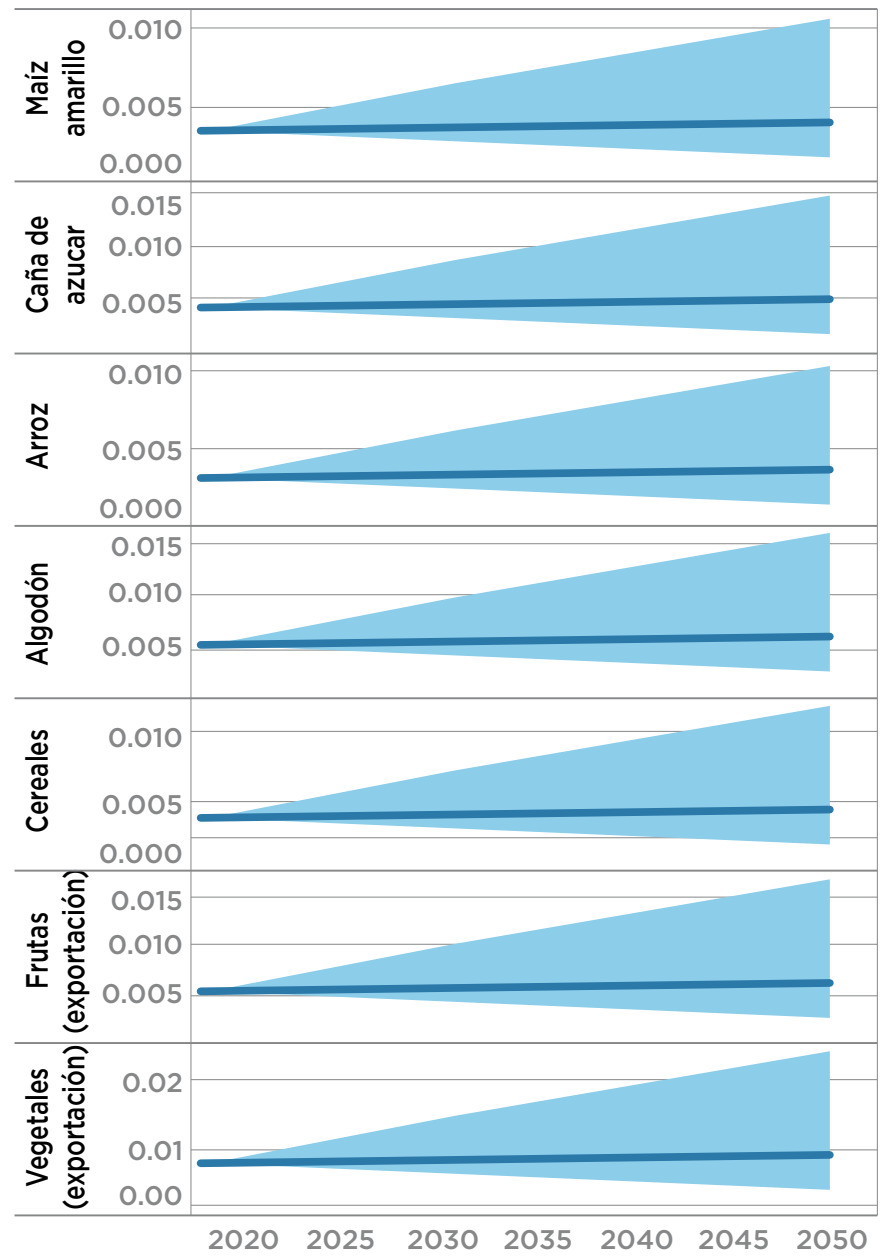

minería, asentamientos humanos y caminos, y otras tierras. Esto significa que las fuentes de deforestación del bosque reducen el stock de bosque, pero incrementan los stocks de otras tierras. No obstante, la información satelital no diferencia claramente la deforestación a causa de tala (madera y leña) y cualquier residual se reparte a tierra agrícola y ganadera.

\section{Modelación de causas de la deforestación}

El bosque primario es el stock de bosque primario menos la deforestación. No se considera crecimiento de bosque primario. El bosque 
primario presenta seis causas de deforestación: agricultura, ganadería, minería, construcciones (asentamientos) y otras causas (como incendios forestales). Se ha considerado que la deforestación por agricultura se explica por el ingreso agrario neto promedio, por la población rural y por el total de caminos pavimentados. Para ganadería, se explica por el ingreso total promedio ganadero, el número de cabezas de ganado y los caminos nacionales no pavimentados. Para construcciones, se ha tomado en cuenta un factor constante de crecimiento y el total de caminos nacionales pavimentados. Para minería, un factor constante de crecimiento y el precio internacional del oro. Por último, la deforestación por otras causas presenta un factor constante.

\section{Modelación de barbecho}

Los cultivos se dejan descansar y pasan a ser bosques secundarios o pasturas, y viceversa. Lamentablemente, la literatura no indica una práctica estándar en términos de tiempos. Se ha aplicado una proporción fija promedio del stock de tierras que pasan a las demás categorías.

\section{Modelación de bosque secundario}

El suelo deforestado que se recupera se considera como bosque secundario. Las tierras mineras, los asentamientos y otras tierras no se incluyen, ya que su aporte es mínimo. Se destaca lo siguiente:

- Solo se aprovecha un $25 \%$ de los bosques deforestados para cultivos.

- Algunas variables explicativas no se incluyeron porque no resultaron significativas (como el ingreso ganadero).

- El precio internacional del oro hacia 2050 se calcula indirectamente empleando data futura de demanda de petróleo, el precio del petróleo y el índice de precios del dólar estadounidense.

- No se incluye el efecto del operativo Madre de Dios.
- La deforestación por otros usos se calcula con la media móvil de los últimos cinco años.

- Una fracción de deforestación por bosques secundarios va a agricultura.

\section{Modelación de la producción del bosque}

Los productos del bosque que se consideran son maderas provenientes de concesiones y plantaciones forestales y leña. En el caso de la leña, se utiliza la estimación futura de coeficientes de consumo per cápita estimado por el CEPLAN. De la misma manera, las plantaciones forestales comerciales también generan ingresos. Se trabaja con matrices, pues las nuevas plantaciones no están listas para cosechar (toman 10 años en crecer). El valor de la madera se construye con un promedio ponderado de los valores ponderados. Su valor futuro se construye sobre la base de la proyección del índice de precios de productos madereros. Cabe tener en cuenta lo siguiente:

- Los períodos de concesión se renuevan automáticamente.

- Se mantiene la tendencia de expiración de concesiones por procesos administrativos.

- Se asume un período de concesión promedio de ocho años.

- Hacia 2050 se alcanza actividad en todas las tierras concesionadas.

- La densidad de bosque ha sido tomada del Inventario Nacional de Gases de Efecto Invernadero (INGEI) 2012 para el cálculo de emisiones de GEl.

- Las plantaciones forestales tienen lugar en tierras eriazas.

- Las plantaciones forestales son renovadas el mismo año en que se cosechan. 
- Las plantaciones forestales consideran una especie de maduración de ocho años.

- Para el cálculo de los ingresos por madera se ha tomado en cuenta un precio de US\$2 por pie cúbico de madera y US $\$ 2,5$ por pie cúbico de madera certificada.

\section{Deforestación por categoría de bosque}

La proyección de la deforestación se reparte de acuerdo con la participación en deforestación (del último año) en 17 categorías de suelo: áreas naturales protegidas, conservación regional, conservación privada, bosque campesino, bosque de comunidades nativas, reservas territoriales, concesiones de madera, concesión de madera de alto rendimiento, reforestación comercial, concesión de conservación, concesiones de turismo, concesiones de fauna, concesiones de madera sin otorgar, bosque rural, humedales, concesiones de otros productos y sin categoría.

\section{Factores de beneficios y costos}

El cuadro B11 muestra los factores base de costos y beneficios utilizados en el UTCUTS.

\section{Cuadro B11: Factores de costos y beneficios para el subsector UTCUTS}

\begin{tabular}{|c|c|c|}
\hline Beneficio & Valor & Fuente \\
\hline $\begin{array}{l}\text { Servicios } \\
\text { ecosistémicos }\end{array}$ & US $\$ 1.108$ por hectárea de bosque primario en pie. & [B23] \\
\hline $\begin{array}{l}\text { Ingresos por } \\
\text { mercado in- } \\
\text { ternacional } \\
\text { de bonos de } \\
\text { carbono. }\end{array}$ & $\begin{array}{l}\text { Estimación para la cual se toma en cuenta un rango de } \\
\text { US } \$ 0 \text { por TM a US } \$ 200 \text { por TM. }\end{array}$ & [B24] \\
\hline $\begin{array}{l}\text { Costos de } \\
\text { operación } \\
\text { y costos de } \\
\text { inversión }\end{array}$ & $\begin{array}{l}\text { Costo de una hectárea de plantación comercial. Costos } \\
\text { de CAPEX }=\text { US } \$ 2.000 \text { y de OPEX }=\text { US } \$ 9.000 \text { por } \\
\text { hectárea. } \\
\text { Costo de una hectárea de plantación de conservación. } \\
\text { Costos de CAPEX = US } \$ 3.900 \text { y de OPEX = US } \$ 100 \\
\text { por hectárea. } \\
\text { Costo de una hectárea de concesión forestal } \\
\text { sostenible. Costos de CAPEX = US } \$ 200 \text { y de OPEX = } \\
\text { US } \$ 1.000 \text { por hectárea activa. } \\
\text { Costo de una hectárea de concesión forestal. Costos } \\
\text { de CAPEX = US } \$ 70 \text { y de OPEX = US } \$ 1.000 \text { por } \\
\text { hectárea activa. } \\
\text { Costo de la asignación de derechos. CAPEX por un } \\
\text { total de US } \$ 328,85 \text { millones. }\end{array}$ & [B25]-[B28] \\
\hline
\end{tabular}




\section{B.2.5. Residuos}

A continuación, se presentan los principales supuestos de modelación del sector residuos, los coeficientes base de los costos y beneficios, y las trayectorias de los parámetros.

\section{Supuestos de modelación}

- Se considera que existe un cambio cultural por parte de la población, que implica una reducción en la generación de residuos sólidos, aguas residuales (a nivel residencial y comercial) y de los efluentes industriales.

- Se supone que existirán políticas que promuevan el reciclaje y la valoración del material recuperado.

\section{Factores de beneficios y costos}

El cuadro B12 muestra los factores base de costos y beneficios utilizados en el sector residuos.

\section{Cuadro B12: Factores de costos y beneficios para el sector residuos}

\begin{tabular}{|c|c|c|}
\hline Beneficio & Valor & Fuente \\
\hline $\begin{array}{l}\text { Valor del material } \\
\text { reciclado }\end{array}$ & US $\$ 1.060 /$ ton de material reciclado & [B29] \\
\hline $\begin{array}{l}\text { Valor del servicio } \\
\text { de alcan- } \\
\text { tarillado para los } \\
\text { ciudadanos }\end{array}$ & US\$299/año/casa & [B30] \\
\hline $\begin{array}{l}\text { Valor del agua } \\
\text { reciclada para } \\
\text { otros usos }\end{array}$ & US $\$ 200 /$ miles de metros cúbicos & {$[\mathrm{B} 31]$} \\
\hline $\begin{array}{l}\text { Costos para } \\
\text { aumentar la } \\
\text { recolección } \\
\text { de residuos }\end{array}$ & US $\$ 72 /$ ton de desecho recolectado & [B32] \\
\hline $\begin{array}{l}\text { Costos de } \\
\text { reciclar }\end{array}$ & US $\$ 293 / \mathrm{m} 3$ de aguas & [B33] \\
\hline $\begin{array}{l}\text { Costos para } \\
\text { aumentar el } \\
\text { tratamiento de } \\
\text { aguas residuales }\end{array}$ & US $\$ 2,13 / \mathrm{kg}$ DBO & [B34] \\
\hline
\end{tabular}

\section{Trayectorias de los parámetros}

El gráfico B14 muestra las trayectorias de la cantidad de residuos generados tanto sólidos como líquidos para las distintas rutas de implementación exploradas. 
Gráfico B14: Trayectorias de la cantidad de residuos generados (sólidos y líquidos)
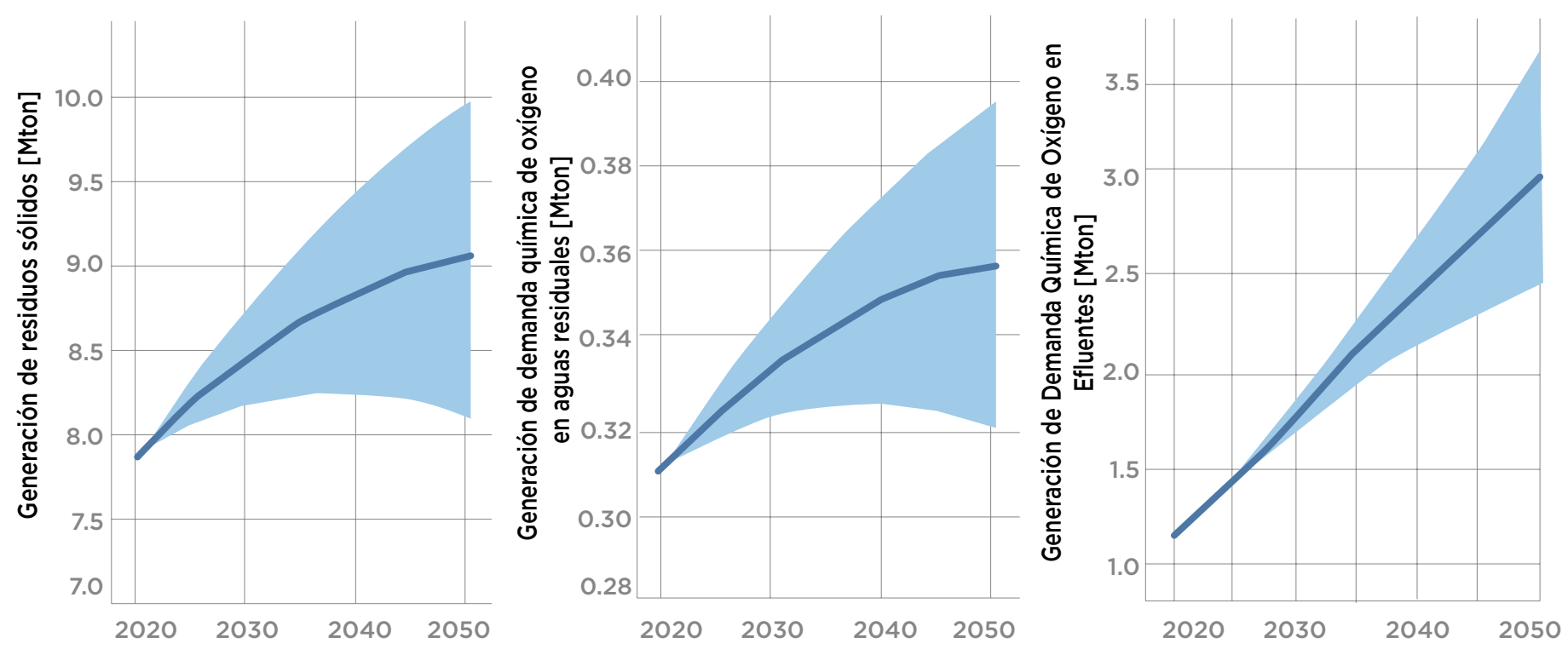

\section{B.2.6. Procesos industriales y uso de productos (PIUP)}

A continuación, se presentan los principales supuestos de modelación del sector PIUP, los coeficientes base de los costos y beneficios, y las trayectorias de los parámetros.

\section{Supuestos de modelación}

Se considera que la industria cementera promoverá una reducción en el uso de clínker, el cual será sustituido por puzolanas.

\section{Factores de beneficios y costos}

El cuadro B13 muestra el costo de reducir emisiones en el sector PIUP. 


\section{Cuadro B13: Factores de costos para el sector PIUP}

\begin{tabular}{l|l|l|l}
\multicolumn{1}{c|}{ Beneficio } & \multicolumn{1}{c|}{ Factor } & \multicolumn{1}{c|}{ Valor } & \multicolumn{1}{c}{ Fuente } \\
$\begin{array}{l}\text { Costo de reducir } \\
\text { las emisiones de } \\
\text { la producción de } \\
\text { cemento }\end{array}$ & $\begin{array}{l}\text { Costo adicional } \\
\text { para producir } \\
\text { cemento } \\
\text { de menores } \\
\text { emisiones }\end{array}$ & US\$88/ton de cemento & [B35]-[B36] \\
\hline
\end{tabular}

\section{Trayectorias de los parámetros}

El gráfico B15 muestra las trayectorias del uso del clínker.

\section{Gráfico B15: Proyecciones del uso del clínker}

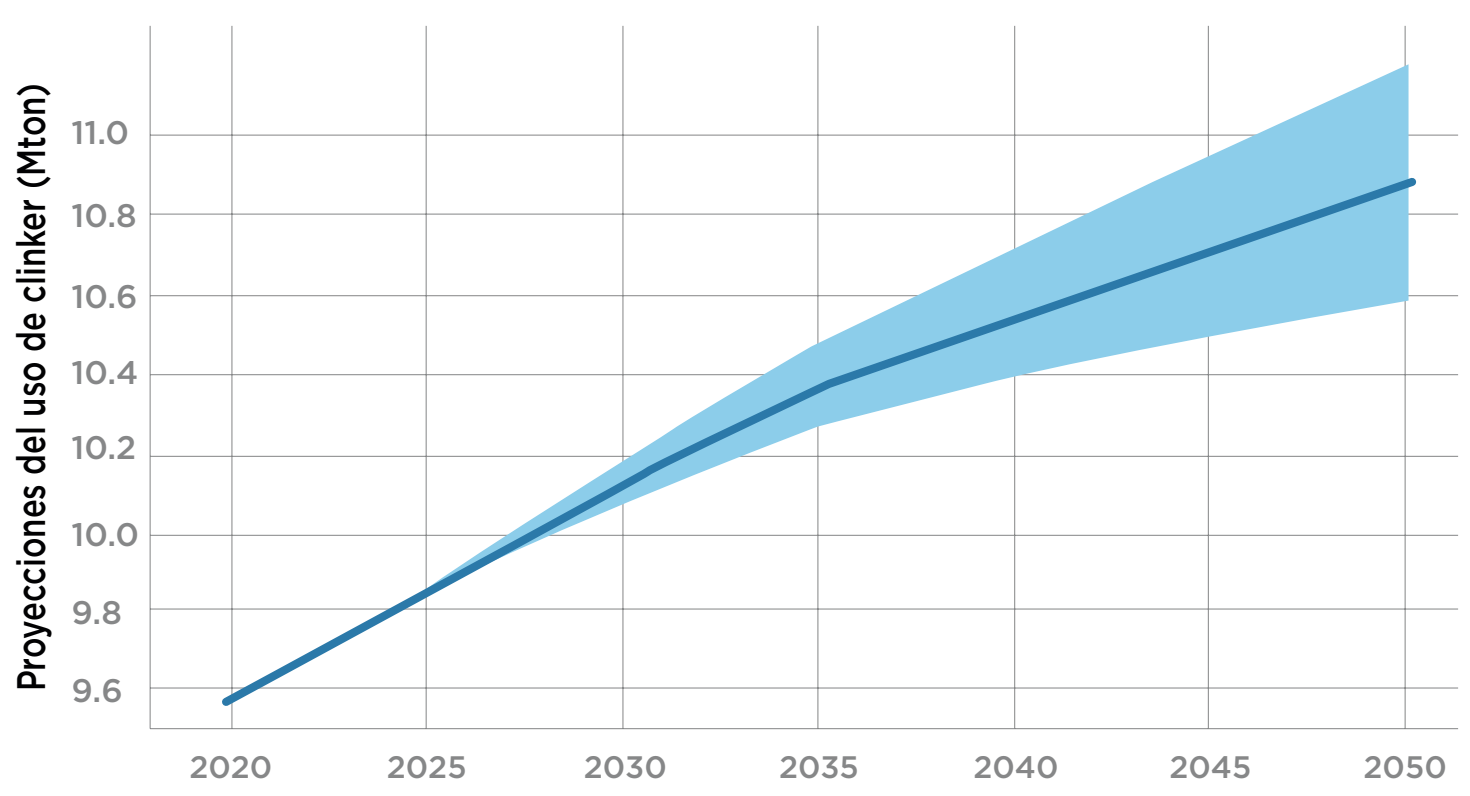




\section{Anexo C: Referencias de los anexos}

[B1] pyDOE: The experimental design package for Python. Disponible en: https://pythonhosted.org/ pyDOE/index.html.

[B2] MINAM. Inventario Nacional de Gases de Efecto Invernadero 2014 y 2015.

[B3] PAGE. Perú: Crecimiento Verde. Análisis cuantitativo de políticas verdes en sectores seleccionados de la economía (2017).

[B4] Centro de Investigación de la Universidad del Pacífico. "Estimación del precio del carbono para la evaluación social de proyectos en el Perú” (2016).

[B5] Coady, D., I. Parry, N.P. Le y B. Shang. 2019. Global Fossil Fuel Subsidies Remain Large: An Update Based on Country-Level Estimates. Documento de trabajo No. 19/89; p. 39. Washington, D.C.: Fondo Monetario Internacional. Disponible en https://www.imf.org/en/Publications/WP/Issues/2019/05/02/Global-FossilFuel-Subsidies-Remain-Large-An-Update-Based-on-Country-Level-Estimates-46509.

[B6] MINEM. Balance Nacional de Energía (2017).

[B7] COES. Informe de Operación Anual del SEI (2019).

[B8] COES. Propuesta definitiva de la actualización del plan de transmisión 2021-2030. Lima (2020).

[B9] Prosemer. Informe 9: Planificación de la Oferta Energética (2019)

[B10] ETSAP-IEA. Data Technology. Disponible en: https://iea-etsap.org/index.php/energy-technologydata. Consultada en mayo de 2020.

[B11] EPERLab-UCR. Documentación de OSeMOSYS-CR. Disponible en: https://osemosys-cr.readthedocs. io/en/latest/.

[B12] García de Fonseca, L; Parikh, M; Manghani, R., Evolución futura de costos de las energías renovables y almacenamiento en América Latina, diciembre de 2019. Disponible en http://dx.doi.org/10.18235/0002101

[B13] IRENA. Renewable power generation cost in 2019 \& 2020.

[B14] EPRI. Estimating the Costs and Benefits of the Smart Grid. A Preliminary Estimate of the Investment Requirements and the Resultant Benefits of a Fully Functioning Smart Grid (2011).

[B15] A. Schroten et al. Overview of transport infrastructure expenditures and costs. Comisión Europea (2019).

[B16] E. Ó Broin y C. Guivarch. Transport infrastructure costs in low-carbon pathways. Transportation Research Part D: Transport and Environment, Elsevier, 55: 389-403 (2016). Disponible en 10.1016/j. trd.2016.11.02. 
[B17] INEI. Encuesta Nacional Agropecuaria 2014-2018.

[B18] INEI. IV Censo Nacional Agropecuario 2012.

[B19] MIDAGRI. Series de Estadísticas de Producción Agrícola (SEPA) (2020)

[B20] INIA. Guía práctica de pastos cultivados. Instalación producción y manejo (2006).

[B21] Entrevista con José Yturrios, director nacional de Alianza Cacao Perú.

[B22] ProNaturaleza. Manual para la implementación y manejo de un sistema silvopastoril en el valle de Palcazú-Oxapampa.

[B23] Carrasco et al. Economic valuation of ecosystem services fails to capture biodiversity value of tropical forest (2014).

[B24] Bush y Engelman. Cost-effectiveness of reducing emissions from tropical deforestation 2016-2050 (2018).

[B25] Entrevista con especialistas de REFORESTA Perú, SERFOR y OSINFOR.

[B26] OSINFOR. Directiva para la compensación del pago de multas mediante el mecanismo de recuperación de áreas degradadas.

[B27] Entrevista con especialistas de REFORESTA Perú, SERFOR y OSINFOR.

[B28] Plan CC, Actualización del inventario de GEl año 2009 (2013).

[B29] S. Lobo et al. Analysis of the challenges in the development of the recycling value chain in Central America. Monografía del BID 485 (2016).

[B30] J. Dixon. Enhanced Cost Benefit Analysis of IDB Waste Water Treatment Projects with Special Consideration to Environmental Impacts: Lessons Learned from a Review of Four Projects. Documento de discusión del BID No. IDB-DP-254 (2012).

[B31] SEDAPAL. Estructura tarifaria por los servicios de agua potable y alcantarillado (2019).

[B32] Banco Mundial. Inside Costa Rica. Costa Rica's Waste Generation Expected to Double by 2025 (2012).

[B33] COVEC-Ministry of Environment, New Zealand. Recycling: Cost Benefit Analysis (2017).

[B34] G. León. Esquema de gestión de aguas residuales (2020).

[B35] FICEM. Reporte (No Verificado) de la aplicación del SMRV-FICEM para la producción de cemento del Perú (2016).

[B36] T. Hills, N. Florin y P. S. Fennell. Decarbonising the cement sector: A bottom-up model for optimizing carbon capture application in the UK Journal of Cleaner Production, 139: 1351-1361 (2016). 
